Q84I

\title{
TRANSPORTATION SECTOR MODEL OF THE NATIONAL ENERGY MODELING SYSTEM
}

Volume II--Appendices

Part 2

January 1998

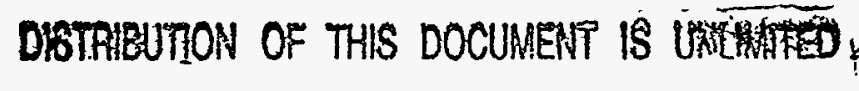

Office of Integrated Analysis and Forecasting

Energy Information Administration

U.S. Department of Energy Washington, DC 


\section{DISCLAIMER}

This report was prepared as an account of work sponsored by an agency of the United States Government. Neither the United States Government nor any agency thereof, nor any of their employees, makes any warranty, express or implied, or assumes any legal liability or responsibility for the accuracy, completeness, or usefulness of any information, apparatus, product, or process disclosed, or represents that its use would not infringe privately owned rights. Reference herein to any specific commercial product, process, or service by trade name, trademark, manufacturer, or otherwise does not necessarily constitute or imply its endorsement, recommendation, or favoring by the United States Government or any agency thereof. The views and opinions of authors expressed herein do not necessarily state or reflect those of the United States Government or any agency thereof. 


\title{
Appendix F. Attachments to the Transportation Model
}

\author{
TABLE OF CONTENTS
}

Attachment 1: Fuel Economy Model

Attachment 2: Alternative Fuel Vehicle Model

Attachment 3: LDV Stock Module

Attachment 4: Light Duty Vehicle Fleet Model

Attachment 5: Light Commercial.Truck Model

Attachment 6: Air Travel Module

$F-161$

Attachment 7: Vehicle Emissions Module

F-165

Attáchment 8: LDV Stock Model

F-205 


\section{LIST OF TABLES}

Table.F-1: Regression Results From LDV Market Share Model $\ldots \ldots \ldots \ldots \ldots \ldots \ldots \ldots \ldots \ldots \ldots \ldots \ldots$ F-5

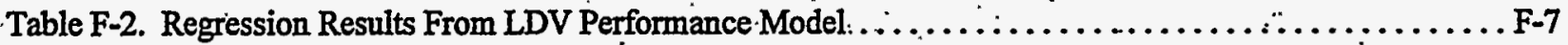

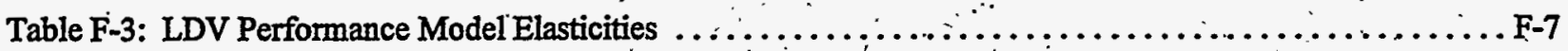

Table F-4. LDV Performance and Price Options ${ }^{-} \ldots \ldots \ldots \ldots \ldots \ldots \ldots \ldots \ldots \ldots \ldots \ldots \ldots \ldots \ldots \ldots \ldots \ldots$

Table F-5: Certainty Levels of Near-Term Technologies for Improving Fuel Economy $\ldots \ldots \ldots \ldots \ldots \ldots \ldots \ldots \ldots$

Table F-7: Standard Technology Matrix For Trucks $\ldots \ldots \ldots \ldots \ldots \ldots \ldots \ldots \ldots \ldots \ldots \ldots \ldots \ldots \ldots \ldots \ldots$ F-12

Table F-8: High Technology Matrix For Cars..$\ldots \ldots \ldots \ldots \ldots \ldots \ldots \ldots \ldots \ldots \ldots \ldots \ldots \ldots \ldots \ldots \ldots \ldots$

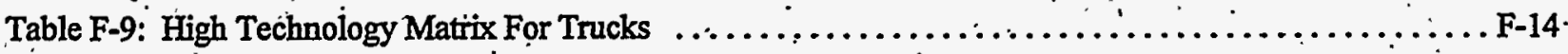

Table F-10: Alternative Fuel Type Potential Application by Size Class.$\ldots \ldots \ldots \ldots \ldots \ldots \ldots \ldots \ldots \ldots \ldots \ldots$ F-17

Table F-11: Altemative Fuel Type Potential Application by Size Class $\ldots \ldots \ldots \ldots \ldots \ldots \ldots \ldots \ldots \ldots \ldots \ldots$ F-18

Table F-12: Conversion of Variable and Fixed Costs to IRPE $\ldots \ldots \ldots \ldots \ldots \ldots \ldots \ldots \ldots \ldots \ldots \ldots \ldots \ldots$

Table F-13: Characteristics of Alcohol Fuel Vehicles Relative to Gasoline ICE's $\ldots \ldots \ldots \ldots \ldots \ldots \ldots \ldots \ldots$ F-20

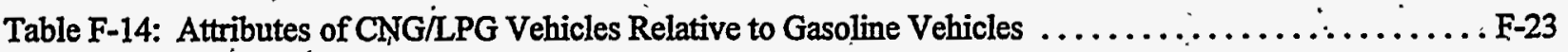

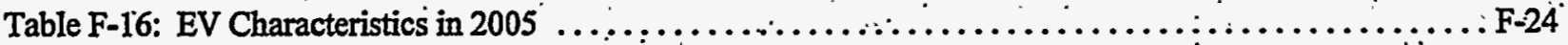

Table F-17. Gasoline Vehicle Characteristics (1990) $\ldots \ldots \ldots \ldots \ldots \ldots \ldots \ldots \ldots \ldots \ldots \ldots \ldots \ldots \ldots \ldots \ldots$. 44

Table F-18. AFV Price Premia by Technology $\ldots \ldots \ldots \ldots \ldots \ldots \ldots \ldots \ldots \ldots \ldots \ldots \ldots \ldots \ldots \ldots \ldots \ldots$ F-52

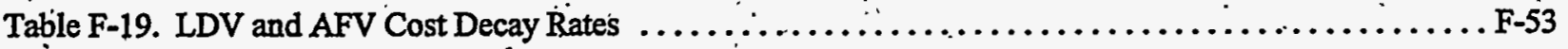

Table F-20. Current Mid-Sized Vehicle Fuel Efficiencies $\ldots \ldots \ldots \ldots \ldots \ldots \ldots \ldots \ldots \ldots \ldots \ldots \ldots \ldots \ldots$. $\ldots \ldots \ldots$

Table.F-21. Annual LDV \& AFV Efficiency Gain, by Technology (Three Scenarios) . .............F-59

Table F-22. Base Mid-Sized Vehicle Emissions (Grams/Mile, 1990) . . . . . . . . . . . . . . . . ...F-63

Table F-23. Minimum Possible Emissions; Mid-Size Vehicle (Grams/Mile, 2030) . . . . . . . . . . . F-64

Table F-24: Pollutant Impact Weighting Factors (Health vs. Environment) $\ldots \ldots \ldots \ldots \ldots \ldots \ldots \ldots \ldots \ldots$ F-66

Table F-25. LDV \& AFV Emissions Decay Rates $\ldots \ldots \ldots \ldots \ldots \ldots \ldots \ldots \ldots \ldots \ldots \ldots \ldots \ldots \ldots \ldots \ldots$ F- 66

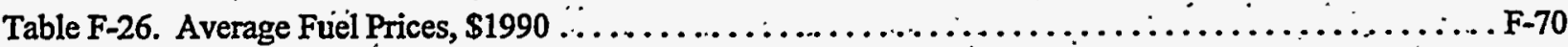

Table F-27. Règional Fuel Price Differences $\ldots \ldots \ldots \ldots \ldots \ldots \ldots \ldots \ldots \ldots \ldots \ldots \ldots \ldots \ldots \ldots \ldots \ldots \ldots \ldots$

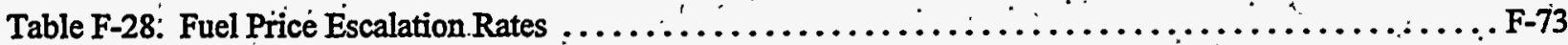

. Table F-29. Base Year (1990) Fuel Availability; by Region $\ldots \ldots \ldots \ldots \ldots \ldots \ldots \ldots \ldots \ldots \ldots \ldots \ldots \ldots \ldots$ F-77

Table F-30. Availability Gap Closure Rates, By Scenario $\quad \therefore . \ldots \ldots \ldots \ldots \ldots \ldots \ldots \ldots \ldots \ldots \ldots \ldots \ldots$ F-79

Table F-31. Current Small Vehicle Rảnge and Size Range Credit $\ldots \ldots \ldots \ldots \ldots \ldots \ldots \ldots \ldots \ldots \ldots \ldots \ldots$

Table F-32. Automobile Fuel Efficiency Gap Projections: Logistic Growth of City Driving Share ... . . . . F-100

Table F-33. Light Truck Fuel Efficiency Gap Projections: Logistic Growth of City Driving Share . . . . . . . F-100

Table F-34. Automobile Fuel Efficiéncy Gap Projections: Logistic Growth of Average Highway Speed . . . . F-105

Table F-35. Light Truck Fuel Efficiency Gap Projection: Logistic Growth of Average Highway Speed .. . . . F-105

Table F-36. Congestion Index Value for Selected Cities $\ldots \ldots \ldots \ldots \ldots \ldots \ldots \ldots \ldots \ldots \ldots \ldots \ldots \ldots \ldots \ldots \ldots$

Table F-37. 1987 Urban Area Rankings by Congestion Index and Cost per Capita ................. F-109

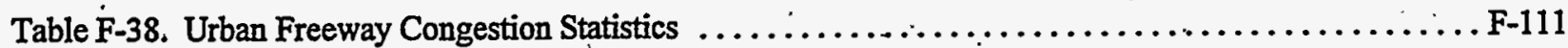


Table F-39. Automobile Fuel Efficiency Gap Projections: Logistic Increasing Congestion Trend . .......F-111 Table F-40. Light Truck Fúel Efficiency Gap Projections: Logistic Increasing Congestion. Trend . . . . . . . F-114 Table F-41. Total Fụel Efficiéncy Gap Projẹctions for Automobiles and Light Duty Trucks . . . . . . . . . . F-114 Table F42: Federal Mandates for Alternative-Fueled Vehicles $\ldots \ldots \ldots \ldots \ldots \ldots \ldots \ldots \ldots \ldots \ldots \ldots \ldots$ F-115 Table F-43: Business Fleet Distribution of Vehicles $\ldots \ldots \ldots \ldots \ldots \ldots \ldots \ldots \ldots \ldots \ldots \ldots \ldots \ldots \ldots \ldots$ F-1.16

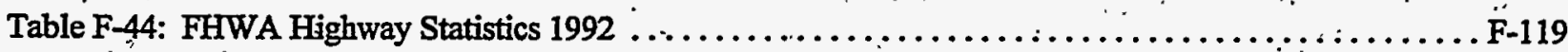

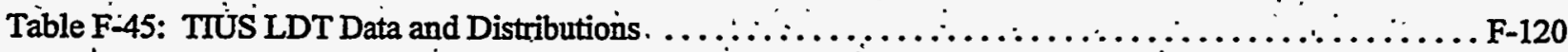

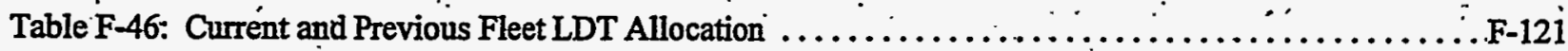

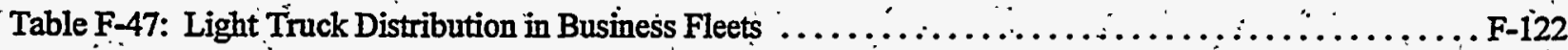

Table F-48: Light Truck Distribution in Utility Fleets $\ldots \ldots \ldots \ldots \ldots \ldots \ldots \ldots \ldots \ldots \ldots \ldots \ldots \ldots \ldots \ldots \ldots \ldots \ldots \ldots \ldots$

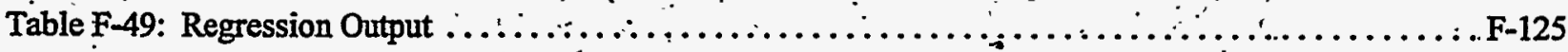

Table F-50: Distribution of LDTs, by Fleet Type and Size $\ldots \ldots \ldots \ldots \ldots \ldots \ldots \ldots \ldots \ldots \ldots \ldots \ldots \ldots \ldots \ldots$

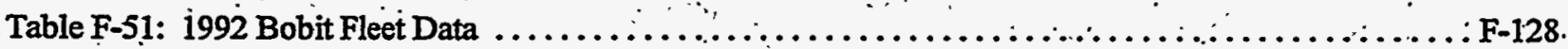

Table F-52: Percentage of Business Fleet Automobiles $\ldots \ldots \ldots, \ldots \ldots \ldots \ldots \ldots \ldots \ldots \ldots \ldots \ldots \ldots$. $\ldots \ldots \ldots$

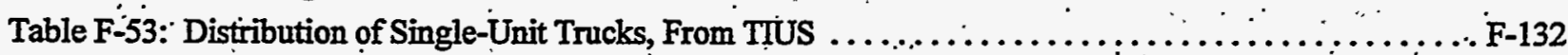

Table F-54: Stock Estimates: All Single-Unit Trucks $\ldots \ldots \ldots \ldots \ldots \ldots \ldots \ldots \ldots \ldots \ldots \ldots \ldots \ldots \ldots \ldots$ F-133

Table F-55: Distribution of Light Truck Sáles from Macro Model $\ldots \ldots \ldots \ldots \ldots \ldots \ldots \ldots \ldots \ldots \ldots \ldots \ldots$ F-133

Table F-56: Linear Interpolation:. Fraction Between 8.5 and $10 \mathrm{k}$ lbs $\ldots \ldots \ldots \ldots \ldots \ldots \ldots \ldots \ldots \ldots \ldots$ F-134

Table F-57: Correspondence of Major Use Categories $\ldots \ldots \ldots \ldots \ldots \ldots \ldots \ldots \ldots \ldots \ldots \ldots \ldots \ldots \ldots \ldots \ldots \ldots \ldots$

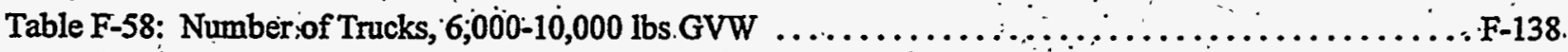

Table F-59: Average Annual Miles, by Major Use $(1992$ TIUS) $\ldots \ldots \ldots \ldots \ldots \ldots \ldots \ldots \ldots \ldots \ldots \ldots$

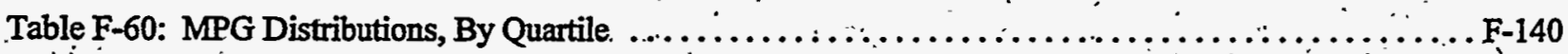

Table F-61: Average MPG: Biweighted Mean Iterated $\ldots \ldots \ldots \ldots, \ldots \ldots \ldots \ldots \ldots \ldots \ldots \ldots \ldots \ldots$ F-141

Table F-62: Single-Unit Truck Characteristics, from FHWA $\ldots \ldots \ldots \ldots \ldots \ldots \ldots \ldots \ldots \ldots \ldots \ldots \ldots$ F-141

Table F-63: Number of Light Commercial Trucks (by Type) $\ldots \ldots \ldots \ldots \ldots \ldots \ldots \ldots \ldots \ldots \ldots \ldots \ldots$ F-142

Table.F-64: New Purchàses of Light Commercial Trucks (by Type) . . . . . . . . . . . . . . . . . . . . . . . F-143

Table F-65: 1992 TIUS vs. FHWA . ....................................... F-149

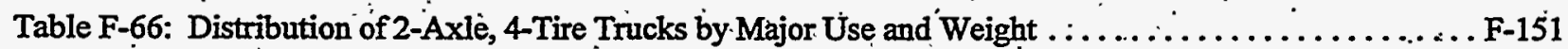

Táble F-67:. Distribution of 2-Axle, 4-Tire Trucks by Major Üse and Weight $\ldots \ldots \ldots \ldots \ldots \ldots \ldots \ldots \ldots \ldots$ F-15̦2

Table F-68: Distribution of Other Trucks by Major Use and Weight $\ldots \ldots \ldots \ldots \ldots \ldots \ldots \ldots \ldots \ldots \ldots \ldots$. 153

'Table F'69: Distribution of Other Trucks by Major Use and Weight $\ldots \ldots \ldots \ldots \ldots \ldots \ldots \ldots \ldots \ldots \ldots \ldots$

Täble F-70: Distribution of 2-Axle, 4-Tire Trucks by Major Ușe and Weight $\ldots \ldots \ldots \ldots \ldots \ldots \ldots \ldots \ldots \ldots \ldots \ldots \ldots$

Table F-71: Distribution of Other Trucks by Major Use and Weight $\ldots \ldots \ldots \ldots \ldots \ldots \ldots \ldots \ldots \ldots \ldots$. 156

Table F-72: Distribution of Light Commercial Trucks by MPG $\ldots \ldots \ldots \ldots \ldots \ldots \ldots \ldots \ldots \ldots \ldots \ldots$ F-157

Table F-73: Distribution of Light Commercial Trucks by MPG $\ldots \ldots \ldots \ldots \ldots \ldots \ldots \ldots \ldots \ldots \ldots$. $\ldots \ldots \ldots$

Table F-74: Light Commercial Truck Stock: Stratification by Major Use Group . . . . . . . . . . . . . F F-159

Table F-75: LCT Sales: Stratification by Major Use Group $\ldots \ldots \ldots \ldots \ldots \ldots \ldots \ldots \ldots \ldots \ldots \ldots \ldots \ldots$

Table F-76. ATA 1990 Air Travel Survey Data.$\ldots \ldots \ldots \ldots \ldots \ldots \ldots \ldots \ldots \ldots \ldots \ldots \ldots \ldots \ldots \ldots \ldots \ldots$

Table F-77. Adjusted MOBILE4.1 Emission Factors $\ldots \ldots \ldots \ldots \ldots \ldots \ldots \ldots \ldots \ldots \ldots \ldots \ldots \ldots \ldots \ldots \ldots$

Table F-78. EPA Highway Vehicle Classification Categories and Definitions $\ldots \ldots \ldots \ldots \ldots \ldots \ldots \ldots \ldots$ F-185

Table F-79. LDV Sulfur Dioxide and Carbọn Dioxide Emission Factors (Grams/Mile) $\ldots \ldots \ldots \ldots \ldots \ldots \ldots$ F-188

Table F-80. Lifetime Average Emission-Factors for Alternative Fuel Vehicles (Grams per Mile) . ........ F-190

Table F-81. TRAN Locomotive Emission Factors $\ldots \ldots \ldots \ldots \ldots \ldots \ldots \ldots \ldots \ldots \ldots \ldots \ldots \ldots \ldots \ldots$ F-193 
Table F-82. Aircraft Emission Factors F-198

Table F-83. Commericial Vessel Emission Factors.$\ldots \ldots \ldots \ldots \ldots \ldots \ldots \ldots \ldots \ldots \ldots \ldots \ldots \ldots \ldots \ldots$ F-201

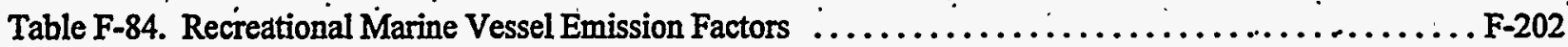

Table F-85. 'Ocean-Going Commercial Vessel Emission Factors $\ldots \ldots \ldots \ldots \ldots \ldots \ldots \ldots \ldots \ldots \ldots \ldots \ldots \ldots$ F-203

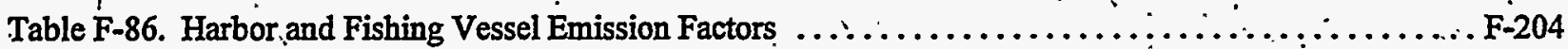

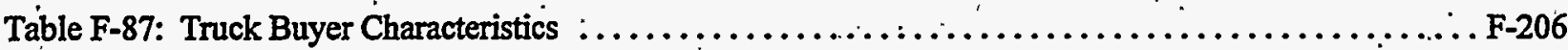

Table F-88: Light Duty Vehicle Purchases by Age and Sex, $1989 \ldots \ldots \ldots \ldots \ldots \ldots \ldots \ldots \ldots \ldots \ldots \ldots$. . . . F 207

\section{LIST OF FIGURES}

Figure F-1. Urban Share of Automobile VMT: Ĺgistic Forecast $\ldots \ldots \ldots \ldots \ldots \ldots \ldots \ldots \ldots \ldots \ldots \ldots \ldots \ldots$ F-94

Figure $\dot{F}-2$. Urban Share of Automobile VMT: Ĺgistic and Linear Forecasts $\ldots \ldots \ldots \ldots \ldots \ldots \ldots \ldots \ldots \ldots$ F-95

Figure F-3. Urban Share of Automobile VMT: $1953-1990 \ldots \ldots \ldots \ldots \ldots \ldots \ldots \ldots \ldots \ldots \ldots \ldots \ldots \ldots$

Figure F-4. Urban Share of Light Truck VMT: $1966-1990 \ldots \ldots \ldots \ldots \ldots \ldots \ldots \ldots \ldots \ldots \ldots \ldots \ldots \ldots \ldots$. . $\ldots \ldots$

Figure F-5. Average Vehicle Highway Speed: ${ }^{\prime} 1945-1990 \ldots \ldots \ldots \ldots \ldots \ldots \ldots \ldots \ldots \ldots \ldots \ldots \ldots$

Figure F-6. Percent of Highway. VMT over 55 MPH: $1981-1990 \ldots \ldots \ldots \ldots \ldots \ldots \ldots \ldots \ldots \ldots \ldots \ldots$. . $\ldots \ldots 4$

Figure F-7. Fuel Efficiency Gap for Automobiles (with Adjusted Driving Share) $\ldots \ldots \ldots \ldots \ldots \ldots \ldots \ldots \ldots$ F-112

Figure F-8. Fuel Efficiency Gap for Light Duty Trucks (Logistic Forecast) $\ldots \ldots \ldots \ldots \ldots \ldots \ldots \ldots \ldots$ F-113

Figure F-9: EPACT Effects on Business Fleet Automobiles $\ldots \ldots \ldots \ldots \ldots \ldots \ldots \ldots \ldots \ldots \ldots \ldots \ldots \ldots \ldots \ldots \ldots$

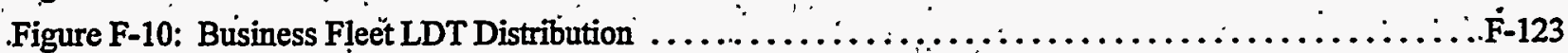

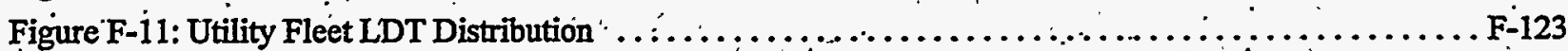

Figure F-12:Distribution of LDT's, by Fleet Size $\ldots \ldots: \ldots \ldots \ldots \ldots \ldots \ldots \ldots \ldots \ldots \ldots \ldots \ldots \ldots \ldots \ldots$ F-124

Figure F-13: Distribution of LDT's, by Fleet Size (Logarithmic Scale) $\ldots \ldots \ldots \ldots \ldots \ldots \ldots \ldots \ldots \ldots \ldots$ F-124

Figure F-14: Distribution of LDT's (Estimated Functional Form) $\ldots \ldots \ldots \ldots \ldots \ldots \ldots \ldots \ldots \ldots \ldots \ldots$ F-126

Figure F-15: Distribution of Business Fleet Vehicles $\ldots \ldots \ldots \ldots \ldots \ldots \ldots \ldots \ldots \ldots \ldots \ldots \ldots \ldots \ldots$ F-128

Figure F-16: Distribution of FHWA Single-Unit Truck Stocks $\ldots \ldots \ldots \ldots \ldots \ldots \ldots \ldots \ldots \ldots \ldots \ldots \ldots \ldots \ldots \ldots \ldots \ldots$

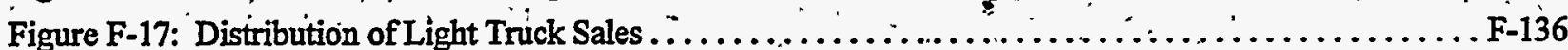

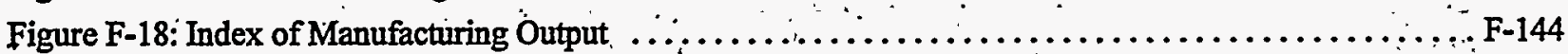

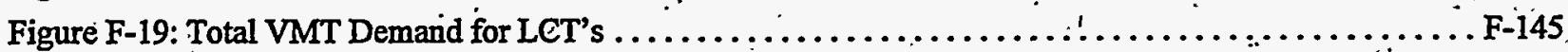

Figure F-20: Stock Average MPG for Light Commercial Trucks $\ldots \ldots \ldots \ldots \ldots \ldots \ldots \ldots \ldots \ldots \ldots \ldots \ldots$. 146

Figure F-21: Energy Consumption by Light Commercial Trucks $\ldots \ldots \ldots \ldots \ldots \ldots \ldots \ldots \ldots \ldots \ldots \ldots \ldots \ldots \ldots$

Figure F-22: Components of VMT Demand for LCT's $\ldots \ldots \ldots \ldots \ldots \ldots \ldots \ldots \ldots \ldots \ldots \ldots \ldots \ldots \ldots \ldots \ldots \ldots$

Figure F-23. Demographic Adjustment Index for Personal Air Travel: $1980-2040 \ldots \ldots \ldots \ldots \ldots \ldots$. F-164

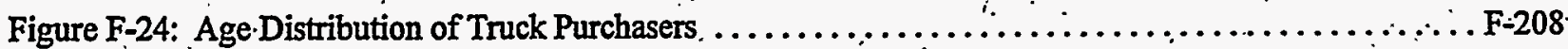

Figure F-25: Cumulative Percentage of Truck Purchasers $\ldots \ldots \ldots \ldots \ldots \ldots \ldots \ldots \ldots \ldots \ldots \ldots \ldots \ldots \ldots$ F-208

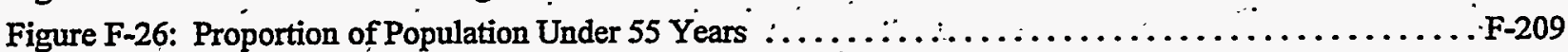

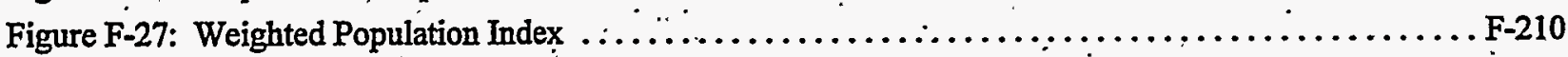

Figure F-28: Forecasts of Truck Sales Shares $\ldots \ldots \ldots \ldots \ldots \ldots \ldots \ldots \ldots \ldots \ldots \ldots \ldots \ldots \ldots \ldots \ldots \ldots \ldots \ldots \ldots \ldots \ldots$ 


\section{Appendix F. Attachments to the Transportation Model}

The attachments contained within this appendix provide additional details about the model development and estimation process which do not easily lend themselves to incorporation in the main body of the model documentation report. The information provided in these attachments is not integral to the understanding of the model's operation, but provides the reader with to opportunity to gain a deeper understanding of some of the model's underlying assumptions. There will be a slight degree of replication of materials found elsewhere in the documentation, made unavoidable by the dictates of internal consistency. Each attachment is associated with a specific component of the transportation model; the presentation follows the same sequence of modules employed in Volume I.

The following attachments are contained in Appendix F:

Attachment 1: Fuel Economy Model (FEM): Provides a discussion of the FEM vehicle demand and performance by size class models.

Attachment 2: Alternàtive Fuel Vehicle (AFV) Model: Describes data input sources and extrapolation methọdologies.

Attachment 3: Light-Duty Vehicle (LDV) Stock Model: Discusses the fuel economy gap estimation methodology.

Attachment 4: Light Duty Vehicle Fleet Model: Presents the data development for business, utility, and government fleet vehicles.

Attachment 5: Light Commercial Truck Model: Describes the stratification methodology and.data sources employed in estimating the stock and performance of LCT's.

Attachment 6: Air Travel Demand Model: Presents the derivation of the demographic index, used to modify estimates of personal travel demand.

Attachment 7: Airborne Emissions Model: Describes the derivation of emissions factors used to associate transportation measures to levels of airborne emissions of several pollutants. 


\title{
Attachment 1: Fuel Economy Model
}

\author{
Demand Models for Vehicle Size Class Mix \\ and Performance by Size Class
}

\section{INTRODUCTION:}

Estimates of the future mix of vehicle classes sold and the performance level by size class requires a detailed econometric demand model of vehicle choice by size class and vehicle performance within size class. There are a few publicly available models that forecast vehicle demand by size class, but those models have proved inaccurate in the past, and do not use a class structure that is compatible with the one used in the FEM. Demand for performance has not been assessed to date in any publicly available study. Both the size mix and performance levels are difficult to estimate because the car purchase decision is complex and consumer choice depends not only on the macroeconomic conditions but also on the attributes of individual products in the marketplace. Some of these attributes are based on the styling of the car, its perceived quality, the manufacturer's image and the status conveyed by owning a specific model, and cannot be easily quantified. Although these variables affect choice of individual models; they can also affect the choice of vehicle sizes or performance levels. For example, many consumers appeared to willing to buy a Japanese car for its quality and reliability even if it's size was smaller than the size actually desired by consumers. There have also been changes in consumer performance that may be linked to demographic variables, e.g., older consumers prefer larger cars:

These factors have made the automotive market notoriously difficult to forecast. - The models incorporated in the FEM do not represent an attempt to provide a comprehensive forecast of future shifts in size class mix or performance levels by size class in response to the potentially large range of influencing or causal variables. Rather, the models attempt to capture the response to broad macroeconomic forces or behavioral (time) trends based on the experience of the last 15 years. It is recognized that these models are relatively simplistic, and it is anticipated that future versions of the FEM will incorporate more advanced models. 


\section{METHODOLOGY}

The methodology employed to assess the influence of macroeconomic and time dependent variables on the mix of size classes and performance was by regression analysis of historical data.

EEA has compiled a very large data base on car and light truck sales over the 1979-1990 period. These data are based on the official CAFE files from EPA, augmented by the addition of vehicle and engine descriptor variables. All of the vehicles were classified by market class according to the scheme utilized in the FEM. Vehicle performance levels were measured by the horsepower to weight ratio (HP/WT) that is well correlated to objective measures such as the 0 to $60 \mathrm{mph}$ acceleration time. Detailed weight data was unavailable for light trucks, and hórsepower alone was used às a surrogate for performance. (Fortunately, truck weight within market classs did not change significantly in the 12 year period analyzed).

The models for size class mix and performance utilized the same set of independent variables

- Disposable income per capita (in 1990 dollars)

- Price of gasoline (1990 dollars)

- Vehicle price average by class

- Vehicle fuel economy

- Rate of change of gas price over two years

- Cost of driving per mile

- Number of nameplates (models) in a class

The last variable is really a composite of fuel cost/fuel economy and not a new independent variable

Performance was defined as the average HP/WT ratio by class for cars, and the average HP by class for trucks. Market share was defined as the sales fraction of the class relative to entire car and light truck market. This definition was chosen to incorporate the effects of consumers switching from cars to light trucks.

In general, the models were linear regressions of the logarithm of all variables, so that the coefficients represented "elasticity" estimates. However, the market share model was modified to utilize the variable $(\mathrm{m} / 1-\mathrm{m})$ as the independent variable in the regression, for two reasons. First, the 
elasticity of market share appears to be dependent on how large a share of the market a size class has. This reflects the fact that at very low market shares, buyers of a particular class are reduced to the diehard consumers who are less likely to switch due to macroeconomic forces, and the market is inelastic. Second the $\log (\mathrm{m} / 1-\mathrm{m})$ form converts a 0 to 1 variable to one that spans the -infinity to tinfinity range. As a result of this variable change the model cannot be driven to $m=1$ for any input set, so that no one market class takes over the entire market for any combination of inputs. Such a variable form has been utilized in prior analysis by Wheaton Econometric Forecasting Associates (WEFA).

\section{RESULTSS}

A "stepwișe linear regression of performance by market class and of class market share was performed to aid in the selection of independent variables with the greatest statistical significance. In addition, the co-efficients were required to be

- directionally consistent with intuitive expectations

consistent.in absolute magnitude across market classes that are similar

For the market share regressions, the variables that were statistically significant included: model year (time), price of gasoline, disposable income, number of nameplates (in some classes). In particular, number of nameplates was significant in those classes where only one or two makes existed in the early 1980's but new makes were introduced in the mid-to-late 1980's; compact vans are a good . example of this phenomenon.

Table F-1 shows the results of the regressions of ( $\mathrm{m}_{\mathrm{i}} / 1-\mathrm{m}_{\mathrm{j}}$ ) against the variables MDLY (model year), LPGAS (price of gasoline), LYD (per capita disposable income), and LNPLT (number of nameplates). The following conclusions are appropiriate:

Subcompact and minicompact market share benefits from a time trend towards smaller cars. Market share increases with increasing gasoline prices (1.33 coefficient) but decreases with increasing income.

- Sports cars market share appears to be declining with time but is insensitive to price of gasoline or income. :

- Compact car market share increase with time and increasing price of gasoline, but is insensitive to income trends. 
Table F-1. Regression Results From LDV Market Share Model

\begin{tabular}{|c|c|c|c|c|c|c|c|}
\hline ঋ & ?.8.1. & $\mathrm{R}^{2}$ & Intercept & $10 x$ & King.4S. & $1 \mathrm{NM} /$. & $1 \mathrm{NPLT}$ \\
\hline 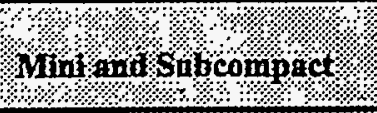 & $14.359^{\circ}$ & 0.891 & -5.428 & $\begin{array}{r}0.056 \\
(1.761) \\
\end{array}$ & $\begin{array}{c}1.33 \\
(1.828) \\
\end{array}$ & $\begin{array}{c}-0.169 \\
(-1.524)\end{array}$ & $\begin{array}{c}1.136 \\
(2.288)\end{array}$ \\
\hline 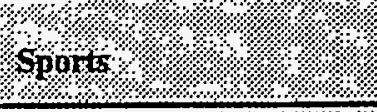 & 11.193 & 0.808 & -2.475 & $\begin{array}{c}-0.049 \\
(-1.903) \\
\end{array}$ & $\begin{array}{r}0.26 \\
(.466) \\
\end{array}$ & $\begin{array}{l}.0068 \\
(.059) \\
\end{array}$ & $\cdot{ }^{\circ}$ \\
\hline eompact. & $r: 5.533$ & 0.76 & -5.021 & $\begin{array}{c}0.111 \\
(2.117) \\
\end{array}$ & $\begin{array}{l}\therefore 1.332 \\
\because \quad(1.35) \\
\end{array}$ & $\begin{array}{l}0.107 \\
(.52) \\
\end{array}$ & $\begin{array}{l}0.383 \\
(.825) \\
\end{array}$ \\
\hline Intermediate. & 3.084: & 0.536 & -1.01 & $\begin{array}{r}-0.051 \\
(-1.742) \\
\end{array}$ & $\begin{array}{r}-0.213 \\
(-.335)\end{array}$ & $\begin{array}{l}-0.0017 \\
(-.013)\end{array}$ & \\
\hline rarge & . 16.880 & 0.864 & -3.312 & $\begin{array}{r}-0.119 \\
(-4.754) \\
\end{array}$ & $\begin{array}{l}0.042 \\
(.077)=-\end{array}$ & $\begin{array}{r}0.231 \\
-(2.018) \\
\end{array}$ & • \\
\hline Kinnox: & 18.458 & 0.939 . & -3.1 & $\begin{array}{r}0.126 \\
(2.336) \\
\end{array}$ & $\begin{array}{l}1.166 \\
(2.704) \\
\end{array}$ & $\begin{array}{r}0.169 \\
(1.441) \\
\end{array}$ & $\begin{array}{r}-0.435 \\
(-.699) \\
\end{array}$ \\
\hline Mintror & 1.378 & 0.341 & 2.268 & $\begin{array}{l}-0.018 \\
(-.168)\end{array}$ & $\begin{array}{c}-3.648 \\
:(-1: 6) \\
\end{array}$ & $\begin{array}{r}0.968 \\
(-2.027)\end{array}$ & \\
\hline compact Prokip. & $19.183^{\circ}$ & 0.916 & $\because$ & $\begin{array}{r}-0.042 \\
(-1.238) \\
\end{array}$ & $\begin{array}{r}-0.811 \\
(-1.48)\end{array}$ & $\begin{array}{c}0.174 \\
(1.247) \\
\end{array}$ & $\begin{array}{c}1.91 \\
(5.122) \\
\end{array}$ \\
\hline \%compackan & 804.167 & 0.998 & -9.3 & $\begin{array}{c}0.01 \\
(.352) \\
\end{array}$ & $\begin{array}{c}0.832 \\
(1.727) \\
\end{array}$ & $\begin{array}{c}0.307 \\
(3.045) \\
\end{array}$ & $\begin{array}{c}1.466 \\
(16.421) \\
\end{array}$ \\
\hline compact Uofility. & 274.104 & 0.994 & -7.36 & $\begin{array}{c}-0.042 \\
(-1.447) \\
\end{array}$ & $\cdot \begin{array}{c}-0.2 \\
(-.396) \\
\end{array}$ & $\begin{array}{c}0.366 \\
(2.933)\end{array}$ & $\begin{array}{r}0.763 \\
(8.474) \\
\end{array}$ \\
\hline 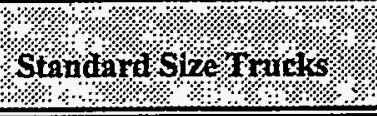 & 1.582 & 0.475 & -2.779 & $\begin{array}{r}-0.056 \\
(-1.523) \\
\end{array}$ & $\begin{array}{l}0.252 \\
(.307) \\
\end{array}$ & $\begin{array}{l}0.144 \\
(.846) \\
\end{array}$ & ; \\
\hline
\end{tabular}

- Intermediate car market.share is decreasing with time but is largely insensitive to either the price of gasoline or income.

- Large car market share decreases with time, but increases with income.

- Luxury car market share increases with time, income and the price of gasoline.

$\because$ Minitruck market share is very sensitive to the price of gasoline, and decreases with increasing gasoline prices and income.

- Compact.trucks and utilities market share are negatively influenced by time trends and price of gas, but positively by income:

- Compact vans have a unique trend relative to all trucks ir showing increasing market share with increasing gasoline prices. It is also positively influenced by increasing income.

- Full size trucks (pickup, vari and utility) show relatively stäble market shares, with a modestly declining time trend. Only utility vehicles' market share appear to be 
sensitive to income, while mạket shares of all full size trucks are insensitive to the price of gasoline.

Some of these trends initially appear to be counterintuitive, but one must consider the impact of a particular variable on sales of the class as well as the total fleet sales.. For example, while sales of

- luxury cars decreases with increasing gasoline ṕrices, the market share increases since sales of all other cars decline by a greater amount for the same change in the price of gasoline. Sales of minitrucks and compact pickup and utility vehịcles, most of which are used for personal $\because$ transportation or recreation, are also more strongly affected by increasing price of gasoline, and their market share drops. On the other hand standard size vehicles are used more commonily in the light commercial sector or for hauling rather than personal transportation and their market shares are relatively stable in response to gasoline prices:

It should be noted that the co-efficients in Table $\mathrm{F}-1$ are not elasticities as the dependent variable is $m_{i} / 1-m_{i}$, not $m_{i}$ alone. In general, the values of $m_{i}$ range from 0.05 to 0.20 . The correct "elasticity". co-efficient is the actual co-efficient times $1-m_{i} / 2$, so that multiplying the co-efficients in Table:F=1 by $0.4 \sim 0.475$ will provide an estimate of elasticity.

The performance model utilized a similar procedure, but the dependent variable was average HP/WT (or HP for trucks) by class. The most significant variables were found to be LFC (fuel consumption), personal income (LYD) and price of gas (LPGAS) in most cases. In some cases, cost . per mile (LCPM) provided a better regression when substituted for LFC and LPGAS. The results of the regression are shown in Table F-2. In general, the regressions yield the elasticities presented. in Table F-3.

The results indicate that virtually all classes respond similarly to the cost of driving, although for small cars (mini-, sub-, and compact cars) an equivalent result was obtained for fuel economy rather than cost per mile. Performance demand is more sensitive to disposable incóme, with the large. :trucks showing very high sensitivity. This particular finding is suspect and may. be due to the fact that significant engine improvements in the late 1980's (which increased rated HP) occurred in the same time frame when incomes were rising. 
Table F-2. Regression Results From LDV Performance Model

\begin{tabular}{|c|c|c|c|c|c|c|}
\hline $1 \% \%, 1$ group & 6. 1.1 & 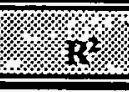 & Tintereept & . 1.160 & $2 / \mathrm{yp}$ & LPGAS \\
\hline Mini andsinbcomingact & 14.819 & 0.848 & 13.893 & $\begin{array}{r}-0.238 \\
(1.706) \\
\end{array}$ & $\begin{array}{c}1.012 \\
(-2.270)\end{array}$ & $\begin{array}{c}0.11 \\
(-.811)\end{array}$ \\
\hline sports & 7.675 & 0.742 & -1.104 & $\begin{array}{l}-0.311 \\
(1.299)\end{array}$ & $\begin{array}{r}-0.533 \\
. \quad(.666)\end{array}$ & $\begin{array}{l}-0.364 \\
(1.616)\end{array}$ \\
\hline Conpapt & 1.1 .613 & 0.813 & 20.7 .09 & $\begin{array}{l}-0.252 \\
(3.094)\end{array}$ & $\therefore \begin{array}{l}1.721 \\
(-3.308)\end{array}$ & $\begin{array}{l}0.403 \\
(-2.679)\end{array}$ \\
\hline Yinteranedinte\% & 57.101 & 0.956 & 14.252 & $\begin{array}{r}-0.099 \\
(.845) \\
\end{array}$ & $\begin{array}{c}1.114 \\
(-3.296) \\
\end{array}$ & $\begin{array}{l}-0.0051 \\
(.050)\end{array}$ \\
\hline 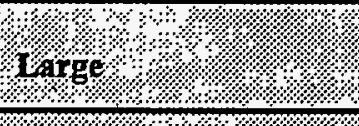 & 72.509 & 0.964 & $\therefore 10.429$ & $\begin{array}{l}-0.168 \\
(1.380) \\
\end{array}$ & $\begin{array}{r}0.704 \\
(-1.902) \\
\end{array}$ & $\begin{array}{l}-0.171 \\
(1.535) \\
\end{array}$ \\
\hline 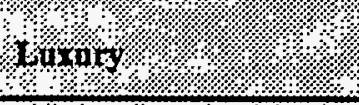 & 151.145 & 0.983 & 11.085 & $\begin{array}{r}-0: 124 \\
(1.859)\end{array}$ & $\begin{array}{r}0.79 \\
\cdot(-2.704) \\
\end{array}$ & $\begin{array}{l}-0.248 \\
(2.912)\end{array}$ \\
\hline 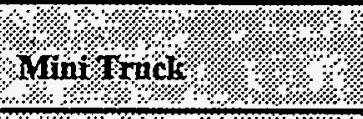 & 0.219 & 0.076 & 0.88 & $\begin{array}{l}0.378 \\
(.550) \\
\end{array}$ & $\begin{array}{r}0.483 \\
.(230) \\
\end{array}$ & $\begin{array}{l}0.035 \\
(.056) \\
\end{array}$ \\
\hline 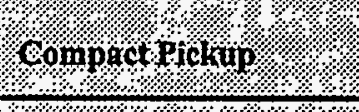 & 35.043 & 0.929 & -9.264 & $\begin{array}{r}-0.119 \\
(-.646) \\
\end{array}$ & $\begin{array}{r}1.409 \\
(3.045) \\
\end{array}$ & $\begin{array}{r}0.03 \\
(.228) \\
\end{array}$ \\
\hline Compact Yan & 57.789 & 0.956 & -33.712 & $\begin{array}{r}-0.853 \\
(-2.375) \\
\end{array}$ & $\begin{array}{l}3.722 \\
(2.960) \\
\end{array}$ & $\begin{array}{r}-0.0044 \\
(-.012)\end{array}$ \\
\hline Qompact Utintir. & 21.804 & 0.891 &.-10.507 & $\begin{array}{r}-0.586 \\
(2.824) \\
\end{array}$ & $\begin{array}{r}1.785 \\
(2.149) \\
\end{array}$ & $\begin{array}{l}-0.063 \\
(-.264)\end{array}$ \\
\hline 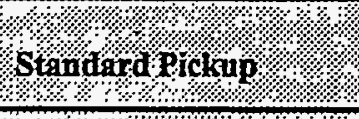 & .16 .854 & 0.863 & -17.358 & $\begin{array}{r}0.276 \\
(1.315) \\
\end{array}$ & $: \begin{array}{c}2.41 \\
(3.182) \\
\end{array}$ & $\begin{array}{l}=0.271 \\
(1.257)\end{array}$ \\
\hline Standardvan & $\ddot{37.117}$ & 0.933 & -14.171 & $\begin{array}{r}.0 .142 \\
(1.061) \\
\end{array}$ & $\begin{array}{r}2.038 \\
(4.393) \\
\end{array}$ & $\begin{array}{r}0.195 \\
(1.72) \\
\end{array}$ \\
\hline standard Utility. & 21.177 & 0.888 & -19.425 & $\begin{array}{r}0.331 \\
(2.144) \\
\end{array}$ & $\begin{array}{r}2.54 \\
(3.398) \\
\end{array}$ & $\begin{array}{c}0.253 \\
(1.176)\end{array}$ \\
\hline
\end{tabular}

Table F-3: LDV Performance Model Elasticities

\begin{tabular}{|c|c|c|c|c|}
\hline 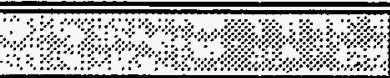 & \%. $\mathrm{\text {HeC }} / \%$ & 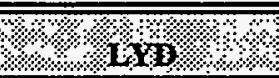 & \% & $1 \%$ LCPM: \\
\hline sman cats $/ 2 \%$ & $-0.23 \sim-0.30$ & +1 to +1.7 & N.S. & . \\
\hline Garge Cars & $-0.10 \sim-0.17$ & 0.7 to 1.0 & Variable & -0.1 to -0.20 \\
\hline Sinalltruncks: & N.S. & +1.4 to +1.7 & N.S. & -0.24 to -0.33 \\
\hline standard hrucks & N.S. & -2.0 to 2.5 & N.S. & -0.23 to -0.35 \\
\hline
\end{tabular}

N.S. - Not Specified 


\section{VALUE OF'PERFORMANCE AND FUEL ECONOMY ADJUSTMENT}

The value of performance is defined as the dollar amount that consumers are willing to pay for horsepower. This value was estimated from the actual list price for the vehicles in the 1988-1990 period and was based on the engine option prices. This method assumes that the manufacturers are pricing horsepower at-levels that consumers are willing to pay. Most domestic models offer an optional engine with higher HP, while several import models offer optional turbocharged engines or 4-valve engine versions. In each case the cost of the engine option alone was identified from manufacturer price lists for 1989/1990 models (very often, the engine option is available with other features such as performance tires, aerodynamic devices etc. so that the vehicle price is higher than the cost of the engine option). Based on the prices of engine options, the following averages are applicable for all cars except sports and luxury cars:

Table F-4: LDV Performance and Price Options

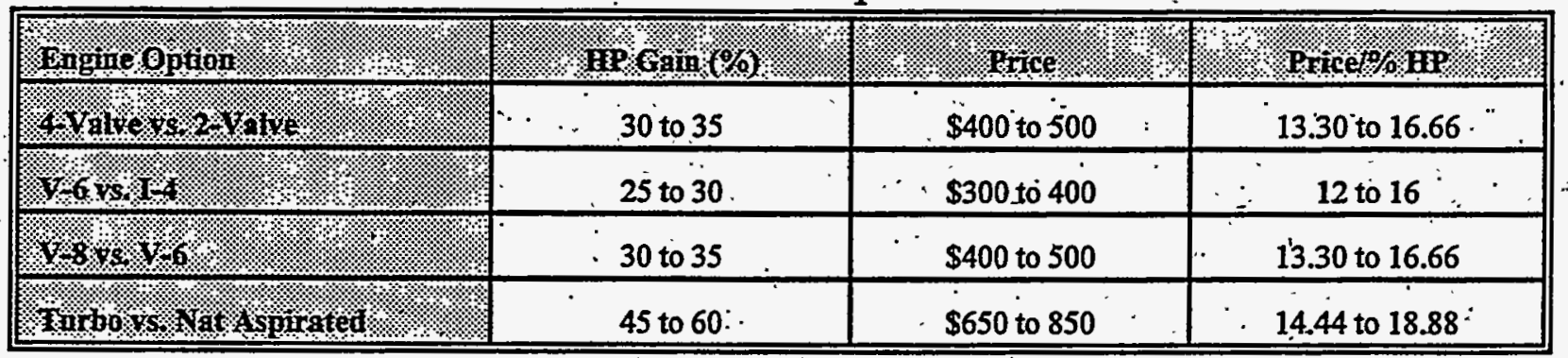

Based on these data, an approximate average value of performance is $\$ 15$ per percent increase in $\mathrm{HP}$. Most sports and several luxury cars charge prices that are 15 to 25 percent higher than the values quoted above.(although some very high priced luxury cars such as:Mercedes, Porsche, and BMW charge more than twice the values quoted above). Accordingly, the value of performance for these classes has been set to $\$ 18$ per percent increase in HP.

Increasing performance also decreases fuel economy and this relationship is derived from a regression analysis of fuel economy data that provides the sensitivity of fuel economy to factors that increase performance. In general, performance can be increased by four methods:

- by increasing the axle ratio

- by installing a larger engine with the same number of cylinders

- by installing a larger engine with more cylinders 
by utilizing 4-valve heads or turbocharging

The first method is suitable only for small changes in performance (less than 10 percent). The second method is useful for changes in the range of 10 to 25 percent. The use of engines with more cylinders can result in HP gains of 30 to 60 percent (4 cylinder to 6 cylinder, or 6 cylinder to 8 cylinder). 4-valve engines generally provide HP gains of 20 to 25 percent relative to a 2-valve engine of equal displacement, while turbocharging can provide an HP increase of 40 to 45 percent relative to a naturally aspirated engine of equal displacement. These technologies can be combined with displacement increases or decreases to achieve any desiresd result.

Based on engineering and regression analysis (see Appendix G, Supplement 1), the fuel economy sensitivity for axles ratio changes is -0.22 (i.e., a 10 percent axle ratio increase decreasès fuel economy by 2.2 percent). The fuel economy sensitivity for displacement changes without changing the number of cylinders is -0.35 (i.e. a 25 percent change in displacement decreases fuel economy by nine percent, including the effect of increased engine weight). Substituting a $V-6$ for a 4-cylinder or a V-8 for a V-8 significantly increases the vehicle weight, and a fifty percent HP increase decreäses fuel economy by about 25 percent.

A non-linear equation that captures these effects is given by

$$
\begin{aligned}
\Delta F E= & -0.22 \Delta H P-0.56 \Delta H P^{2} ; \quad \triangle H P=0 \\
& =-0.22 \Delta H P+0.56 \Delta H P^{2} ;: \Delta H P<0
\end{aligned}
$$

where both $\triangle \mathrm{HP}$ and $\triangle \mathrm{FE}$ are expressed as percent changes. The equation is valid for $\Delta \mathrm{HP}$ values between 0 and 60 percent: 


\section{TECHNOLOGY IMPROVEMENTS FOR AUTOMOBILES}

The characteristics of the automotive technologies considered in the LDV module have been developed by Energy and Environmental Analysis, Inc: of Arlington Virginia, and are tabulated on the following pages in Tables F-6 to F-9.1 Much of this research has been derived from an 'earlier study of technological change and its potential application to fuel economy improvements. ${ }^{2}$ In this study, numerous automotive technologies have been evaluated in regard to both their estimated impacts on vehicle performance and their cost-effectiveness from a producer's standpoint. Individual technologies or groups of technologies have been assigned to one of three "certainty levels", defined below, which indicates the likelihood of their incorporation in the near-term:

The ${ }_{2}$ Standard Technology Matrices for cars and light trucks (Tables F-6 and F-7) represent a relatively conservative estimation of technology cost, availability, and impact over the course of the forecast. The corresponding High Technology Matrices (Tables F-8 and F-9) reflect a more optimistic assessment of the potentials of selected technologies. In order to permit a ready comparison of technology characteristics, those elements in the High Technology Matrices which - differ from their Standard Technology counterparts are shaded.

\begin{tabular}{|c|c|}
\hline \multicolumn{2}{|c|}{ 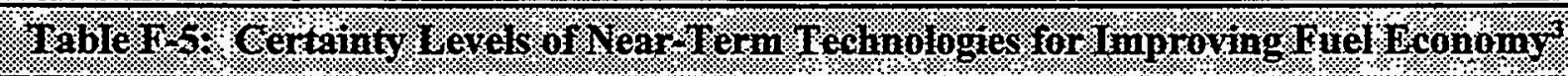 } \\
\hline 1.2\%: & rechnology diaracterisios \\
\hline : & $\begin{array}{l}\text { Technologies currently in production in at least one mass market vehicle worldwide and which have } \\
\text { no technical risk in the sense that they are fully demonstrated and are available to all manufacturers } \\
\text { through either direct production or licensing. Level } 1 \text { improvements are therefore available for } \\
\text { production use within one product cycle: }\end{array}$ \\
\hline (3. & $\begin{array}{l}\text { Techinologies ready for commercialization and for which there are no engineering constraints (such } \\
\text { as- emissions control considerations) } \cdot \text { which would inhibit their use in production - vehicles. } \\
\text { Technologies assessed at Level } 2 \text { are considered to have low technical risk in the sense that some } \\
\text { "debugging" effortmay be required because of a lack of on-road experience }\end{array}$ \\
\hline (4) & $\begin{array}{l}\text { Technologies in advanced stages of development but which may face some technical constraints } \\
\text { before they can be used in production vehicles. Because Level } 3 \text { technologies bear some uncertainty } \\
\text { as to when they will be fully available for use in production, it is not possible to presently establish } \\
\text { with certainty that they are available for incorporation into new vehicles over the course of a complete } \\
\text { product cycle. }\end{array}$ \\
\hline
\end{tabular}

${ }^{1}$ NEMS Fuel Economy Model: LDV High Technology Update, Decision Analysis Corporation of Virginia, DE-AC0192EI21946, Task 95124, Subtask 9-2, 6/17/96.

'DeCicco, J., and Ross, M., An Updated Assessment of the Near-Term Potential for Improving Automotive Fuel Economy, American Council for-an Energy-Efficient Economy, Washington DC, 11/93.

3Ibid. p. 12. 


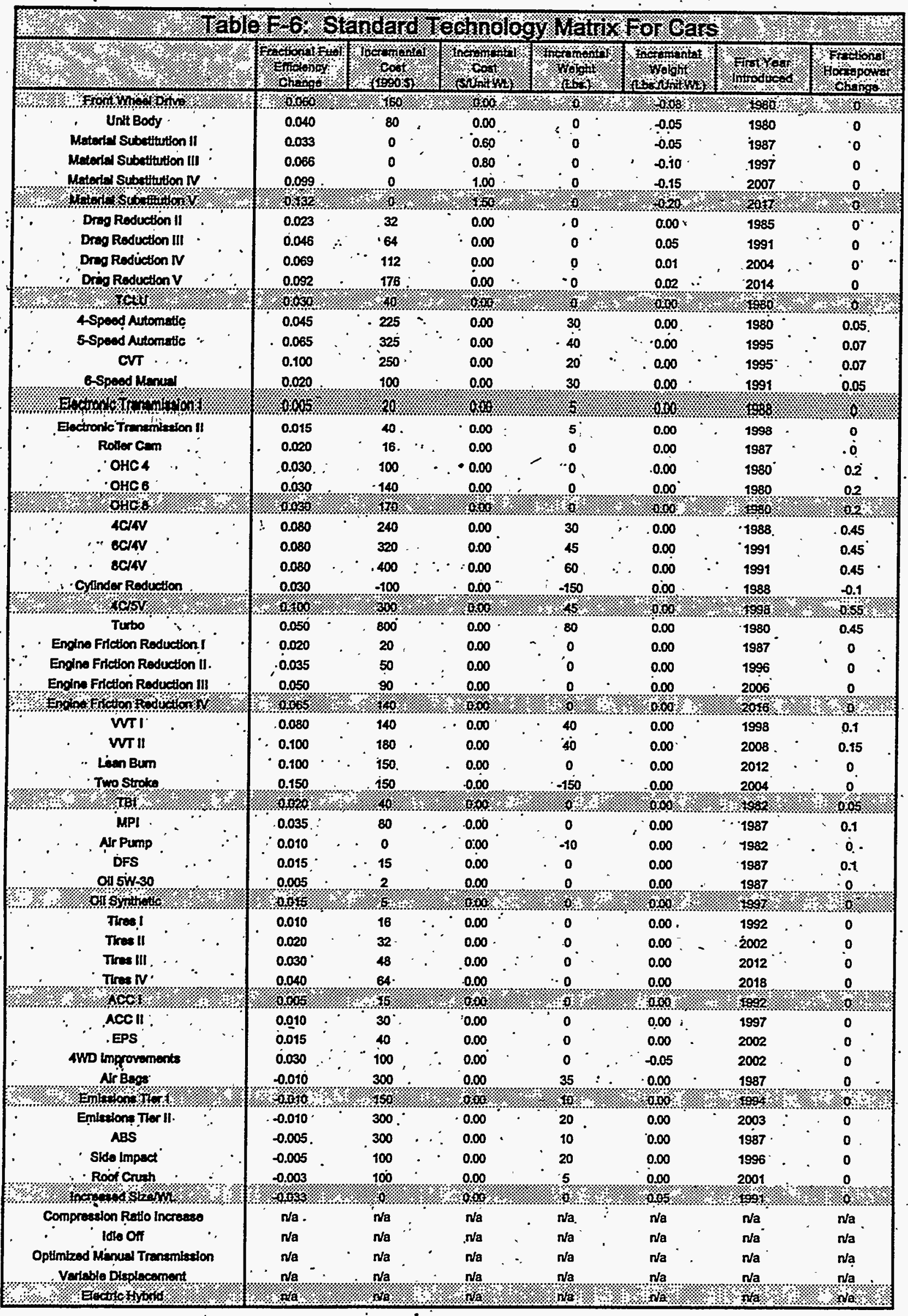




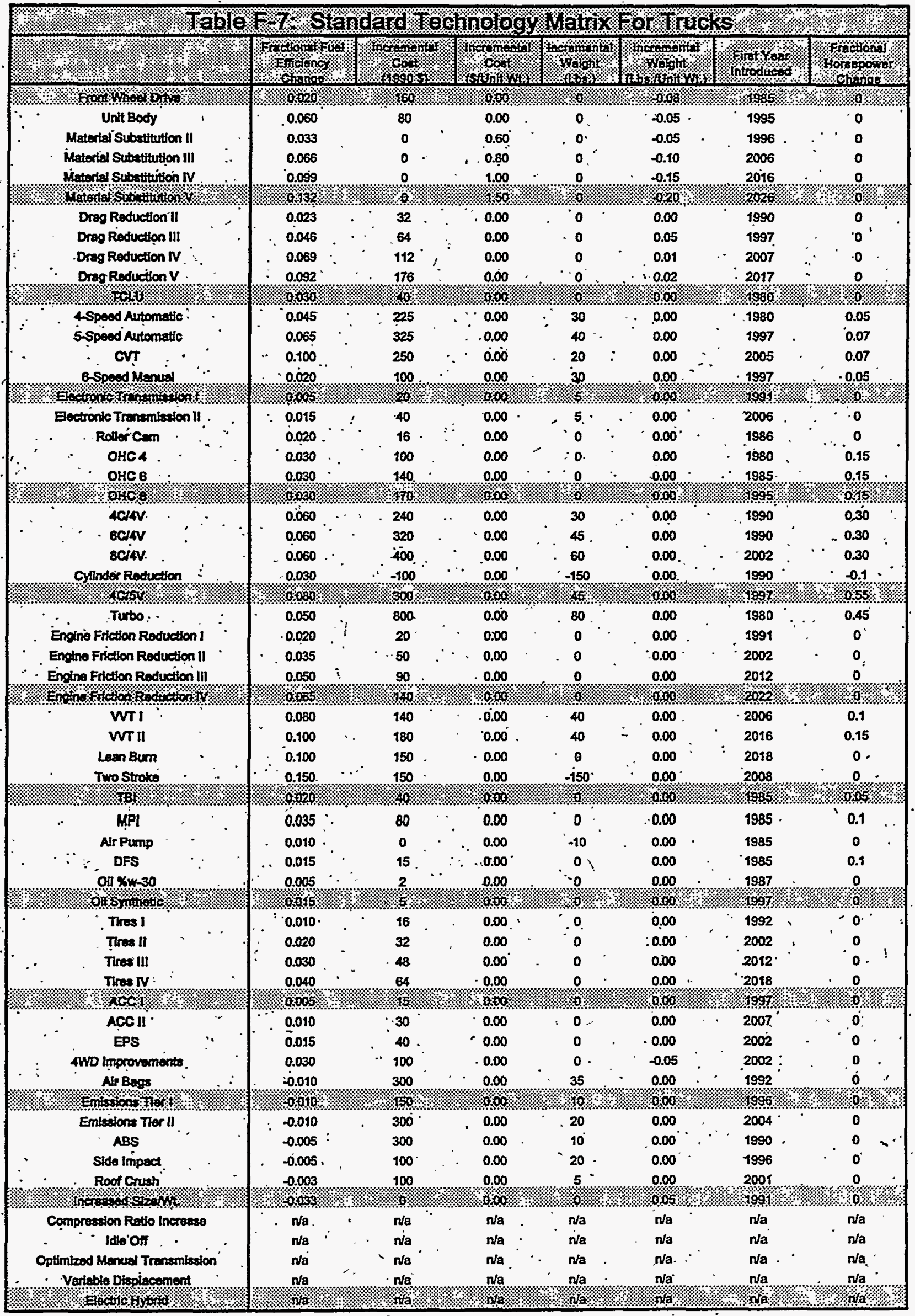




\begin{tabular}{|c|c|c|c|c|c|c|c|}
\hline ?. & tablo: & oligin & Canolog & Mats & For \%ars & & ই. \\
\hline \%ै। & 6enonaffior & $\% 100 \%$ & 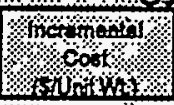 & \%orioging & Whoonting & 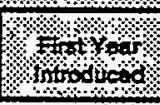 & Houtionst: \\
\hline \%\% \%onknolod & $10060 \%$ & 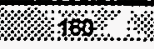 & $\% 00 \%$ & $10 \%$ & 1008. & $1600 \%$ & \% \\
\hline Unit Body' & 0.040 & 80 & 0.00 & 0 & -0.05 & 1980 & 0 \\
\hline Materdel Subetititition II & 0.033 & 0 & 稵 & 0 & -0.05 & 1987 & 0 \\
\hline Meterial Subetthution III & 0.066 & 0 & 实 & 0 & -0.10 & 1997 & 0 \\
\hline Materes Subettitition N & $0.099^{\circ}$ & 0 & (x) & 0 & -0.15 & 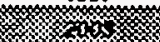 & 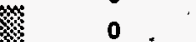 \\
\hline Iato sobmitoon & $0.132 \%$ & 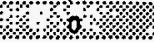 & 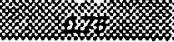 & 0. & 1.1 .020 & \% & \%. \\
\hline Drag Roduction II & 0.023 & 32 & 0.00 & 0. & 0.00 & 1985 & 0 \\
\hline Drag Reduction III & 0.046 & 64 & 0.00 & 0 & 0.05 & .1991 & $\cdot 0$ \\
\hline Drag Roduction NV & 0.069 & .112 & 0.00 & 0. & 0.01 & 慈 & 0 \\
\hline$\therefore$ Dreg Reduction V & 0.092 & 178 & $\ddot{0} 000$ & 0 & 0.02 & 玆 & 0 \\
\hline$\%$ & $0 \%$ & 40. & oos. & $1 \%$ & $000 \%$ & oso: & १०: \\
\hline 4spoed Automatic & 0.045 & 225 & 0.00 & 30 & 0.00 & 1980 & 0.05 \\
\hline 5-Speod Automitic & 0.065 & 325 & 0.00 & 40 & 0.00 & $\because \quad 1995$ & 0.07 \\
\hline CVT & 0.100 & $250^{\circ}$ & 0.00 & 20. & 0.00 & $\cdots 1995$ & 0.07 \\
\hline ESpood Manued & 0.020 & .100 & 0.00 & $30^{\circ}$ & 0.00 & 1991 & 0.05 \\
\hline 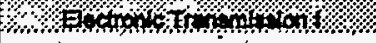 & $\cos x$ & $.20 \%$ & osoo & s. & 0 & 1986 & 80 \\
\hline Eectronic Trmemiertion I & 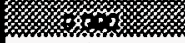 & 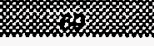 & $.0 .00^{\circ}$ & 5 & 0.00 & 1998. & 0 \\
\hline Roller Cam & 0.0 .020 & 16 & 0.00 & 0 & .0 .00 & 1987 & 0 \\
\hline OHC4: :. & 0.030 & 4 & 0.00 : & 0 . & 0.00 & 1980 & 0.2 \\
\hline $\mathrm{OHCO}$ & 0.030 & s. & 0.00 & 0 & 0.00 & 1980 & 02 \\
\hline ৭ & \%agso & $x$ & $60 \%$ & 0 & 0000 & 81080 & $802 \%$ \\
\hline ; $\quad$ ACAV. & $\therefore 0.080$ & ; & 0.00 & 30 & 0.00 & 1988 & 0.45 \\
\hline - 6CAK & 0.080 & 镐 & 0.00 & 45 & 0.00 & 1991 & 0.45 \\
\hline - $8 \mathrm{CAN}$ & 0.080 & 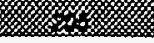 & 0.00 & 60 & 0.00 & 1991 & 0.45 \\
\hline Oyinder Roduction & 0.030 & -100 & 0.00 & -150. & 0.00 & 1988 & -0.1 \\
\hline $1 \%$ \% 1 Ler & 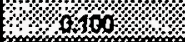 & 800 & $660 \%$ & 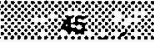 & $000 \%$ & $\%$ \%ss & $0655 \%$ \\
\hline$\therefore$ Tuto & 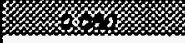 & 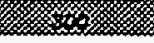 & 0.00 & 80 & 0.00 & 1980 & 0.45 \\
\hline Endine Fritition Reduction I & 0.020 & 20 & 0.00 & .0 & 0.00 & 1987 & 0 \\
\hline Engline Friction Reduction II & 0.035 & 50 & 0.00 & 0 & 0.00 & 1996 & 0 \\
\hline Enoine Frletion Roduction III & 0.050 & 90 & 0.00 & 0 & 0.00 & 2006 . & 0 \\
\hline 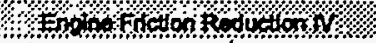 & 洛os & 嬥 & $0.0 \%$ & 30 & $000 \%$ & 2016 & 1 \\
\hline WTI I & 0.080 & 级 & 0.00 & 40 & 0.00 & 1998 & 0.1 : \\
\hline wTI! & 0.100 & 媇 & 0.00 & 40 & $0.00^{\circ}$ & 2008 & $0.15^{\circ}$ \\
\hline Lean Bim : & 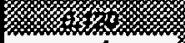 & 㮡 & 0.00 & o & 0.00 . & 2012 & 0 \\
\hline Tro Stroke & .0 .150 & & 0.00 & $-150^{\circ}$ & 0.00 & 2004 & 0 \\
\hline \% \% \%া & $+\infty, 800$ & $\$$ & 600 & o. & $8000 \%$ & $2.98 \% \%$ & $\% .0 .05 \%$ \\
\hline MPI & 0.035 & 80. & 0.00 & 0 & 0.00 & $1987^{\circ}$ & 0.1 \\
\hline Aṛ Pump & 0.010 & 0. & 0.00 & -10 & 0.00 & $1982^{\circ}$ & 0 \\
\hline DFS & .0 .015 & 15 & 0.00 & 0 & 0.00 & 1987 & 0.1 \\
\hline 요 $\%$ - $30^{\circ}$ & 0.005. & 2 & 0.00 & 0 & $0.00^{\circ}$ & 1987 & 0 \\
\hline 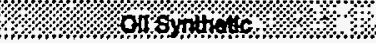 & ons & 5 & 0.000 & 10 & $600 \%$ & 1097 & $10 \%$ \\
\hline$\therefore$ Trees I & 0.010 & 聯 & 0.00 & 0 & 0.00 & 1992 & 0 \\
\hline Tires II : & 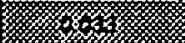 & 6 & 0.00 & 0 & 0.00 . & 2002 & .0 \\
\hline Troe III $\because$ & 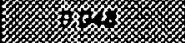 & sx & 0.00 & 0 & 0.00 & 2012. & 0 \\
\hline Tros $N$ & 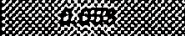 & 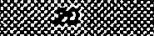 & 0.00 & 0 & 0.00 & $2018^{\circ}$ & 0 \\
\hline $14 \%, \% \mathrm{cct} / \%$ & 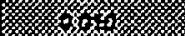 & 筮 & $800 \%$ & 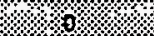 & $0.00 \%$ & 1892 & 60.4 \\
\hline$\cdot$ ACC II . & 聯缨 & (x) & $0.00 ;$ & $\cdot 0^{\prime}$ & 0.00 & 1997 & 0 \\
\hline$\because$ EPS & 0.015 & 40 & 0.00 . & 0 & 0.00 & 2002 & 0 \\
\hline AWD Improvernents & 0.030 & 100 & 0.00 & 0 & -0.05 & 2002 . & 0 \\
\hline Ar Bege & -0.010 & 300 & 0.00 & 35 & 0.00 . & 1987 & 0 \\
\hline \%२ Emintion 1101 & $00010 \% \%$ & $130 \%$ & $1.000 \%$ & 1. $00 \%$ & 1000 & $1004 \div 1$ & $100 \%$ \\
\hline Emlextone Ther II: & -0.010 & 300 & 0.00 & 20 & .0 .00 & 2003 & 0 \\
\hline ABS & -0.005 & 300 & 0.00 & 10 & 0.00 & 1987 & .0 \\
\hline Sida Impenct & -0.005 & 100 & 0.00 & $20^{\circ}$ & 0.00 & -1996 & $\cdots 0$ \\
\hline Roof Cruph & -0.003 & $100^{\circ}$ & 0.00 & 5 & 0.00 & 2001 & 0 \\
\hline 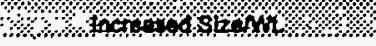 & $\% 00030 \%$ & $\%$ & $10.0 \%$ & \%1\% & $40.05 \%$ & \%. & \% \\
\hline Compropiton Retio Increase & 0.010 & 0 & 0.00 & 0 & 0.00 & 1895 & 0.02 \\
\hline Idte on & 0.110 & .200 & 0.00 & 0 & 0.00 & 1997. & $\because 0$ \\
\hline Optinized Manual Tranamlacion & 0.120 & 60 & 0.00 & 0 & 0.00 & 1997 & 0 \\
\hline - Verieblo Displacement & 0.030 & 65 & 0.00 & $0 \vdots$ & 0.00 & 1999 & 0 \\
\hline 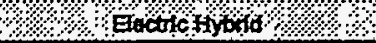 & $\% .0 .660$ & 4785. & $0: 00$. & 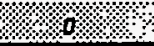 & 0.00 & $2001 \% 1$ & ! \\
\hline
\end{tabular}




\begin{tabular}{|c|c|c|c|c|c|c|c|}
\hline 0 & 000 & 8000 & 0 & 000 & 6 & 0930 & 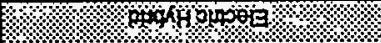 \\
\hline .0 & 6661 & $000 \ldots$ & 0 & 000 & 59 & 0.000 & 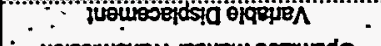 \\
\hline $0_{1}$ & $268 \mathrm{~b}$ & $\infty 0^{\circ}$ - & 0 & $\infty$ & $\infty$ & $0 z 10$ & uojsspusures $\perp$ fenuew poẓum \\
\hline 0 & $\angle 661=$ & $\infty 0^{\circ}$ & 0. & $\infty$ & 0,2 & OLt'o. & $\therefore$ 1001py. \\
\hline 20 & S66L & 000 & 0. & $\infty$ & 0 & $010^{\circ} 0$ & 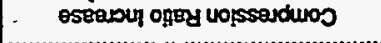 \\
\hline 8 & 466 & $10 \%$ & $\%$ & $\%$ & $\%$ & $\cos \alpha$ & Horsoph \\
\hline 0 & 1002 & $000^{\circ}$ & $\mathbf{s}$ & 000 & कot & $800 \%$ & HSint 1000 . \\
\hline 0 & $966 L^{\prime}$ & $00 \%$ & oz & 0,0 & oot. & 5000 & peduy opIS. \\
\hline 0 . & 然衫㥪 & $00^{\circ}$ & or & $00 \%$ & $00 \varepsilon$. & 9000 & sgy \\
\hline 0 & 3 & 000 & $\because, 0 z$ & $00 \%$ & $00 \varepsilon$ & 0100 & 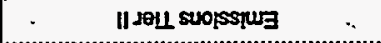 \\
\hline \% & 4 & $0 \%$ & ol & $00 \%$ & $09 \%$ & $0 \%$ & Pow \\
\hline 0 & 4 & 000 & $s$ & 000 & 008 & $060^{\circ}$ & . . S6e日 IN \\
\hline $0 \cdot$ & $200 z$ & soo. & 0 & $\infty 0^{\circ} 0$. & oor & $080^{\circ} 0$. & strourenojdu aMt. \\
\hline .0 & $200 z=$ & 000 & 0 & $\therefore \infty 0^{\circ}$ & or. & $\therefore$ sioo & $\operatorname{Sdg}$ \\
\hline & \% & $\infty 0^{\circ}$ & 0 & $.000_{=}$ & F & 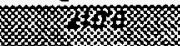 & - $1100 \%$ \\
\hline \%o & 3 & $60 \%$ & 然 & $\% \%$ & 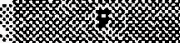 & 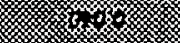 & WOH \\
\hline 0 & 960 & 000 & 0 & 1000 & 邺 & 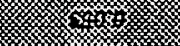 & $N$ sell \\
\hline 0 & $z 10 z$ & $00 \%$ & $0^{-1}$ & 000 & 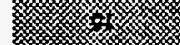 & ; & . III sint \\
\hline 0 & $\cdots z 00 z$. & $00 \%$ & 0 & $00 \%$ & 桠 & s & : $\quad 11 \operatorname{san} 4$. \\
\hline 0 & 2661 & $\infty 0^{\circ}$ & $0^{-}$ & $00 \%$ & 聯 & 0600 & 1 san1 \\
\hline \%o & 465 & $1000 \%$ & $\%$ & $\% 00 \%$ & 3 & sive & Who \\
\hline 0 & 2861 & 000 & 0 & 000 & $\bar{c}$ & 9000 . & OEMS 110 . \\
\hline 10 & 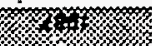 & $00 \%$ & 0 & $\infty 0^{\circ}$. & St & s10.0 & SAa \\
\hline & s & $\infty 0^{\circ}$ & $\therefore$ ot- & 00.0: & 0 & OLOOO & dund $4 \nabla$. \\
\hline LOO & 誃彩 & .000 & $\therefore .0^{\circ}$ & 000. & 08 & seo.0. & $\therefore \quad:$ IdW \\
\hline stro & 缕稵 & $\infty$ & \%. & $\%$ & 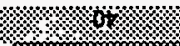 & 6 & max \\
\hline 0 & s & $00^{\circ}$ & ost: & 000 & 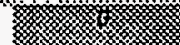 & .0 sto & oxans om 1 \\
\hline 0 & 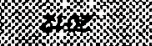 & $00 \%$ &.$\quad 0$ & $\infty 0^{\circ} 0$ & 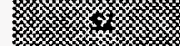 & ooto & 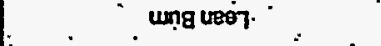 \\
\hline sto & th & $\infty 00$. & ot & $00^{\circ}$. & 协 & 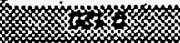 & IIM \\
\hline 10. & 8 & 00 & $\therefore$ os. & 000. & 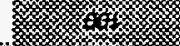 & 0800 & ILM. . \\
\hline$\%$ & 8 & $\%$ & 列 & $0 \%$ & 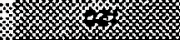 & $5 \%$ & 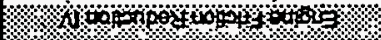 \\
\hline 0 & ks & $00^{\circ}$ & 0 & 000 & 06 & 0000 & 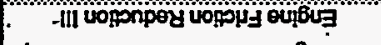 \\
\hline 0 & $z^{2}$ & $00^{\circ} 0^{\circ}$ & $\ddot{0}$ & $00 \%$ & os & seoro & \| uopanpey uoppu \\
\hline 0 & 4 & $\infty 0^{\circ}$ & 0 & 000 & oz. & $0200^{\circ}$ & - 1 vopnpey voppy oupits \\
\hline sto & 0861 & 000 & 08 & 000 . & 4 & m & . : $\alpha n \perp$. \\
\hline sso & resis & $000 \%$ & in & $\%$ & 00 & 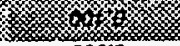 & 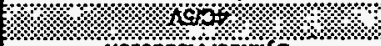 \\
\hline 10 & 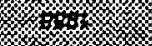 & 000 & OSt- & 000 & $002^{-}$ & 0800 & - Uoporpoy Jopugiko \\
\hline$\alpha$ & 4 & $00^{\circ} 0$ & 09 & $\infty 0^{\circ} 0$. & 要数 & 聯 & $\Lambda * 108$ \\
\hline 嘫 & 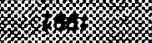 & $00 \%$ & st & 000 & 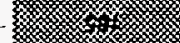 & 㩁 & 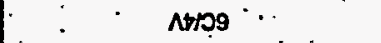 \\
\hline 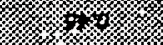 & 3 & $00^{\circ}$ & $0 \varepsilon$ & $\infty$ & $x$ & xy & $\therefore$ Nrtor \\
\hline 多䊽 & 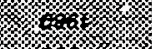 & $00 \%$ & 0 & $60 \%$ & 證 & $\cos 00$ & H人 \\
\hline x & 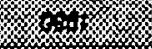 & 000 & 0 & 000 & 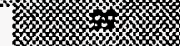 & $0 \varepsilon 00$ & $90 \mathrm{HO}$ \\
\hline 4 & .0865 &,$\infty 00$ & 0 i. & $\dot{0} 0$ & 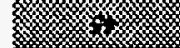 & $\therefore 080^{\circ} 0$ & ТOHO. \\
\hline 0 & \% & 000 & 0 . & .000 & 96 & 02000 & - بep say \\
\hline o & 6 & $00 \%$ & s & $00 \%$ & 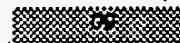 & $3 x$ & 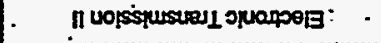 \\
\hline $8 \%$ & 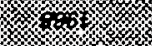 & $\%$ & 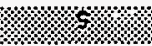 & 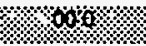 & $x$ & 19030 & 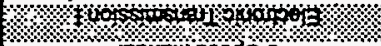 \\
\hline soo. & $\%$ & 000 & $\alpha \varepsilon$ & 000 & $\because 00 t$ & 0200 & 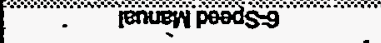 \\
\hline $20^{\circ} 0$ & 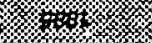 & $\infty$ & $0 z$ & 0,0 & osz' & 0010. & 1100. \\
\hline $20^{\circ} 0$ & 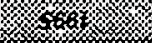 & $000^{\circ}$ & $0 t$ & $00^{\circ} 0$ & SEE & $590 \% 0$ & : . ogewormy poods \\
\hline SO0. & 0861 & $000^{\circ}$ & $0 \varepsilon$ & 000 & szz & $5+0 \%$ & - oneworny poodst \\
\hline$\%$ & ofot & 0 & \% & $0 \%$ & $\%$ & 80 & $x$ \\
\hline 0 & 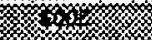 & 200 & 0 & 000 & 921 & 2600 & Auoponpoy Besa \\
\hline o. & 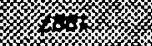 & $10 \%$ & 0 & $\infty 0^{\circ}$ & $\dot{z}$ & 6900 & Nuopopoy Bas . \\
\hline 0 & 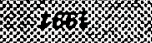 & soto & $0 \quad 1$ & $00^{\circ} 0$ & +9 & $960 \%$ & . . ili uoporpey besa \\
\hline 0 & 8 & $\infty \%$ & 0 & $00 \%$ & ¿ะ & $\varepsilon 20^{\circ} 0$ & II voponpoy Besa \\
\hline$\%$ & 3 & $0 \%$ & $\%$ & 4 & 详: & $20 \%$ & Wrophospos \\
\hline 0 & $\xi$ & sio: & 0 & 被 & $\because 0$ & $660^{\circ} 0$ & 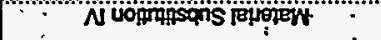 \\
\hline 0 & $\%$ & $010^{\circ}$ & 0 & \% & 0 & $990^{\circ} \sigma$. & Ill voprunsans repoian \\
\hline 0 & \% & soo. $=$ & ? & 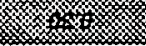 & 0 & $\varepsilon \varepsilon 0^{\circ} 0$ & 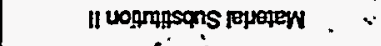 \\
\hline 0 & 5661 & soo & 0 & 000 & .08 & $090^{\circ} 0$ & fógiun \\
\hline 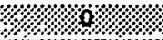 & 880 & opo & $\%$ & 18000 & 80 & 0000 & 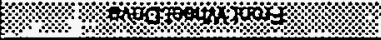 \\
\hline$\%$ & $\%$ & 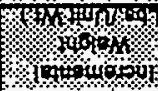 & xyots & Kon & $1+10606$ & \%onthos & $\%$ \\
\hline \% & 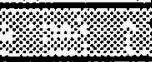 & 8 & Karte & Solon & 6. & Sonsero & $1 / 1$ \\
\hline
\end{tabular}




\section{CHARACTERISTICS OF ALTERNATIVE FUEL VEHICLES}

This section provides a documentation of the updated Fuel Economy Model that also forecasts attributes of Alternative Fuel Vehicles (A'FVs) for incorporation into the NEMS transportation model. The NEMS model requires a forecast of vehicle attributes consistent with those provided for conventional gasoline powered vehicles. The existing AFV module considers only three size classes, and requires five attributes by size class, which includes vehicle price and fuel.efficiency as well as - range, fuel availability and an estimate of emissions relative to gasoline. In general, fuel availability is specified exogenously, while the Fuel Economy Model (FEM) is expected to supply other attributes: The updated FEM provides attributes for AFV's in up to 12 market classes and five fuel types.

Other than gasoline and diesel powered vehicles, the model considers a variety of alternative fuel vehicles that are of both the dedicated and bi-fuel (alternative fuel/gasoline) type. The fuels considered include methanol, ethànol, electricity, compressed natural gas and liquified petroleum gas for a matrix of 10 alternative fuel vehicle types. The existing AFV module contains two other AFV types that are engine technology based classifications (assuming that the 10 described above use piston i.c. engine based technology). The two others are turbine powered using gasoline or CNG, and fuel cell powered using methanol or pure hydrogen; for an additional four AFV classes.

Available data for the manufacturers suggest that turbine powered vehicles are most unlikely to be produced as they have significantly higher costs and lower fuel economy than i.c. engines of equal power. Fuel cell powered vehicles using either methanol or pure hydrogen are unlikely to see commercial production before 2010: Attributes of all other vehicle types are summarized in this report, and a preliminary estimate of fuel cell vehicle attributes is also provided. Most of the data provided are drawn from ongoing work by EEA for the DOE's: Alternative Fuel Transition Model, or from a recently completed EEA analysis for the Office of Technology Assessment.

The specification of AFV attributes requires a series of supply side issues to be resolved largely. based' on the judgement of EEA. Essentially, manufacturers can choose to tradeoff first cost against. vehicle range, performance and even emissions. The choice of such parameters should ideally be made by the demand forecasting model, but such capabilities are not yet-available in demand forecasting models.

The first consideration in forecasting AFV demand is that all fuels are not well suited to all vehicle size classes. For example, the size and weight of CNG tanks make it a poor choice for small cars. 
Based on engineering considerations; EEA has estimated the likely combinations of fuel types and. vehicle types that will be available in cars and light trucks. These combinations are shown in Table F-10 and F11, respectively: It should be noted that are no technical barriers to any particular. combination of fuel type and size class, and these favored combinations are based on EEA's judgement about márket acceptability and economic barriers facing AFV.s in each class.

A second and more important consideration is that vehicle price is a strong function of sales volume. There are significant fixed costs associated with the design, tooling and certification of an AFV model, and if a model has a sales volume of only a few hundred units per year, the fixed costs allocations to each unit are quite large. A typical (non-luxury) gasoline car model is produced at annual volumes of 100,000 to 200,000 units, while most current AFV model sales are only in the range of a few tens to hundreds of units per year. Since the supply and demand models are not interactive, the pre-specification of vehicle price involves estimating sales volumes. Other analysis by EEA suggests that economies of scale result in similar percentage price reduction for every order of magnitude increase in production volume. In this analysis, EEA has assumed that AFV's will be derived from gasoline vehicles and sales volume per model will be in the 2,000 to 3,000 range so that modest economy of scale is achieved, but the full extent is not; for the near term. Pricing at volumes of 20,000 to 30,000 units per year is also considered. Based on other analysis for DOE, EEA recommends that prices at intermediate volumes be scaled in proportion to the logarithm of sales.

EEA analysis for the DOE indicates that auto-manufacturers must anticipate a sales volume of about 2500 units per year of a given AFV model in order to enter the market. At much lower sales volumes in the range of a few tens of vehicles to a fewhundred vehicles per year, automanufacturers have typically subcontracted the work to small conversion shops, or else these AFVs have been aftermarket conversions of existing gasoline vehicles. In general, manufacturers believe that most aftermarket conversions are not well engineered in terms of emissions, fuel economy, and safety, and often have poor performance at high or low ambient temperatures. However, these conversions are much cheaper than automanufacturer designed products at the same sales volume, so that an aftermarket conversion is usually sold at 250 units/yr at the same price as an OEM conversion sold at 2500 units/year. The poor quality is a deterrent to consumer purchase. 


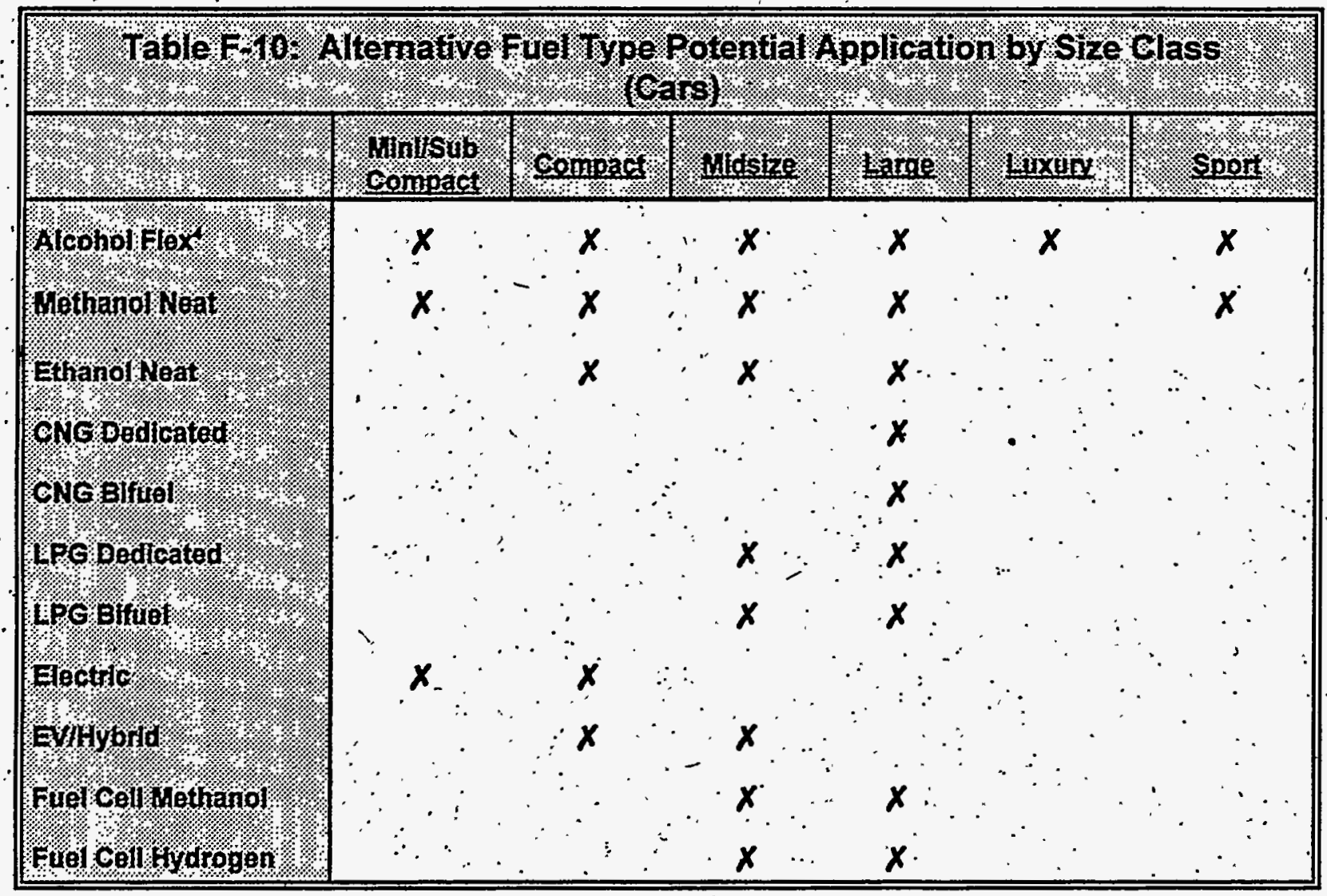

The following sections summarize the changes required to develop each particular AFV type from a gasoline based car, which EEA believes will serve as the base design, since developing a unique "ground up" AFV design is not likely as long as AFV sales volumes per model are less than 10 - percent of similar gasoline engine model sales. Manufactu-rer's may contemplate offering a unique "ground up" design only for EVs, if a specific model can be sold in volumes of 50,000 units per year or more, which appears unlikely to this time. In addition, only OEM products are conisidered so that quality issues đó not influence purchase considerations.

As a result, future model specific improvements for all AFV types will follow those for gasoline vehicles, except for inapplicable technologies for a specific AFV type. These inapplicable technologies are recognized in the descriptions that follow. In addition, it should be emphasized that there is a sales volume based price affect, but there is no "learning curve" effect for all engine technologies that are very similar to gasoline engine technologies, namely engines for alcohol fuels, CNG and LPG. Learning curve effects for EVs and hybrid vehicles are primarily associated with future cost reductions in energy storage media; either batteries or ultracapacitors, and in power electronics. Learning curves also exist for CNG fuel tanks, but the cost reductions will be less

4. Includés methanol/ethanol. 


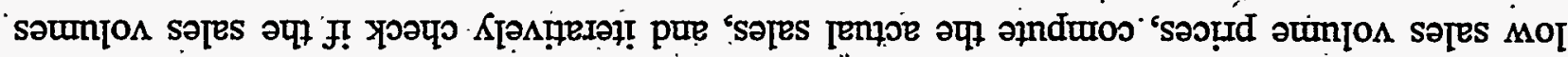

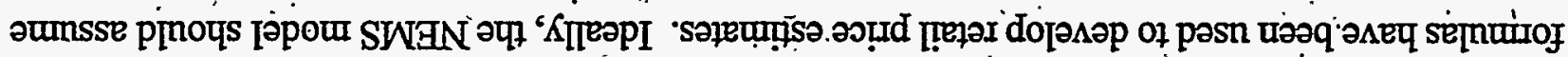

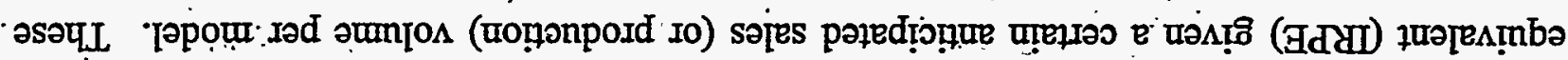

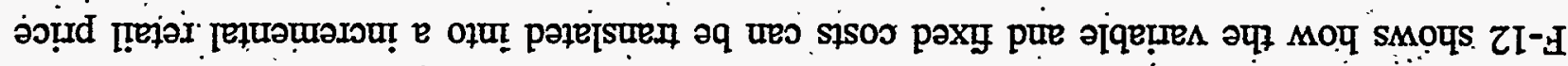

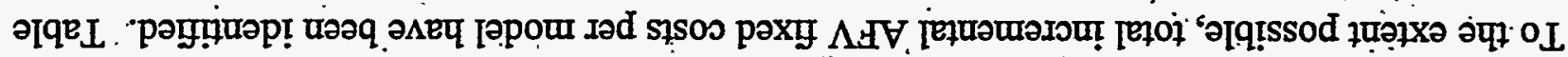

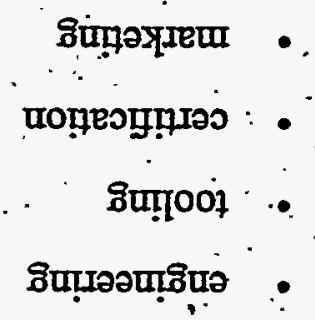

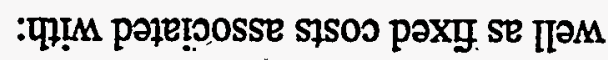

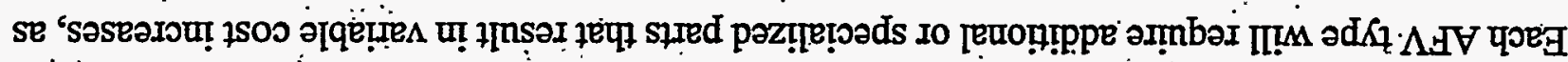

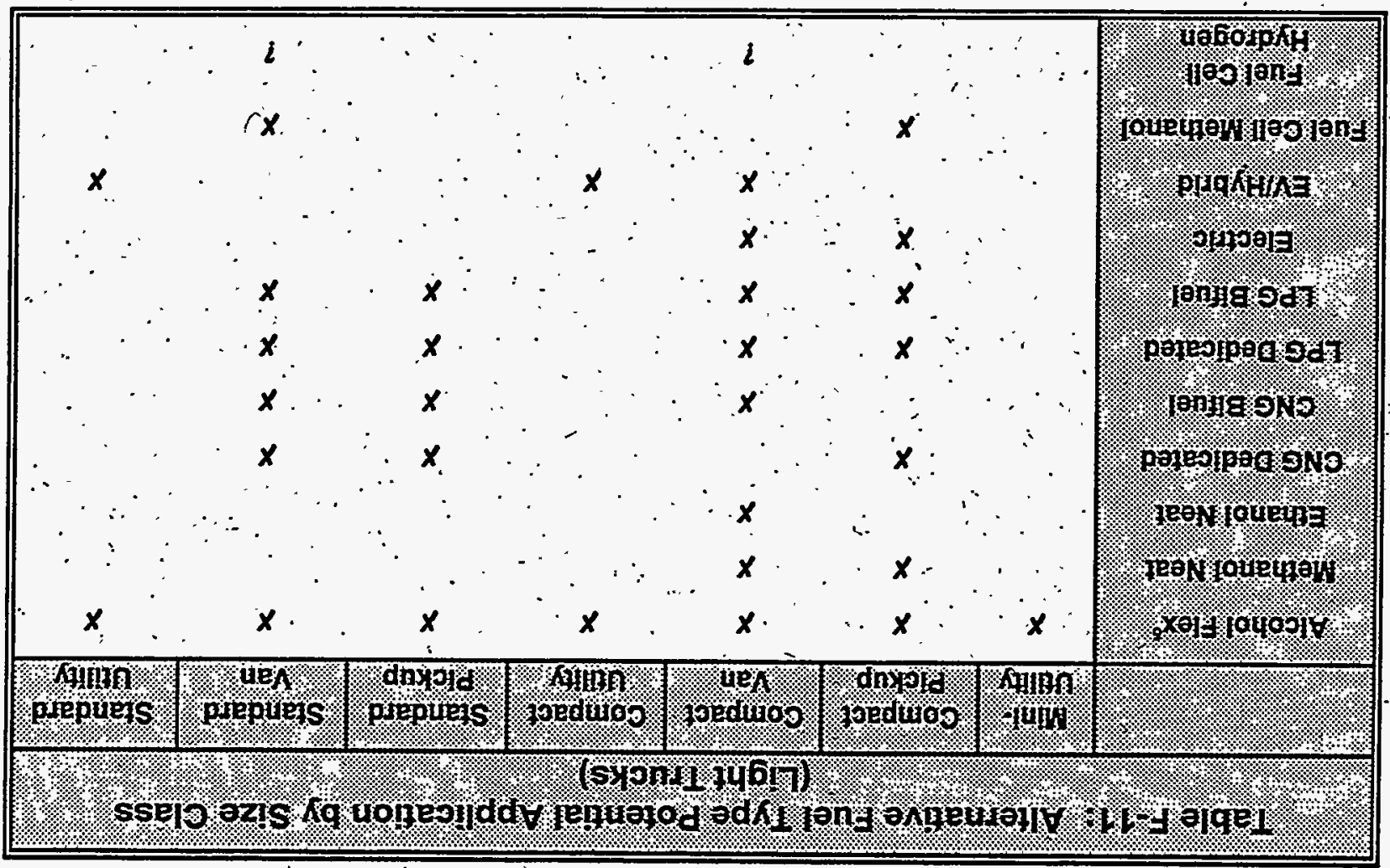


predicted are in line with pricing assumptions.

\begin{tabular}{|c|c|}
\hline Suppler costs to manufactirer $1 \%$ & A \\
\hline Totallnanutacturer huestriments: & B \\
\hline 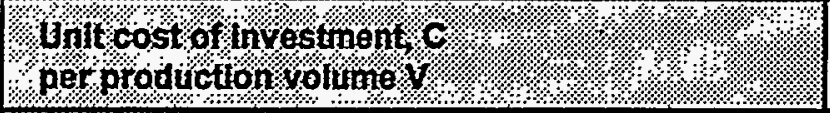 & $\frac{B \times 1.358}{V \times 4.487}$ \\
\hline 4utomanutactire cost" & $A \times 1.4+C=D$ \\
\hline 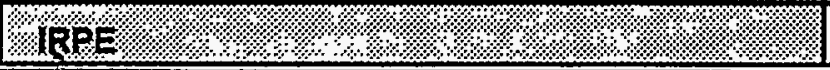 & $D \times 1.25$ \\
\hline
\end{tabular}

\section{FLEXIBLE FUEL AND DEDICATED ALCOHOL VEHICLES}

- These vehicles closely resemble the gasoline engine powered vehicle, and the modifications of a conventional vehicle to be either a flexible fuel vehicle (FFV) or dedicated alcohol fuel vehicle are relatively minor. At present, all alcohol vehicles are OEM products and no aftermarket conversions are expected. The most significant modifications are:

- Upgrade of the fuel tank and fuel lines materials to be corrosion resistant to alcohol :

- New high flow fuel pump that can provide up to twice the flow rate of conventional pumps

- Modified fuel injectors and a new fuel/spark calibration for alcohol fuel

- Modifications to the evaporative emission control system to handle alcohol gasoline blends (FFV only)

The FFV also has a unique component, the fuel alcohol sensor that signals the engine electronic control system on the alcohol gasoline blend being used. The variable cost of all of the above parts is typically about $\$ 300$ to $\$ 500$ at low sales volume, with much of the cost associated with the fuel pump and fuel sensor. The high end of the range of costs is associated with converting a vehicle whose current fuel system requires significant materials changes; whereas the lower end would be ffor a vehicle whose current fuel system is corrosion resistant to alcohol.

Dedicated alcohol vehicles require similar changes but do not need the fuel sensor. If the engine is optimized for alcohol, it needs a new high compression ratio cylinder head, which partly offsets the cost of the sensor. Dedicated alcohol vehicle will have a simpler evaporative emission control system, although cost savings here are expected to be small. The net variable cost of a dedicated alcohol vehicle will be only slightly lower than that of an FFV and is estimated at $\$ 250$ to 350 at low 
sales volume. Variable costs (which include supplier fixed costs) are expected to be reduced to half the low volume levels, i.e. $\$ 150$ to 250 , due to reduced per unit supplier costs, if volumes increase to 25,000 units/year.

Fixed costs for the automanufacturer are estimated at $\$ 7$ to $\$ 8$ million per model line, based on input from the manufacturers, for an assumed sales volume of 2500 units/year. However, significantly higher sales volume does not require much higher investment, and it is estimated that 25,000 units/year sales capability would require only an additional $\$ 2$ million more to expand assembly capacity and enhance the marketing network.

Attributes of flexible fuel and dedicated vehicles are shown in Table F-13, relative to gasoline vehicle attributes: Prices are shown as if manufactures are pricing thesè vehicles as a standard product, (which they are clearly not) and EIA may wish to modify the prices to reflect current pricing. All of the improvements possible for conventional vehicles are applicable to FFV's and dedicated alcohol vehicles. At present, EEA believes that dedicated vehicles and FFVs operated on alcohol fuel may have small benefits in reactivity adjusted HC emissions (in the range of -10 to -20 percent) relative to an equal technology gasoline vehicle, but other emission benefits are negligible. In general; the range of prices shown at each sales volume are associated with vehicle size changes, with smaller cars at the low end of the price range, large trucks at the high end of the range, and midsized/large cars and compact trucks at the middle of the range.

\begin{tabular}{|c|c|c|c|c|}
\hline I. & Iretianol & :. Ethanol & $\begin{array}{l}\text { Hemanol: } \\
\text { Dedicated }\end{array}$ & $\begin{array}{l}\text { Ethanol] } \\
\text { Eedicateds }\end{array}$ \\
\hline Yorseporer & +4 & +3 & +8 & $+\dot{6}$ \\
\hline Range on M85iE 85 . & $\cdot-43$ & -27 & -37 & -24 \\
\hline Fireleconomy & +2 & +1 & +8 & +4 \\
\hline Whatementalk efce $(s)$ : & $\because$ & $\therefore$ & & . \\
\hline 1.: & $1650-2000$ & 1650-2000 & $1560-1820$ & $1560-1820$ \\
\hline 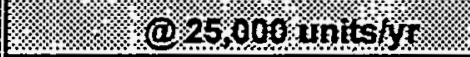 & $410-500$ & $410-500$ & $370-425$ & $370-425$ \\
\hline
\end{tabular}

\section{CNG/LPG'VEHICLES}

CNG/LPG vehicles are the next step in complexity from an alcohol fueled vehicle for conversion

\footnotetext{
6 Assumes manufacturer makes normal return on investment.
} 
from a conventional gasoline vehicle. The major difference is that the fuel tanks are more complex, heavy and expensive, especially for CNG. Currently, most CNG and LPG vehicles are aftermarket conversions, but the OEMs have recently entered this market with a range of new products.

Outside of the fuel tanks, engine and fuel conversion costs are quite similar to these for a dedicated alcohol fuel vehicle. These include more expensive fuel lines, new fuel injectors and more expensive fuel injector drivers. The pump in an alcohol fuel vehicle is replaced by a pressure regulator, which can be a relatively expensive piece of equipment for a CNG vehicle that is certified. to a stringent emission standard. Low pressure LPG pressure regulators are less expensive, but some manufacturers are experimenting with liquid LPG injection for optimal emission control. Engine improvements for both CNG and LPG systems are also similar, requiring revisions to the valve seats; pistons and rings and head gasket.

For dedicated systems, increases to the engine compression ratio (CR) by 0.5 to 1 point for LPG and -1.5 to 2 points for CNG are optimal. Such increases may, in turn, lead to revisions to the cooling system and air intake system. The increases in CR lead to a fuel economy benefit of and 4 and 8 percent for $L P G$ and $C N G$, respectively.

Engine components and costs for a dual fuel system of high quality that is emission certified is estimated at $\$ 350$ to 450 . Engine improvements for dedicated CNG/LPG engines that are optimized will increase these costs to $\$ 500$ to $\$ 600$. However, there will be a cost savings of $\$ 350$ associated with the elimination of the gasoline fuel system and evaporative system, for anet cost of $\$ 150$ to 250. The costs are for volumes of 2,500 units/year and could decrease by 50 percent at 25,000 units/year, based on interviews with CNG system-manufacturers.

Costs of fuel tanks are significant. For CNG, the incremental costs of tanks are estimated at $\$ 100$ - 125 per gasoline equivalent gallon, and a typical tank for cars is about 9 gallons, while one for trucks is 12 gallons. Hence, CNG tank costs are $\$ 900$ to 1125 for cars, and $\$ 1200$ to 1500 for trucks at low volume. The tanks add about 150 lbs weight for cars and $200 \mathrm{lbs}$ for trucks. LPG tanks cost approximately one-third as much as CNG tanks. One significant uncertainty is how much the cost of CNG/LPG tanks can decline as a function of volume. It has been estimated that costs will decline by $33 \%$ as sales volume increases from 2500 units/year to 25,000 units/year, but this figure may indicate benefits from "learning". as well,

Engineering and tooling costs for CNG and LPG.vehicles are significantly higher than for alcohol fueled vehicles, because of the need to modify the body and chassis to accommodate the tanks, and 
the need to upgrade suspension tires and brakes to accommodate the increased weight. In addition, the vehicle will have to be crash tested due to the extensive changes to the fuel system, to verify system integrity. At low volume it has been estimated that engineering; tooling and certification costs per model for dual fuel vehicle are about $\$ 15$ million. Additional engine engineering costs for a dedicated CNG/LPG vehicle are estimated at $\$ 3$ million: Expansion of special assembly facilities to accommodate a volume of 25,000 units per year is estimated to cost an additional $\$ 5$ million for facilities.

Costs and vehicle attributes for CNG/LPG vehicles are shown in Table F-14. In addition, it is assumed that future CNG/LPG vehicles will be certified as ILEVs for emissions to meet Clean Fleet and California requirements. As before, the range of costs span the size range of vehicles from small cars to large trucks. At sales volumes of a few hundred units per year, only aftermarket conversions are expected to be available at approximately the same price is OEM products at a sales volume of 2500 units/year.

Future improvements to CNG/LPG vehicles will not differ from those for gasoline vehicles, with the sole of exception of VVT (Variable Valve Timing). Pumping losses in CNG/LPG engines are lower because of the air displacement effect of gaseous fuels. EEA estimates that VVT benefits will be reduced to half its gasoline benefit when used in conjunction with these fuels.

\section{ELECTRIC, FUEL CELL AND HYBRID VEHICLES.}

These vehicles are a significant departure from conventional vehicles in that their drivetrain and fuel system is very different from a gasoline engine and its fuel tank/fuel system: The pricing analysis of these vehicles reflects the fact that there are no electric vehicles (EVs) or Hybrid Electric Vehicles (HEVs) in production and that data must be extrapolated from current prototypes and pre-production vehicle models. Fuel cell powered vehicles are still' at least a decade or two away from commercialization.

\section{Electric Vehicles}

In the electric vehicle, the engine is replaced by an electric motor and controller, while the gasoline tank is replaced by a battery. EEA analysis for the OTA for an EV with a production volume of 25,000 units/yr revealed a range of attributes that depend on battery technology. Table F-15 provides the data for four vehicle classes for several different batteries for the year 2005 , which is believed to be the earliest point where relatively high EV production volume can be realized. However, the table assumes that a relatively high technology body would be used. 


\begin{tabular}{|c|c|c|c|c|}
\hline \multicolumn{5}{|c|}{ 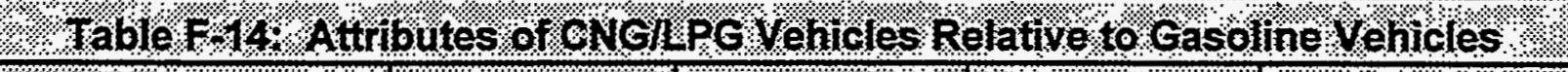 } \\
\hline \% & \%. & 6\%: & \%. & \% \\
\hline Horsepower 4 & -15 & -8 & -5 & 0. \\
\hline Range. & -50 & -20 & -40 & -15 \\
\hline 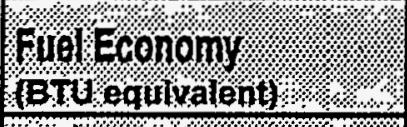 & $\therefore 0$ & $-0^{\circ}$ & +8 & +4 \\
\hline 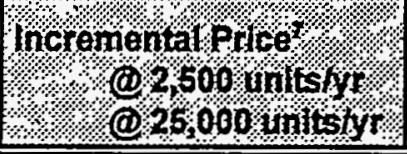 & $\begin{array}{l}4750 / 5350 \\
1825 / 2225 \\
\end{array}$ & $\begin{array}{l}3550 / 3950 \\
1085 / 1175 \\
\end{array}$ & $\begin{array}{l}4840 / 5440 \\
1695 / 2100\end{array}$ & $\begin{array}{c}3670 / 3860 \\
920 / 985\end{array}$ \\
\hline
\end{tabular}

Note that range is based on an assumed tank size that holds approximately half the gasoline energy equivalent for CNG vehicles and 80 percent of the gasoline energy equivalent for LPG. Other tank sizes could be incorporated at different costs.

EEA believes that the Lead Acid battery is potentially the only viable near term solution. Some analysts claim that the Nickel Metal Hydride battery (Ni-MH) can became cost competitive at $\$ 200 / \mathrm{kwh}$ relative to a lead-acid battery at $\$ 125 / \mathrm{kwh}$ by the year 2002 , but others believe that the Ni-MH batteries are more likely to cost $\$ 400 / \mathrm{kwh}$ initially: A range of 80 to 100 miles is the best that can be considered in the entire time frame to 2015 , given the steep increase in costs to obtain - a 200 mile range. Beyond 2005, the Ni-MH battery could be dominant, although it is very speculative to make suich a prediction. Of course, all EVș are zero emission vehicles.

Electric vehicles can be conversions of existing gasoline vehicles, but the conversion is rather extensive. Essentially, the entire drivetrain must be replaced, necessitating removal of the gasoline .engine and transmission. In addition, the fuel tank must be removed, and the vehicle equipped with batteries. The EV.motor/controllers and batteries have very different characteristics of weight and size relative to the components displaced in a conventional gasoline car, so that the repackaging of these components, especially the battery, requires significant engineering and design effort. The conversion process typically utilizes a vehicle built without any of the gasoline vehicle's drivetrain and fuel systems, and such vehicles are referred to as gliders.

7 Cars/Light Trucks. 


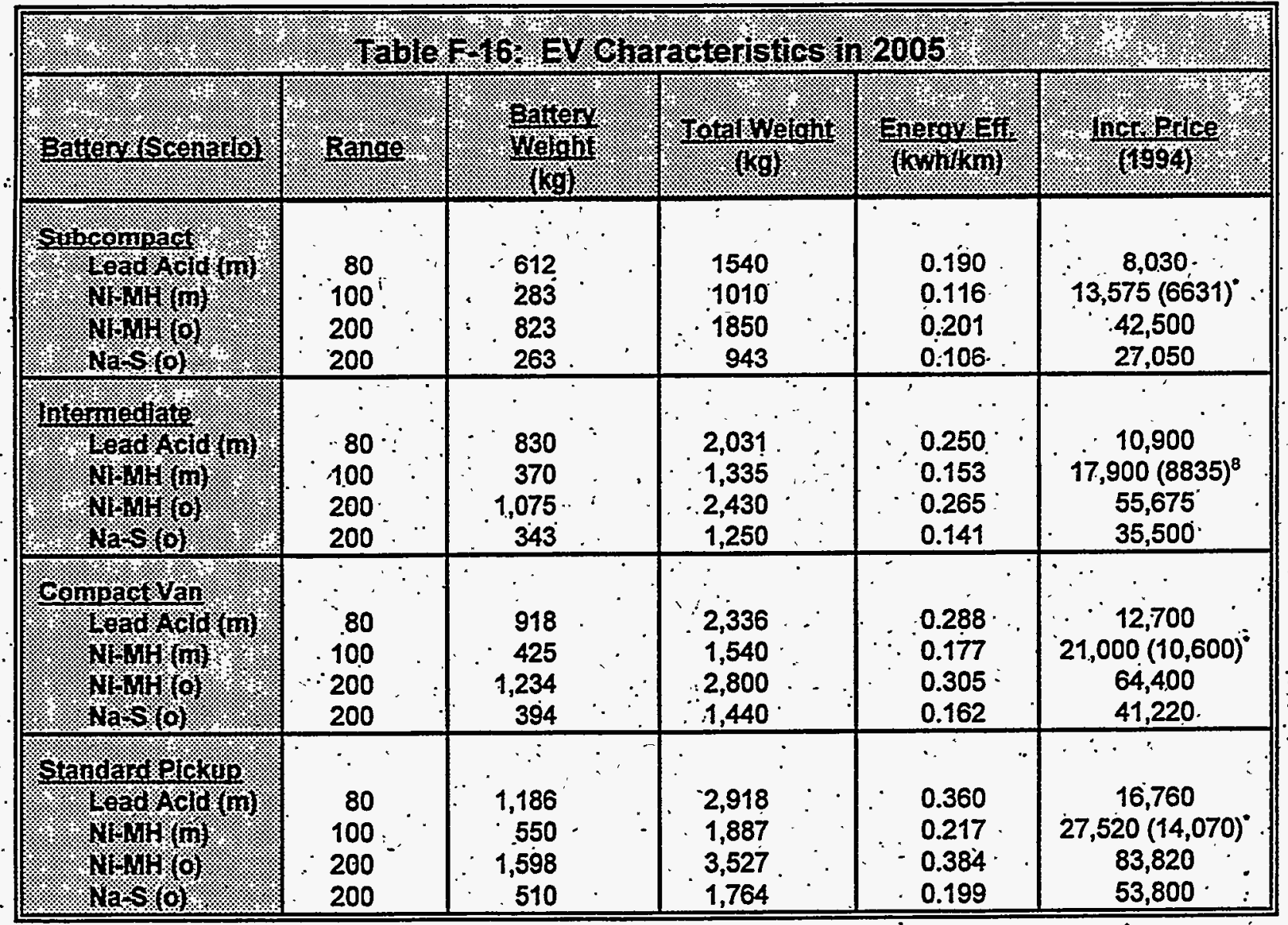

Energy Efficiency is based on electrical consumption at wall plug. Price increment is relative to advanced conventional vehicle for the same scenario.

Purpose designed EVs have been displayed by some automanufacturers such as GM and BMW, but most industry analysts doubt that such vehicles will be produced at a production capacity level of less than 100,000 units/year because of the very high investment in the design, tooling and certification for a unique design. Indeed, $\mathrm{GM}$ officials have stated that they can never recover the \$260 million invested in the design and engineering for the purpose-built "Impact" EV.: Even at 100,000 units/year, media reports suggest that a purpose built EV would require investments similar to that for a conventional car (about $\$ 1$ billion per model) but the incremental investment for a glider derived $\mathrm{EV}$ would be about one-tenth that amount.

8 Price if Ni-mH battery can be manufactured at $\$ 200 / \mathrm{kwh}$ : 
For electric vehicles derived from a glider, investment costs have had to estimated since none of the manufacturers provided this information. Approximate estimates from published magazine articles and other anecdotal information support an estimate of $\$ 50$ million in engineering, tooling, certification and launch cost for a production capacity of 2;500 units per year. This investment increases to $\$ 80$ million for 25,000 units per year and $\$ 100$ million for 100,000 units/year, based on the media reports discissed; as well as anecdotal information from the automanufacturers. However, the major capital expense is the construction of a battery plant, which is not treated here, since the battery is a "variable cost" to the automanufacturer. In addition, the same battery type or model can be used across different vehicle series and different automanufacturers.

In the near term (certainly to 2000 and perhaps to 2005), EEA believes that the only realistic battery option is the Advanced Lead Acid Battery. EEA interviewed the only manufacturer (Horizon) of such a battery that is nearing commercial production, and obtained costs at low volume production (of approximately 5000 vehicle battery packs per year) and at high volume (50,000 per year). Horizon's estimates for the high volume production rate battery was for a future unspecified date and may involve economies of both scale and learning, since such a battery has never been produced before.

The post-2002 estimate assumes emergence of the Nickel Metal Hydride battery, and its attributes have been estimated from current prototype performance. Although there is considerable uncertainty about its costs, it is assumed that the resulting EV will be cost competitive with a 2010 lead-acid battery powered $E V$, given a learning cost reduction schedule for the lead-acid battery. Although it is not necessary to specify the battery under this assumption to derive IRPE, it is necessary to do so to derive the characteristics of the EV in terms of weight, size and performance. EVs will also benefit from future improvements to weight, drag and rolling resistance.

For the computer model, it is assumed that all EV production will be based on a "glider" derived from a conventional gasoline car. The weight of the glider with no electrical components is estimated at 54 percent of the weight of the gasoline car. For an EV-with performance levels equivalent to a gasoline car, battery weight $\left(\mathrm{W}_{\mathrm{Batt}}\right)$ is 'given by: - 


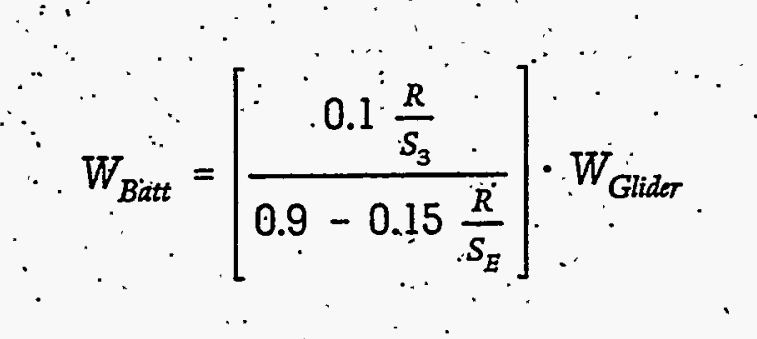

where $R$ is the $E V$ range (in $\mathrm{km}$ ), $S_{\mathrm{E}}$ is the battery specific energy

in watt hours per kilogram, and $\mathrm{W}_{\text {GIDER }}$ is glider weight in $\mathrm{kg}$. An advanced lead acid battery has a specific energy of $40 \mathrm{wh} / \mathrm{kg}$. while the Nickel Metal Hydride battery has an $S_{E}$ of 72 . These equations are used to estimate battery weight.

The IRPE of the EV at 25,000 units/year is estimated based on the assumption that the cost of the electric motor and electronic controller will offset the cost of the gasoline engine, fuel system and emission control system while the cost of the battery will be the most significant cost increment to the EV. In volume production, Lead Acid batteries are expected to cost (the automanufacturer) $\$ 125$ per kwh or $\$ 5 \mathrm{per} \mathrm{kg}$. The Nickel Metal Hydride battery is initially expected to cost $\$ 400 \mathrm{per}$ kwh or $\$ 28.80$ per $\mathrm{kg}$. These costs apply in 1998 , but Ni-MH batteries in 2002 should decrease to about $\$ 250$ per kwh.

Costs are expected to go down significantly with experience, but the "learning curve" is difficult to quantify objectively. Costs are expected to decline by 25 percent per decade based on interviews with battery manufacturers so that, for example, lead-acid batteries will sell for \$94 per kwh in 2008. The IRPE calculation amortizes the $\$ 80$ million in fixed costs as per the formula in Table F-12. Costs at low sales volumes of 2,500 units/year have been calculated externally, and in general, it has been found that an offset of $\$ 10,000$ in IRPE provides a reasonable representation of the low volume sales price relative to the calculated high volume sales price:

\section{Fuel-Cell Vehicles}

In a full cell vehicle, the fuel cell is similar to the EV battery in that it supplies motive power to the motors. The sizing of the fuel cell is based on the continuous power requirement of the vehicle, but all other factors will be quite similar to those for an EV.: However, the present state of development 


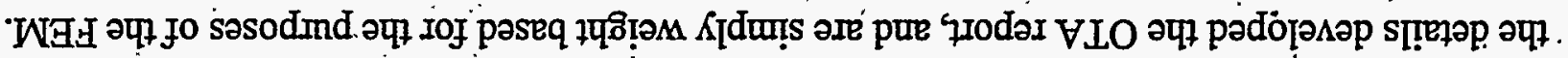

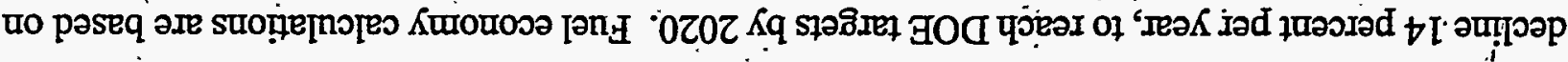

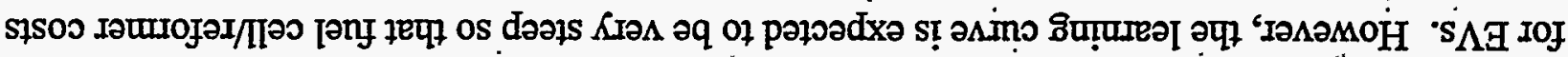

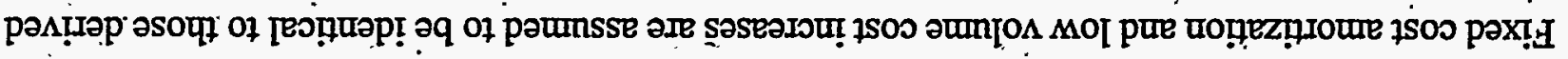

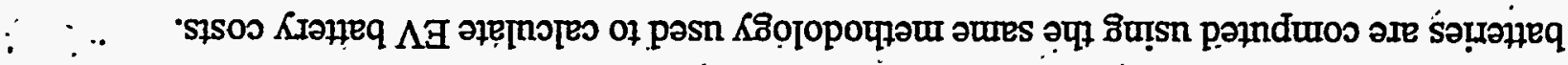

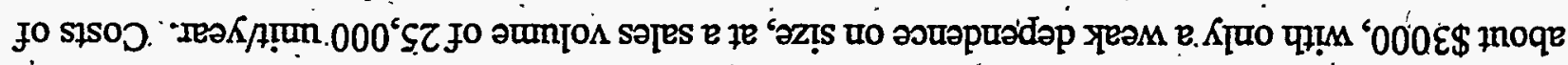

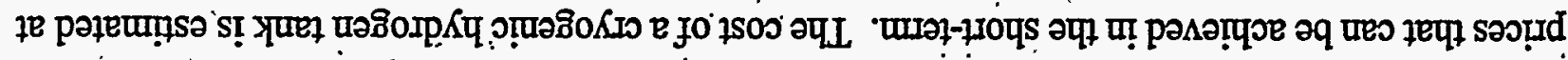

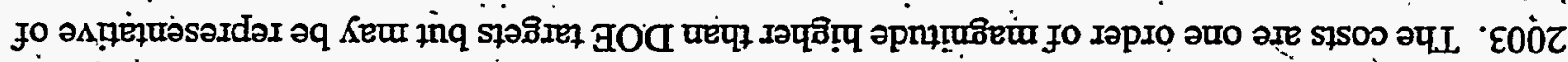

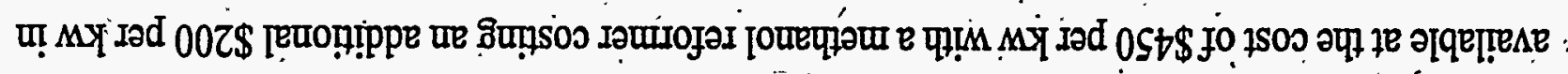

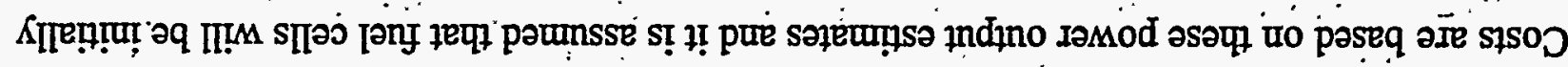

8ิy/M OOS Jo

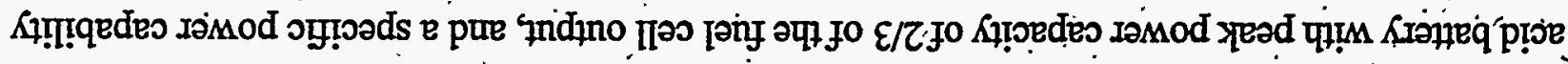

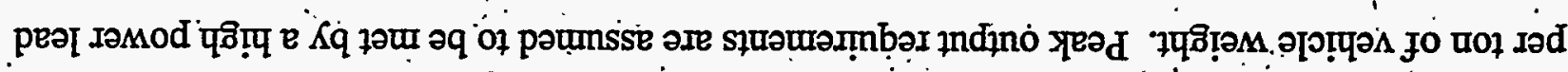

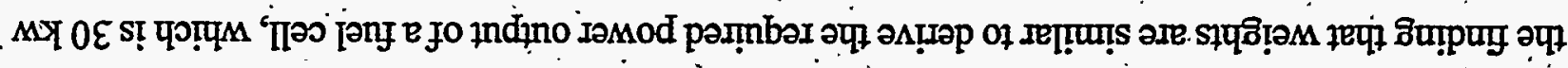

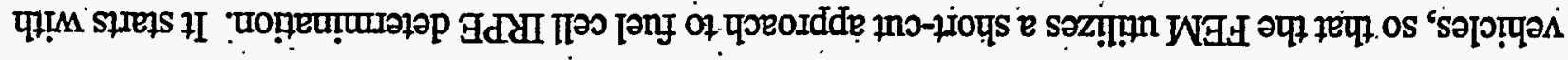

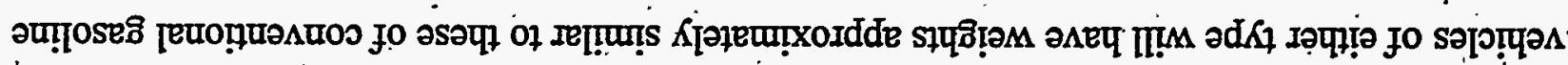

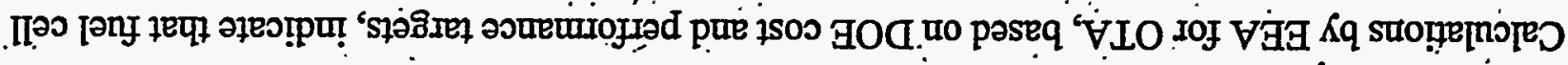

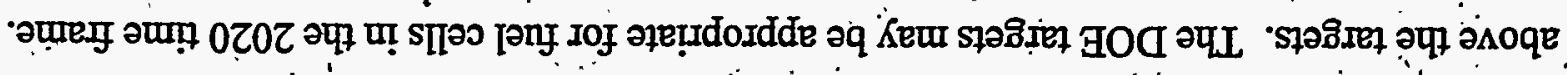

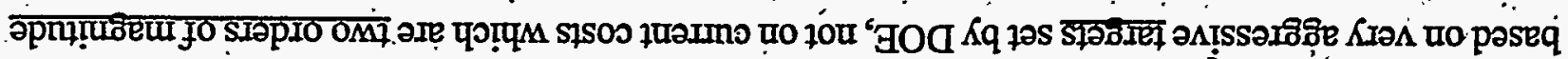

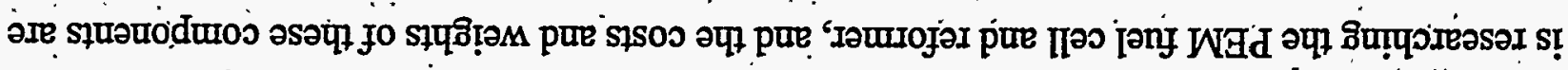

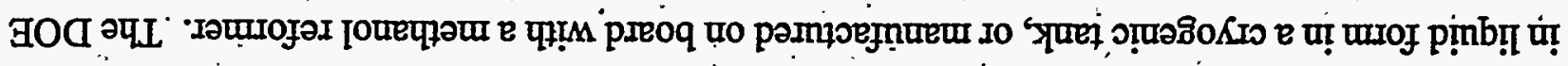

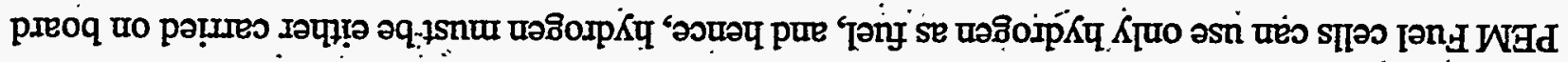

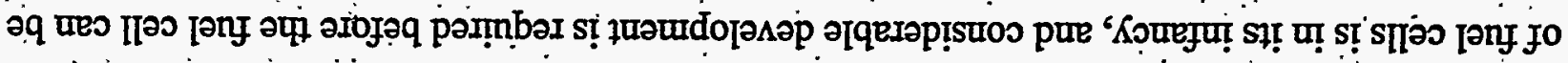




\section{Electric Hybrid Vehicles}

Electric Hybrid Vehicles feature both an engine and an electric motor as part of the drivetrain, but there can be a wide variety of designs that allow for large variations in the relative sizes of the electric motor, i.c. engine, and electric storage capacity: Hybrids are often classified as șeries or parallel, and also as charge depleting or charge sustaining. Even within these four categories, manufacturers disagree about the optimal relative size of the engine versus the electric motor. Due to these uncertainties, EEA has selected one promising approach which is a series, charge sustaining hybrid, with an engine sized to be able to produce the continuous power requirement of 30 kilowatts per ton of loaded vehicle weight; as an example for determining the IRPE.

Since the calculations to derive hybrid vehicle characteristics are relatively complex, a reduced form based on EEA's work for OTA has been used. Most of the costs of the vehicles scale in approximate proportion to vehicle weight, so that the gasoline vehicle weight is used as an indicator, and the calculated midsized hybrid vehicle costs and fuel economy àre used as a reference point for scaling. The IRPE of hybrid vehicles are scaled based on an expected midsized vehicle IRPE of $\$ 4400$ in 2002 under a production rate of 25,000 units/year. A learning curvè reduces these costs at 25 percent per decade, while low volume production at 2,500 units/year imposes an IRPE penalty of $\$ 10,000$ :

Series hybrid vehicles are expected to have 30 percent better composite fiel economy than current conventional gasoline cars. However, future engine improvements to reduce pumping loss and drivetrain improvements are not applicable to such vehicles, due to the electric drivetrain used. Emissions of these vehicles are expected to conform to California ULEV regulations, much like CNG vehicle emisșions. 


\section{Attachment 2: Alternative Fuel Vehicle Model}

Data Input Sources and Extrapolation Methodology.

\section{INTRODUCTION}

This Attachment documents the AFV database used in the National Energy Modeling System Transportation Sector Model. The database includes the present values and forecast methodologies of six attributes for three classes of light-duty vehicles. These attributes apply to sixteen vehicletechnology types and three scenarios for nine regions of the United States.

\section{DEFINITIONS}

The vehicle classes are:

1. Small light-duty

2. Medium light-duty.

3. Large light-duty

The attributes are: .

1. Purchase price (1990\$, including the NPV of periodic battery and fuel cell replacements)

2. Fuel Operating Cost (1990\$/MMBtu)

3. Fuel Availability (Fraction of stations)

4. . Vehicle Efficiency (Miles/MMBtu)

5. Emissions (impact-weighted index to gasoline in each year)

6. Vehicle Range (miles between refueling) 
The vehicle-technology types are:

1. Gasoline

2. Methanol Flex

3. Methariol Neat

4. : Ethanol Flex

5.: Ethanoi Neat

6. CNG

7. - LPG

8. Electric

9. Electric Hybrid - Large ICE

10. Electric Hybrid - Small ICE

11. Electric Hybrid Gas Turbine

12. Gas Turbine Gasoline

13. Gas Turbine CNG

14. Fuel Cell Methanol

15. Fuel Cell Hydrogen

16: Diesel

\section{OTHER TECHNOLOGIES}

There are two limitations in the database in terms of other technologies: The technologies that could have been included in the database but were not are:

- 'hydrogen i:c.e.- near-conventional engines that burn hydrogen as opposed to electrochemical generation of powier in fuel cells (as was considered in the database). Hydrogen-burning engines have been manufactured for some time and outperform gasoline engines in terms of emissions. As with fuel cells, their main drawback is fuel price, as tremendous amounts of energy are needed for the production of hydrogen 
from water.

hydrogen-CNG mix (hythane)-also burned in i.c.e.'s and already in use. Offers great advantages in terms of emissions at a more reasonable price than pure hydrogen.

The technologies in the database that are misspecified are: $:$

Fuel cells/hydrogen \& methanol- at this early stage of development it would be more practical to consider these two as one technology. Each rely on essentially the same power train and electrochemical energy cońversion technology; the only difference being the way the fuel is stored. Hydrogen is extremely unwieldy due to its low mass, which means that to fit in a fuel tank of manageable size it must be liquified or bonded to other substances. Methanol, with its high hydrogen content, falls within the latter category as the hydrogen in it is the only participant in the èlectrochemical conversion.

\section{APPROACH}

The approach to the database development is as follows:

1. Identify data sources in the open literature and through industry contacts.

2. Obtain the data and organize it for use in the database.

3. Define and design the database to characterize the data usefilly.

\section{FORECASTTING METHOD}

The data base is provided in a spreadsheet format. The basic forecasting method is to identify 
current values for fuel prices; vehicle prices, fuel availability, etc. and one or more forecast values. The current data are entered in the 1990 column of cells for each attribute and extrapolated exponentially to and through the other data points. (In some cases, the 1990 values are assigned so that the curve fit through the 1992 values is based on 1992 actual data.). Each of the eight sections for vehicle attributes contains a detailed log of relationships and data sources.

\section{DATABASE LIMITATIONS}

Three main types of limitations apply to the database and to its usage within a transportation choice model. They are discussed below.

\section{GENERAL DATA AND MODELING ISSUES}

Model and data:do not distinguish fleet and non-fleet users. Fleet criteria include the availability of a central station, set and known use patterns, large cargo requirements (taxi, delivery, etc.), longer permissible refueling times, and limited luxury features. Non-fleet users need public stations, much longer range; luggage space, luxury features, better performance, and higher reliability. These markets are on different legislative paths and ATF adoption schedules. They cannot be mixed and cannot be modeled using the Bunch approach:

Model and data do not recognize non-economic forces currently distorting markets. In 1991, SAIC contacted the owners of every CNG vehicle refueling station in the , country. We found that the number and use of CNG vehicles is exaggerated by about $200 \%$ and that current usage patterns and interests by non-utility users are biased by artificially low-cost CNG (e.g., no compression costs). Moreover, many of the public refueling stations have very limited refueling capability. These stations are operated mostly as demonstrations rather than as commercial stations. A similar deficiency exists at the LPG outlets, most of which are not equipped to refuel vehicles. The 
Bunch approach, which is geared to open-market, non-fleet purchase decisions, requires an accurate and economic.(i.e., non-interventionist) baseline tied specifically to private vehicles. This baseline does not exist.

Model specifies six decision variables cited in Bunch. SAIC work suggests that actual technology choice depends on additional variables. The following variables omitted from the model significantly affect consumer choice: reliability, maintenance cost, certainty of maintenance availability, salvage or resale value, performance, utility (trunk space in $\mathrm{CNG}$ vehicles, $\mathrm{A} / \mathrm{C}$ in electric vehicles, etc.), saféty issues (real or perceived); ease of refueling, and refueling time. A few of these omitted variables appear in other work by the Transportation Modeling committee but were not requested of SAIC. The omission of these variables is highly significant when large differences exist but are not well-understood by survey participants (e.g., 5-minute refueling for gasoline vs. 8-hour.refueling for electric).

\section{MACROECONOMIC ISSUES}

The database model is generally optimistic about the current rate of technological progress and innovation and assumes it will continue to grow progressively faster. Limitations in the database suggest that these forecasts may be overly optimistic in a macroeconomic sense.

Diversion of Resources - the diversion of government and private sector resources toward alternative investments is not considered, i.e., large sums could go into infrastructure and mass transportation systems that are more efficient than any pássenger vehicle alternative.

Institutional Barriers - the created interests of significant economic or political actors, or groups of actors, could override market considerations for the benefit or detriment of any alternative technology or fuel. 
Environmental Barriers - one or more AFVs may receive significant opposition or backing purely for its environmental impact; moreover, public opinion as well as the environmental movement's preferences may shift in the near future, i.e., the environmental movement currently supports methanol-fueled vehicles, but that could change if'a cleaner way to produce hydrogen for hydrogen-burning vehicles was found.

Psychological Barriers - acceptance by the public is also a function of misperceptions and psychological factors, e.g., CNG, LNG, LPG and hydrogen may be perceived as dangerous to handle and thus avoided even if their safety records are objectively similar to that of gasoline.

Information Barriers - accurate data do not exist for most of the exotic vehicle-fuel combinations (fuel cells, hybrid electric, etc.). Also cost and performance estimates for many of the emerging alternatives, especially electric vehicles, differ by a factor of 2-10 from source to source. In many cases; there is no clear basis för distinguishing among such inconsistencies.

\section{DESCRIPTION OF VEHICLE TECHNOLOOOGIES}

The AFV module currently analyzes 15 alternative-fuel technologies against a single conventional gasoline powered vehicle ${ }^{9}$ in the spreadsheet analysis. Additional conventional and nonconventional technologies can be added to the analysis; however, for simplicity, conventional technologies are represented as a single category. This section of the report describes the characteristics of the alternative-fuel technologies as well as the criteria used in selection of alternative fuel-vehicle types.

\footnotetext{
9. This study assumes all gasoline powered internal combustion engines under a single technology category even though there is significant variation within gasoline fúeled engines.
} 
Four primary technology selection criteria are employed for this study. The four criteria are the following:

- Vehicle operates utilizing a non-gasoline fuel or a significantly new engine technology.

.Technology holds the potential to penetrate the light-duty vehicle market by the year 2030. Technology possesses distinct fuel use, performance and/or cost characteristics relative to all other technologies considered.

Data is available on important attributes for the vehicle technology.

Variations within each technology class based on vehicfe subclass are not being analyzed as a distinct category but are incorporated into the collective category for the technology ${ }^{10}$-: Future work in estimating market share growth for alternative-fuel technology may breakdown technology classes. by engine and combustion technology; however, the complexity of such an analysis is unwarranted at.the present time.

This study has identified 15 alternative-fuel technologies which have met the four criteria previously stated. Conventional gasoline technology has been grouped into one single category. using average vehicle attributes taken across all conventional vehicles. Following is a list of the sixteen vehicle technologies incorporated in this study: The advantages and disadvantages of each of the individual technologies will be briefly described in the following sections.

\section{Gasoline Internal Combustion Engine Vehicles}

Presently, the vast majority- of transportation vehicles utilize an internal combustion engine (ICE) which was first patented in 1876 by Nikolaus Otto: The ICE is a heat driven engine which operates by mixing air and fuel vapor together, compressing the fuel mix in a cylinder, and igniting the fuel mix by means of an electric spark. The ignited fuel mix pushes a piston which in turn drives the vehicle $^{11}$. Since the invention of the internal combustion engine the primary power source has been

\footnotetext{
10 'Significant variations exist in the gasoline powered technology sich as fuel injected engines versus carbureting engines; however, for simplicity all technologies utilizing a single fuel mix will be categorized together.

11 Glasstone, S., Energy:Deskbook, Van Nostrand Reinhold Company, New Yọrk, 1983, pp. 364-368.
} 
gasoline, although, many other fuels such as alcohols, natural gas and diesel can be utilized. It is speculated that if the discoveries of enormous petroleum deposits in Texas had not occurred during the early development years, the automobile would have developed as an alcohol vehicle rather than gasoline.

One of the primary advantages of conventional-ICE vehicles is that economically these vehicles are inexpensive to operate due to the large development and refining infrastructure established for petroleum products. An abundance of petroleum deposits occur throughout the world and transportation of petroleum is not difficult in comparison to methanol and natural gas.

The conventional gasoline ICE vehicles are more harmful to the environment than the majority of alternative-fuel vehicles. Environmental concerns is one of the leading incentives for the development of alternative-fuel vehicles due to the problems associated with greenhouse gasses and urban ożone formation problems.

\section{Diesel Vehicles}

The diesel engine, like the gasoline engine, is an internal combustion engine which is heat driven from the ignition of diesel fuel in the cylinder which in turn drives the pistons. Unlike the gasoline ICE, a spark plug is not used to ignite the fuel mix but rather the combination of the compression and heat of the cylinder causes ignition of the fuel mix.

\section{Ethanol Vehicles}

Ethanol is a fuel which is currently being used to supply ethanol powered vehicles in a ratio of approximately 85 percent ethanol to 15 percent gasoline as well as a gasoline supply extender for conventional gasoline powered engines in a ratio of approximately 5 percent ethanol:and 95 percent gasoline. This study is considering only ethanol vehicles (vehicles using the $85 / 15$ percent-mix) as a category separate from conventional vehicles. Two technology categories exist under the ethanol fuel heading. Ethanol Neat Vehicles which use only ethanol fuel and Ethanol Flex Vehicles which 
have the ability to switch between gasoline and ethanol fuels.

Ethanol can be produced from food sources such as corn and sugar cane or from non-food biomass such as trees, grass, waste paper, and cardboard. Presently, approximately 95 percent of ethanol fuel being produced in the United States comes from com. Neat ethanol engines are expected to produce a 30 percent increase in efficiency over conventional gasoline engines; however, ethanol fuel has a lower energy content of only. 67 percent of gasoline. A variation in cost estimates for ethanol fuel production exist depending on the source material and the distillation process. The EPA'estimates that the "gasoline equivalent".ethanol price using corn stock is between $\$ 1.47$ and $\$ 2.07$ per gallon ${ }^{12}$.

Ethanol fuel provides several important environmental benefits over gasoline in both the consumption and production stages. Ethanol is produced from a renewable energy source such as corn or sugar cane, where as petroleum is a non-renewable energy source which could be depleted in the future. Ethanol fueled-vehicles emit a lower amount of carbon dioxide, nitrogen oxide and hydrocarbons than gasoline ${ }^{13}$. The Environmental Protection Agency estimates that carbon dioxide emissions, the major component of "greenhouse gases", are reduced to zero using ethanol produced from com or sugar cane when considering the carbon reabsorption factor of corn during the growing stage ${ }^{14}$.

\section{Methanol Vehicles}

Methanol fuel is similar in some respects to ethanol since it also is used as a gasoline extender in conventional gasoline engines and as a fuel in methanol engines. Presently methanol is mixed with gasoline in an 85 percent methanol/ 15 percent gasoline (M85) ratio and is consumed in a methanol engine. Two technologies exist for this analysis under the methanol heading; Methanol Neat which

\footnotetext{
Environmental Protection Agency, Analysis of the Economic and Environmental Effects of Ethanol as an Automobile Fuel, April, 1990, pp. 15-22.

13. The Gas Research Institute, The Energy Information Administration, and Science Applications International Corporation, Identification and Analysis of Factors Affecting the Adoption of Alternative Transportation Fuels; 1991, pp. 20-21.

14 Environmental Protection Agency, Analysis of the Economic and Environmental Effects of Ethanol as an Automobile Fuel, April, 1990, pp. 49-50.
} 
operates on M85 and Methanol Flex which has the ability to switch between M85 and gasoline depending on economic and availability factors.

Currently natural gas is the primary source of methanol although other materials such as coal, biomass and cellulose can be used. Methanol allows countries with excess natural gas supplies to export fuel without the expense of pipelines and LNG process. It is estimated that the wholesale price of methanol produced from natural gas is approximately $\$=40 /$ gallon. However, because methanol has only about one half of the energy per gallon of gasoline, the cost per gasoline equivalent gallon is estimated at $\$ .75^{15}$ :

Environmental advantages of methanol fueled vehicles are reductions in ozone formation, volatile organic compounds (VOC) and "greenihouse gas" emissions ${ }^{16}$. Ozone formation is a significant problem in urban areas linked to the emission of gasoline vehicles: Methanol emissions produce a lower photochemical reactivity than gasoline emissions; therefore, reducing the urban ozone formation problem. It is estimated that methanol vehicles emit 80 percent less VOC emissions than gasoline vehicles. Methanol vehicles emit increased volumes of formaldehyde and methanol gas which can be harmful in concentrated amounts. Further research is being conducted on the health risks associated with methanol and formaldehyde emissions.

\section{Electric Vehicles}

Extensive alternative fuel vehicle research is now being done to improve electric vehicle performance. The primary obstacle of electric car development is battery technology. Various automobile manufacturers and research groups are concentrating on improving battery capabilities; however, at the present time battery technology limits electric vehicle range and performance attributes. For this reason electric vehicle motors have been combined with other conventional and

15 The Gas Research Institute, The Energy Information Administration, and Science Applications International Corporation, Identification and Analysis of Factors Affecting the Adoption of Alternative Transportation Fuels, 1991, p. 28.

${ }^{16}$ Energy Protection Agency, Analysis of the Economic anid Environmental Effects of Methanol as an Automobile Fuel, April, 1990, pp. 15-18. 
non-conventional technologies in order to enhance vehicle performance. Technologies combined with electric motors include the internal combustion engine and gas turbine engine. This study will consider four technologies under the electric vehicle heading; electric, electric hybrid, electric hybrid/small ICE, and electric hybrid/gas turbine.

The primary advantage of electric-powered vehicles is that they produce virtually no direct emissions at the point of consumption. Direct emissions produced by electric vehicles are largely. hydrogen 'emissions released during the battery recharging stage.: Although hydrogen is an explosive emission in high concentration, hydrogen poses no problem to atmospheric air pollution ${ }^{17}$. While electric yehicles produce almost no direct emissions there are emissions associated with the electricity. production stage depending on the power source of the electricity generation. Centralized power plants located away from urban centers eliminate urban ozone formation problems and can effectively control emissions associated with fossil fuel consumption. Electric motors have the advantage over internal combustion engines (ICE) because electric motors do not idle when the motion is stopped as ICEs do thus eliminating the idling power loss which can be significant in urban transportation settings.

Considering present electricity prices, exclusive electric vehicles as an alternative to gasoline vehicles are not as cost effective as ethanol, methanol, and natural gas vehicles. Even though electricity as a transportation fuel delivers 50 percent more miles per Btu than other fuels, the current price of electricity makes electric fuel transportation notably more expensive than conventional vehicles. ${ }^{18}$

\section{Compressed Natural Gas/Liquid Petroleum Gas Vẹicles}

Compressed Natural Gas (CNG) and Liquid Petroleum Gas (LPG) vehicles are grouped together in this summary because the engine technology is similar for the two vehicles utilizing different fuel sources. CNG vehicles have been in use for several decades in the United States while in other parts

17. The Gas Research Institute, The Energy Information Administration, and Science Applications International Corporation, . Identification and Analysis of Factors Affecting the Adoption of Alternative Transportation Fuels, 1991, p. 21.

18 Ibid, p.30. 


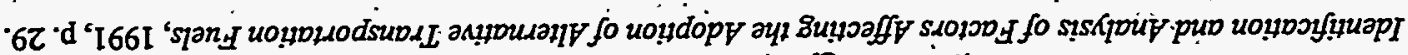

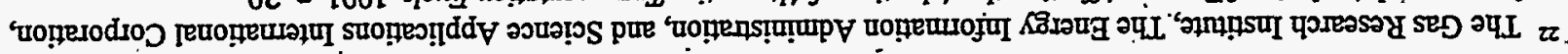

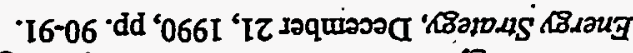

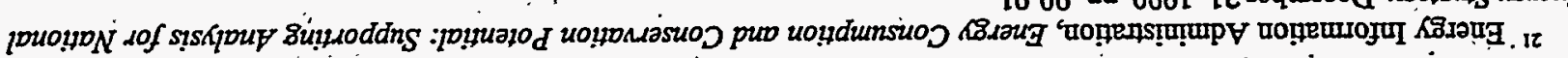

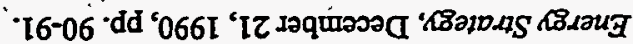

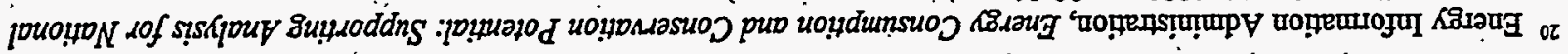

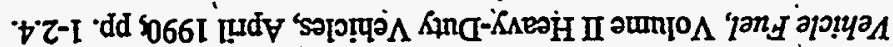

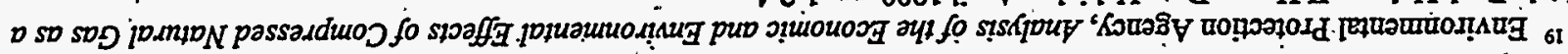

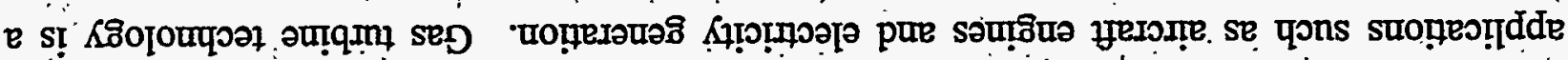

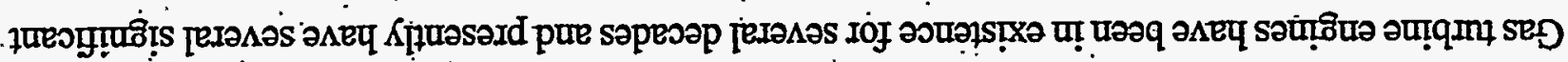

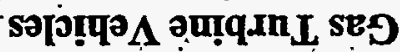

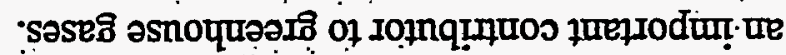

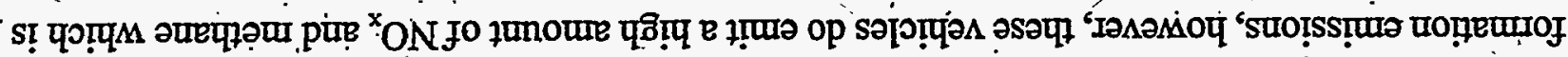

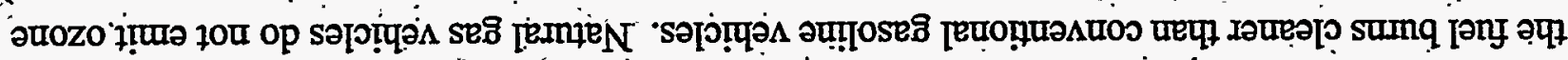

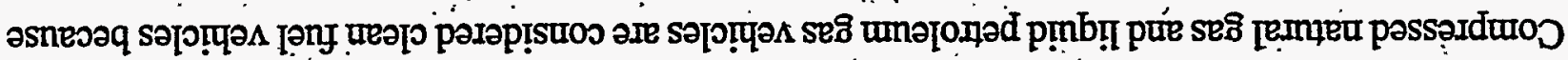

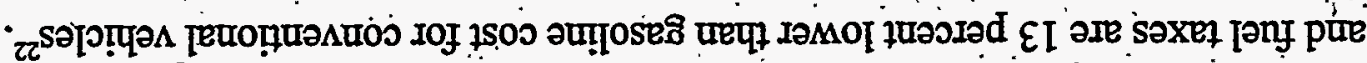

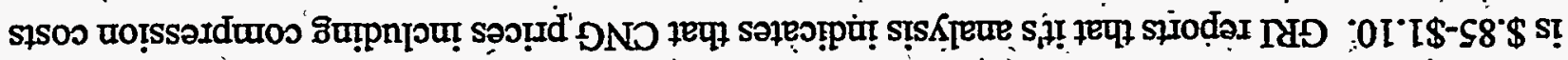

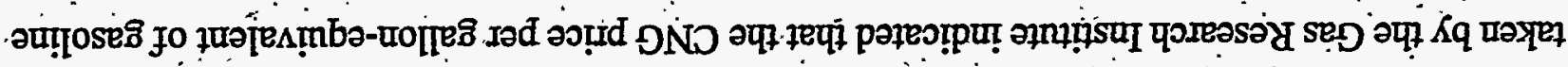

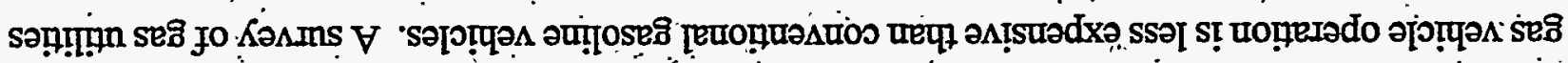

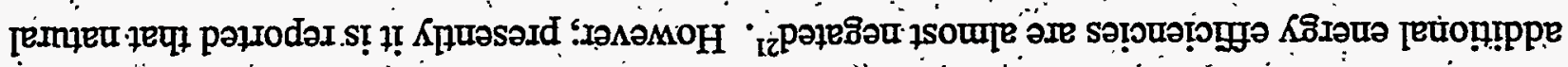

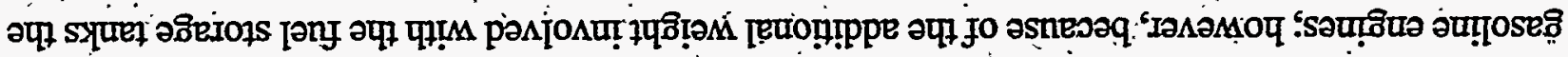

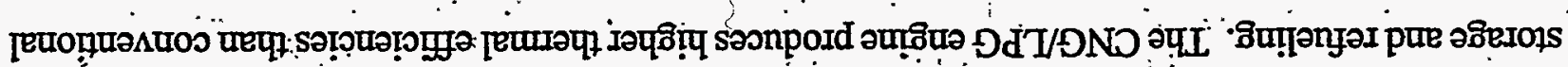

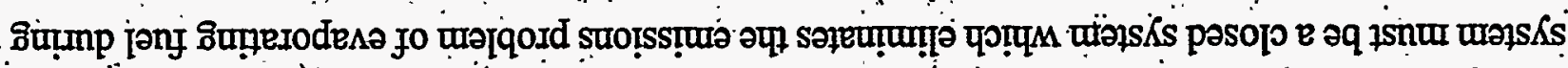

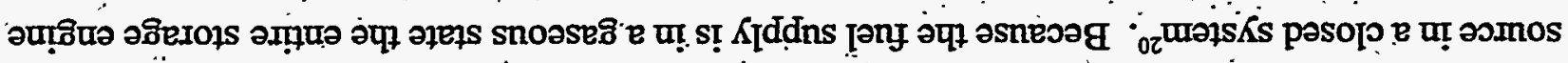

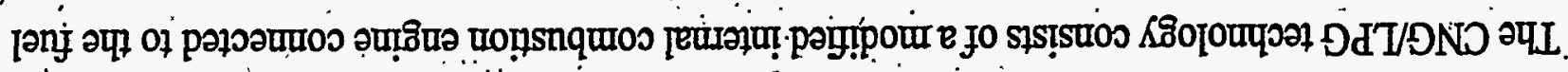

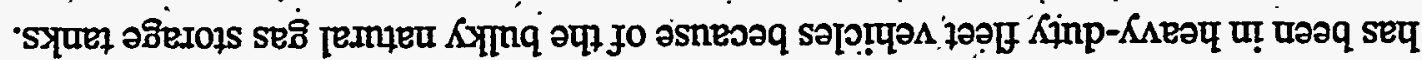

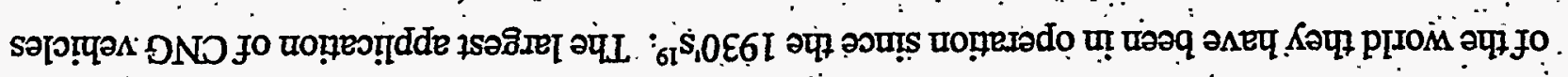


significant variation from ICE technology. . A gas turbine engine consists of three principle components; a compressor which compresses outside air to be mixed with fuel, a combustion chamber where the compressed air and fuel are ignited, and turbine which is turned by the exhaust of the ignited fuel $\mathrm{mix}^{23}$.

Gas turbine vehicles potentially could be up to 50 percent more efficient than conventional internal combustion engine vehicles ${ }^{24}$. The increased efficiency is due to the fact that a turbine engine utilizes a larger percentage of the.work being performed by the fuel than ICE's. Small turbine engines suitable for use in transportation vehicles are not being produced now on a large scale; - therefore, the current cost of turbine engines are prohibitive for vehicle use:

Gas turbine engines could be designed to burn different fuels ranging from alcohols to diesel fuel. This study will consider two technologies under the gas turbine engine, compressed natural gas and conventional gasoline.

\section{Fuel Cell Vehicles}

The concept of fuel cells as a power source for transportation vehicles is similar to electric vehicle technology because an electric current powers a motor which drives the vehicie. The difference is that an electric vehicle runs off of a battery which is recharged periodically while a fuel cell is charged by a separate power source such as methanol or hydrogen. The first large scale applications of fuel celi technology were the Apollo and Gemini space missions which sparked interest in fuel cell technology in vehicle transportation.

Fuel cell technology has the advantage of higher conversion efficiency from the fuel source into electricity than a combustion engine. A large portion of the energy derived in a heat driven internal combustion engine is lost in the form of external heat which does not occur in the fuel cell

${ }^{23}$ Glasstone, S. Energy Deskbook, Van Nostrand Reinhold Company, New York, 1983, pp. 152-156.

24 Energy Information Administration, Energy Consumption and Conservation Potential: Supporting Analysis for National . Energy Strategy, December 21, 1990, pp. 90-91. 
technology. Fuel cell technology remains in the development stage and cost projections of transportation vehicles are extremely high. Further research may lower the costs of fuel cell technology; however, for now fuel cell technology seems unrealistic for large șcale adoption.

\section{VEHICLE PRICES}

This section documents vehicle purchase prices in the database. The output of the database is a vehicle price for sixteen technologies for three vehicle sizes and three penetration scenarios; from 1990 through 2030 , in thousands of 1990 dollars.

The general approach is to establish current and ultimate price premia for AFV's (alternative fuel vehicles) over the price of a gasoline I.C.E. (internal combustion engine) vehicle, and to use an exponential decay fiunction (expressed as a compound percentage decline rate) to project each price premium towards its ultimate value. The shape of the curve implied by the price decay is based on forecasted future price levels or SAIC's judgment where no data are available: 'A non-fuel escalation rate was used to establish future prices of gasoline vehicles for each of three vehicle sizes (small, medium, and large $)^{25}$ through the year 2030.

Vèicle prices were obtained from the following inputs:

Current price of gasoline vehicles by size $(\mathrm{S}, \mathrm{M}, \mathrm{L})$.

Current price premia for 15 other vehicle types independent of size (i.e., fuel-related premium or discount to base gasoline vehicle).

\footnotetext{
${ }^{25}$ Size categories are defined primarily by weight, and secondarily by passenger cabin volume. These definitions are consistent with usage in all of the literature, and in terms of.weight are: below $2600 \mathrm{lbs}$ for small vehicles, between 2600 and $3200 \mathrm{lbs}$ for mid size, and above 3200 for large.
} 
Ultimate long-run price premia for 15 other vehicle types independent of size.

Non-fuel escalation rate independent of vehicle type.

Annual, compound percentage decline in current premium towards ultimate premium; or premium decay, for 15 vehicle types for three scenarios $(B, H, L)$.

The approach has the following advantages:

Projected AFV prices should be relatively cônsistent vis a vis conventional gasoline and other AFV prices.

Incorporating the price of gasoline vehicles into $\mathrm{AFV}$ prices ensures that the non-fuel escalation rate is taken into-account for all technologies.

Updating and revising figures based on future developments are facilitated.

\section{CURRENT VEHICLE PRICES}

Determining current vehicle prices required two steps: finding the price for gasoline vehicles of three sizes (small, medium, and large), and obtaining current AFV purchase prices by adding a premium to the gasoline vehicle price for each technology.

\section{GASOLINE VEHICLE PRICES}

Prices for gasoline vehicles were, established by averaging the prices of three representative vehicles for each size category. The vehicles were selected on the basis of market share ${ }^{26}$. All prices are.

${ }^{26}$ Market sharé source: NADA, August 1992, p.32. 
manufacturer's suggested retail prices obtained from the National Automobile Dealers Association (NADA) used vehicle price guide. Table F-17 below provides detailed information on the selected gasoline vehicles.

Table F-17: Gasoline Vehicle Characteristics (1990)

\begin{tabular}{|c|c|c|c|}
\hline$\sqrt{1.1 \%}$ & 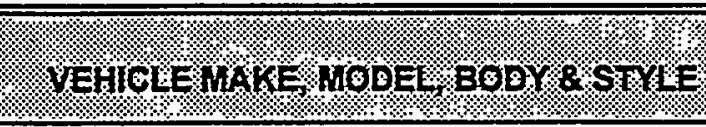 & \%ontor & MEIGUI \\
\hline \multirow{3}{*}{ । } & Förd Ltd Crown Victoria V8/ 4D Sedan & $\$ 17,257$ & $3821 \mathrm{lbs}$ \\
\hline & Cadillac DeVille/ 4D Sedan & $\$ 27,540$ & $3546 \mathrm{lbs}$ \\
\hline & Dodge B250/ Van & $\$ 12,575$ & NA \\
\hline \multirow{3}{*}{ (1) } & Beretta Corsica/ 2D coupe GT2 & $\$ 13,750$ & 2839.lbs \\
\hline & Ford Taurus/ 4D sedan, GL & $\$ 13,834$ & $3089 \mathrm{lbs}$ \\
\hline & Honda Accord/4D sèdan LX & $-\$ 14,895$ & $2857 \mathrm{lbs}$ \\
\hline \multirow{3}{*}{ : } & Honda Civie/ 3D hatchback DX & $\$ 8695$ & $2165 \mathrm{lbs}$ \\
\hline & Cheviolet Cavalier L4/ 4D sedan & $\$ 8820$ & $2471 \mathrm{lbs}$ \\
\hline & Ford Escort/2D hatchback LX & $\$ 7806$. & $\mathrm{c} 2312 \mathrm{lbs}$ \\
\hline
\end{tabular}

Sources for price and weight:

Large:

(NADA, July-August; 1992, ps.23, 75, 271)

Mid-sized:

(NADA, July-August, 1992, ps.29, 74, 174)

Small:

(NADA, July-August, 1992, ps.29; 73, 173)

\section{CURRENT PRICE PREMIA FOR AFV'S}

Current price premia are the premia paid in the market today over conventional gasoline vehicle prices for each technology in the database. All current AFV prices are calculated by adding these premia to the current gasoline vehicle price values for each category. The premia areadded to the current gasoline vehicle price to obtain the current $A \dot{F V}$ prices for each vehicle size, type, or scenario. All premia and SAIC's assumptions, rationales, and comments for each technology are provided below. Each entry also contains the citations consulted by SAIC; abbreviations are more fully defined at the end of this report.

- Diesel-\$1000. Average premia for representative diesel passenger vehicles; figure was slightly higher in the past.

Sources: (NADA, July-August, 1992 \& SAIC). 
Ethanol Flex - \$4,500. Figure was set at the upper end of the range in the literature because of recent DOE data that places a much higher premium on flexible fuel vehicles.

Sources: FFV range $\$ 2000-5000$ (Cogan, August 1992, p.94); average of $\$ 6,400$ for DOE AFV's (including ethanol, methanol and CNG) procured in 1990.(G.A.O, May 1991, p.20).

Ethanol Neat - \$2000. As is the case with ethanol flex, estimate is at the upper end of the range to make it more consistent with recent DOE data.

Sources: $\$ 300-2000$ (Cogan, August 1992, p.94), DOE AFV's data (G.A.O., May 1991, p.20).

Methanol Flex - $\$ 4,700$. Premium is equal to that of ethanol flex plus $\$ 200$ for higher manufacturing costs due the corrosive nature of the fuel, i.e., stainless steel or specially treated materials are needed for the engine. Figure is consistent with the literature consensus.and recent $\mathrm{DOE}$ data.

Sources: Fully optimized.vehicle not engineered yet (CRS, 1989, p.17); higher corrosiveness (Rouse, 1991).

Methanol Neat - \$2,200. Premium is equal to that of ethanol neat plus $\$ 200$ for higher manufacturing costs due the corrosive nature of the fuel, i.e., stainless steel or specially treated materials are needed for the engine. Figure is consistent with the literature consensus and recent $\mathrm{DOE}$ data:

Sources: \$2000 1992 Ford econoline van (NREL, 1992); FFV range \$2000-5000 (Cogan, August 1992, p.94); average of $\$ 6,400$ for DOE AFV's (includes ethanol, methanol and CNG) procured in 1990 (G.A.O, May 1991, p.20); \$210-340 by. 1995 (D.O.E, Auguist 1990, p.ï); higher corrosiveness (Rouse, 1991).

Electric - \$45,000. This figure includes an estimate of the net present value of battery replacements. It is consistent with most recent sources and manufacturerquoted prices of soon-to-be released vehicles.

Sources: 1989 GM G vans priced at $\$ 32,500$ in 1989 (SAIC/report, 1991, p.25); 1993 Ford small van priced at $\$ 100,000$ (NREL, 1992, on-line); batteries premium $\$ 6 ; 000$ by 1995 ; 1993 GM Impact production cost range $\$ 15-20,000$ (O.T.A., 1990, p.119); GM Impact price range $\$ 20,000-30,000$ (Woodruff, 1991, p.58); batteries premium $\$ 2,600-8,200$ for advanced lead-acid battery (ICAMF, 1990, 1.16); Fiat Electra priced 
at $\$ 22,000$ or twice the price of its I.C.E. twin (Woodruff, 1991, p.57); current battery price $\$ 1,500$, replaced every 20,000 miles (Woodruff, 1991; p.58).

Electric Hybrid/Large I.C.E. - $-\mathbf{\$ 5 0 , 0 0 0}$. Figure includes the price of a regular electric vehicle $(E V)$ plus a premium for the large I.C.E. The premium accounts for the fact that two engines would be costly and inefficient in terms of maintenance and use of space. A large I.C.E. acts as a range extender in the same way as a conventional gasoline I.C.E. The difference in price between a small and large I.C.E. is deemed to be insignificant at any stage. The figure is consistent with manufacturer prices of soonto-be released yehicles and the consensus of the literature.

Sources:1993 Ford small hybrid van priced at $\$ 100,000$ (NREL, 1992, on-line); high cost of adding batteries and electric motors to the engine of an I.C.E. (Woodruff, 1991, p.59).

Electric Hybrid/Smanall I.C.E. - \$50,000. See Electric Hybrid/Large I.C.E. above. A small I.C.E. only serves as a generator to recharge the batteries for the electric engine to operate. $\because$ The difference in price between a small and large I.C.E. is insignificant at any stage.

Sources:1993 Ford small hybrid van priced at $\$ 100,000$ (NREL, 1992, on-line); high cost of adding batteries and electric motors to the engine of an I.C.E. (Woodruff, 1991, p.59).

Electric Hybrid/Turbine - $\mathbf{\$ 1 2 5 , 0 0 0}$. Figure includes the price of an electric hybrid/I.C.E. plus a high premium that reflects the absence of a viable prototype at.this time: Gas turbine vehicles were manufactured in the fifties without success due to lack of competitively-priced, heat-resistant materials; however, new developments may solve such obstacles and a prototype vehicle may be successfully produced by 1998.

Soúrce: (The Economist, September 28, 1991).

CNG - \$2,750. Although some economies of scale are already present, all CNG vehicles are essentially retrofitted rather than optimized, therefore a significant premium (and potential for improvement) remains. The selected figure is consistent with the middle to the higher end of the 1992 literature ranges.

Sources: Range of \$2000-5000 (Cogan; August 1992,p.94); 1992 Chrysler Dodge BSeries Van Wagon $\$ 5000$ (NREL, 1992, on-line); $\$ 2,550-3,250$ (EPA, 1990, p.10); 
$\$ 2550-3250$ for light-duty automobile (large), $\$ 1650-2250$ (small-medium), $\$ 2350$ 3050 light duty truck; mass-produced dual-fuel $\$ 1600$ (ICAMF, 1990; p.5.7); average of $\$ 6,400$ for DOE AFV's (includes ethanol, methanol and CNG) procured in 1990 (G.A.O, May 1991,p.20); $\$ 800$ by 1995 (D.O.E.,August 1990, p.ix).

LPG - \$1,500. Although some economies of scale are already present; all LP.G vehicles are éssentially retrofitted rather than optimized; therefore a significant premium (and potential for improvement) remains. The selected figure is consistent with the middle to the higher end of the 1992 literature ranges.

Sources: $\$ 1,200-2,200$, (ICAMF, 1990, p.1:15.); 1992 Ford F-700 medium duty truck conversion option at $\$ 800$ (NREL, 1992, on-line).

Turbine/Gasoline $-\$ \mathbf{\$ 1 2 5 , 0 0 0}$. Figure includes a high premium that reflects the absence of a viable prototype at this time. Gas turbine vehicles were manufactured in the fifties without success due to lack of competitively-priced, heat-resistant materials; however, new developiments may solve such obstacles and a prototype vehicle may be successfully produced by 1998: The figure is consistent with the electric hybrid/turbine vẹhicle premium. No significant estimated price differential between CNG and gasoline technologies at this time.

Source: (The Economist, September 28,1991).

Turbine/CNG - \$125,000. See Turbine/Gasoline above. No significant estimated . price differential between $\mathrm{CNG}$ and gasoline technologies at this time.

Source: (The Economist, September 28, 1991).

Fuel Cell/Hydrogen $-\$ 150,000$. Figure includes a high premium for fuel cells because they are far more expensive than conventional batteries; there is also a premium included for fuel storage. Production prices in the literature diverge widely. Both hydrogen and methariol technologies rely on hydrogen for their electrochemical reactions and differ only in the way it is stored, i.e., as a component of methanol, or, independently; therefore, no significant difference between them exists at this stage. Hydrogeh-burning (as opposed to fuel cell) vehicles are far more feasible and less costly at this time.

Sources: Fuel cells cost and premium for fuel storage (McCosh, 1992, p.29); 1995 prototype's price: drive system and engine $\$ 225,000$, plus a fuel storage tank with a price range of $\$ 2,253$ to $\$ 7,709$, for a subtotal of $\$ 225,203$ to $\$ 232,659$ not including 
chassis (C.E.C., June 1991, pp.25-30).

Hydrogen I.C.E. Sources: feasibility; prototypes in Japan, i.e., Nissan's joint effort with Musashi Institute of Technology (Maruyama, 1991); Mazda hopes to sell a few hydrogen-burning cars in California within ten years; current models are not optimized; premium for hydrogen tank is $\$ 26,000$ (Templeman, 1991, p.59).

Fuel Cell/Methanol-\$150,000. See Fuel Cell/Hydrogen above. Both hydrogen and methanol technologies rely on hydrogen for their electrochemical reactions and differ only in the way it is stored, i.e., as a component of methariol, or independently; therefore, no significant difference between them exists at this stage.

Sources: See Fuel Cell/Hydrogen.

\section{FUTURE VEHICLE PRICES}

Ultimate price premia are defined as the minimum future price differentials between gasoline and ATF vehicles. An extensive literature search and SAIC's own resources yielded forecast future prices, which were used to set ultimate price premia and the approximate expected year they will be reached. All ATF vehicle prices falling between the ultimate and the current price premia are calculated by using the price premia decay rate described in the subsequent section.

\section{FUTURE GASOLINE.VEHICLE PRICES}

For all gasoline models, the prices beyond 1992 escalated at $2 \%$ per year. Non-fuel escalation factors inclựe:

The historical tendency of options to become standard equipment through time.

- Progressively higher additional costs for emissions controls and efficiency requirements. These are estimated to be $\$ 70$ for a TLEV and $\$ 170$ for LEV/ULEV (CARB, August 1990, p.IX.13).

Increased investment in more efficient, lighter engines such as the 2-stoke engine (The Economist. September 28, 1991) and higher cost super-light body materials such as 
carbon composites (GM, 1992, pp.14,15).

\section{DEVELOPMENT OF ULTIMATE PRICE PREMIA}

Minimum price differentials are reached once all criteria for improvement relative to conventional prices have been met. The criteria include the maximization of well-known economic principles such as economies of scale, returns to scale, and learning curves. The future year and value assigned to AFV premia were found by applying the above criteria to the current status of the technology, the short-term and future projected gains, and relevant theoretical limitations:

Once values for ultimate cost and associated year were calculated, the premia were added to the corresponding year's conventional gasoline price. After an AFV has reached its ultimate premium, price differentials between that $\mathrm{AFV}$ and a conventional vehicle remain constant except for non-fuel escalation. Assumptions, rationales and comments for each technology are provided bèlow.

Diesel $-\$ 1,000$. Average premia for representative diesel passenger vehicles; figure was slightly higher in the past, but is not expected to decline further.

Sources: (NADA, July-August, 1992 \& SAIC).

Ethanol Flex - \$0. Near-zero ultimate price premium assumes economies of scale and optimization achieved prior to switch to ethanol neat vehicles. Figure consistent with EPA and most recent literature.

Source: (EPA/ethanol, 1990, Appendix C, p.2).

Ethanol Neat - \$o. Near-zero ultimate price premium assumes economies of scale and optimization of both ethanol types. Prior development of flex vehicle would provide learning curve feedback. Figure consistent with EPA and most recent literature.

Source: (EPÁ/ethanol, 1990, Appendix C, p.2).

- Methanol Flex-\$200. Premium is equal to that of ethanol flex plus $\$ 200$ for higher manufacturing costs due the corrosive nature of the fuel, i.e., stainless steel or specially treated materials are needed for the engine.

Sources: Premia for corrosion-resistant materials, fuel sensing and control systems, and larger fuel tank for a total range of $\$ 150-500$ in the late nineties, down to near-zero premium after that (CRS,1989,p.17); \$150-300 at high volume production (EPA, April 
1990,p.35); \$300 with large scale production (ICAMF, 1990; p.1114).

Methanol Flex - \$100. Premium is equal to that of ethanol neat plus $\$ 100$ for higher manufacturing costs due the corrosive nature of the fuel, i.e., stainless steel or specially treated materials are needed for the engine. Such a premium would be smaller for a dedicated neat vehicle due to greater economies of scale, optimization, and transfer of knowledge from flexible fuel vehicles.

Sources: (EPA, 1990, Appendix C, p.2, \& CRS, 1989, p.17).

Electric - \$6,500. Figure includes an estimate of the ultimate price premium of a battery, assuming steady improvements in battery technology and mass production taking place as zero-emission vehicle laws take effect. Advanced batteries now in an infant stage of development could considerably extend the range of the vehicle without the need for replacement. Differences between $\mathrm{EV}$ and $\mathrm{EH}$ vehicles äre unimportant, as their most expensive component, the batteries, is the same. The figure is consistent with the consensus of the literature.

Sources: Premium for ZEV \$1350 (SAIC/report, 1991, p.35); advanced batteries, such as sodium-sulfur, with a 100,000-mile life may.be available by 1994 (Ẅoodruff, 1991, p.58).

Electric Hybrid/Large I.C.E. — \$6,500. See Electric above. Differences between EV and EH vehicles are unimportant, as their most expensive component; the batteries, is the same. The additional cost of a range-extender I.C.E. (regardless of size) ultimately approaches zero as economies of scale, transfer of knowledge and innovation arrive. The figure is consistent with the consensus of the literature.

Sources: SeeElectric above.

Electric Hybrid/Small I.C.E. — \$6,500. See Electric and Electric Hybrid/Large I.C.E. above. The additional cost of a range-extender I.C.E. (regardless of size) ultimately approaches zero as economies of scale, transfer of knowledge, and innovation arrive. The figure is consistent with the consensus of the literature.

Sources: See Electric Hybrid/Large I.C.E. above.

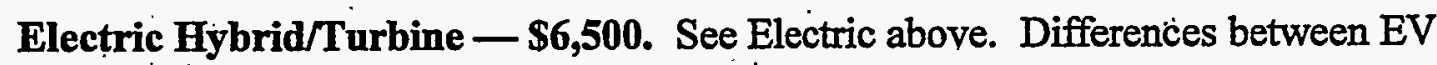
and $\mathrm{EH}$ vehicles are unimportant, as their most expensive component, the batteries, is the same. The additional cost of a range-extender turbine ultimately approaches zero 
as economies of scale, transfer of knowledge, and innovation arrive. The figure is consistent with the consensus of the literature.

Sources: See Electric Vehicle above, and Turbine/Gasoline \& CNG below.

CNG - \$750. Assumes mass-production of optimized dedicated vehicle. The figure is consistent with the consensus of the literature.

Sources: $\$ 700-800$ for optimized and dedicated vehicle (O.T:A., 1990, p.101); $\$ 800$ for optimized large-scale production, less for dedicated vehicle (ICAMF, 1990, p.1.14).

LPG - \$500. Assumes mass-production of optimized dedicated vehicle. The figure is consistent with current price differences between LPG and CNG vehicles, and : assumes such differences will persist.

,Source: \$500 (SAIC judgment).

- Turbines/Gasoline-\$1,500. Assumes likely advances in high temperature ceramics and electronic combustion controls will take place by the end of the decade and eventually make this technology cost-competitive with conventional technology.

Source: (The Economist, September 28, 1991, p.95).

Turbines/CNG - \$1,500. See Turbine/Gasoline above. Assumes there will be no significant price differential between CNG and gasoline technologies.

Source: (The Economist, September 28, 1991, p.95).

Fuel Cell/Hydrogen - \$6,500. Assumes significant advances in storage technology and fuel cell manufacturing are accomplished due to high demand.

Sources: storage technique breakthroughs: liquid hydrogen, or hydrogen bonded with powdered metals or stored in metal alloy balls may render it as safe as gasoline (Templeman, 1991, pp.59, 60); by 2010 the fuel cell hybrid will be $\$ 6,562$ plus chassis (C.E.C., June 1991, pp.25-30).

Fuel Cell/Methanol $-\$ 6,500$. Assumes significant advances in storage technology and fuel cell manufacturing are accomplished due to high demand.

Sources: Hydrogen-rich methanol would allow a fuel cell vehicle to refuel as rapidly as an I.C.E. vehicle (Economist, September 1991, p.75); storage technique breakthroughs: liquid hydrogen, or hydrogen bonded with powdered metals or stored in metal ailoy balls may render it as safe as gasoline (Templeman, 1991, pp.59, 60); 
by 2010 the fuel cell hybrid will be $\$ 6,562$ plus chassis (C.E.C., June 1991, pp.25-30).

A comparison of the current and ultimate price premia discussed above is provided in the following table.

Table F-18. AFV Price Premia by Technology

\begin{tabular}{|c|c|c|}
\hline \multirow{2}{*}{ [4. } & \multicolumn{2}{|c|}{ 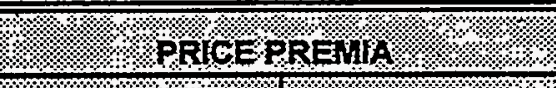 } \\
\hline & SERREHT: & (8) \\
\hline Blesel & 1,000 & $1,000^{\circ}$ \\
\hline Ethanol 1 ar & $4,500^{\circ}$ & 0. \\
\hline Ethanolyeat & 2,000 & 0 \\
\hline Madanol textex & 4,700 & 200 \\
\hline Hethanol reat & 2,200 & .100 \\
\hline Bectric & 45,000 & 6,500 . \\
\hline Electro Hybudilargelce & 50,000 & 6,500 \\
\hline 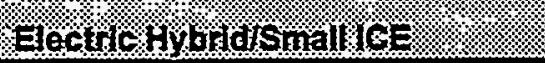 & 50,000 & $6,500^{\circ}$ \\
\hline 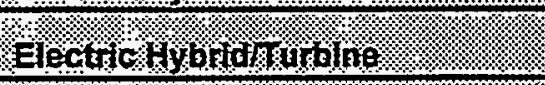 & 50,000 & 6,500 \\
\hline SOM. & $2,750^{\circ}$ & 750 \\
\hline 120 & 1,500 & 500. \\
\hline 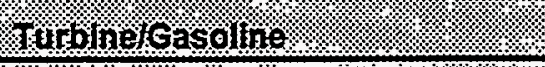 & 125,000 & $1,500^{\circ}$ \\
\hline rubinetche $:$ : & 125,000 & 1,500 \\
\hline ruelcedingethang! & 150,000 & 6,500 \\
\hline firel cediny grogen & $-150,000$ & 6,500 \\
\hline
\end{tabular}

\section{APPLICATION OF THE DECAY FUNCTION}

This rate is the annual, compound percentage decline in the current premium towards the ultimate premium for all AFV technologies. AFV prices are assumed to fall along a curve between the current and the ultimate price premia. The curve's shape is determined by the decay rate. If the exponential decay rate is rapid, the vehicle price reached its ultimate price well before 2030 (e.g., ethanol and methanol). If the decay rate is slow, the ultimate pricemay not be reached in the 40 -year period. 


\section{Table F-19. LDV and AFV Cost Decay Rates}

\begin{tabular}{|c|c|c|c|c|}
\hline अHUAT MO & sow: & BASE. & MUGH & 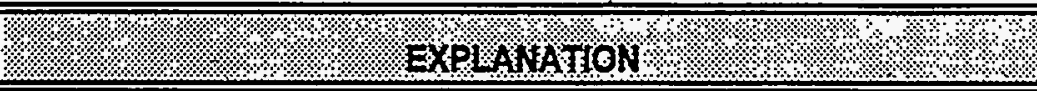 \\
\hline plesel icE. & $10 \%$ & $1 \%$ & $1 \%$ & $\begin{array}{l}\text { Diesel engines are advantageous only for medium and heavy-duty } \\
\text { vehicles. Unsuccessful previous attempt to penetrate the passenger } \\
\text { car market. }\end{array}$ \\
\hline Ethanol $8 \%$ & $5 \%$ & $10 \%$ & $15 \%$ & $\begin{array}{l}\text { Similar technologies are assumed to have near identical decay rates } \\
\text { and constitute the alcohols flexible fuel.market segment. Because of } \\
\text { initial fuel.availability advantages over neat vehicles and already } \\
\text { existing technology (retrofitted gasoline engines), flex ones are } \\
\text { expected to be mass-produced much sooner than optimized neat } \\
\text { vehicles. Consistent with the consensus of the.literature. }\end{array}$ \\
\hline Ethanol 8 & $2,5 \%$ & $5 \%$ & $7.5 \%$ & $\begin{array}{l}\text { Because optimized neat vehicles necessitate more engineering, they } \\
\text { will take longer to develop and be mass-produced than flex vehicles. } \\
\text { It is assumed that there will be a trend towards optimization and that } \\
\text { flex vehicles will not be available in significant numbers by the end of } \\
\text { the next decade. The rates were rounded off to figures equal to half } \\
\text { of those for flex vehicles and are consistent with the consensus of } \\
\text { the literature. }\end{array}$ \\
\hline Electric $\%$ & $7.5 \%$ & $12.5 \%$ & $\begin{array}{l}15 \% \\
\because \\
\because\end{array}$ & $\begin{array}{l}\text { Assuming steady improvements in battery technology and the } \\
\text { expansion of zero emissions state limit programs, the overall } \\
\text { advantages of electric and hybrid vehicles will. translate into the } \\
\text { fastest annual increase in production for any AFV. The rates seem } \\
\text { even faster because initial production is much lower than other. } \\
\text { competing technologies, i.e.; CNG, LPG, and alcohol flex. }\end{array}$ \\
\hline $\mathrm{ONG} \%$ & $5 \%$ & $\cdot 10 \%$ & $15 \%$ & $\begin{array}{l}\text { Assuming retrofit conversion through } 2000 \text {; dedicated mass- } \\
\text { produced optimized vehicle after that year. }\end{array}$ \\
\hline अPGे\% & $2 \%$ & $4 \%$ & $6 \%$ & $\begin{array}{l}\text { Dedicated mass-production will come later than CNG vehicles; due } \\
\text { to the latter's greater advantages vis a vis the non-fleet passenger } \\
\text { vehicle market segment. }\end{array}$ \\
\hline Turbines: 8 Cho & $5 \%$ & $10 \%$ & $\begin{array}{l}15 \% \\
\because:\end{array}$ & $\begin{array}{l}\text { Rates consistent with, and slightly lower than, those for electrical } \\
\text { vehicles. Both technologies are in their infancy but are also very } \\
\text { promising. Assuming technology is operational by the end of the } \\
\text { century, costs should decrease rapidly after that due to high initial } \\
\text { leaming curve position (e.g., turbine technology) and use of } \\
\text { conventional fuel. }\end{array}$ \\
\hline Muelogl $5 . \%$ & $5 \%$ & $10 \%$ & $\begin{aligned} & 15 \% \\
= & \because\end{aligned}$ & $\begin{array}{l}\text { Rates are consistent with electrical vehicles and rounded off to equal } \\
\text { those of turbine vehicles. The development of this technology } \\
\text { presents' more obstacles than turbines but offers more potential } \\
\text { rewards, i.e., lower emissions and seemingly limitless fuel supply. }\end{array}$ \\
\hline
\end{tabular}

SOURCES:

Diesel - Rate tied to gasoline rate; the price premium is assumed to remain constant through time. The usefulness of this technology is limited to large vehicles. 
Ethanol Flex - $\$ 300$ premium with large production in the future (EPA, April 1990, p.2); limited production by 1993 , full by 2000 (C.E.C., 1989, p.7).

MethanolFlex - Costs dropping since Chrysler began selling its Dodge Spirit and Plymouth Acclaim without a price premium, other auto makers will presumably follow (Cogar, August 1992, p.94); limited production by 1993, full by 2000 (C.E.C., August 1989, p.6); Federal fleet assumptions for cost premia: $1993=\$ 2,500,1994=\$ 1500$, $1995=\$ 1000,1996=\$ 275,2001=\$ 150$ (D.O.E., May 1992, p.26).

Methanol Neat - No significant production for dedicated vehicles before 2007-2010 (CRS, 1989, p.17-18).

Electric - Large resources from Detroit's consortium going into EV research (Woodruff, 1991); estimated manufacturing cost versus annual production volume (no. of vehicles manufactured/EV cost in 1988 $\$$ ): $30 / \$ 48,200,100 / \$ 40,000,1000 / \$ 29,500$, 10,000/\$21,000, 50,000/\$18,100 (C.E.C., August 1989, p.6); limited production 19932000 (C.E.C., 1989, p.7); economies of scale after 1998 (60,000-100,000 units) and replacement of DCEV (direct current electric vehicle) by ACEV (alternating current. e.v.); NiFe batteries and advanced battery use beginning 2003 and 2005 respectivèly, by $20091 / 2$ of the EV and EV/hybrid market captured (A.F., 1990, p.18-22); GM Impact plant production will be $25,000 /$ year (Woodruff; 1991 , p.54, p.58); it takes production runs of at least 50,000 /year to make a profit on a reasonably priced vehicle (Woodruff. 1991, p.59).

Electric Hybrid/Large I.C.E. - NiFe battery car by 2003; by 2010 half of the EV's may be EV/hybrid (A.F., 1990, p.18-22). See other applicable references above under Electric:

- - Electric Hybrid/Small I.C.E. - NiFe battery car by 2003; by 2010 half of the EV's may be EV/hybrid (A.F., 1990, p.18-22). See other applicable references above under. Electric.

Electric Hybrid/Turbine - NiFe battery car by 2003; by 2010 half of the.EV's may be EV/hybrid (A.F., 1990, p.18-22). See other applicable references above under Electric, and under Turbine. 
CNG - Retrofit conversion 1993-2000 (C.E.C., 1989, p.7).

LPG - Retrofit conversion 1993-2000 (C.E.C., 1989, p.7).

Turbine/Gasoline - (The Economist, September 28, 1991, p.95).

Turbine/CNG - (The Economist, September 28, 1991,p.95):

Fuel Celi/Hydrogen - Prototype vehicle by 1993 , demonstration vehicle by 2000 (C.E.C., 1989, p.7); prototype by 1995 possible, limited production 1000 to 10,000 units/year by 2002 (C.E.C., June 1991, p.20); main current obstaclès are safety, compact storage, and competitive production costs; factory site vehicles by 2000 , road vehicles beyond that (Tyler, 1990, p.20).

Fuel Cell/Methanol - See references for Fuel Cell/Hydrogen above:

\section{VEHICLE EFFICIENCY}

This section documents vehicle efficiency in the database. The output of the database is the efficiency rate for sixteen technologies for three vehicle sizes, from 1990 to 2030 . The rate is given in miles per MMBtu.

The general approach consists of establishing the current mid-size vehicle mileage per.MMBtu for each fuel. The mileage figures are then adjusted for differences in vehicle size (e.g., small and large) using an index of mileage by size, as a function of mid-size mileage, while holding fuel constant. A fuel-use adjustment is needed to correct the miles/MMBtu estimates for pure fuel use vs. hybrid fuel use (e.g., electric vis. electric hybrid).

To obtain future vehicle éfficiency, an annual simple percentage efficiency gain by vehicle type was developed. Fuels with greater potential for engine efficiency improvements were assigned greater estimated efficiency gains over time (e.g., gasoline I.C.E. vs. EV.). 
Thus, the vehicle efficiency inputs are:

- . Current mileage per MMBtu for each fuel.

- . Mileage by vehicle size (small, large) as a function of mid-șize vehicle mileage.

- A fuel-use efficiency adjustment to correct the miles/MMBtu estimates for pure fuel use vs. hybrid fuel use.

-. ' Annual simple percentage.efficiency gain by vehicle type for all vehicle types.

The approach has the following advantages:

Projected efficiency rates should be relatively consistent vis a vis conventional gasoline I.C.E. and other technology efficiency/rates.

Updating and revising figures based on future developments are facilitated.

\section{CURRENT VEHICLE EFFICIENCY.}

This section describes the process of obtaining current efficiency rates and adjusting for size and fuel use. As explained in the previous section, current mileages per MMBtu for each vehicle technology were initially obtained for a mid-size vehicle only. The following table shows these current efficiency rates. The sources consulted and the specific references and/or figures used are given immediately after the table. ${ }^{27}$ Efficiencies for the other two vehicle sizes were obtained by applying an adjustment factor of $+10 \%$ for small, and $-10 \%$ for large, to the base mid-size vehicle efficiency rate shown in the following table.

27 Some improvements in the efficiency of gasoline vehicles also apply to AFV's, i.e., super-light materials and on-board computers, while others do not, i.e., two-stroke engines. Those that do apply do so differently from one technology to aniother, i.e., it will be easier to reduce air drag in a vehicle that has a small, powerful engine and does not require large fuel storage capacity. 
Table F-20. Current Mid-Sized Vehicle Fuel Efficiencies

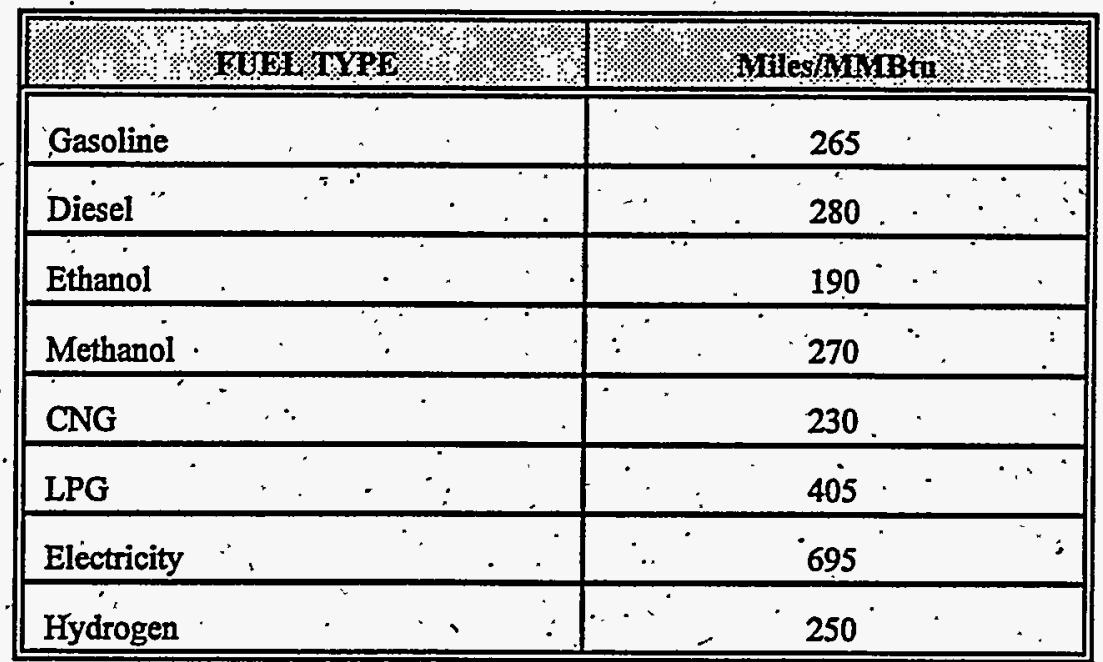

SOURCES AND REFERENCES:

Gaśoline - Efficiency rates of 24 MPG for Buick Park Avenue V6; 25 MPG for a Buick LeSabre; 24 MPG for Toyota Camry (G.M.,1992, pp.14, 15, 36); Clean, highly efficient engines already developed in Japan, i.e., M-Miller cycle engine (Japan 21st; 1992); recent impressive gains in mileage, i.e., 65 MPG for a 1992 Honda Civic hatchback VX (Woodruff, 1991, p.56).

Ethanol Flex - Efficiency of 0.0505 ethanol gallons per mile (EPA, April 1990, p.53).

Ethanol Neat - Efficiency of 0.0418 ethanol gallons per mile (EPA, April 1990, p.53).

- Methanol Flex - Efficiency of 11.4 MPG for 1992 Ford Econoline Van (NREL, 1992, On line).

- Methanol Neat - Dedicated vehicle improvement over gasoline vehicle (CRS, 1989; p.18); dedicated vehicle is $4-15 \%$ better in energy input due to higher compression ratios (Oil \& Gas, Dec 1991, p.59).

Electric - SAIC data. 
Electric Hybrid - SAIC datạ.

CNG - SAIC data.

LPG - Efficiency for a 1992-1993.Ford F-700 Medium Duty Truck is 15 to $20 \%$ less than its gasoline equivalent (N.R.E.L., 1992, On-line).

Turbine/Gasoline - SAIC data.

Turbine/CNG - SAIC data:

Fuel Cell/Hydrogen - Energy density is about 3.8 watts per pound, or less than that of an EV's lead-acid batteries (McCosh, August 1992, p.29); the theoretical limit to energy conversion is $80-85 \%$ (Templeman, 1991, p.59).

Fuel Cell/Methanol - See Fuel Cell/Hydrogen above. Both hydrogen and methanol technologies consume hydrogen as a fuel; so they are essentially the same technology, differing only in the way the fuel is stored.

\section{FUTURE EFFICIENCY RATES}

Future efficiency rates were obtained by applying an annual percentage gain by technology type, for each of the three penetration scenarios. This section describes how the gain rates were determined and provides the sources used.

\section{ANNUAL PERCENTAGE GAIN IN EFFICIENCY}

The following table shows the efficiency gain rates by vehicle technology for three penetration scenarios. Each vehicle technology entry is accompanied by comments or an explanation of assumptions where applicable. 


\section{Table F-21. Annual LDV \& AFV Efficiency Gain, by Technology (Three Scenarios)}

\begin{tabular}{|c|c|c|c|c|}
\hline \multirow{2}{*}{ मHemolog\% } & \multicolumn{3}{|c|}{ 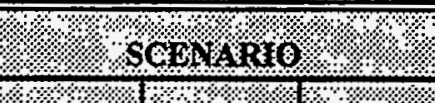 } & \multirow{2}{*}{ (1. } \\
\hline & BrSSE & ingu & 1000 w & \\
\hline Gasofines pie & $1.00 \%$ & $0.00 \%$ & $2.00 \%$ & $\begin{array}{l}\text { Based on historical rate, i.e.; since } 1974 \text { GM vehicles have improved } \\
\text { efficiency by } 125 \% \text {, and assuming current trends continue, i:e., increased } \\
\text { investment in order to meet policy goals and competitive challenges of } \\
\text { AFV's. The efficiency escalation rate cannot remain constant, because the } \\
\text { easier gains have been already achieved. Nevertheless, even the auto- } \\
\text { makers themselves have set ambitious goals, i.e., Chrysier's } 29 \text { MPG by } \\
\text { 1996. Diesel rate parallels gasoline's and is consistent with the historical } \\
\text { record. }\end{array}$ \\
\hline Alcoholingis & $1.00 \%$ & $2.00 \%$ & $0.50 \%$ & $\begin{array}{l}5-10 \% \text { operation efficiency increase through technological improvements } \\
\text { in the near future. Since ethanol and methanol have higher heat content } \\
\text { than gasoline or diesel, higher efficiency can be expected from a vehicle } \\
\text { that nums on neat fuel, but the annual gains in efficiency would be almost } \\
\text { the same for both neat and flex fuels. }\end{array}$ \\
\hline 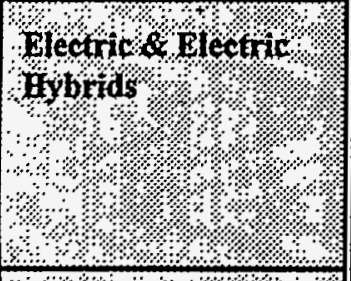 & $0.50 \%$ & $0.75 \%$ & $0.00 \%$ & $\begin{array}{l}\text { Much higher initial efficiency, but fast improvements in baittery and/or } \\
\text { engine technology are unlikely, resulting in a relatively low efficiency } \\
\text { gains rate. Note that this technology is not affected by the Carnot cycle's } \\
\text { theoretical limit. Similar rates are projected for all types of hybrids, as } \\
\text { their respective complementary technologies are secondary to the electric } \\
\text { technology. }\end{array}$ \\
\hline CNG \& $1 \mathrm{PA}$ & $1.00 \%$ & $2.00 \%$ & $0.50 \%$ & Gain rates equivalent to those of alcohol fuels assumed. \\
\hline Tubineforsoline & $1.25 \%$ & $.0 .00 \%$ & $2.00 \%$ & $\begin{array}{l}\text { Based on existing technology applied to other types of vehicles, i.e., } \\
\text { Abrahms M1 tank, hovercraft, and assuming the technology will fulfill its } \\
\text { theoretical expectations once applied to passenger vehicles. Efficiency } \\
\text { gains should parallel those of conventional gasoline-vehicles to a large } \\
\text { extent. }\end{array}$ \\
\hline TurbinereNG & $1.25 \%$ & $.2 .00 \%$ & $.0 .50 \%$ & $\begin{array}{l}\text { See:TURBINE/GASOLINE entry above. Efficiency gains should parallel } \\
\text { those of conventional CNG vehicles to a large extent. }\end{array}$ \\
\hline Methanol \& & $1.25 \%$ & $2.00 \%$ & $0.00 \%$ & $\begin{array}{l}\text { Although the technology is in its infancy, because of its vast potential a fast } \\
\text { gain rate similar to that of turbines is expected, i.e., it has a theoretical . } \\
\text { efficiency of } 80 \text { to } 85 \% \text { when the heat of the process is recovered for use } \\
\text { elsewhere. It is assumed that there will be continuous technical } \\
\text { breakthroughs as projected today, i.e., proton exchange membrane, or other. } \\
\text { advanced systems fully developed. }\end{array}$ \\
\hline
\end{tabular}

SOURCES.AND REFERENCES:

- Gasoline - Carnot cycle's theoretical maximum (Romano, 1989, p.75); 2-stroke. engine (The Economist, September 28, 1991 \& Scientific American, October 1992; pp.

${ }^{2 s}$ Regardless of fuel choice, all ICE's are limited by the Camot cycle's theoretical maximum of 40 to $50 \%$. 
112-113); super-light materials (GM, 1992, p.14, 15); reduced air drag, upgraded onboard computers (Woodruff, 1991, p.56); reformulation (Unzelman, 1991,p.64). Since $1974 \mathrm{GM}$ vehicles have improved efficiency by $125 \%$ (GM, 1992, p.14, 15); Chrysler's. efficiency goal is to achieve an average 29. MPG by 1996 (Woodruff, 1991, p.54).

Already existing promising prototypes (Maruyama, 1991); policy and industry goals in the U.S. and elsewhere (Woodruff, 1991, p.54); CAFE's standards by 2001; the historical efficiency escalation rate, defined as a reduction in gallons/year per vehicle, is $4.95 \%$ (Oil \& Gas, Dec 1991, p.58).

Diesel - Carnot cycle's theoretical maximum (Römano, 1989, p.75); super-light materials (GM, 1992; p.14, 15); reduced air drag, upgraded on-board computers (Woodruff, 1991; p.56); reformulation (Unzelman, 1991,p.64):

Ethanol Flex - 5-10\% operational efficiency increase (Oil \& Gas, Dec 1991, p.59); Carnot cycle's theoretical maximum (Romano, 1989, p.75).

Ethanol Neat - Higher heat content and efficiency rates; learning curve gains of 20 to $30 \%$ over gasoline by the time dedicated vehicles enter the market (CRS, 1989, p.18); Carnot cycle's theoretical maximum (Romano, 1989; p.75).

Methanol Flex - 5-10\% operational efficiency increase over gasoline (Oil \& Gas, Dec 1991, p.59); Carnot cycle's theoretical maximum (Romano, 1989, p.75); improvement over gasoline: low case $4 \%$, base $6 \%$, and high $13 \%$ (CRS, 1989, p.18).

Methanol Neat - Higher heat content and efficiency rate; learning curve gains of 20 to $30 \%$ over gasoline by the time dedicated vehicles enter the market (CRS, 1989, p.18); Carnot cycle's theoretical maximum (Romano, 1989, p.75).

Electric - SAIC data.

Electric Hybrid/Large I.C.E. - Efficiency rates of 36 MPG for an average passenger vehicle, and $21 \mathrm{MPG}$ for a light truck (A.F., 1990, p.18-22).

Electric Hybrid/Small I.C.E. - Efficiency rates of 36 MPG for an average passenger vehicle, and $21 \mathrm{MPG}$ for.a light truck (A.F., 1990, p.18-22). 
Electric Hybrid/Turbine - (The Eçonomist, September 28, 1991, p.95).

CNG - Carnot cycle's theoretical maximum (Romano, 1989, p.75).

'LPG - Carnot cycle's theoretical maximum' (Romano, 1989, p.75).

Turbine/Gasoline - (The Economist, September 28; 1991, p.95).

Turbine/CNG - (The Economist, September 28, 1991, p.95).

Fuel Cell/Hydrogen - (Templeman, 1991, pp.59-60).

Fuel Cell/Methanol - (Templeman, 1991, pp.59-60).

\section{VEHICLE EMISSIONS}

This section describes vehicle emissions from conventional and ATF vehicles over time.

\section{INDEX APPROACH}

The general approach uses an index value tied to the impact-weighted emissions from mid-size 'gasoline vehicles. In each year from '1990-2030, the emissions impact from the base-case gasoline vehicle is estimated. As gasoline vehicle emissions decline (e.g., due to reformulation), the absolute 'emissions level declines but the index value remains constant (at 1.0). The emissions impact of the alternative fuels is benchmarked against the absolute level to create the index value for the alternatives. If the emissions of an AFV declines faster than that of the gasoline vehicle, the emissions index for that $\mathrm{AFV}$ will decline. If the emissions of an $\mathrm{AFV}$ increases or declines less rapidly than that of the gasoline vehicle, the emissions index for that AFV will increase. The technology choice module can make use of this relative indexing in annually selecting vehicle types.

The weight given to emissions and emissions indexing in the technology choice module is outside the scope of this database. Whether decisions will ultimately be made with respect to some 
thireshold emissions level is also not considered.

The emissions index is constructed from the following inputs:

Current emissions from a mid-size car for five pollutants $\left(\mathrm{CO}, \mathrm{CO}_{2}, \mathrm{NO}_{x}\right.$ methane, and NMHC) in grams/mile for 16 vehicle types. See Tablè F-22.

- Minimum possible emissions by 2030 for the same pollutants for the same vehicle types. See Table F-23:

Annual simple percentage decline in emissions towards the minima, same vehicle types.

Impact-weighting of the five pollutants on health and environmental criteria.

The index constructed from these data is necessary; because the impact on human health and the environment from a gram of one pollutant is not equivalent to the impact of another pollutant. This non-equivalence is particularly apparent when one compares the typical emissions of $\mathrm{NO}_{x}$ (about 1 gram/mile) to that of $\mathrm{CO}_{2}$ (about 450 grams/mile). Clearly, $\mathrm{CO}_{2}$ is not 450 times more hazardous to health or the environment than $\mathrm{NO}_{\mathrm{x}}$. Thus, a weighting scheme (i.e., an index) must be constructed to properly compare the overall emissions index. 


\begin{tabular}{|c|c|c|c|c|c|c|}
\hline thonvologr & 8 & NpAre. & Mat: & $\sqrt{20}$ & eo. & ASSUII ITONS A AB OXPRANATIONS \\
\hline Gasoline & 9.00 & 1.00 & 0.00 & 1.03 & .452 & $\begin{array}{l}\text { Representative vehicle for size category. Standard catalytic } \\
\text { converter. }{ }^{29} \because\end{array}$ \\
\hline busel & $3: 40$ & $0 . \dot{4} 1$ & 0.00 & 1.00 & 450 & $\begin{array}{l}\text { Representative vehicle for size category. Consistent with } \\
\text { data entered under gasoline. Standard catalytic converter. }\end{array}$ \\
\hline Ettianol flex 4. & 2.00 & 0.60 & 0.00 & 1.10 & $435^{\circ}$ & \multirow{4}{*}{$\begin{array}{l}\text { Consistent with data entered under gasoline and diesel. } \\
\text { Retrofitted representative vehicle for size category. } \\
\text { Generally higher } \mathrm{NO}_{x} \text { than gasoline and diesel due to higher. } \\
\text { combustion temperature. Formaldehyde not included for } \\
\text { methanol emissions. }\end{array}$} \\
\hline Ethanoldeat & 1.57 & 0.36 & 0.00 & 1.10 & 429. & \\
\hline Methanol Mer & .1 .75 & 0.29 & 0.00 & 1.10 & 447 & \\
\hline Mettunol heat & 1.50 & 0.20 & 0.00 & 1.10 & $450^{\circ}$ & \\
\hline Eléctric $\% \%$ & 0.00 & 0.00 & 0.00 & 0.00 & $0.00^{\circ}$ & Near zero emissions. Rounded off for manageability. \\
\hline letection ingit: & $2.00^{\circ}$ & 0.10 & 0.00 & 0.20 & 90 & $\begin{array}{l}\text { Due to smaller size and less use, i.c.e.'s emissions are } 1 / 4 \text { or } \\
\text { less of a conventional engine. }\end{array}$ \\
\hline Steetrichytrit: & 1.00 & 0.05 . & 0.00 & $0.10^{\circ}$ & 45 & $\begin{array}{l}\text { Due to smaller size and less use, i.c.e's emissions are } 1 / 2 \text { of } \\
\text { large i.c.e.'s }\end{array}$ \\
\hline 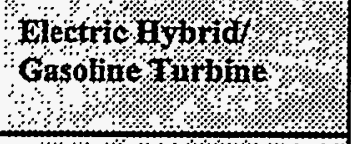 & 0.50 & 0.03 & 0.00 & 0.06 & 25 & $\begin{array}{l}\text { Near zero for electric part. See TURBINE entry below. Due } \\
\text { to.less use and smaller size emission's are about } 1 / 1 / 4 \text { of } \\
\text { conventional turbine's. }\end{array}$ \\
\hline aNG $\% \%$ & 0.30 & 0.23 & 1.20 & $0: 97$ & 419 & \multirow{2}{*}{$\begin{array}{l}\text { Representative vehicle, consistent with alcohol and gasoline } \\
\text { vehicles selected above. }\end{array}$} \\
\hline $\mathrm{HPG}$ & 0.28 & 0.29 & 0.00 & $0: 59$ & 437 & \\
\hline Tunbine/Gasolune & 2.00 & 0.10 & 0.00 & 0.25 & 100 & \multirow{2}{*}{$\begin{array}{l}\text { Theoretically very low emissions, around } 1 / 4 \text { of conventional } \\
\text { fuel (gasoline or CNG respectively) vehicle. }\end{array}$} \\
\hline rübinetors & 0.08 & 0.06 & $0.35^{\circ}$ & 0.40 & 95 & \\
\hline Fuel Cellimathanol & 0.00 & 0.00 & 0.20 & 0.01 & 0.01 & \multirow{2}{*}{$\begin{array}{l}\text { Near zero emissions. Small methane figure for methanol } \\
\text { vehicle. }\end{array}$} \\
\hline Huel ceintydrogen & $0.00^{\circ}$ & 0.00 & 0.00 & 0.01 & 0.01 & \\
\hline
\end{tabular}

${ }^{29}$ For all technologies, pollution produced by the power source or fuel production process is not included. 
Table F-23. Minimum Possible Emissions, Mid-Size Vehicle (Grams/Mile, 2030)

\begin{tabular}{|c|c|c|c|c|c|c|}
\hline theghotogr & 86. & 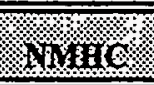 & $1+1+12$ & 10. & $\sqrt{10} 0_{2}$ & ?. \\
\hline Gasoline: & 1.70 & 0.04 & 0.00 & 0.20 & 250 & \multirow{2}{*}{ Advanced catalytic converters and reformulation. } \\
\hline 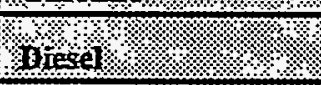 & 1.25 & 0.04 & 0.00 & .0 .20 & 250 & \\
\hline atcotiol ririst & 1.00 & 0.04 & 0.00 & 0.20 & 250 & Advanced catalytic converters. ${ }^{31}$ \\
\hline milectirit: & 0.00 & 0.00 & $0 . \dot{0} 0$ & 0.00 & 0.00 & Power source and accidental leakage not included. \\
\hline 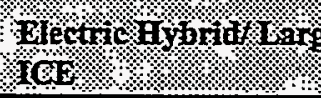 & 0.40 & 0.01 & 0.00 & 0.04 & 60 & $\begin{array}{l}\text { Due to less use and smaller size, ICE's emissions } \\
\text { are } 1 / 4 \text { or less of conventional engine. }\end{array}$ \\
\hline 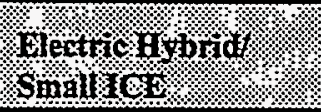 & 0.20 & $\therefore 0.01$ & 0.00 & 0.02 & 30. & $\begin{array}{l}\text { Due to smaller size, ICE's emissions are } 1 / 2 \text { of large } \\
\text { ICE hybrid. }\end{array}$ \\
\hline Giectric Hybrit: & 0.01 & $0.00^{\circ}$ & 0.00 : & 0.01 & 12 & Advanced catalytic converter and reformulation. \\
\hline 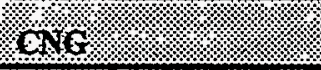 & 0.20 & 0.01 & $0.20^{\circ}$ & $0.20^{\circ}$ & .250 & \multirow{2}{*}{ Advanced catalytic converter. $\quad \because \ldots$} \\
\hline Leg: & 0.10 & 0.04 & 0.00 & 0.20 & 250 & \\
\hline Molibirictsasoline & $0: 50$ & $0.02:$ & 0.00 & 0.05 & 25 & Advanced catalytic converter and reformulation. \\
\hline Kuninersic & $0.05^{\circ}$ & 0.00 & 0.05 & 0.05 & 25 & Advanced catalytic converter. \\
\hline 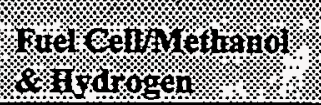 & 0.00 & $0.00^{\circ}$ & 0:00 & 0.01 & 0.01 & Negligible emissions. \\
\hline
\end{tabular}

${ }^{30}$ For all technologies, emissions from fuel source and accidental leakage is not included.

${ }^{31}$ For ethanol, the 30 to $50 \%$ emissions reduction must be weighed against the considerable $\mathrm{CO}, \mathrm{CO}_{2}$ and nitrogen compounds produced by growing, fertilizing, harvesting, drying and transporting the crops to produce the fuel. EPA estimates the pollution created by producing and burning a gallon of ethanol is up to six times as much as producing and burning a gallon of gasoline. However, aldehydes are not produced (Frank, August 1992, p.106). 


\section{IMPACT WEIGHTING}

The weighting scheme assumes that all impacts will be in the area of health (85\% of the decision) or environment (15\%) and will be based on each pollutant's contribution to impacts in those areas. For example; $\mathrm{CO}_{2}$ has an impact on the environment but little or no impact on health. For $\mathrm{CO}$, the reverse is true. Note that we are not considering health impacts derived from environmental impacts as health impacts. We are using the more conventional understanding that, for example, $\mathrm{CO}_{2}$ is not considered a respiratory hazard (health) but is a greenhouse gas (environment).

In general, the reaisoning behind the weightings is as follows:

Carbon Monoxide (CO) - A moderate health hazard for its role in surface-level ozone creation; its environmental effect is negligible.

Non-Methane Hydrocarbons (NMHC) - Serious health hazard for its significant role in surface-level ozone creation; its environmental effect is negligible.

Methane (Met) - Important greenhouse gas; negligible health threat.

Nitrogen Oxides $\left(\mathrm{NO}_{x}\right)$ - Serious health hazard for their role in surface-level ozone creation; also a significant greenhouse gas:

- Carbon Dioxide $\left(\mathrm{CO}_{2}\right)$ - Statistically insignificant health impact but some greenhouse impact.

The choice of the five pollutants ( $\mathrm{CO}, \mathrm{CO}_{2}, \mathrm{NO}_{x}$, methane, and $\mathrm{NMHC}$ ) was based partly on the availability of detailed technical literature and partly on SAIC's judgment about the pollutants likely to affect vehicle choice and public policy in the eoming decades. Additional pollutants, notably. aldehydes and particulates, could have been added. The ultimate selection of five pollutants was based on computational tractability. The specific inclusion of methane and non-methane, hydrocarbons was based on the need to distinguish natural gas-fueled vehicles based on smog-related and non-smog-related emissions. The impact of the various pollutants per unit emitted.is assumed not to change over time. 
Table F-24. Pollutant Impact Weighting Factors (Health vs. Environment)

\begin{tabular}{|c|c|c|c|c|c|c|}
\hline \% & 4 XEIG & .co & NMIBC. & 14a & XNO & $\mathrm{co}_{2} .2$ \\
\hline Heartir. & 0.85 & 0.02 & 0.44 & 0.00 & 0.39 & 0.00 \\
\hline 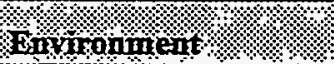 & 0.15 & $0.00^{\circ}$ & $0.00^{\circ}$. & 0.09 & 0.06 & 0.0005 \\
\hline
\end{tabular}

The database treats electric vehicles as zero-emissions vehicles (ZEVs) in accordance with California regulations and shows them with zero emissions. Powerplant emissions are not included in the database. Emissions for the gas turbine engines are generally guesses. Emissions levels for the fuel cells are approximately zero, except for $\mathrm{NO}_{\mathrm{x}}$. The emissions for converting coal or natural gas to methanol or hydrogen for use in the fuel cells are not included. Similarly, emissions from ethanol exclude the $\mathrm{CO}, \mathrm{CO}_{2}$, and nitrogen compounds emitted dựing growing, fertilizing, harvesting, drying, and transporting the crops. Emissions and leakage from tanks (e.g., CNG and hydrogen releases) are also not considered.

\section{DECLINES IN EMISSIONS OVER TIME}

The simple annual percentage rate at which the vehicle emissions decline is based on an extensive review of the literature for both the vehicles and the fuels. The decay rates are provided in the following table.

\section{Table F-25. LDV \& AFV Emissions.Decay. Rates}

\begin{tabular}{|c|c|c|c|c|c|}
\hline (.:. & 60 & N1MHCO & 1 Hes. & No. & $\mathrm{cos}_{3}:$ : \\
\hline 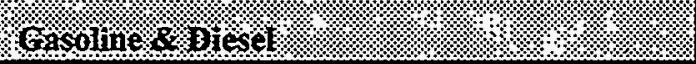 & $10.0 \%$ & $10: 0 \%$ & $0.0 \%$ & $5.0 \%$ & $0.0 \%$ \\
\hline 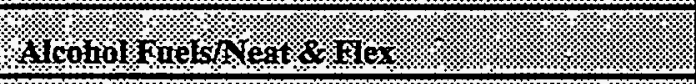 & $5.0 \%$ & $10.0 \%$ & $0.0 \%$ & $5.0 \%$ & $0.0 \%$ \\
\hline 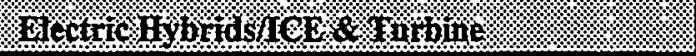 & $0.0 \%$ & $0.0 \%$ & $0.0 \%$ & $0.0 \%$ & $0.0 \%$ \\
\hline (CNG. & $5.0 \%$ & $10.0 \%^{\circ}$ & $10.0 \%$ & $5.0 \%$ & $3.0 \%$ \\
\hline 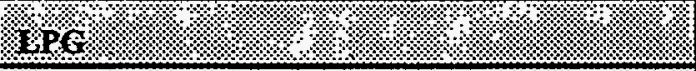 & $5.0 \%$ & $10.0 \%$ & $0.0 \%$ & $5.0 \%$ & $3.0 \%$ \\
\hline Turbine Gasoline: & $10.0 \%$ & $10.0 \%$ & $0.0 \%$ & $5.0 \%$ & $0.0 \%$ \\
\hline 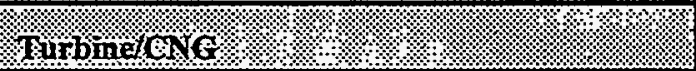 & $5.0 \%$ & $10.0 \%$ & $10.0 \%$ & $5.0 \%$ & $3.0 \%$ \\
\hline 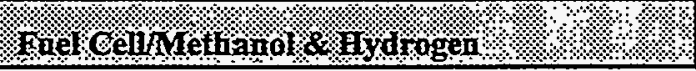 & $0.1 \%$ & $0.1 \%$ & $: 0.1 \%$ & $0.1 \%$ & $0.1 \%$ \\
\hline
\end{tabular}


In general, the following factors were considered.

Gasoline - Development of upgraded on-board computers for more precise spark timing and fuel injection (so gasoline burns more completely and less HC's escape); widespread use of catalytic converters that will eliminate up to $99 \%$ of $\mathrm{CO}$ and $\mathrm{NO}_{x}$ pollution by electronically preheating before a car starts; consequent increase in $\mathrm{CO} 2$.

Electric - Assigned zero emissions in isolation of power source, therefore decay function is also zero. Even if power source is included there will be dramatic. reductions compared to gasoline emissions, depending on fuel burned (natural gas or coal) to generate power. Improvements in emission controls at the source are expected to keep electricity ahead of gasoline.

Electric Hybrid/Gas Turbine - Gas turbine would emit insignificant amounts of pollutants, so they may not need a catalytic converter. Without including power source, the electric part would have zero emissions (see above paragraph.) Although not yet engineered as such, turbine technology has been fully developed.

Turbine/CNG - Widely used in other applications, with well-known emissions. For passenger vehicle applications this technology will emit insignificant amounts of pollutants and may not need catalytic converters.

\section{SOURCES AND REFERENCES:}

Gasoline - Clean, highly efficient vehicles such as the M-Miller Cycle engine vehicle are being developed in Japan (Japan 21st, 1992).

Methanol Neat - A dedicated vehicle has higher compression ratios, thus higher heat and $\mathrm{NO}_{x}$ than gasoline I.C.E.; high level of formaldehyde (Oil \& Gas, Dec 1991, p.59); high level of çarcinogen formaldehyde (Oil \& Gas, Dec 1991, p.59).

CNG - The cleanest running nonelectric production vehicle available today full-size Dodge van (Frank, August 1992, p.105). CO level is $1 / 2$ to $1 / 10$ lower, but $\mathrm{NO}_{\mathrm{x}}$ is higher due to higher peiak combustion temperature in the presence of excess oxygen (Oil \& Gas, Dec 1991, p.59). 
LPG - Low CO and HC; higher NO (Oil \& Gas, Dec 1991, p.60): In the 1992 Ford F-700 Medium Duty. Truck, $-\mathrm{HC}$ and $\mathrm{NO}_{\mathrm{x}}$ are significantly lower than their conventional equivalent, while CO emissions are comparable (NREL, 1992, On line).

Fuel Cell/Hydrogen and Methanol - Would meet California's no-emissions requirements for 1994 (McCosh; 1992, p.29); cleanest emissions of any fuel; emissions are water and a low quantity of $\mathrm{NO}_{\mathrm{x}}$ (SAIC/report 1991, p.22); temperature of the electrochemical reaction is low enough to keep NO from being a problem (Romano, 1989, p.75).

Production process reverses gains in emissions; $\mathrm{CO} 2 \& \mathrm{NO}_{\mathrm{x}}$ are byproducts of hydrogen production (Ondrey; 1992, p.30).

Japan in investing in hydrogen-burning vehicles that are far cleaner than any other AFV (Maruyama, 1991); environmentally-friendly $H R-X$ by Mazda, a prototype with a hydrogen-burning rotary engine developed already (Japan 21st, 1992).

Gasoline - Upgraded on-board computers for more precise spark timing and fuel injection; future catalytic converters may eliminate $99 \%$ of pollution by electronically preheating before a car starts (Woodruff, 1991, p.56).

Possibilities of catalytic converters: Ford's 1993 Escort/Mercury Tracer models pass California's 1994 TLEV standard; Corning's EHC prototype passes 1997 ULEV standard (Cogan, September 1992, ps.35); $96 \% \mathrm{HC}$ and $76 \% \mathrm{NO}_{x}$ reduction comparing 1992 to 1960's vehicles (Frank, August 1992, p.103); improvements in refueling connection (Oil \& Gas, Dec 1991, p.38): By 2003 the CAA could require $25 \%$ of all US cars to cut $\mathrm{HC}$ by $40 \%$, and $\mathrm{NO}_{x}$ by $50 \%$. By $2006100 \%$ of US cars must meet that standard (Woodruff, 1991, p.59).

- Electric - Dramatic reductions compared to gasoline emissions depending on fuel burned (natural gas: or coal), emissions controls at the power plant and type of generating equipment (Frank, Áugust 1992, p.105).

Electric Hybrid/Turbine - No direct reference. See relevant entries ELECTRIC above and TURBINE below. 
CNG - Considerable improvement potential for emissions in three areas: fuel metering and mixing, lean/dilute combustion systems, catalytic converters (Weaver, 1991, ps.4-7).

Turbine/Gasoline - Gas turbine would emitinsignificant amounts of pollutants, may not need a catalytic converter (The Economist, September 28, 1991, p.95).

Fuel Cell/Hydrogen - Hydrogen already is the cleanest fuel available; only emissions are water and small quantities of $\mathrm{NO}_{x}$ (SAIC/report, 1991, p.22).

\section{FUEL OPERATING COST}

This section documents fuel operating cost in the database. The output of the database is operating cost for eight fuels, for nine regions, through three penetration scenarios (base, high; and low), from 1990 to 2030; The results are expressed in constant $1990 \$ / M M B t u$.

The general approach is to establish the current national average fuel operating cost for each fuel. Regional differences are obtained using a percentage deviation from the minimum regional price and are assumed to remain constant over time. The sustainability of any such regional price deviations absent government intervention (or unusually skewed tax policies) is questionable. This issue is raised in Section 2 of the report.

Projected operating costs are found using a compound annual percentage fuel price escalation rate for each individual fuel, for each scenario (base, high, low).

The inputs used to forecast fuel costs are:

\section{Fuel operating cost in 1990 \$MMBtu.}

Regional fuel price differences, as a percentage deviation from the minimum regional prices, by region, by fuel.

- Fuel price escalation, compound annual percentage, all fuels individually, by scenario. 
The approach has the following advantages:

Projected fuel prices should be relatively consistent vis a vis conventional gasoline and other fuel prices.:.

Updating and revising figures based on future developments are facilitated.

\section{CURRENT AVERAGE FUEL OPERATING COST}

Operating cost is derived from the current national average retail price usually given in $\$ /$ gallon or similar measure. To allow comparisons between fuels, retail price was converted into dollars per energy content ( $\$ / M M B$ tu). Retail prices by fuel are tabulated below.

Table F-26. Average Fuel Prices; $\$ 1990$

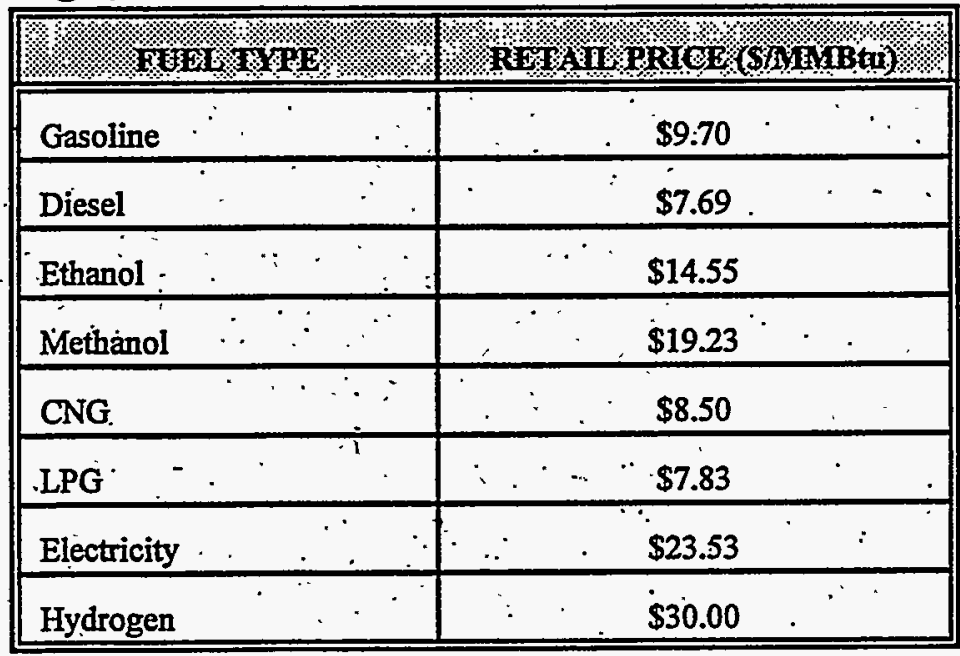

\section{REGIONAL DIFFERENCES, ASSUMPTIONS, AND CRITERIA}

Regional fuel prices are calculated by adding a percentage price differential to the national average retail prices found in the preceding table. The price differentials for each region shown. in Table F-27 are based on factors such as proximity or access to major ports, production fields, refineries, state/regional consumer price index, adequate infrastructure, local producer and government support. 
These factors, assumptions and caveats are discussed after the table. The subsequent notes raise questions about the sustainability of these differences in a national market.

Tablë F-27. Regional Fuel Price Differences

\begin{tabular}{|c|c|c|c|c|c|c|c|c|c|}
\hline 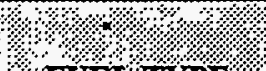 & & $\%$ & PE & ENMA & MITEERR & $\mathbf{E B Y}$ & $610 X$ & & \\
\hline FUESTPEF & \% 1 16. & 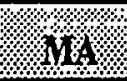 & S1 & are & 1. & 1780 & WNC & 1112 & PAC \\
\hline Gasoline & 0.05 & 0.025 & 0.025 & 0.01 & $\therefore 0.025$ & 0 & 0.05 . & 0.025 & 0.01 \\
\hline Diesel $/ 2.1 \%$ & 0.05 & 0.025 & 0.025 & 0.01 & 0.025 & 0 & 0.05 & 0.025 & 0.01 \\
\hline Ethanol $\% 1$. & 0.075 & 0.0375 & 0.037 & 0 & 0 & $0: 01$. & 0 & 0.0375 & 0.05 \\
\hline Metianol $\%$ & 0.05 & 0.025 & 0.025 & 0.01 & -0.025 & $0:$ & 0.05 & 0.025 & .0 .01 \\
\hline CNG & 0.05 & 0.025 & 0.0375 & 0.025 & 0.025 & 0 & -0.025 & .0 & $0.025^{\circ}$ \\
\hline trat $1.9 \%$ & 0.05 & 0.025 & 0.025 & 0.01 & 0.025 & 0 & 0.05 & 0.025 & 0.01 \\
\hline Blectricity $\%$ & 0.1 & 0.05 & 0.025 & 0.01 & 0.025 & 0.01 & 0 & 0 & 0.0375 \\
\hline Hydrogen & 0.05 & 0.025 & -0.025 & 0.01 & 0.025 & 0 & 0.05 & 0.025 & 0.01 \\
\hline
\end{tabular}

Abbreviations:

\begin{tabular}{|c|c|}
\hline NE & New England \\
\hline MA & Mid-Atlantic \\
\hline SA & South Atlantic \\
\hline ENC & East North Central \\
\hline WSC. & West South Central \\
\hline WNC & West North Central \\
\hline MTN : & Mountain \\
\hline$A C$ & Pacific \\
\hline
\end{tabular}

\section{EXPLANATIONS}

Gasoline In the U.S. national market gasoline prices are essentially the same.

Diesel - In the U.S. national market diesel prices.are essentially the same.

Ethanol - Mainly produced from corn in Midwest states; the regions that are part of it, or closest to it, enjoy lower prices due to advantages such as access, convenient transportation, and local support (i.e., state subsidies, farmers interestś).

Methanol - Mostly imported, therefore regions enjoying proximity and easy access 
to major ports and processing infrastructure, i.e., Los Angeles and New Orleans, would have a price advantage. The Pacific region also benefits from California's acute interest in this fiel, i.e., special incentive from the state. Inflexible infrastructure and the high cost of living in NE and WNC explain higher prices in those regions.

Electricity - Regions with access to relatively abundant and cheap power produced by hydroelectric and coal-fired power plants benefit, e.g., WNC, WSC, MTN, and ENC. More expensive power from regions without low-cost fossil fuels drives prices up in NE and MA.

CNG - Proximity to the rich fields in WSC and MTN benefits those regions and ESC, WNC, ENC and PAC. 'Competing imports benefit areas near major ports, i.e., PAC, ESC. The high cost of living and inaccessibility to fields drive prices up in NE.

LPG - Access to competitive imports andd refineries benefits PAC, ESC and ENC. Local production and support would benefit ENC and PAC. Higher transportation costs, infrastructure inflexibility and higher cost of living puts $\mathrm{NE}$ at a disadvantage.

Hydrogen - Access to abundant raw materials, i.e., especially low-cost electricity benefits such regions as $\mathrm{PAC}$ ENC, SA, WSC. Infrastructure and local support also push prices down in PAC. WSC, and MTN.

\section{IMPORTANT ASSUMPTIONS AND CAVEATS}

- Regional fuel price differences may persist due to transportation costs from producing or importing regions. These differences, however, are likely to be no more than $\$: 05 /$ gallon equivalent and are generally less than differences in state excise taxes.

Differences in state excise taxes within a region can easily exceed differences in transportation costs from region to region.

Electricity is shown at an average price. Off-peak electricity will cost less and on-peak electricity will cost much more. If EV sales are induced with the promise of daytime refueling at the office, much higher charges than those shown on the table will apply. 


\section{PROJECTED FUEL OPERATING COSTS}

Projected fuel operating costs are found using a fuel price escalation rate. This section describes the escalation rate in more detail, and provides a representative sample of the output.

\section{FUEL PRICE ESCALATION RATE}

The escalation rate is a compound annual percentage, applied to each fuel individually. The rates for each fuiel and the assumptions behind them are shown below:

Table F-28. Fuel Price Escalation Rates

\begin{tabular}{|c|c|c|}
\hline \%., FUTES: & Rorat & 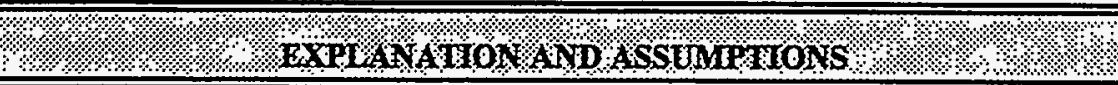 \\
\hline oasoline: & $2 \%$ & $\begin{array}{l}\text { Rate consistent with projections of oil prices based on current and future demand, } \\
\text { output, refining capacity, etc. }\end{array}$ \\
\hline \%tonol & $3 \%$ & $\begin{array}{l}\text { Mostly from domestic production, ethanol is a net energy loser (which implies the } \\
\text { need of subsidies to make it competitive.) Assuming the cost of subsidies is } \\
\text { incorporated, and due to the cyclical nature of the corn crops; the escalation rate } \\
\text { would be the highest for all ATFs. }\end{array}$ \\
\hline Methapo: & $1 \%$ & $\begin{array}{l}\text { Assuming it is produced mostly from cheap imports without significant supply } \\
\text { disruptions. }\end{array}$ \\
\hline Etectrictity & $1 \%$ & $\begin{array}{l}\text { Assuming most power is used during off-peak hours when power plants have. } \\
\text { excess capacity. Also assuming regions with excess capacity will compensate.for } \\
\text { areas where increasing capacity would be prohibitive. }\end{array}$ \\
\hline QNG & $1 \%$ & Mostly from cheap, large fields in the U.S. \\
\hline $\mathrm{WRG} / \%$ ४ै\% & $1 \%$ & Mostly from domestic production. \\
\hline hatrogen & $1 \%$. & $\begin{array}{l}\text { Assuming the current trend in production costs reduction continues, and assuming } \\
\text { that sufficient power for production process is obtained from a reliable.source. }\end{array}$ \\
\hline
\end{tabular}

\section{SOURCES OF ESTIMATES:}

- Gasoline-Escalation rates for periods: $1990-95=1.3 \%, 1995-2000=3.18 \%, 2000$ $2005=1.63 \%, 2005-2010=1.24$ (D.O.E., July 1991, p.25); escalation rates due to reformulation: from 1990 to 2010 a $13.53 \%$ increase every five years.(SAIC \& Oil \& Gas, Dec 1991, p.61). Fuel prices will go up as oxygenate-hydrocarbon shift takes place by replacing aromatics with ethers (Unzelman, 1991). 


\section{Diesel - SAIC.}

Ethanol - Current production is 1 billion gallons per year; 3 to 8 billion gallons. possible by 2010 without exerting strong upward pressure on feedstock prices.

Methainol-Increase of $19.31 \%$ every ten years (SAIC \& Oil \& Gas, Dec 1991, p.60).

Electricity - SAIC:

CNG - Increase of $29.18 \%$ every ten years'(SAIC \& Oil \& Gas, Dec 1991,p.60).

LPG - Increase of 27.94\% every ten years (SAIC \& Oil \& Gas, Dec 1991, p.60).

Hydrogen - Projected operating costs for five-year intervals: $\$ 0.69$ per mile by year 2000 , down to $\$ 0.18$ by $2005, \$ 0.15$ by 2015 ; and $\$ 0.12$ by 2020 (SAIC/report, 1990); the fuel is projected to be cost equivalent with $\$ 1$ /gallon of diesel in the near future (SAIC/Ballard, 1992; p.1-22); demand stimulated by the Clean Air Act.CAA) of 1994; already there is new related investment; new production processes could cut costs by $.5-10 \%$ and increase capacity by $50 \%$ (i.e., high temperature steam electrolizer); $80 \%$ of production costs are electricity-related (Ondrey, 1992, pp.31-35).

\section{FUTURE FUEL PRICES IN THE LITERATURE}

(In Gasoline-Gallon-Equiválent Unless Specified)

- Gasoline - $\$ 11.00$ per MMBtu (réformulated) By the year 2000 (SAIC/report, 1991, p.26). $\$ 1.25-1.39$ by the year 2000 (C.E.C., 1989, p.11). $\$ 1.58$ (D.O.E., July 1991, p.25). $\$ 0.20$ per gallon rise for reformulated gasoline (Woodruff, 1991, p.56). $\$ 0.32$ - per gallon (1990\$) for gasoline reformulation for \$2.08 pump price in the year 2010; 26 cents for $\$ 1.70$ by 2005 (Oil \& Gas, Dec 1991, p.59).

Ethanol Flex - \$1-1.50 per gallon under expanded fuel ethanol program; produced from corn (EPA, April 1990, p.i).

Ethanol Neat - $\$ 17.70$ per.MMBtu by year 2000 (SAIC /report, p. 26 ) $\$ 2.33$ by year 2000 (C.E.C., 1989, p.11). 
Methanol Flex - \$1.01-1.14 established market with guarantees. \$1.14-1.35 with few guarantees (O.T.A., 1990, p.76). $\$ 1.39$ by year 2000 (C.E.C., 1989, p.11). $\$ 2.79$ (Oil \& Gas, Dec 1991, p.60).

Methanol Neat - \$0.55-0.83 wholesale per gallons of methanol, by years 2004-2007 (CRS,1989,p.16). $\$ 1.35-1.75$ by 2007 (A.P.I., August 1989, p.10). $\$ 14.50 \mathrm{MMBtu}$ by year 2000 (SAIC /report, 1991, p.26). $\$ 1.29-1: 37$ during a transition phase, with strong market guaranteés,\$1.61-1.81 with few guarantees. $\$ 0.89-1.09$ for an established market, with strong guarantees. \$1.02-1.27 with few guarantees (O.T.A.,1990; pp.75-6).

Electric - $\$ 18.00$ MMBtu by year 2000 (SAIC/report, 1991, p.26). $\$ 1.31$ by year 2000 (C..E.C., 1989 , p.11). $\$ 5.28$ or 15 cents $\mathrm{kw} / \mathrm{hr}$ if produced with nuclear power (Oil \& Gas, Dec 1991, p.61):

CNG - $\$ 9.60$ MMBtu by year 2000 (SAIC/report, 1991, p. 26 ) $\$ 0.84$ by year. 2000 (C.E.C., 1989, p.11). \$2.16 (Oil \& Gas, Dec 1991, p.60).

LPG - $\$ 0.98$ by year 2000 (C.E.C., 1989, p.11). \$1.29 (Oil \& Gas, Dec 1991, p.60).

-: Fuel Celi/Hydrogen - $\$ 0.18$ per mile (SAIC/report, 1990); below $\$ 2.00$ if. substantial improvements can be made in photovoltaic technology (O.T.A.,1990, p.129). $\$ 3.50$ if nuclear power costs 15 cents $\mathrm{kw} / \mathrm{hr}$ (Oil \& Gas, Dec 1991, p.61). $\$ 0.10$ per mile year 2030 (SAIC/report, 1990) More efficient solar energy technology (substantially above $30 \%$ today) is needed to produce hydrogen by electrolysis (Tÿler, 1990, p.20); research into photochemical and photovoltaic conversion (Gross, 1992, p.74; \& Hodgson, 1991, p.58); pre and post-reformers to increase capacity of existing hydrogen plants, boost yields, no major changes in existing basic technology (Ondrey, 1992, pp.31-35). Efficiency improvements in the production of hydrogen can be expect to reach 70 to $90 \%$ once improved electrolysis methods are developed (Tyler, 1990 , p.20). Promising production methods may bring hydrogen closer to gasoline's production cost, e.g., photobiological and photochemical conversions (though the latter's theoretical maximum efficiency is 32\%)(Hodgson, 1991, p.58); hydrogen is the most likely main energy source replacing oil in all applications in the 21 st century (Templeman, 1991, pp.60-61). 


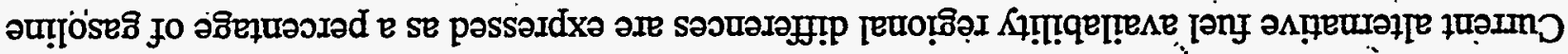

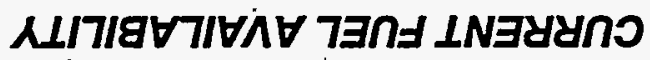

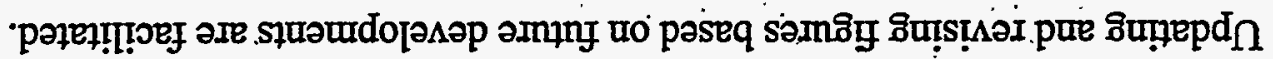

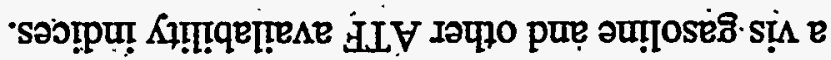

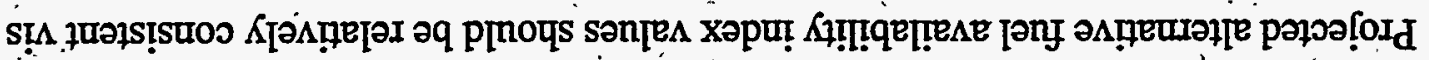

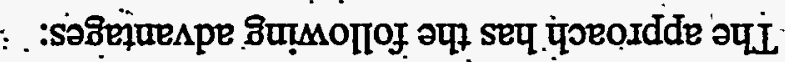

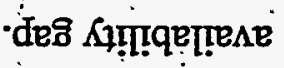

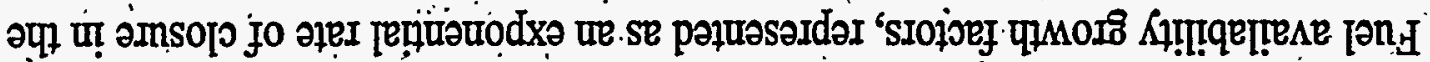
'siony IIIe.

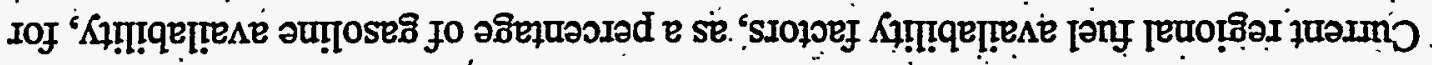

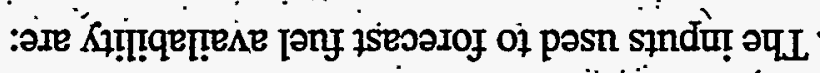

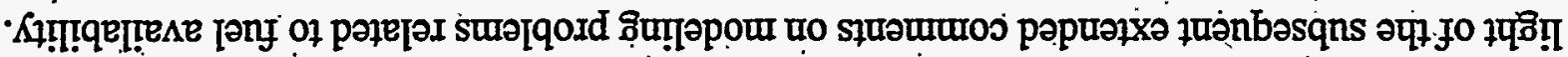

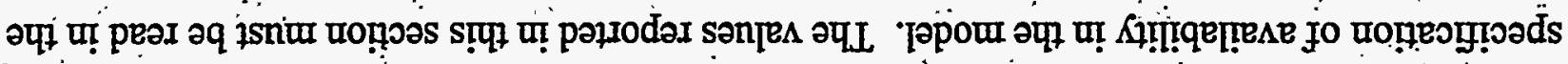

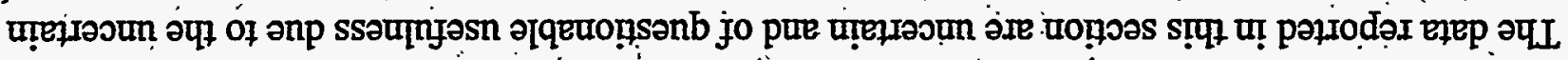

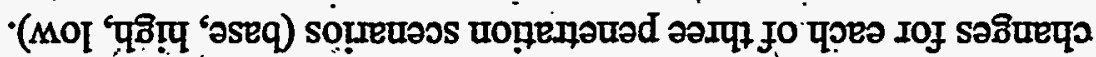

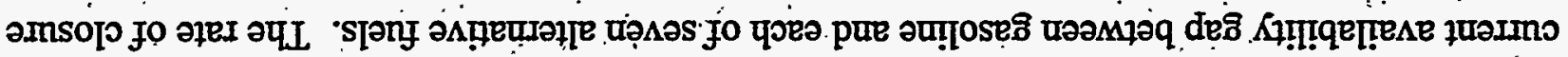

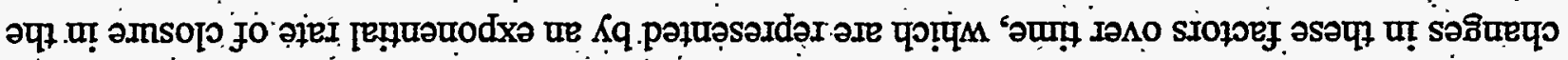

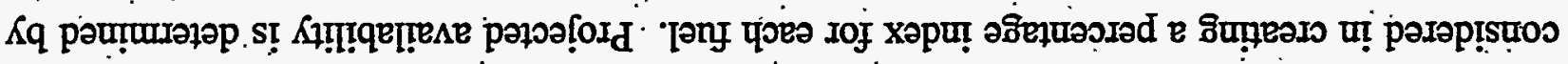

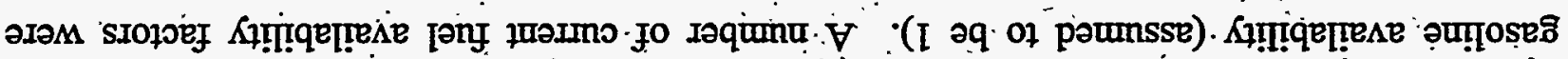

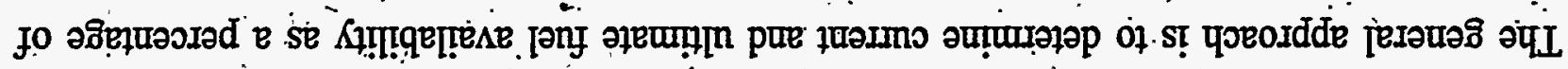

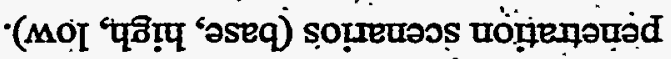

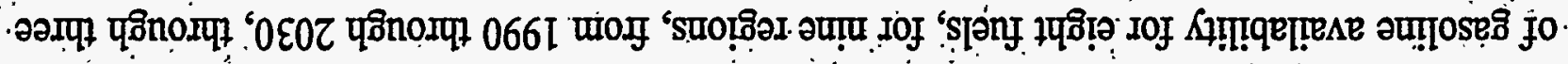

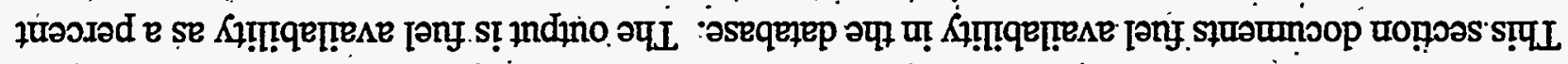


availability in the base year 1990 as shown in the following table. Important limitations on these values and their usage are subsequently discussed.

Table F-29. Base Year (1990) Fuel Availability, by Region

\begin{tabular}{|c|c|c|c|c|c|c|c|c|c|}
\hline 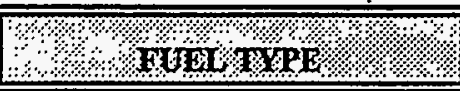 & $\% /, \mathrm{nE} . \%$ & Mk: & 1. & EARe & Essc. & WNe & wse & 10.NA & $\mathrm{NAC}$ \\
\hline GASOCINE \& DIESES & 1 & $\cdot 1$ & 1 & 1. & 1 & 1 & 1 & 1 & 1 \\
\hline $\mathrm{mraANOH} / \% / \% / \%$ & $0.01^{\prime}$ & 0.02 & 0.02 & 0.1 & 0.02 & 0.02 & 0.02 & 0.05 & 0.05 \\
\hline murm nol $/ . \%$ & 0.01 & 0.05 & 0.02 & 0.02 & 0.02 & 0.02 & 0.01 & 0.05 & 0.1 \\
\hline $\mathrm{axa} \% \% . \%, \%, \%$ & $0.01^{\circ}$ & 0.02 & 0.02 & 0.05 & 0.02 & 0.02 & 0.05 & 0.05 & 0.05 \\
\hline $\mathrm{HPG} \%$ & 0.01 & .0 .02 & 0.02 & 0.05 & -0.02 & 0.02 & 0.1 & 0.05 & 0.1 \\
\hline MGKARCLU & 0.05 & $.0 .05^{\circ}$ & 0.05 & 0.05 & 0.05 & 0.05 & 0.05 & 0.05 & 0.05 \\
\hline 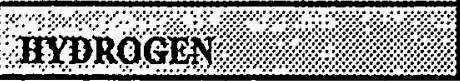 & 0.01 & 0.01 & 0.01 & 0.01 & 0.01 & 0.01 & 0.01 & 0.01 & 0.01 \\
\hline
\end{tabular}

\section{FUTURE AVAILABILITY}

.. Changes in infrastructure and other growth factors that are demanded by an economically significant ATF are discussed in this section, along with pertinent assumptions and caveats.

Future availability is determined by changes in the regional availability factors outlined in the previous section. Such changes affect the differences between gasoline and each ATF, so they are represented by an exponential rate of closure of the availability gap between gasoline and each ATF.

\section{GASOLINE INFRASTRUCTURE AND OTHER GROWTH FACTORS.}

There are roughly a million gasoline stations in the United States at the present time. For any ATF to be accepted by the public a certain threshold of availability must be reached (aside from economic and other considerations). Attaining the threshold level would require government and private investments in infrastructure in the order of tens of billions of dollars in a very short time. It would also exclude the possibility of having more than one or two competitive different fuels at one time. The infrastructure required would vary considerably from fuel to fuel. The implications are explored 
for each fuel below.

Ethanol and methanol - a large proportion of the existing equipment could be easily adapted as these two fuels have obvious physical similarities to gasoline, i.e., use same pumps and dispensing equipment. However in the case of methanol, its corrosive nature would demand upgrading the system's reservoirs and pipes. There are additional expenses associated with differences in water tolerance and fuel contamination, fire, and explosion hazards.

CNG and LPG - there is a small infrastructure capable of handling vehicle fleets successfully. Both fuels are, and will continue to be, attractive for the vehicle fleet subset, because a central refueling site can service the entire fleet. However, for private passenger cars, adapting a single existing gasoline service station would require a minimum of $\$ 250,000$ for a compressor. Such a price tag would rule out a wide distribution network for passenger vehicles unless there is some government subsidy.

Electricity - the extensive existing electricity infrastructure should be capable of servicing a large number of vehicles in terms of megawatts of off-peak capacity. Onpeak demand would cause massive cost and availability problems. Moreover, since long refueling time would make service station refueling impossible, costly adapters. would have to find a place in every user's household.

Hydrogen - although there is an almost limitless supply of raw materials (e.g."' water), there is no existing infrastructure for the distribution of hydrogen. Hydrogen's low mass makes it expensive to store since it must be liquified or bound to other substances. For these reasons reaching the necessary threshold level would involve a much higher price tag than for other ATFs.

\section{EXPONENTIAL RATE OF CLOSURE}

The growth factors described above were used to determine the exponential rate of closure in the availability gaip between gasoline and each ATF, for each penetration scenario. Assumptions and caveats in addition to the ones outlined above are provided after the table. 
Table F-30. Availability Gap Closure Rates, By Scenario :

\begin{tabular}{|c|c|c|c|}
\hline \multirow{2}{*}{ \%. } & \multicolumn{3}{|c|}{ 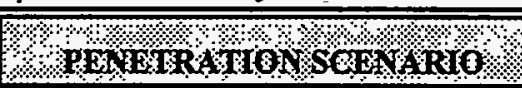 } \\
\hline & : & IIIGH: & $.801 \%$ \\
\hline polesel $1 . / . \%$ & $99 \%$ & $99 \%$ & $99 \%$ \\
\hline Vittignol & $10 \%$ & $20 \%$ & $2 \%$ \\
\hline Hethanot & $10 \%$ & $20 \%$ & $2 \%$ \\
\hline$\sqrt{64 c}$ & $10 \%$ & $20 \%$ & $2 \%$ \\
\hline HRC.\%. & $10 \%$ & $20 \%$ & $2 \%$ \\
\hline Electritity & $10 \%$ & $40 \%$ & $2 \%$ \\
\hline Hororogen. & $10 \%$ & $10 \%$ & $2 \%$ \\
\hline
\end{tabular}

\section{ASSUMPTIONS ÁND CAVEATS}

- Accelerated exponential rates in all penetration cases, especially in the high case, such that a common market would appear in the United States within ten to twenty years. The market arrival time span for each fuel was calculated based on each fuel individually without any other ATF challenger. Such a individual : competition approach is inconsistent with the model specifications.

Regional-differences in availability are highly unlikely in any national market, though they can exist initially.

Even though regional fuel price differences may persist due to transportation costs from producing or importing regions, availability differences cannot, and will not persist if a national market develops.

It is not clear what constitutes availability for EV's, i.e., whether refueling time refers to recharging batteries as opposed to switching them. Therefore arbitrary assumptions have been made for this category. 


\section{SPECIFIC REFERENCES AND SOURCES}

- Gasoline - Reformulated gasoline may require $\$ 20$ to $\$ 40$ billion in upgraded refineries (Woodruff, 1991, p.56):

Methánól - Cannot be integrated into current distribution system without modifying the system: water tolerance and fuel contamination, materials compatibility in storage and distribution systems; fire and explosion hazards (A.P.I., September 1990, p.27).

CiNG - High pressure compressors cost $\$ 250,000$ each (Woodruff, 1991, p.57).

LPG - There are 10,000 propane refueling stations in the United States (Frank, 1992, p.106).

Hydrogen - Supply of Hydrogen (Frank, August 1992, p.106).

\section{VEHICLE RÄNGE}

This section documents vehicle range in the database. The output of the database is vehicle range in miles for sixteen technologies for three vehicle sizes, through three penetration scenarios (high, low and base) from 1990 through 2030

The general approach is to establish range (defined as average current miles between refueling) for a small vehicle, through an extensive literature search. The findings are used as base range figures to derive the other two vehicle sizes' (e.g.; large and medium) using a range credit or perialty. The credit/penalty is expressied as a percentage that lowers the base small vehicle range. Projected range is found by applying an annual simple percentage gain on the base current figures for each technology.

Thus, the inputs used to forecast vehicle range are:

Miles between refueling for small cars in 1990 , for all technologies. 
Range credit or penalty for mid-size and large cars in 1990; all fuels.

Annual simple percentage gain in range, by vehicle type to 2030 .

The results are displayed in miles for all vehicle-fuel types from 1990 to 2030.

\section{CURRENT VEHICLE RANGE}

This section describes current vehicle range. For each technology, the base small vehicle range in 1990 is based on the average number of miles between refueling found in the literature. These figures are shown in the following table, which also features the range credit or penalty for vehicle size. The credit is expressed as a percentage ranging from $-10 \%$ to $-15 \%$, for mid and large size vehicleś respectively. Sources for these figures are provided at the end of this section.

Table F-31. Current Small Vehicle Range and Size Range Credit.

\begin{tabular}{|c|c|c|c|}
\hline \multirow{2}{*}{ \% } & \multirow{2}{*}{, } & \multicolumn{2}{|c|}{ S. SIFERRAGECRERI } \\
\hline & & $1,1110 \times 5129$ & 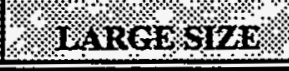 \\
\hline 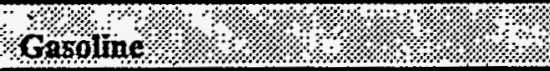 & 350 & $-10.00 \%$ & $-15: 00 \%$ \\
\hline 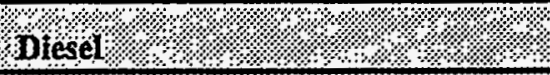 & 400 & $-10.00 \%$ & $-15.00 \%$ \\
\hline 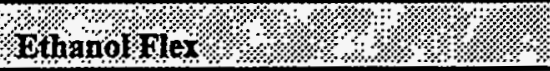 & 260 & $-10.00 \%$ & $-15.00 \%$ \\
\hline 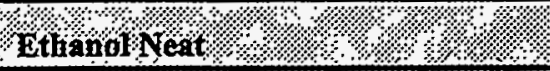 & 235 & $-10.00 \%$ & $-15.00 \%$ \\
\hline Methanol piex & $220^{\circ}$ & $-10.00 \%$ & $-15.00 \%$ \\
\hline 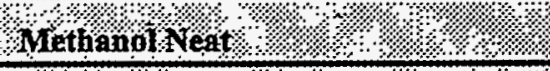 & $1966^{\circ}:$ & $-10.00 \%$ & $-15.00 \%$ \\
\hline 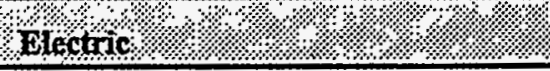 & 120 & $-10.00 \%$ & $-15.00 \%$ \\
\hline Electric Iybrarger & 250 & $-10.00 \%$ & $-15.00 \%$ \\
\hline 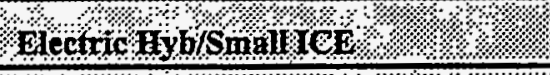 & 200 & $-10.00 \%$ & $-15.00 \%$ \\
\hline Electric Hy briaraunbine & 300 & $-10.00 \%$ & $-15.00 \%$ \\
\hline 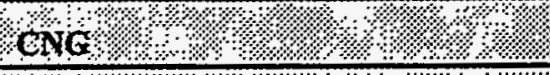 & 225 & $-10.00 \%$ & $-15.00 \%$ \\
\hline UrG & 300 & $-10.00 \%$ & $-15.00 \%$ \\
\hline 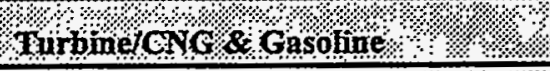 & 100. & $-10.00 \%$ & $-15.00 \%$ \\
\hline Fuei Celimethanol \& Hydrogen & $\therefore$. & $-10.00 \%$ & $-15.00 \%$ \\
\hline
\end{tabular}




\section{SPECIFIC REFERENCES AND SOURCES: (Range in Miles)}

- Gasoline -424 (U.C.E.T.F., 1990, p.40).

Diesel - 488 (U.C.E.T.F., 1990, p.40).

Ethanol Flex - 331 (U:C.E.T.F., 1990, p.40).

Methanol Flex - 350 for 1991 Ford Taurus 4D sedan; 400 for 1992 Ford Econoline yan.(NREL, 1992; on line); lower range than gasoline's by $40-43 \%$, by $1995.38-41 \%$. (D.O.E.; August 1990, p.13); 292 (U.C.E.T.F., 1990, p.40).

Methanol Neat - 265 (U.C.E.T.F., 1990, p.40).

Electric - 120 for 1992 GM Impact (G.M. Impact, 1992); 100 for Ford small van (NREL, 1992, on line); $\mathrm{Pb}$-acid battery $=44, \mathrm{NiFe}=90, \mathrm{NaS}=207$ (D.O.E.,August 1990 , p.13);100 (U.C.E.T.F., 19.90, p.40); 340 at $25 \mathrm{mph}$ for Tokyo Electric Power prototype (Gross, 1992, p.74).

- Electric Hybrid/Large I.C.E. - 250 for 1993 Ford small Van (NREL, 1992, on line); 40 for electric engine extended range gasoline i.c.e. for the LA301 by International Automotive Design's (The Economist, September 28, 1991, pp.95,96).

Electric Hybrid/Small I.C.E. - 300 for GM's HX3 gasoline prototype; 40 kilowatt generator to recharge its own batteries (Woodruff, 1991, p.59).

CNG - 200 for 1992 GMC medium-duty truck (GM Natural Gạs Powered, 1992); 200 for 1992 Chrysler Dodge B-series van/wagon NREL, 1992, on line); 1990-95 lower than gasoline by $61 \%$ (D.O.E.,August 1990,p.13); 106 (U.C.E.T.F., 1990,p.40).

LPG - 34 (U.C.E.T.F., 1990, p.40).

Fuel Cell/Hydrogen - 300-500 with electric engine and improved storage, i.e. liquid or absorption process (Rouse, 1991, p.15); 190 for BMW's liquid-hydrogen storage vehicle; 75 for Mercedes hydracide vehicle (Romano, 1989, pp.60, 61). 


\section{- PROJECTED VEHICLE RANGE}

Projected vehicle range for all technologies is found by applying an annual simple percentage gain to the current base for each technology: The annual gain is assumed to.be $1 \%$ because most improvements in technology apply equally to all fuels, i.e., reduce air drag, advanced body materials. It is also assumed that there will be similar advances in areas that are not shared because the rationale for investment in $\mathrm{R} \& \mathrm{D}$ is the same regardless of fuel technology, i.e., fuel reformulation, engine enhancements. Market penetration does not affect the annual gain; therefore, the rate of $1 \%$ is valid for all penetration scenarios.

\section{SOURCES}

À.F. (Alternative Fuels), Potential Alternative-Fuel Use Scenario, 1991.

A.F.F.E.S. (Alternative Fuel Fleet Evaluation System), Data Summary Screen. On-line, City \& County of Denver, Department of Health and Hospitals, 1990.

A.P.I. (American Petroleum Institute), Gasoline Distribution and Service Station Margins: An Assessment of EPA Assumptions and Implications for Methanol: Study \#,055, September 1990.

A.P.I. (American Petroleum Institute), The Economics of Altemative Fuel Use: Substituting Methanol for Gasoline, Study \# 047, August 1989.

Bunch, et. al., Demand for Clean-Fuel Personal Vehicles in California; A Discrete Choice Stated Preference-Survey, UCI-ITSWP-91-8, ISSN 0193-5860, and UCD-ITS-RR-91-14, University of California, Davis, December; 1991.

C.A.R.B. (California Air Résources Board), Proposed Regulations for Low-Emission Vehicles and Clean Fuels: Technical Support Document; Aùgust 1990.

C.E.C. (California Energy Commission), AB 234 Report-Cost and Availability of Low Emission Motor Vehicles and Fuels- Update Los Arigeles, August 1991。

C.E.C. (California Energy Commission), Hvdrogen-Fueled Vehicles: Technology Assessiment Report. June 1991.

Cogan, Ron, Alternative Fuel Vehicle. Products of Frenetic Engineering Motor Trend, Vol.44, No.8, August 1992.

Cogan, Ron, Trends, Environmental Report, Motor Trend, Vol 44, No.9, September 1992.

CRS Report for Congress, Methanol fuel; Economics and Implementation-A Review of Current Studies. 1989.

D.O.E. (Department of Energy), Assessment of Costs and Benefits of Flexible and Alternative Fuel Use in the U.S. 
Transportation Sector. Progress Report One, January 1988.

D.O.E. (Department of Energy); Assessment of Costs and Benefits of Flexible and Alternative Fuel Use in the U.S." Transportation Sector: Technical Report Four. August 1990.

D.O.E. (Department of Energy), Assessment of Costs and Benefits of Flexible and Alternative Fuel Use in the U.S. Transportation Sector. Technical Report Six. July 1991.

D.O.E. (Department of Energy), Assessment of Costs and Benefits of Flexible and Alternative Fuel Use in the U.S. Transportation Sector, Technical Report-Ten. May 1992.

EPA, Analvsis of the Economic and Environmental Effects of Compressed Natural Gas as a Vehicle Fuel. Special Report, Office of Mobile.Sources. Vol.i, April 1990.

EPA, Analysis of the Econiomic and Environmental Effects of Compressed Natural Gas as a Vehicle Fuel. Special Report, Office of Mobile Sources. Vol.2, April 1990.

EPA, Analysis of the Economic and Environmental Effects of Ethanol as Vehicle Fuel. Special Report, Office of Mobile Sources. April 1990. '

EPA, Analysis of the Economic and Environimental Effects of Methanol as a Vehicle Fuel. Special Report, Office of Mobile Sources: September 1989.

Frank, Len \& Dan McCosh, The Alternate Fuel Follies-Part 2. Power to the People. Popular Science. Vol. 241, No.2, August 1992.

G.A.O. (United States General Accounting Office, Alternative Fuels: Increasing Federal Procurement of Alternative-Fueled Vehicles, GAOPCED-91-169, May 19.90.

General Motors, Impact Electric Viehicle: (Brochure) 1992

General Motors, Natural Gas Powered-1992 Program Highlights. (Brochure) 1992.

General Motors, Public Interest Report. 1992.

Gross, Neil, The Green Giant? It May-Be Japan, Business Week, February 24, 1992.

Haggin, Joseph, Direct Conversion of Methane to Fuels, Chemicals Still Intensely Sought Chemical \& Engineering News, April 27, 1992.

-Hodgson, Gregor, Stepping On The Gas, Far East Economic Review, April 4, 1991.

Interagency Commission on Alternative Motor Fuels, First Interim Report of the I.C.A.M.F 1990.

Maruyama, Tsuneyoshi, Developing Environment Friendly Autos. Tokyo Business Today, January 1991. 
McCosh, Dan, Automotive Newsfront. Popular Science, Vol.241, No.2, August 1992.

National Automobile Dealers Associatioñ, Automotive Executive. August 1992.

National Automobile Dealers Association, N,A,D,A. Official Used Car Guide. July-Àugust 1992.

National Renewable Energy Laboratory, Altemative Fuels Datá.Center, (On line) 1992.

Oil \&"Gas Journal, Alternative Auto Fuels Pose Cost or Technical Challenge. December 9; 1991.

Ondrey, Peter; et al, Green Laws Spark Hydrogen Technologies. Chemical Engineèring, May 1992.

O.T:A. (Office of Technology Assessment, Replacing Gasoline: Alternative Fuels for Light-Duty Vehicles. OTA-E-364, Congress of the United States, U.S. Government Printing Office, 1990.

Romano, Samuel, Fuel Cells For Transportation. Mechanical Engineering, August 1989.

Rouse, Nancy \& Stephanie J. Muraski, Indusiry Takes a Fresh Look at Altemative Fuels. Machine Design, March 21, 1991.

S.A.I.C. (Science Applications International Corporation), Identification and Analysis of Factors Affecting the Adoption of Alternative Transportation Fuels. Developed for the Gas Research Institite under Contract No. 5087-254-1621, Final Report, 1991.

S.A.I.C. (Science Applications International Corporation), Reniewable Energv Technology Characterizations. September 1990.

S.A.I.C. \& Ballard, PEM Fuel Cell Powered Electric Transit Bus Zero Emission Vehicle (ZEV) (Proposal) May 1992.

Scientific American, Two-Cycle Green Machine, Volume 267, No.4, October, 1992.

Templeman; John, et at, Eill'er Uj-With Hydrogen. Please; Business Week, March 4, 1991.

The Economist, The Car That Drinks Cocktails, September 28, 1991.

The Economist, The Electric Car's Achilles's axle. September 19, 199,2.

Tyler, Geoff, Solar Power for 'Conventional' Fuel. Management Accounting, November 1990.

U.C.E.T.F. (Urban Consortium Energy Task Force), An Alternative Fuels Evaluation System for Fleet Vehicles, December: 1990.

Unzeiman, George.H., Oxygenate/Hydrocarbon Shift Will Rewrite Gasoline Recipes. Oil \& Gas Journal, April 29; 1991.

Weaver, Christopher S., Natural Gas Vehicles.missions and Air Quality Benefits. Natural Gas Vehicle Coalition, 1991.

Woodruff, David, et. al., The Greening of Detroit: Business Week, April 8, 1991. 


\title{
Attachment 3: LDV Stock Module
}

\author{
Fuel Economy Gap Estimation
}

\section{INTRODUCTION}

This attachment presents long-term projections of the fuel efficiency degradation factor for. automobiles and light-duty trucks. The projections are based on the analysis of important trends in driving patterns that affect fuel economy. These trends include the increase in urban share driving, urban congestion, and highway speeds. The projections are developed for the period 1990 through 2030. This appendix also outlines other efforts to project fuel economy dégradation factors. ${ }^{32}$

\section{BACKGROUND}

A discrepancy exists between automotive fuel economy as :measured by the Environmental Protection Agency (EPA) under controlled laboratory conditions and the actual fuel efficiency observed under real "on road" conditions. Public and private organizations such as the Department of Energy (DOE); the Environmental Protection Agency (EPA), Ford Motor Company, General Motors Corporation, and Mitsubitshi Motors Corporation have conducted independent research on fuel economy, in the past, confirming this discrepancy. ${ }^{33}$ The fuel efficiency degradation factor (also known as "the gap") measures this discrepancy and is defined as the difference between on-road fuel economy and EPA tested fuel economy. When fuel economy is expressed in terms of miles per gallons (MPG), the degradation factor or gap is formulated as:

${ }^{32}$ This appendix is taken from a report which was prepared by Decision Analysis Corporation of Virginia (DAC) for the Energy Demand Analysis Branch of the Energy Information Administration (EIA), under Task No. 92010, Subtask 1, Contract No. DEAC01-92EI2́1946.

${ }^{33}$ Davis, S. and Morris, M., Oak Ridge National Laboratory, Transportation Energy Data Book: Edition 12; ORNL-6710, (Edition 12 of ORNL-5198), p.3-9,March 1992. .

34 Westbrook, F. and Patterson, P., "Changing Driving Patterns and Their Effect on Fuel Economy," presented May 2, 1989 at . the 1989 SAE Government/Industry Meeting, Washington, D.C. 


$$
G A P=\frac{E P A \text { Test MPG }- \text { On-Road MPG }}{\therefore \text { EPA Test MPG }}
$$

On-road fuel efficiency depends on several determinants which can be classified into technological factors, driver behavior and habits, driving trends, and road and climate conditions. Furthermore, the magnitude of the gap between tested fuel efficiency and on-road fuel efficiency depends on the specific procedures and conditions used during the test and the closeness of the formulations used to represent real driving conditions.

EPA fuel economy estimates for city and highway driving are published every year for each new model available in the U.S. ${ }^{35}$ 'These MPG estimates are obtained based on vehicle tests performed under controlled laboratory conditions and then adjusted downwards to reflect actual driving conditions. Separate tests are used to generate the city and highway MPG estimates. :

The EPA city fuel economy estimates are based on a test that simulates a 7.5 mile, stop-and-go trip with an average speed of $20 \mathrm{mph}$. The trip lasts 23 minutes and has 18 stops. About 18 percent of the time is spent idiing, such as waiting for traffic lights or in rush hour traffic. Two types of engine starts are used: a cold start and a hot start. The cold start is similar to starting the car in the morning after it has been parked all night. The hot start is similar to restarting a vehicle after it has been warmed up, driven and stopped for a short time.

The EPA highway fuel economy estimates represent a mixture of "non-city" driving. Segments corresponding to different kinds of rural roads and interstate highways are included. The test simulates a 10-mile trip and averages $48 \mathrm{mph}$.The test is run from hot start and has little idling time and no stops."

EPÁadjusts these laboratory fuel economy estimates downwards to reflect actual driving on the roadconditions. In the 1992 Gas Mileage Guide: EPA Fuel Economy Estimates the city estimates are lowered by 10 percent and the highway estimates by 22 percent from the laboratory test results. These adjustment factors represent the EPA estimates of the fuel efficiency gap for both city and highway driving.

Fuel economy can also be represented by a composite number that combines city and highway fuel

35 DOE/EPA, Gas Mileage Guide: EPA Fuel Economy Estimates, DOE/CE-0019/10. 
economies. EPA computes composite fuel economies using the following formulation:

$$
\text { EPA Composite MPG }=\left[\frac{0.55}{M P G_{c}}+\frac{0.45}{M P G_{h}}\right]^{-1}
$$

where:

$$
\begin{aligned}
& M P G_{c}=\text { Miles per gallon for city driving } \\
& \mathrm{MPG}_{\mathrm{b}}=\text { Miles per gallon for highway driving }
\end{aligned}
$$

EPA's composite formulation is developed based on $55 \%$ city driving and $45 \%$ highway driving. This formulation, combined with the EPA city and highway fuel efficiency gaps, leads to a base composite MPG gap for all new vehicles of 15 percent.

Previous attempts at estimating the base fuel efficiency gap have been made: In 1978, McNutt et al., measured the gap for model year 1974 through model year 1977 cars. The resulting estimates of the gap were between 6 and 9 percent. ${ }^{36}$ In 1984, Hellman and Murrel estimated a composite. MPG gap of 15 percent. ${ }^{37}$. More recently in 1992, Oak Ridge National Laboratory (ORNL) reported. composite gap estimates that apply to all automobiles and light trucks in operation. ${ }^{38}$ The ORNL base composite gap estimate for all automobiles in operation pre-1974 to 1989 was 15.2 percent: The ORNL gap estimate for light trucks in operation pre-197.6 to 1989 was 28.3 percent. For this analysis, ORNL' used EPA tested fuel economy data which was verified by the National Highway. Safety Administration (NHTSA). These data were compared against on-road fuel economy data from (1) the Federal Highway Administration(FHWA) Highway Statistics 1989, (2) the Department of Energy, Energy Information Administration, 1988 Residential Transportation Energy Consumption Survey (RTECS), and (3) the Bureau of the Census, 1987 Census of Transportation, Truck Inventory and Use Survey (TIUS).

Very few attempts to forecast trends in the fuel economy gap are available. In 1989, Westbrook and

\footnotetext{
${ }^{36}$ SÄE 780037

37. SAE 840496

${ }^{38}$ Davis, S. and Morris, M., Oak Ridge National Laboratory, Transportation Enerov Data Book: Edition 12 ORNL-6710, (Edition 12 of ORNL-5198), p.3-9,March 1992.

Maples, John D., and Philip D. Patterson, "The Fuel Economy Gap for All Automobiles and Light Trucks in Operation;" Draft, Washington, DC,1991.
} 
Patterson analyzed trends in driving patterns and produced forecasts of the fuel economy gap for the year 2010.39 Their results indicated a composite gap of 29.7 percent for automobiles for the year 2010. This combined fuel efficient gap corresponded to a city fuel efficiency gap of 23.5 percent and a highway fuel efficiency gap of 30.5 percent. Organizations such as Data Resources Incorporated (DRI) and Wharton Econometrics.Forecasting Associates (WEFA) use values for the degradation factors that remain constant over their forecasting horizon. The Department of Energy (DOE) and the Energy Information Administration (EIA) in the 1990 National Energy Strategy (NES) projected the fuel efficiency gap to reach 30 percent by 2030 in the NES reference case. ${ }^{40}$ The projected gap for the High Conservation and the Very High Conservation cases of NES were 25 and 20 percent respectively. Also, EIA in the Annual Energy Outlook 1992 (AEO) projected the fuel efficiency gap to increase from 20 percent in 1990 to 25 percent in 2010 .

An ongoing effort by DOE's Office of Transportation Technologies in conjunction with the University of Tennessee is focused on forecasting the fuel efficiency gap for automobiles and light duty trucks through 2010. This work considers three scenarios based on differing assumptions: about urban shares, highway speed, and congestion trends.

This attachment presents independent projections of the fuel efficiency gap to the year 2030 for two vehicle typeś:
1) Automobiles, and
2) Light Duty Trucks.

The projections are generated based on the analysis of three important trends in driving patterns that affect fuel efficiency. These factors are:

1) . increasing urban share of vehicle miles traveled,

2) . - increasing average highway speed, and

3) increasing level of urban highway congestion.

\footnotetext{
39 Westibrook, F. and Pattersòn, P., "Changing. Driving Patterns and Their Effect on Fuel Economy," presented May 2, 1989 at the 1989 SAE Government/Industry Meeting, Washington, D.C.

40 EIA, Energy Consumption and Conservation Potential: Supporting Analysis for the National Energy Strategy, SRNES/90-02, Service Report, p. 89, Washington, D.C., December 1990.
} 
Initially, forecasts for each of these factors wère developed based on two different growth scenarios:

1). Logistic Growth, and

2). Linear Growth

These scenarios are fully described as follows, using urban share growth as an example:

\section{Logistic Approach}

Figure F-1 shows the historical urban share of automobile VMT driving from 1972 through 1990 and a logistic curve fitted to the historical period and extended through the year 2030. The logistic share values are developed based on a logistic functional form originally formulated by Fisher and Pry ${ }^{41}$ and defined by:

$$
f_{t}^{U}=\frac{f_{\infty}^{U}}{1+e^{-(\alpha+\beta t)}}
$$

where:

$f_{t}^{U} \quad$ is the urban share in year $t$

$f_{\infty}^{U}$, is the urban share asymptotic limit, $\underline{\alpha}$ and $\beta$ are parameters of the logistic curve defined by:

$$
\begin{gathered}
\alpha=\ln \left[f_{0}^{U} /\left(f_{\infty}^{U}-f_{0}^{U}\right)\right] \\
\dot{\beta}=(1 / h) \ln \left[\left(f_{\infty}^{U}+f_{0}^{U}\right) / f_{0}^{U}\right]
\end{gathered}
$$

where:

$$
f_{0}^{U} \text { is the base year urban share, and }
$$

4 Fisher, J.G. and Pry, R.M., "A Simple Substitution Model of Technology Change." Technological Forecasting and Social Change, Vol.3, pp.75-88, 1971. 
$h^{\text {u . }}$ is the halving factor for the logistic curve. The haiving factor is the time required from the base year for the urban share to reach the midpoint between its base year value and its asymptotic limit.

The logistic curve in Figure F-1 represents the curve that best fits the historical data on urban share for the 1972-1990 period. This curve is generated by assuming two logistic parameters and by selecting a base share year. These two parameters are the asymptotic limit and the halving factor. The asymptotic limit represents an upper limit to the growth of the urban share. The halving factor is a measurement of the time needed for the share to reach this upper limit. The values for both parameters are specific to the best fit curve and they are determined using an iterative approach which minimizes the sum of the squares of the difference between the historical shares and the logistic estimated shares.

\section{Linear Approach}

If it is assumed that the urban share will continue growing linearly, the impact on the fuel efficiency gap differs. Figure F-2 shows the historical urban share of automobile VMT driving from 1972 through 1990 and both a logistic curve and a straight line, fitted to the historical period and extended through the year 2030. The linear share forecasts developed by simple regression are considerably larger than those resulting from the logistic functional form.

The conclusions of the report noted that the logistic approach seemed to yield a more realistic projection of the gap. This was based largely on intuition, as the logistic approach can account for constraints which the linear approach cannot. As a result, logistic data were used in forming the model and-are presented herein.

A total of two sets of projections were generated for each of the vehicle types, factors, and scenarios. The first was based on the assumption that all urban driving is city driving and all rural driving is highway driving. Fuel economy gap projections generated in the past are based on such an assumption, as it makes the gap calculations considerably easier. However, the assumption oversimplifies reality since some of the urban driving is on interstate highways and other freeways located in urban areas, and some of the rural driving includes stop-and-go city type of driving. The second set of projections were generated taking into consideration the decomposition of urban and rural driving into city and highway driving according to road types. This adjusted city/highway driving share approach was deemed more realistic. This is due to the fact that such an approach more closely resembles actual driving behaviour and consequently avoids the restricting assumption 
that urban driving is equal to city driving and rural driving is equal to highway driving. As such, only these calculations are included in this attachment.

The decomposition is based on road types. Thus, VMT driving on roads identified as "interstate". and "other freeways and expressways" in urban areas are considered part of the highway driving share. Other road types located in urban areas are considered part of the city driving share. In addition, VMT driving on roads defined as "minor collectors". and "local" in rural areas are classified as city driving while the rest of the road types in rural area are considered highway driving. Although this road classification does not exactly replicate reality, it is a closer representation of the actual city/highway driving composition.

Approximately 63 percent of total 1990. VMT consisted of driving in urban areas and 37. percent in rural areas. 68 percent of the urban VMT is considered city driving and 32 percent highway driving. In rural areas, 17 percent is considered city driving and 83 percent highway driving. This composition represents overall city and highway driving shares for 1990 of:

City Share:

Highway Share:
$49.1 \%$

$.50 .9 \%$

These adjusted city and highway shares are the bases for the calculations of the fuel efficiency gap projections in this chapter. The impact on fuel efficiency, from each of the three factors considered in this study, is affected by these adjusted shares. The impact from the increasing urban share trend is diminished since only part of the urban share $(68 \%$ in 1990$)$ is considered city share. The impact from increasing highway speeds is amplified since highway driving in both urban and rural areas is considered. Finally, the impact from increasing urban highway congestion is diminished since only part of the urban share is considered highway driving. The resulting fuel efficiency gap projections for automobiles and light duty trucks using the logistic approach based on these adjusted shares will be presented. 
Figure 3: Auto Urban Share VMT Driving

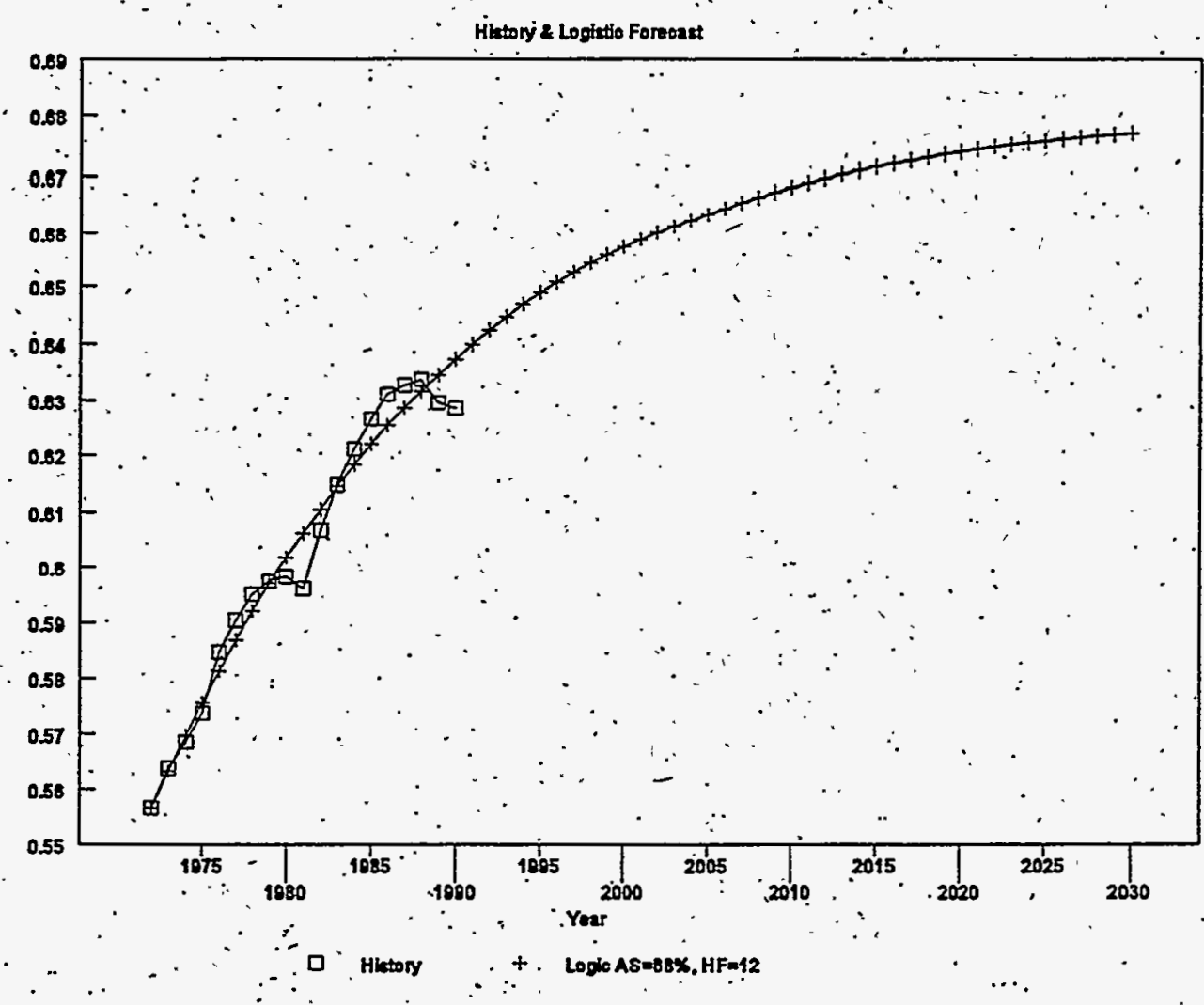

Source: $\quad-\quad$ Historical Values from U.S.DoT, FHWA, Highway Statistics, different yearly issues. 
Figure.F-2. Ürban Share of Automobile VMT: Logistic and Linear Forecasts .

Figure 5: Auto Urban Share VMT Driving

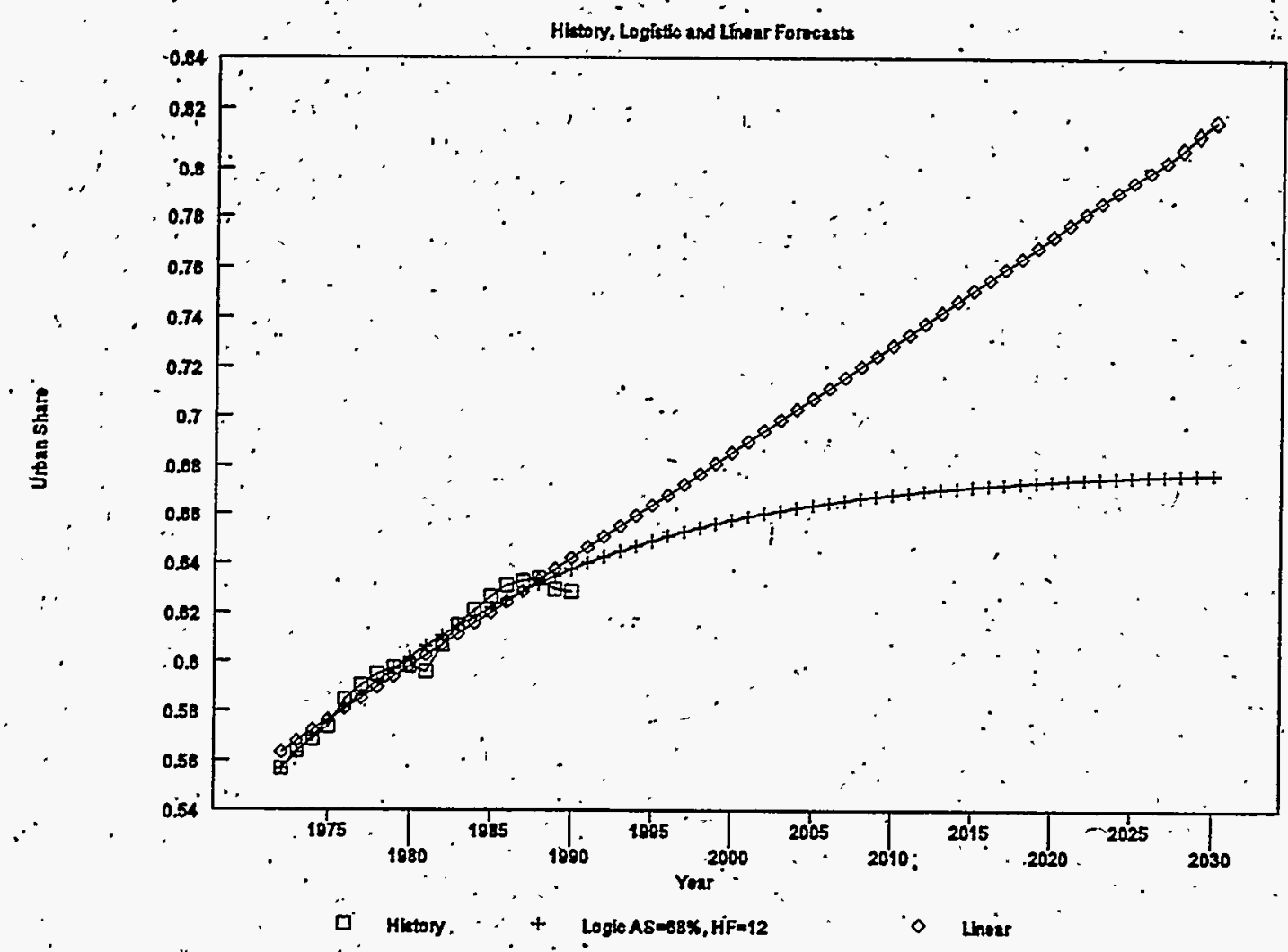

Source: $\quad$ Historical Values from U.S. DoT, FHWA, Highway Statistics, different yearly issues.' 


\section{FUELEFFICIENCY GAP PROJECTIONS}

This section outlines the three trends which are assumed to affect the fuel efficiency gap estimates of the EPA: It then presents the projections of the fuel efficiency gap which have been ritilized in the NEMS Transportation Sector Model.

\section{Increasing Urban Share Driving}

A review of the data from the last few decades on VMT for both automobiles and light duty trucks reflects a continuous increase in the share of urban driving. ${ }^{42}$ For automobiles the urban share increased from 45.4 percent in 1953 to 62.9 in 1990 . Figure F-3 shows the historical urban share of VMT for automobiles. This represents a 38.5 percent increase in 37 years, or an average annual rate of increase of 0.88 percent. For light duty trucks the urban share increased from 39.5 percent in 1966.to 55.4 in 199.0. Figure F-4 shows the historical urban share of VMT for light duty trucks. This represents a 40.3 percent.increase in 24 years, or an average annual rate of increase of 1.42 percent.

Westbrook and Patterson investigated the reasons for this increase in urban share by analyzing the data for the period from 1975 through $1985^{43}$ Their results indicated that the major reasons for this increase are the larger fraction of travel in urban roads and a larger fraction of roads being classified as urban. Population shifts to urban areas and driving shifts within metropolitan areas account for the larger fraction in urban driving which was estimated to be the cause for 58 percent of the increase in urban share. The other 42 percent increase was determined to be the consequence of the reclassification of roads from rural to urban. Any area reclassified by the U.S. Bureau of the Census from rural to urbaniresults in the reclassification of all roads (regardless of the type) as urban.

Forecasts of the shares of urban-and highway driving are necessary in order to forecast the change in the fuel efficiency gap due to changes in driving shares. It is very difficult to draw conchisions about the increasing trend in urban driving. Nevertheless, it can be expected that population shifts to urban areas will continue and that future land developments will force

12 Data on VMT is published annually by the U.S. Department of Transportation, Federal Highway Administration, in Highway Statistics.

43. Westbrook; F. and Patterson, P., "Changing Driving Patterns and Their Effect on Fuel Economy," presented May 2, 1989 at the 1989 SAE Government/Industry Meeting, Washington, D.C. 
Figure 1: Auto Urban Share VMT Driving

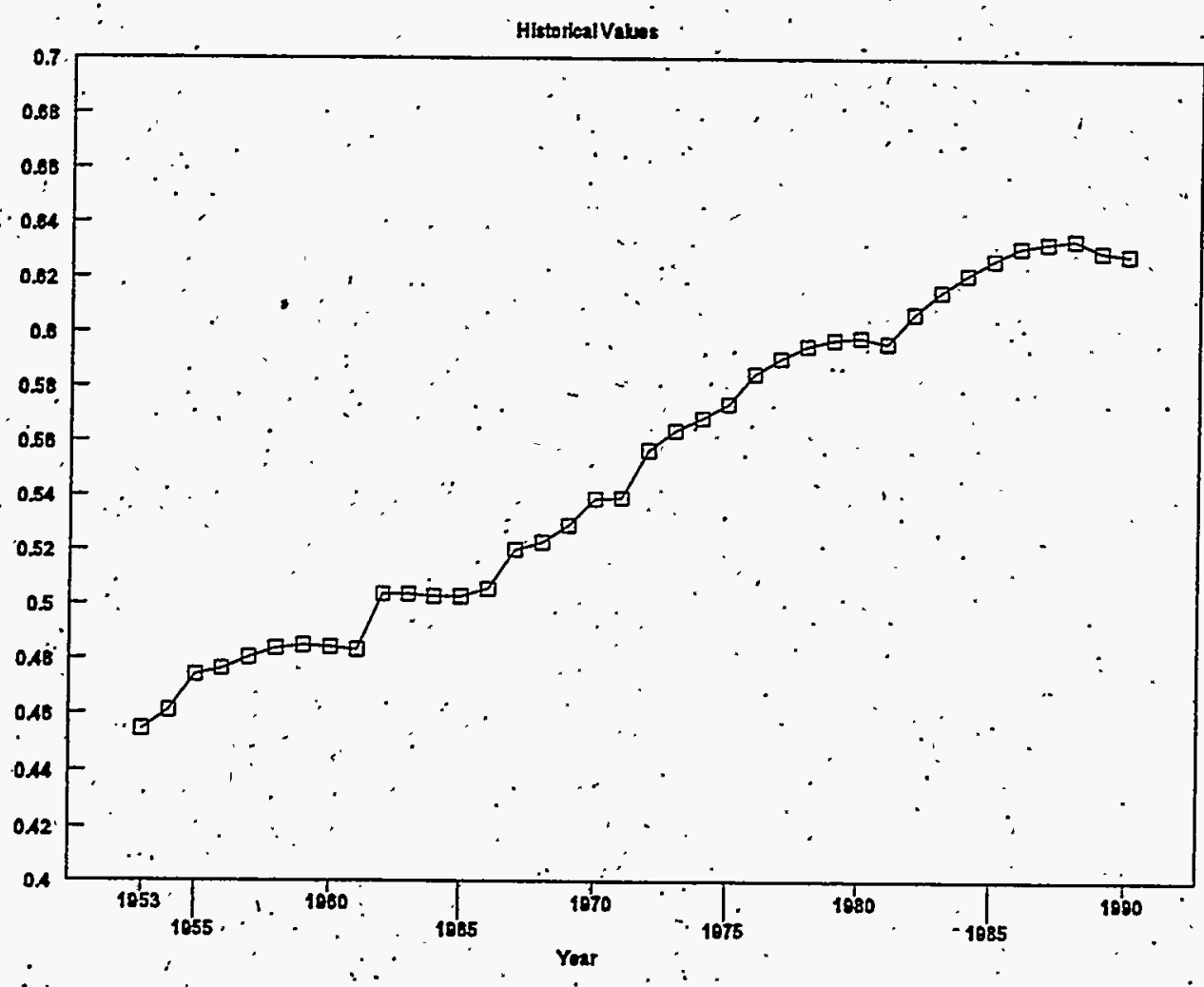

Source: Historical Values from U.S. DoT, FHWA, Highway Statistics, different yearly issues. 
Figure 2: Truck Urban Share VMT Driving

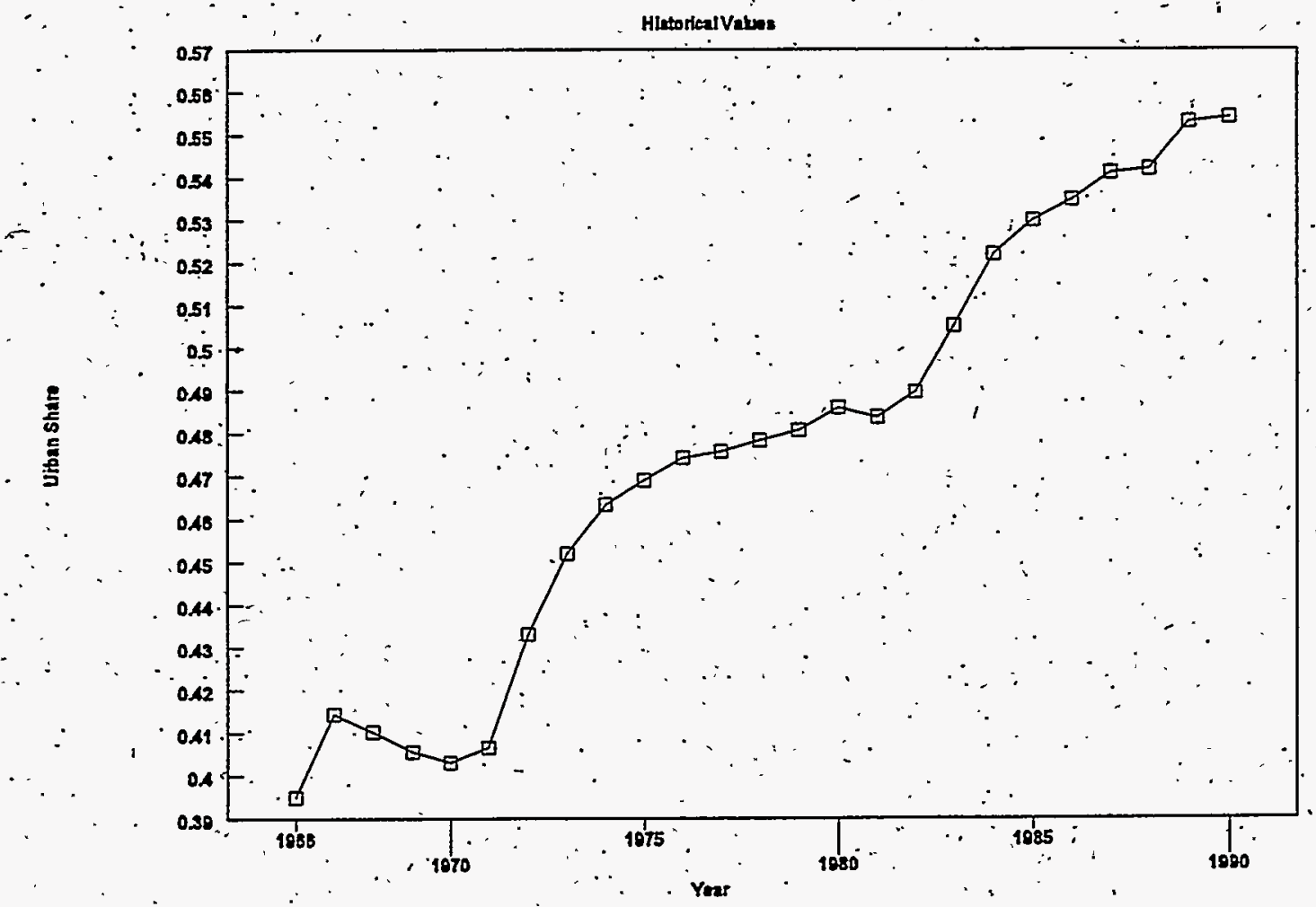

Source: Historical Values from U.S. DoT, FHWA, Highway Statistics, different yearly issues. 
the reclassification of rural areas into urban areas. If we assume that this rate of increase in urban share will gradually diminish and level off, the logistic path applies (see Figure F-1). The calculations for:logistic growth of increased urban share for automobiles and light trucks follow.

\section{Automobiles:}

Table F-32 summarizes the impact of the adjusted logistic city.share growth on the composite fuel efficiency gap for automobiles. The adjusted logistic city share projection for the year 2010 becomes 51.1 percent as compared to the unadjusted logistic share of 66.8 percent; in the year 2030, the projection levels off at 51.5 percent as compared to an unadjusted 67.7, percent projected logistically. The adjusted logistic forecasts of city share increase are transiated into a fuel efficiency gap of 16.05 percent by the year 2030. This represents an increase of only $0: 85$ percentage points over the base gap of 15.2 percent.

\section{Light Duty Trucks:}

The influence of the adjusted logistic urban share growth on the composite fuel efficiency gap for light duty trucks is presented in Table F-33. For the year 2010 the adjusted logistic city share projection becomes 48.8 percent as compared to an unadjusted logistic share of 62.3 percent. For the year 2030 , the projection begins to level off at 50.3 percent as compared to an unadjusted 65.2 percent projected logistically. The adjusted logistic forecasts of urban share increase are translated into a fuel efficiency gap of 29.73 percent by the year 2030. This represents an increase of only 1.43 percentage points over the base gap of 28.3 percent. 
Table F-32. Automobile Fuel Efficiency Gap Projections: Logistic Growth of City Driving Share (with Adjusted City Driving Share)

\begin{tabular}{|c|c|c|c|c|c|c|c|c|c|c|}
\hline 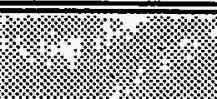 & 1888 & 1020 & 1896 & 2619 & 2005 & 204 & 20.15 & 2020 & 42025 & $1 \% 2030$ \\
\hline 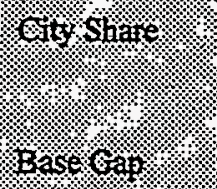 & 15:20 & $\begin{array}{c}49.1 \% \\
. \\
15.20 .\end{array}$ & $50.1 \%$ & $\begin{array}{l}50.5 \% \\
:\end{array}$ & $\begin{array}{r}.50 .8 \% \\
. . \\
15.20\end{array}$ & $51.1 \%$ & $.51: 2 \%$ & $.51 .4 \%$ & $\begin{array}{c}51.5 \% \\
.\end{array}$ & $51.5 \%$ \\
\hline Graptrotecast & .15 .27 & 15.19 . & 15.56 & 15.73 & $\cdot 15.82$ & 15.90 & $15: 97$ & $16: 02$ & .16 .04 & 16.05 \\
\hline (4yange. & 0.07 & -0.01 & $0.36^{\circ}$ & 0.53 & 0.62 & 0.7 .0 & 0.77 & 0.82 & 0.84 & 0.85 \\
\hline
\end{tabular}

Sourcës: Basé Gap from ORNL 1992, Ưrban Share Forecasts based on Fishèr \& Pry Logistic Function.

\section{Table F-33. Light Truck Fuel Efficiency Gap Projections: Logistic Growth of} City Driving Share (with Adjusted City Driving Share)

\begin{tabular}{|c|c|c|c|c|c|c|c|c|c|c|}
\hline ; & 1088 & rog & 1095 & 20 & 2006 & 2610 & 2913 & 2628 & 2025 & 2030 \\
\hline Seity Strare & $44.6 \%$ & $45.3 \%:$ & $46.3 \%$ & $47.3 \%$ & $48.1 \%$ & $48.8 \%$ & $49.3 \%$ & $.49 .7 \%$ & $50.0 \%$ & $50.3 \%$ \\
\hline '. & - & & & & & & & & & \\
\hline basegap & 28.30 & 28.30 & 28.30 & .28 .30 & 28.30 & 28.30 & 28.30 & 28.30 & 28.30 & 28.30 \\
\hline Gavprorecast & $28.30^{\circ}$ & 28.48 & .28 .72 & 28.98 & 29.21 & 29.35 & $.29: 50$ & 29.60 & 29.66 & $29: 73$ \\
\hline texange & 0.00 & 0.18 & 0.42 & 0.68 & 0.91 & 1.05 & $\mathrm{1} .20$ & 1.30 & 1.36 & 1.43 \\
\hline
\end{tabular}

Sources: Base Gap from ORNL 1992, Urban Share Forecasts based on Fisher \& Pry Logistic Function. 


\section{Increasing Highway Speeds}

The level of speed of a vehicle is one of the relevant factors that affects its fuel efficiency. Specifically, it has been determined that speeds over $45 \mathrm{mph}$ decrease fuel efficiency for most vehicles. Furtheimore, EPA estimates that traveling at $65 \mathrm{mph}$ as compared to $5.5 \mathrm{mph}$ lowers fuel economy over 15 percent. ORNL's 1992 Transportation Energy Data Book presents the findings of a fuel economy study performed by the Federal Highway Administration in $1984^{45}$. This study concluded that, on average, vehicles experience fuel efficiency losses of about 17.8 percent when their speed is increased from $55 \mathrm{mph}$ to $65 \mathrm{mph}$. This is equivalent to a reduction of 1.78 percent for each mile per hour increase over speed ranging from $55 \mathrm{mph}$ to $65 \mathrm{mph}$.

Average highway speeds in the United States have shown an increasing trend for several years with. few exceptions. Figure F-5 presents average highway speeds in mph for the last 45 years. The data in this figure indicate two different increasing trend periods. The first period from 1945 through 1973 corresponds to the largest rate of increase on highway speeds; During these years, highway speed increased at an annual rate of 1.13 percent. In 1973, àverage highway. speed suddenly dropped

- from about $66 \mathrm{mph}$ to about $55 \mathrm{mph}$. This sudden drop corresponds to the implementation of the nationwide $55 \mathrm{mph}$ speed limit. After 1974, the increasing trend has continued at a more moderate rate. In the 1974-1990 period the annual rate of speed increase has been 0.15 percent. A closer look at the post-1973 period indicates that through the rest of the 1970 s, the average speed remained fairly constant between 55 and $56 \mathrm{mph}$; and, through the 1980s, the annual rate of increase was 0.34 percent.

The increase in highway speed can also be illustrated by considering the percentage of rural and urban VMT driving over $55 \mathrm{mph}$ on highways with posted speed limits of $55 \mathrm{mph}$. Figure F-6 presents these data for the 1981-1990 period. In only 9 years, the percent of rural VMT driving over the $55 \mathrm{mph}$ speed limit rose from 46.4 percent to 58.7 percent for a total of 12.3 percentage points. The percentage increase in urban VMT driving.was even more dramatic, from 37.6 percent to 53.8 percent for a total of 16.2 percentage points. The percentage exceeding the speed limit is far from homogeneous. Significant differences exist across states, highway.types, and location for rural or urban areas. For instance, in 1990 the percentage of vehicles exceeding the $55 \mathrm{mph}$ limit in urban interstate highways in New.York was 82.5 as compared to 68.2 in California and only 33.7 in South

4 DOE/EPA, 1992 Gas Milage: EPA Fuel Economy Estimates, DO'E/CE-019/10, October 1991.

15 Davis, S. and Morris, M., Oak Ridge National Laboratory, Transportation Énergy Data Book: Edition 12, ORNL-6710, (Edition 12 of ORNL-5198), Table 3.42, p.3-66,March 1992. 1984 data from U.S. Department of Transportation, Federal Highway Administration, Fuel Consumption and Emission Values for Traffic Models, Washington, D.C., May 1985. 
Dakota.

The estimation of the overall impact of speed trends in fuel economy is dependent on the specific data type selected to measure this trend and on the methodology used to forecast this trend. One could choose a disaggregated approach in which speed trend forecasts are developed by urban and rural driving, highway.type, and vehicle type, for each state: Given the time limitations, the current study utilizes the nationwide average highway speed for all vehicles and highway types. Average speeds post-1980 are used as the basis to generate forecasts.

As Figure F-5 illustrates, average highway speed is influenced by regulatory policies such as the implementation of the nationwide speed limit in 1973:1974. Other factors affecting speed might include safety and environmental regulations, gasoline prices, oil shortages, income fluctuations, etc: Although a methodology to forecast speed trends which includes all relevant factors is desirable, a logistic approach based on historical trends has been applied.

\section{Automobiles:}

Table F-34 summarizes the impact of the a'djusted highway share speeds on the composite fuel. efficiency gap for automobiles using the logistic approach. Unlike the adjusted results for the urban driving share, the fuel efficiency gap forecasts indicate that in 2010 the gap has increased to 17.02 percent, which is greater than the unadjusted logistic forecast of 16.58 percent. By the year 2030, the adjusted forecast is 18.27 percent, which is above the unadjusted logistic forecast of 17.47 . By the year 2030, the adjusted gap is 3.07 percent above the base gap of 15.2 percent. 
.Figure 7: Average Highway Speed

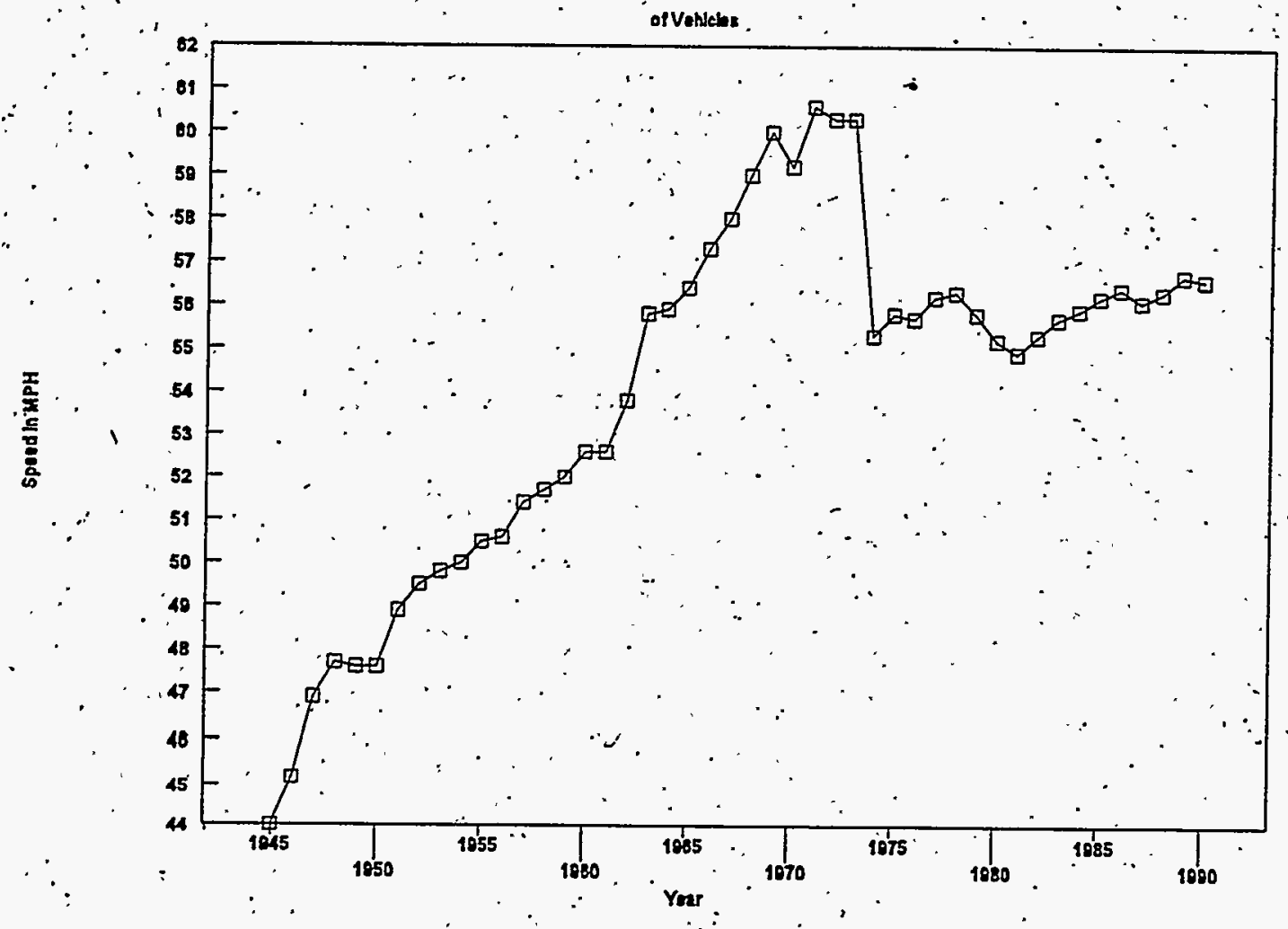

Source:" Historical Values from U.S. DoT, FHWA, Highway Statistics, different yearly issues. 


\section{Figure F-6. Percent of Highway VMT over 55 MPH: 1981-1990}

Figure 8: Percent of Rural. \& Úrban VMT

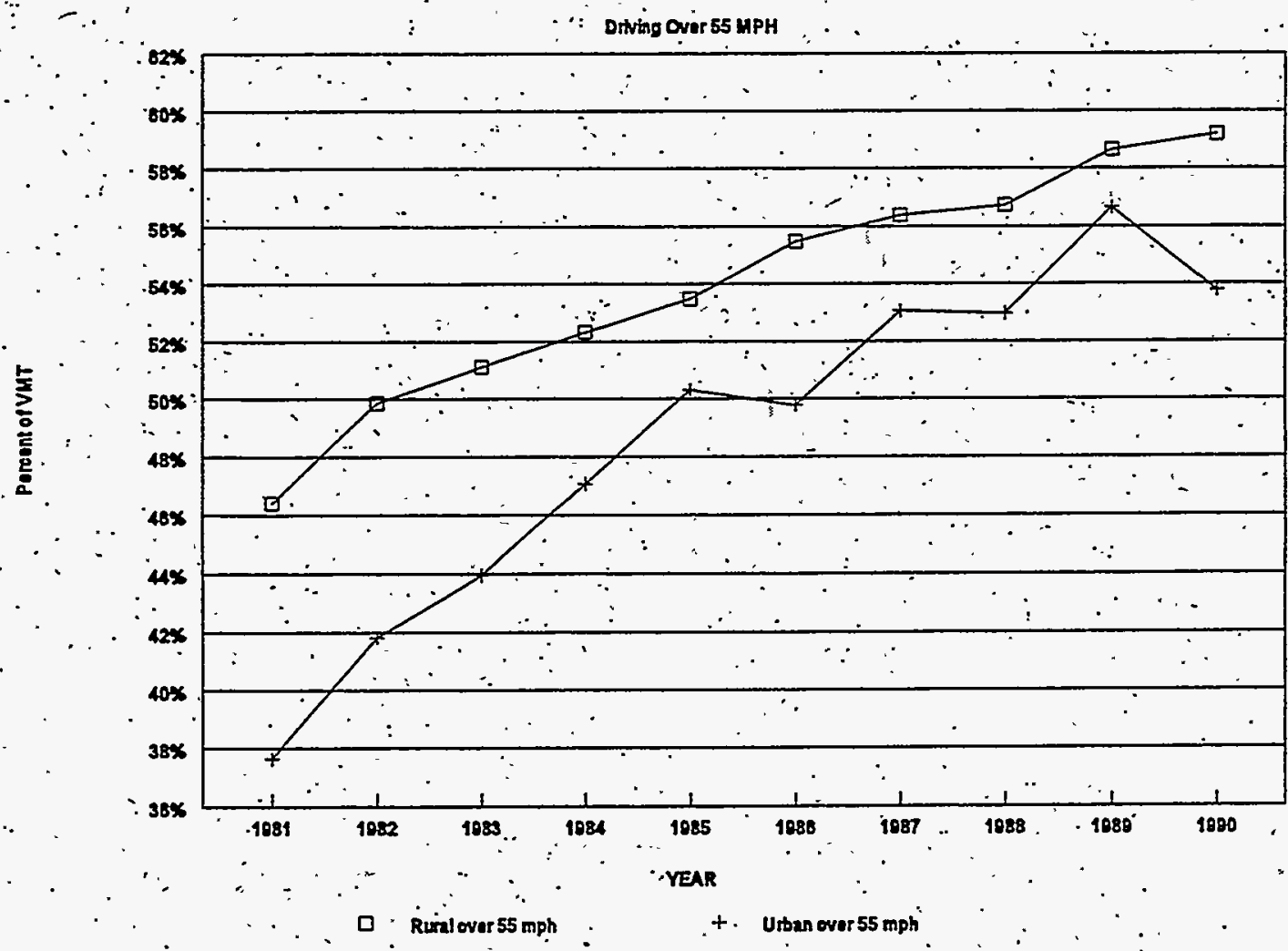

Note: Based on data for roads with posted speed limit of $55 \mathrm{mph}$.

Source: - Historical values from U.S. DoT, FHWA, Highway Statistics, different yearly issues. 
Table F-34. Automobile Fuel Efficiency Gap Projections: Logistic Growth of Average Highway Speed (with Adjusted Highway Driving Shares)

\begin{tabular}{|c|c|c|c|c|c|c|c|c|c|c|}
\hline \%। & $\% 1988$ & 1090 & 1995 & 8.23000 & $\frac{1}{2605}$ & $2 x+10$ & 2015 & 8,2020 & 2025 & 2030 \\
\hline 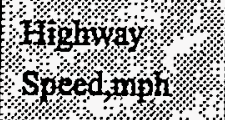 & 56.30 & 56.60 & 57.41 & 58.06 & 58.66 & 59.22 & 59.75 & 60.23 & 60.69 & .61 .11 \\
\hline Basem Gap & 15.20 & $\cdot 15.20$ & $\begin{array}{l}15.20 \\
-.\end{array}$ & $\begin{array}{l}15.20 \\
\sim \quad .\end{array}$ & 15.20 & 15.20 & 15.20 & 15.20 . & $\begin{array}{l}.15 .20 \\
.\end{array}$ & 15.20 \\
\hline Gap forecast & 15.19 & 15.39 & 15.89 & 16.31 & 16.67 & 17.02 & $17.38^{\circ}$ & 17.70 & 18.00 & 18.27 \\
\hline \%change & -0.01 & 0.19 & 0.69 & 1.11 . & 1.47 & 1.82 & 2.18 & $\cdot 2.50$ & 2.80 & 3.07 \\
\hline
\end{tabular}

Sources: Base Gap from ORNL 1992, Highway Speed Forecasts based on Fisher \& Pry Logistic Function.

Table F-35. Light Truck Fuel Efficiency Gap Projection: Logistic Growth of Average Highway Speed (with Adjusted Highway Driving Share)

\begin{tabular}{|c|c|c|c|c|c|c|c|c|c|c|}
\hline & $1 \% 1988$ & 109 & 1096 & 28006 & 28685 & 2016 & 2010 & 8,20 & 2025 & 2030 \\
\hline Hinguray & 56.30 & 56.60 & $57.41^{\circ}$ & 58.06 & 58.66 & 59.22 & 59.75 & 60.23 & $60: 69$ & 61.11 \\
\hline Base Ga & 28.30 & $28.30^{\circ}$ & 28.30 & 28.30 & 28.30 & 28.30 & 28.30 & $\begin{array}{c}28.30 \\
.:\end{array}$ & 28.30 & 28.30 \\
\hline Gaplsorecas! & 28.29 & 28.49 & $28.95^{\circ}$ & 29.35 & 29.74 & 30.07 & 30.43 & 30.73 & 31.01 & 31.29 \\
\hline Charms? & $-0: 01$. & 0.19 & 0.65 & 1.05 & $1: \dot{44}$ & $1.77^{\circ}$ & 2.13 & 2.43 & 2.71 & 2.99 \\
\hline
\end{tabular}

Sources: Base Gap from ORNL 1992, Highway Speed Forecasts based on Fisher \& Pry Logistic Function. 


\section{Light Duty Trucks:}

Table F-35 displays the fuel efficiency gap projections for light duty trucks assuming logistic growth for average highway speed-and an adjusted driving share to reflect the city to highway driving proportion. The adjusted logistic projections imply that the fuel efficiency gap for light duty trucks will be 30.07 percent for an increase of 1.77 percentage points over the base gap in the year 2010 . The gap forecast is larger than the unadjusted logistic projection of 29.74 percent. 'By 2030 the adjusted logistic forecast is 2.99 percent above the base gap of 28.30 percent, while the unadjusted. logistic is 2.39 percent above the base gap. This implies a fuel efficiency gap of 31.29 percent in 2030.

\section{Increasing Urban Highway Congestion}

Congestion is a primary issue of the domestic transportation system. Urban congestion has increased in the last decades in most metropolitan areas as expansion and improvement of the transportation system lagged behind the rapid growth of travel demand.

The Federal Highway Administration (FHWA) classifies the two major causes of urban road congestion as recurring congestion and non-recurring congestion. Recurring congestion is that congestion which is the consequence of inadequate road capacity, reduction of through-put lanes, narrowing of lane widths, physical barriers, inadequate traffic light synchronization, and other similar causes. FHWA estimates that recurrent congestion accounts for 40 percent of all urban road congestion. Non-recurring congestion is that congestion resulting from disabled vehicles and accidents. FHWA estimates that disablement account for 55 percent of overall urban congestion, with the remaining 5 percent due to accidents.

One of the most important road types within urban areas in which congestion takes place is urban freeways. In 1990, 32 percent-of the total vehicle miles of travel in urban areas corresponded to freeways, while freeways comprised only 5.7 percent of the urban roadway mileage. ${ }^{46}$ The increase in urban congestion can be further analyzed by considering the increase in urban VMT as compared to the increase in urban lane miles. Data corresponding to the period 1975-1987 indicate that urban VMT demand growth rate is over 4 times the rate of new urban lane capacity growth. This corresponds to an increase in the average urban through-put (urban VMT per mile) of 38.9 percent.

46 U.S. DOT, FHA, Highway Statistics 1990. 
Differing methodologies have been developed recently to measure the extent and duration of freeway congestion in urban areas. ${ }^{47} 48$ Hanks-and Lomax of the Texas Transportation Institute (TTT). have developed congestion indices for 39 urban areas. Table F-36 lists VMT, VMT per lane-mile, congestion indices, and rankings for each of the urban areas analyzed by TTI. Table F-37 lists, in . addition to the congestion indices, estimates of the congestion cost per capita for each of these urban areas. Few attempts to forecast urban congestion and its effect on fuel economy are available. ${ }^{49}$

47. Cottrell, P., "Measurement of the Extent and Duration of Freeway Congestion in Urbanized Areas, "ITE 61st Annual Meeting, Milwaukee, Wisconsin, Sept. 1991.

48 Hanks, J., and Lomax, T., Roadway Congestion in Maior Urban Areas: 1982 to 1987, Texas Transportation Institute, Research Report 1131-2, College Station, Texas, Oct. 1989.

49 Lindley, J., "Üban Freeway Congestion Problems and Solutions: An Update," ITE Journal, Dec. 1989, pp. 21-23. Feng, An, "Automobile Fuel Economy and Traffic Congestion," Dissertation for PhD in Applied Physics, University of Michigan, 1992. Westbrook, F. and Patterson, P., "Changing Driving Patterns and.Their Effect on Fuel Economy," presented May 2, 1989 at the 1989 SAE Government/Industry Meeting, Washington, D.C. 


\section{Table F-36. Congestion Index Value for Selected Cities}

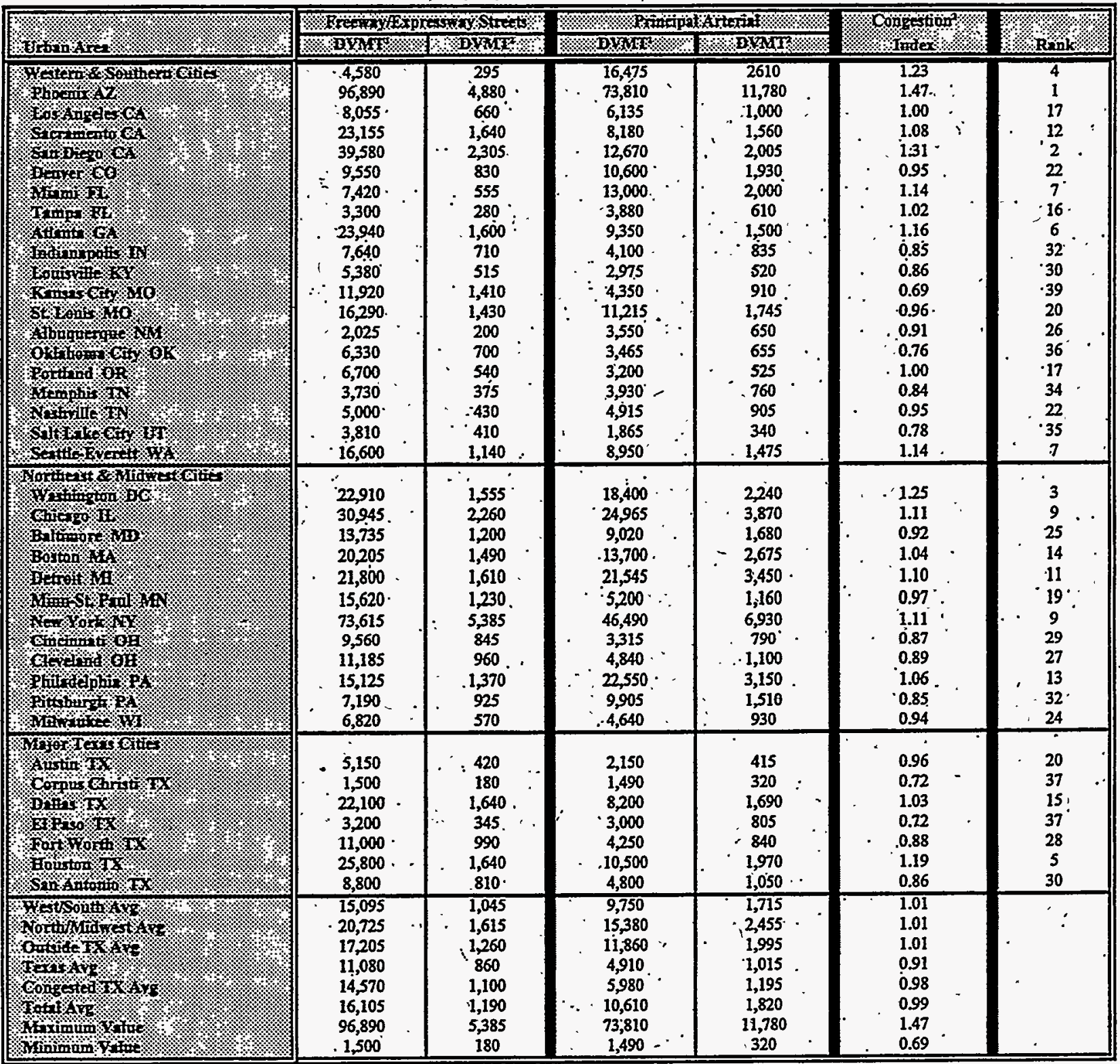

Note: Congested Texas cities average inciudes Austin, Dallas, Fort Worth, Houston, and San Antonio.

'Daily'vehicle-miles of travel

Daily vehicle-miles of travel per lane-mile

'See Equation s-1 
Table F-37. 1987 Urban Area Rankings by Congestion Index and Cost per Capita

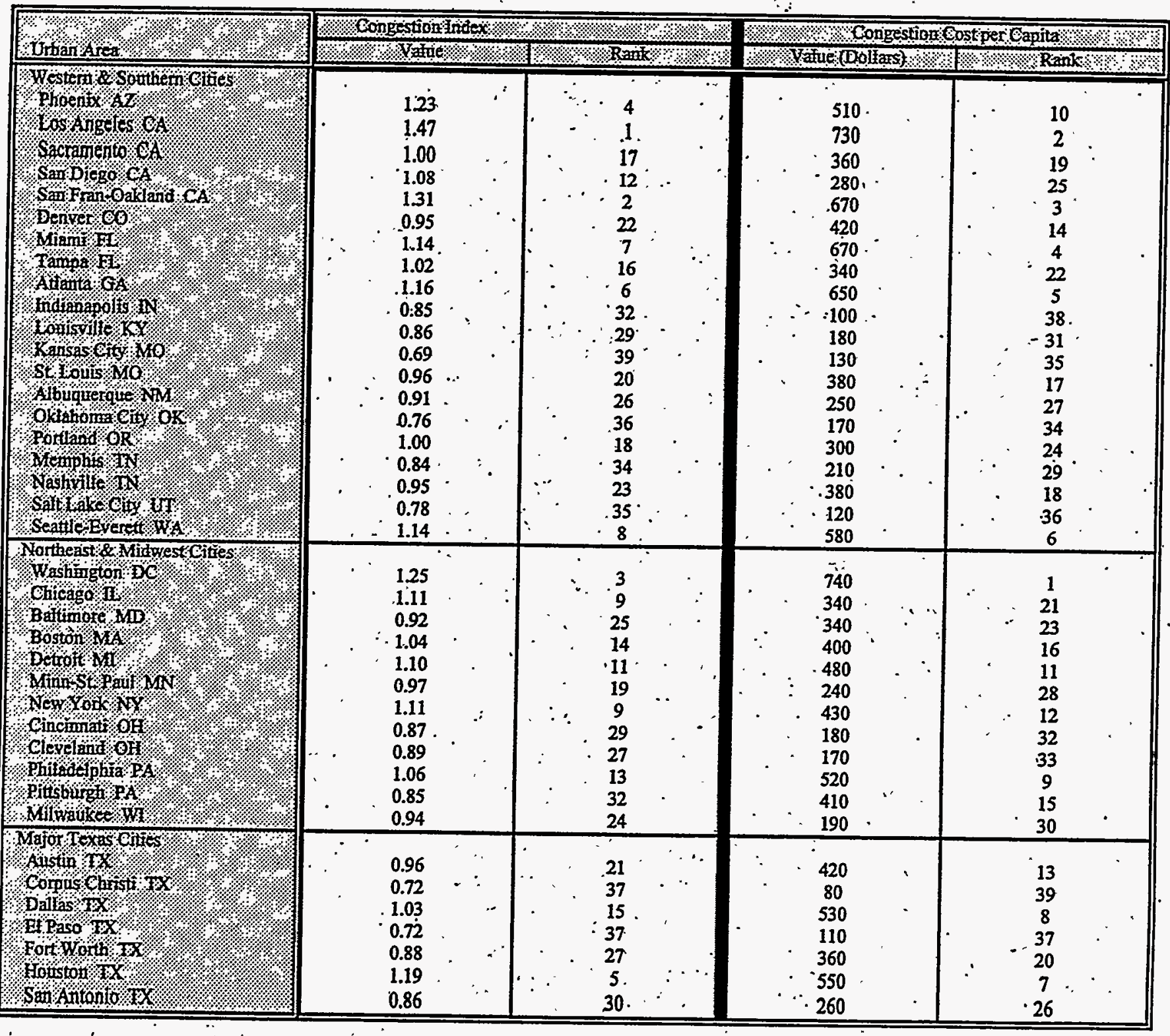

Source: Hanks, J., and Lomax, T:, Roadway Congestion in Major Urban Areas: 1982 to 1987. TTI, Research Report 1131-2, College Station, TX; Oct. 1989. 
Lindley's projections of consumption statistics for the year 2005 take into account factors including time delays, wasted fuel, and user cost. The urban freeway congestion statistic projections developed by Lindley are presented in Table F-38.

The projections generated in this study utilize the wasted fuel values developed by Lindley as the basis to measure the impact of urban congestion on the fuel efficiency gap. The study further àssumes that the amount of wasted fuel due to congestion will increase following a logistic trend.

The amount of wasted fuel is divided between automobiles and light duty trucks assuming that the light duty trucks VMT driving share will increase from 23.4 percent in 1989 to 33 percent in 2010, and will remain constant at 33 percent through 2030.

\section{Automobiles:}

The wasted fuel forecast due to traffic delays for the year 2010 is 9,164 mil.gal. and for the year 2030 it is 11,426 mil.gal. as summarized in Table F-39. This implies that the fuel efficiency gap will be 18.66 percent in 2010 and 23.08 percent in 2030 . These are lower projections as compared to the unadjusted figures of 21.53 percent and 26.32 percent corresponding to the same years.

\section{Light Duty Trucks:}

Table F-40 presents the fuel efficiency gap projections for light duty trucks based on adjusted city/highway shares and assuming logistic growth of wasted fuel due to congestion. The wasted fuel forecast for light duty trucks for the year 2010 is 4,513 mil.gal. and for the year 2030 it is $5 ; 628$ mil.gal. This implies that the fuel efficiency gap will be 32.77 percent in 2010 and 33.43 percent in 2030 as compared to the unadjusted figures of 32.91 percent and 34.09 percent.

\section{Overall Degradation Factor. Forecast}

Figures F-7 and F-8 summarize the projections of the fuel efficiency gap using assumptions of logistic grawth and adjusted city/highway shares for automobiles and light duty trucks, respectively. The overall results are listed in Table F-41.

As illustrated in Table F-41, the logistic approach generates lower forecasts for the overall fuel efficiency gap for both automobiles and light duty trucks.as compared to the ones generated using the linear approach. The overall fuel efficiency gap for automobiles is expected to increase from a base of 15.2 to 27.00 by the year 2030 assuming a logistic trend. The fuel efficiency. gap will 
increase further to 34.07 if a linear trend is assumed instead. The overall fuel efficiency gap for light duty trucks is expected to increase from a base of 28.3 to 37.85 or 42.91 by the year 2030 assuming logistic and linear growth respectively.

Table F-38. Urban Freeway Congestion Statistics

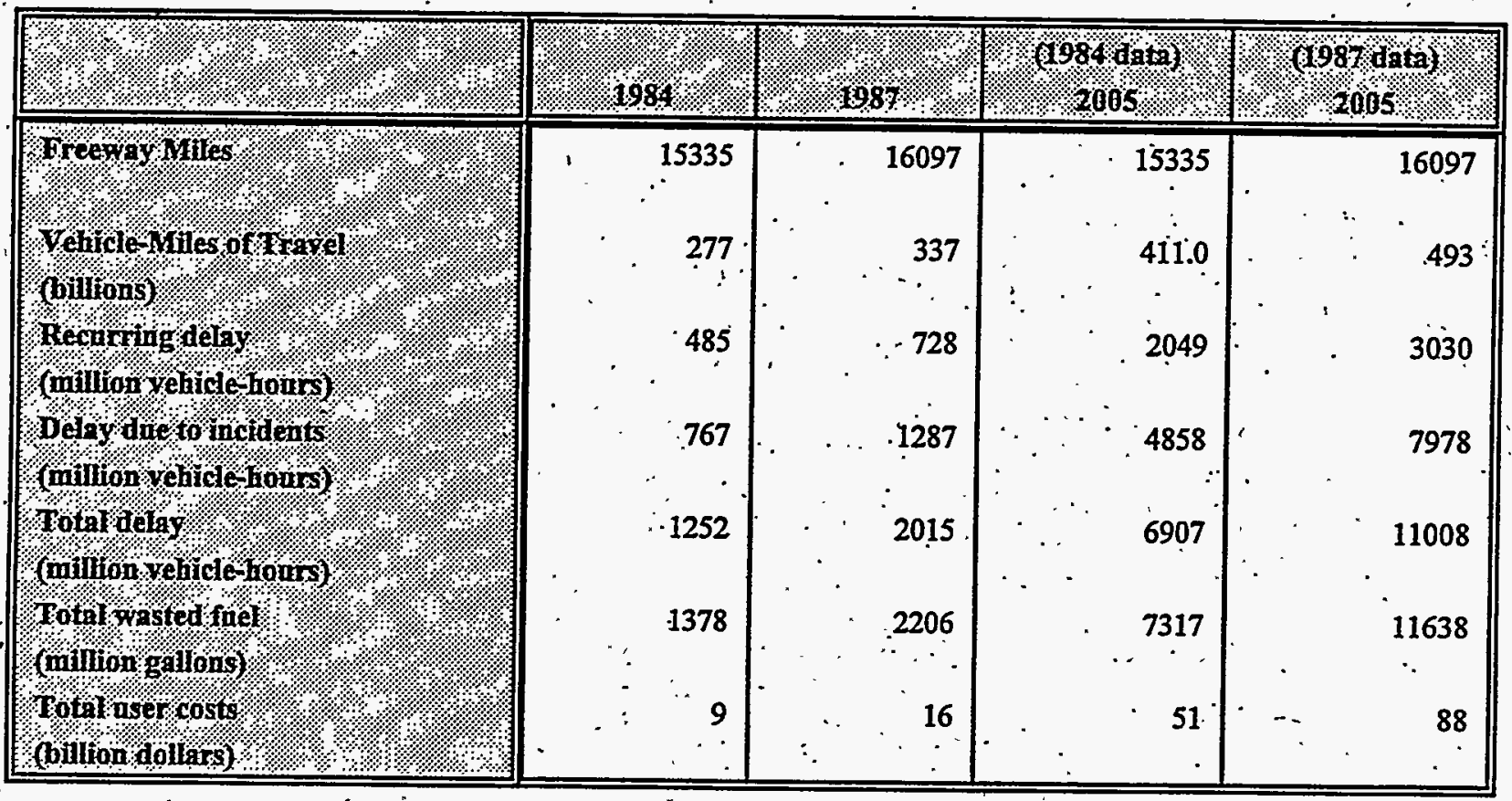

Source: . Lindley, J., "Urban Freeway Congestion Problems and Solutions: An Update," ITE $\because \quad$ Journal, December 1989, pages 21-23.

Table F-39. Automobile Fuel Efficiency Gap Projections: Logistic Increasing Congestion Trend (with Adjusted City/Highway Driving Share)

\begin{tabular}{|c|c|c|c|c|c|c|c|c|c|}
\hline \%४ & 1990 & \% & 2000 & 2005 & 2010 & 2035 & 2020 & 2025 & 2030 \\
\hline (Mailion Gallogst) & $\begin{array}{r}2252 . \\
.\end{array}$ & 3865 & 5788 & 7764 & 9164 & 10284 & .10924 & .11259 & 11426 \\
\hline Brse Gap & 15 & 15 & 15 & 15 & 15 & $\cdot 15$ & 15 & 15 & 15 \\
\hline Gap forecsist & 15.69 & 16.37 & 17.34 & 18.20 & 18.66 & 22.08 & 22.50 & 22.79 & 23.08 \\
\hline Change $)$ & 0.49 & 1.17 & 2.14 & 3.00 & 3.46 & 6.88 & 7.30 & 7.59 & 7.88 \\
\hline
\end{tabular}


Figure F-7. Fuel Efficiency Gap for Automobiles (with Adjusted Driving Share)

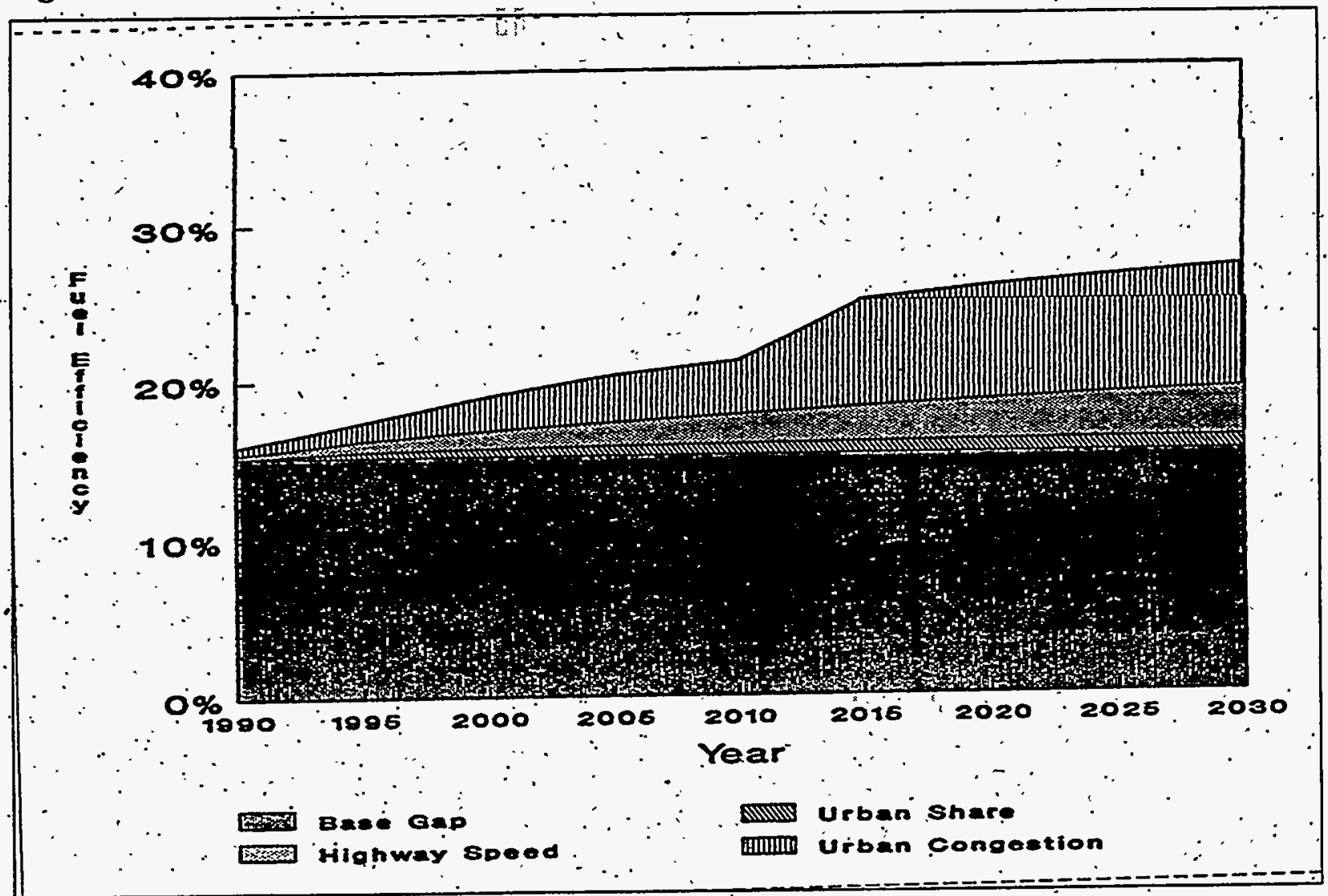


Figure F-8. Fuel Efficiency Gap for Light Duty Trucks (Logistic Forecast)

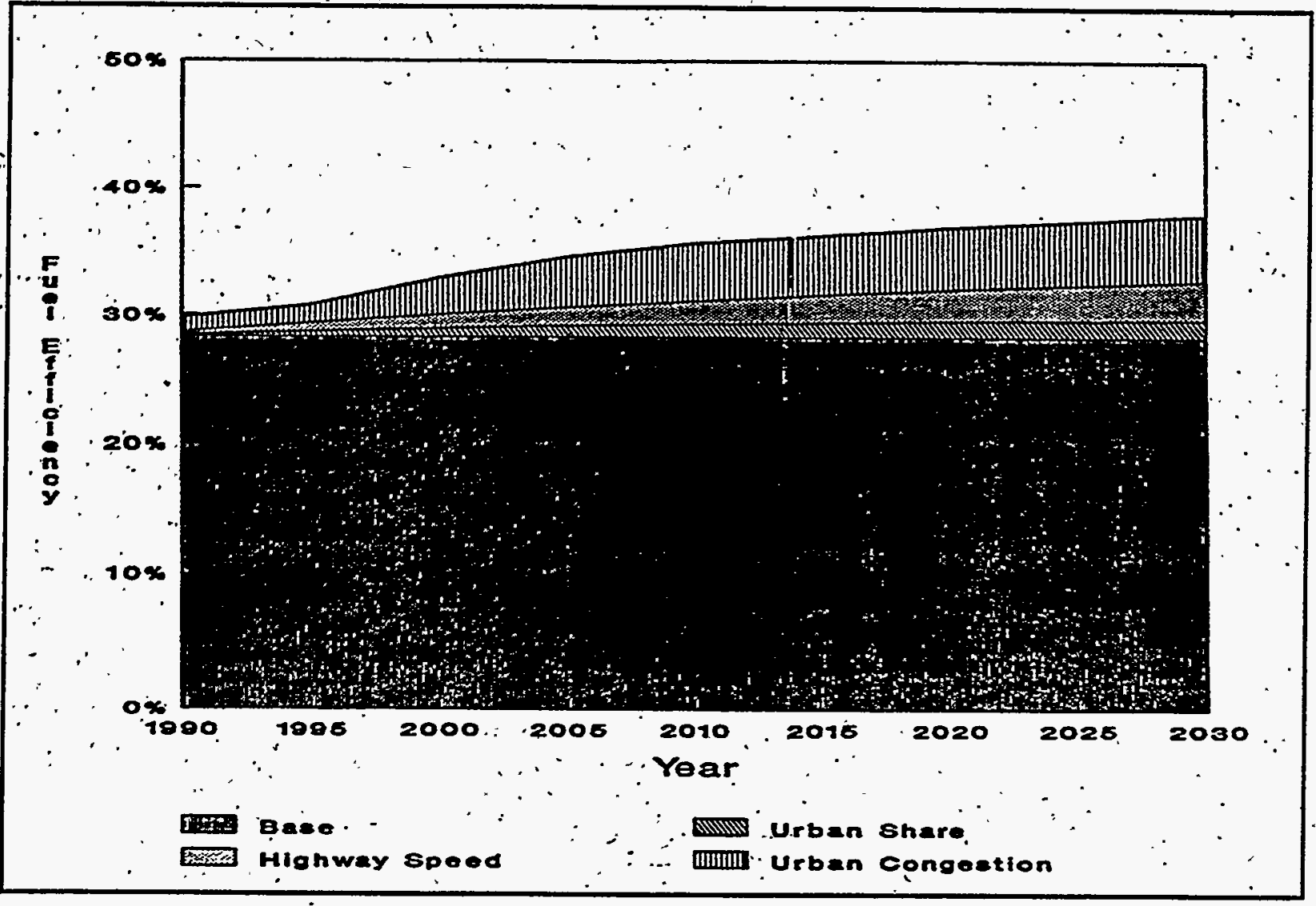


Table'F-40. Light Truck Fuel Efficiency Gap Projections: Logistic Increasing Congestion Trend (with Adjusted City/Highway Driving Share)

\begin{tabular}{|c|c|c|c|c|c|c|c|c|c|}
\hline (1. & 1890 & 1995 & 2000 & 2005 & 2010 & 2015 & 2020 & 2025 & 2030 \\
\hline Wasted niret & 611 & 1203 & 2240 & 3375 & 4513 & 5065 & $\begin{array}{l}.5380 \\
\therefore\end{array}$ & 5545 & 5628 \\
\hline Basseresp & 28.3 & 28.3 & .28 .3 & 28.3 & 28.3 & 28.3 & 28.3 & 28.3: & 28.3 \\
\hline 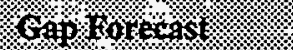 & 29.41 & 29.76 & 31.17 & 32.17 & 32.77 & .32 .89 & 33.14 & 33.28 & 33.43 \\
\hline (8hang & $1: 11$ & $1.46 \ldots$ & 2.87 & 3.87 & 4.47 & 4.59 & 4.84 & 4.98 & 5.13 \\
\hline
\end{tabular}

Table F-41. Total Fuel Efficiency Gap Projections for Automobiles and Light Duty Trucks with Adjusted City/Highway Driving Share

\begin{tabular}{|c|c|c|c|c|c|c|c|c|c|}
\hline ঋ/. & 1990 & 1995 & 2010 & 2005 & 2010 & 2016 & 20120 & 2015 & 2030 \\
\hline MOMNOBHAS & & & & & & & & & \\
\hline Basergar & 15.20 & -15.20 & 15.20 & 15.20 & 15.20 & 15.20 & $\therefore 15.20$ & 15.20 & 15.20 \\
\hline Gaphorecost & $15: 87^{\circ}$ & $17.42^{\circ}$ & 18.98 & 20.29 & 21.18 & 25.03 & 1. 25.82 & 26.43 & 27.00 \\
\hline Chiange & 0.67 & 2.22 & 3.78 & 5.09 & 5.98 & $\therefore 9.83$ & 10.62 & 11.23 & 11.80 \\
\hline W D. MNUGKS & & & & . & & & : & & \\
\hline Basckg & 28.30 & 28.30 & 28.30 & 28.30 & 28.30 & 28.30 & 28.30 & 28.30 & 28.30 \\
\hline Gap formengs & 29.78 & 30.83 & 32.90 & 34.52 & 35.59 & 36.22 & 36.87 & 37.35 & 37.85 \\
\hline rehangent & 1.48 & 2.53 & 4.60 & 6.22 & $7: 29$ & 7.92 & 8.57 & 9.05 & 9.55 \\
\hline
\end{tabular}




\section{Attachment 4: Light Duty Vehicle Fleet Model}

\section{Characteristics of Fleet Vehicles}

\section{Aggregation of EPACT Requirements}

Under the provisions of EPACT, purchases of vehicles by fleets meeting certain criteria are affected by the requirement thaf a proportion be alternatively füeled. The specific conditions under which these provisions are in effect, and the fleet sizes which are affected are not static, but are subject to revision. The impact of the current legislation on different fleet types is tabulated below. ${ }^{50}$

\begin{tabular}{|c|c|c|c|c|c|}
\hline \multicolumn{6}{|c|}{ 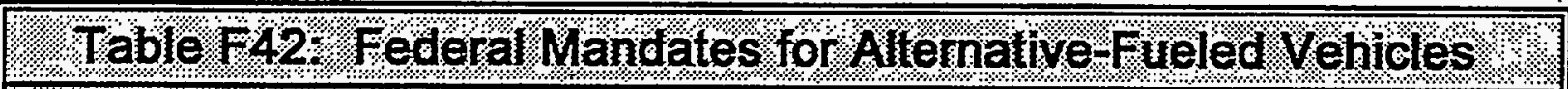 } \\
\hline \multirow{2}{*}{ \% } & \%. & \multicolumn{3}{|c|}{ 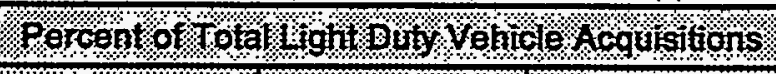 } & \\
\hline & H.poderal & State & fruel providers & Erectro & Muncipals \\
\hline : 1996 & 25 & 10 & 30 & - & - \\
\hline 1997 & 33. & 15 & $\therefore \quad 50$ & $\because \div$ & - \\
\hline 1998 & 50 & 25. & 70 & 30 & - \\
\hline 1999 & 75 & 50 & 90 & .50 & 20 \\
\hline 2000 & 75. & 75 & $90 "$ & 70 & 20 \\
\hline 2001 & 75 & 75 & 90. & 90 & $20^{\circ}$ \\
\hline 2002 & 75 & 75 & 90 & 90 & 30. \\
\hline 2003 & 75 & 75 & 90 & $90 \ldots$ & 40 \\
\hline 2004 & $75^{\circ}$ & 75. & 90 & $90^{\circ}$ & 50 \\
\hline 2005 & $\because 75$ & $\ldots 75$ & 90 & 90 & 60 \\
\hline Thereafter & $7 \dot{5}$ & 75 & 90 & 90 & $70^{\circ}$ \\
\hline
\end{tabular}

Affected fleets are also distinguished by geographical location: fleets of 50 or more of which 20 or more are located in metropolitan areas with a population over 250,000 with the capability of central refueling. ${ }^{51}$ Federal mandates for the three fleet types considered by the model are estimated using a stock-weighted average of the relevant categories above, and identified as.EPACT ${ }_{\text {MYY, }}$ in the code.

$\therefore$ '50 The table has been reproduced from Alternatives To Traditional Transportation Fuels 1994, Volume 1, U.S: Department of Energy, Energy Information.Administration, DOE/ELA-0585(94)1, February 1996, Table 1.

sIPL 102-486 §301(5)(A)\&(B), and §301(9), 10 CFR 106 STAT. 2866, et. seq. 


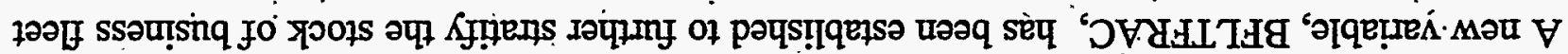

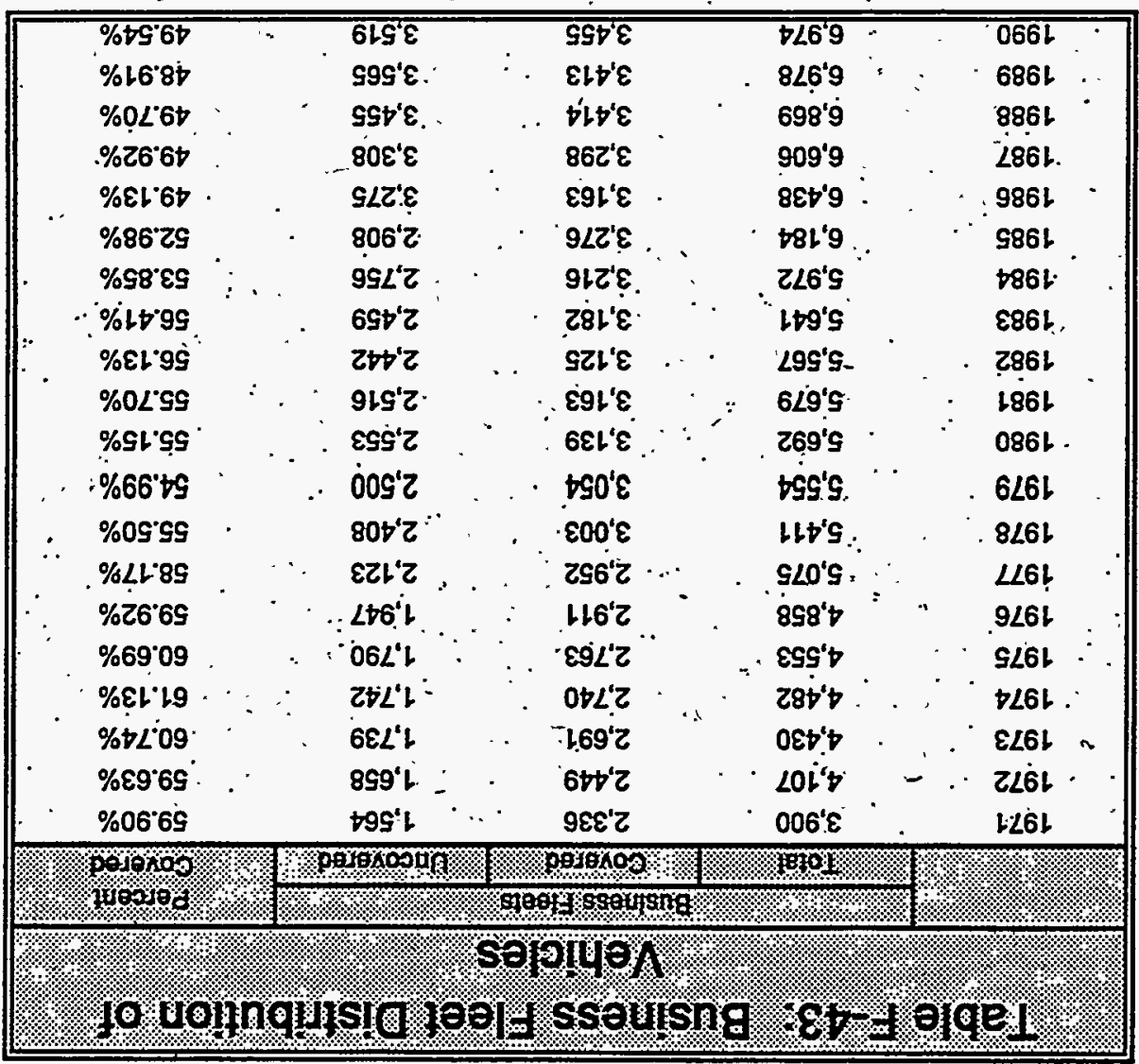

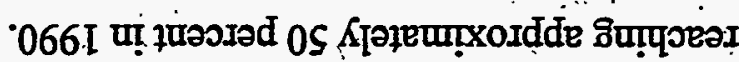

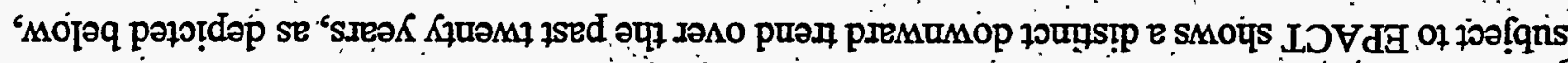

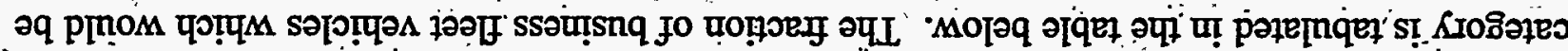

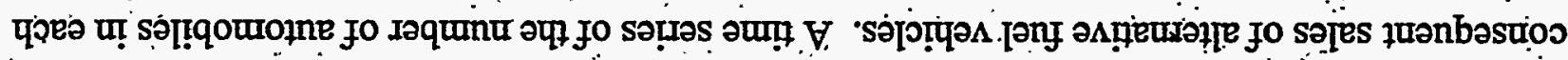

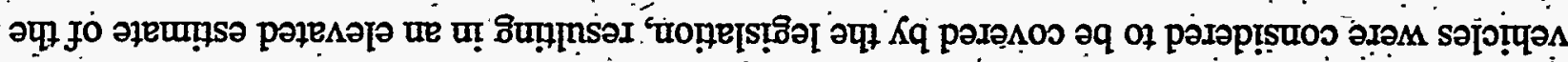

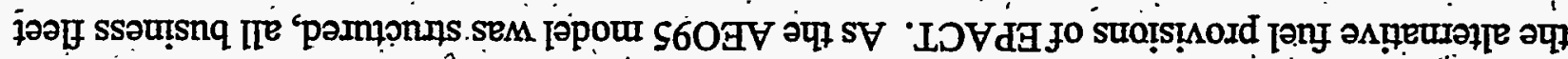

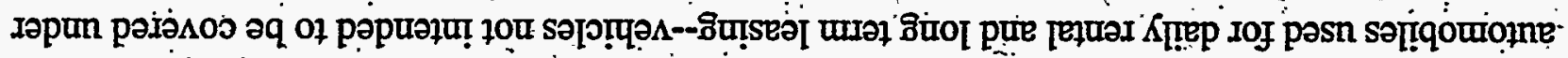

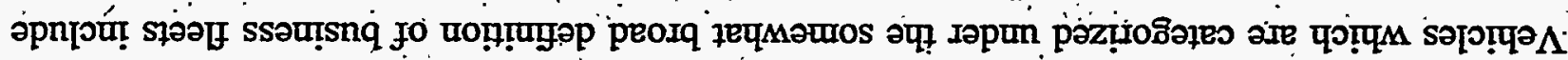

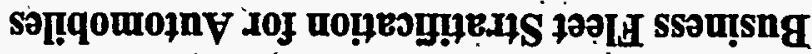

'นo!̣ș

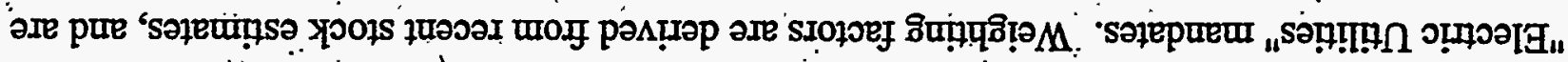

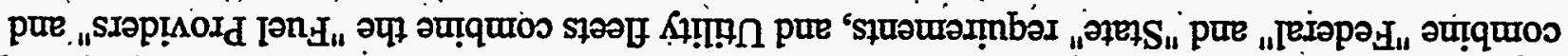

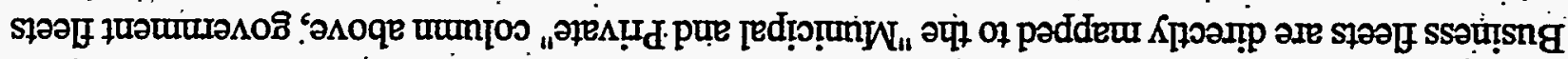


cars; with only the "covered" vehicles being used to estimate AFV purchases under EPACT. This variable is estimated using an asymptotic extrapolation of the historical trend, using an assumed lower limit of 40 percent, and a functional form.as follows:

$$
\text { BFLTFRAC }_{T-1971}=\text { BFLTFRAC }_{\text {MIN }}+\left(B F L T F R A C_{M A X}-B_{\text {BFLTFRAC }}\right.
$$

The input assumptions, estimated coefficients, and extrapolated values of BFLTFRAC are provided below.

\begin{tabular}{|c|c|}
\hline \multicolumn{2}{|c|}{ Sorered Busmess Fed Extrapolation ? } \\
\hline \multicolumn{2}{|c|}{ Input Assumptions } \\
\hline BFLTFRAC $_{\mathrm{MAN}}$ & $40 \%$ \\
\hline BFLTFRAC & $61.2 \%$ \\
\hline Base Year. & 1971 \\
\hline \multicolumn{2}{|c|}{ Regression Output } \\
\hline$k_{2}$ & -0.0404 \\
\hline $\mathrm{R}^{2}$ & 0.839 \\
\hline
\end{tabular}

Figure F-9: EPACT Effects on Business Fleet Automobiles

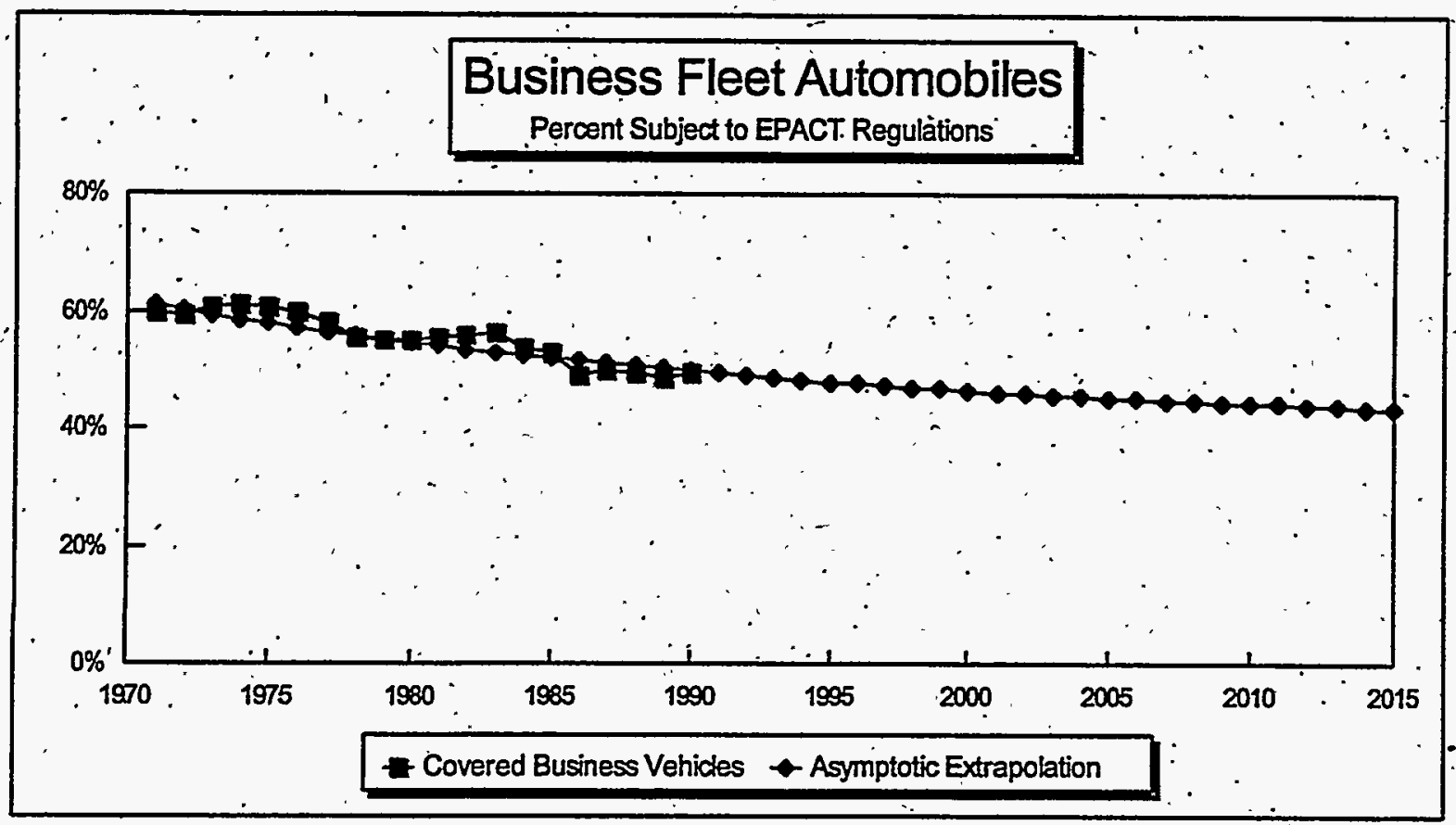




\section{Distribution of Fleet Light Trucks}

As noted in the amended documentation, the Light Duty Vehicle Fleet Module first estimates the sales of light trucks to fleets as follows:

$$
\text { FLTSAL }{ }_{V T=2, T T Y, T}=F L T T R A T \cdot S Q D T R U C K S L_{T} \cdot F_{T S T H R}
$$

where:

FLTSAL $=$ Sales to fleets by vehicle and fleet type

FLTTRAT = Fraction of total truck sales attributed to fleets

SQDTRUCKSL $=$ Total light truck sales in a given year, obtained from the NEMS Macroeconomic Module

FLTSHR = Fraction of fleet trucks purchased by a given fleet type

$V T=$ Index of vehicle type: $1=$ cars, $2=$ light trucks

ITY = Index of fleet type: $1=$ business, $2=$ government $3=$ utility

The fleet allocation factor, FLTTRAT, has been previously extracted from data provided in the $\because$ Transportation Energy Data Book, ${ }^{52}$ which provides and estimate of the fraction of light trucks sold for personal use, and a survey of fleet vehicles; 33 which provides a mechanism for further stratifying non-personal sales into fleet/non-fleet categories. Under the current revision, only the personal/nonpersonal distinction is used, with all non-personal sales of light trucks being allocated to the fleet module. There are two reasons to re-estimate the value of FLTTRAT rather than merely redefining it as the percentage of trucks sold for non-personal use: first, the value of the personal-use sales share reported by ORNL is derived from the 1987 TIUS, which has been superseded by the recently published 1992 survey; and second, because TIUS does not survey government and publicly-owned vehicles, the sales share derived from its summary tends to overestimate the fraction of LDT's sold for personal use. A derivation of the updated value for FLTTRAT follows.

In estimating this factor, it is necessary to combine elements of two different data samples: the relevant components of TIUS, $: .54$ and the annual data collected by FHWA. ${ }^{55}$. Although these surveys are drawn from different populations and are not directly comparable, it is assumed that the

${ }^{52}$ Transportation Energy Data Book: Edition 12, Oak Ridge National Laboratory, ORNL-6710, March 1992, Page $\mathrm{A}-12$.

${ }^{53}$ Fleet Vehicles in the United States: Composition, Operating Characteristics, and Fueling Practices, Oak Ridge National Laboratory, ORNL-6717, May 1992.

${ }^{54} 1992$ Census of Transportation:- Truck Inventory and Use Survey, U.S. Department of Commerce, Bureau of the Census, TC92-T-52, May 1995.

${ }^{55}$ Highway Statistics 1992, U.S. Department of Transportation, Federal Highway Administration, FHWA-PL-93-023. 
relationships among elements of one data set are also valid in the other. Vehicle characteristics from the 1992 FHWA survey are tabulated below:

\begin{tabular}{|c|c|c|}
\hline Total Number of Trucks. (All Typés) & $45,504,067$ & \multirow{2}{*}{ Table VM-1 } \\
\hline Toțal Light Duty Trucks (2-Axle, 4-Tire) & $39,533,142$ & \\
\hline Total Federally-Owned Trucks & 281,623 & \multirow{2}{*}{ Table MV-1 } \\
\hline Total State \& Municipal Trucks & $1,547,020$ & \\
\hline
\end{tabular}

1) First, the FHWA data is used to estimate the fraction of two-axle, four tire trucks in the truck population:

$$
\text { Percent } L D T=\frac{\text { Total } L D T}{\text { Total Trucks }}=\frac{39,533,142}{45,504,067}=86.88 \%
$$

2). Assuming that the distribution of trucks is uniform across sectors, the number of LDT's owned by federal, state, and municipal agencies can be estimated:

Public $L D T=($ Federal Trucks + State \& Municipal Trucks $) \cdot$ Percent $L D T=1,588,693$

3) Using the numbers.above, the fraction of LDT's owned by public agencies is estimated:

$$
\text { Percent Public LDT }=\frac{\text { Public LDT }}{\text { Total LDT }}=4.02 \%
$$

It is assumed that this figure represents the degree of underestimation of LDT stock in the TTUS survey, which does not include publicly-owned vehicles.

4) To reconcile this discrepancy, the total number of privately-owned LDT's from the TIUS microdata file (on CD-ROM) is subsequently adjusted: 


\section{Implied TIUS LDT Population $=\frac{\text { Total TTUS LDT }}{1-\text { Percent Public } L D T}$}

5) Using TIUS estimates of the number of LDT's employed for personal use, the percentage of personal-use trucks can then be calculated:

$$
\text { Percent Personal LDT }=\frac{\text { Total TIUS Personal LDT }}{\text { Implied TiuIUS LDT }}
$$

6) Finally, the percentage of:LDT's assigned to the Fleet Module is simply calculated:

$$
\text { Fleet Percent }=\text { FITTRAT }=(1-\text { Percent Personal LDT })
$$

The results are tabulated below.

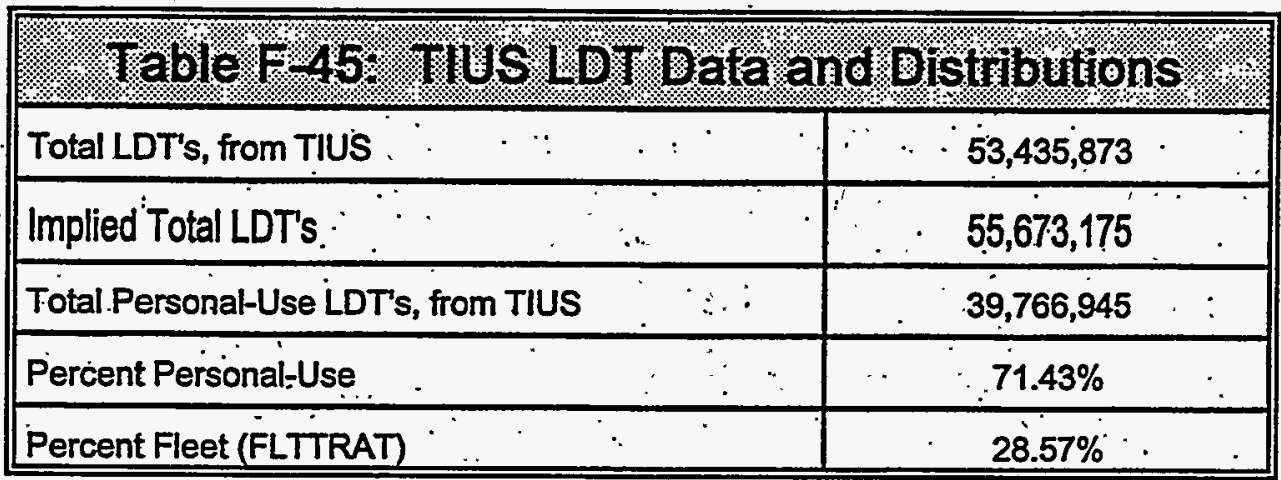

The use of this revised allocation factor will result in a more accurate distribution of light-duty trucks in both the persional-use and fleet modules.

\section{Fleet Share Distribution}

The above information, combined with vehicle-use information from TIUS can be used to reestimate the allocation of trucks among fleet types. This parameter, FLTTSHR, allocates total fleet LDT purchases àmong business, government, and utility fleets according to a fixed ratio, the derivation of which has not been previously documented. Using the implied estimate of the number of publicly-owined LDT's, presented above, and TIUS estimates of the number of utility and commercial LDTs (excluding those used for personal transport), the following distribution has been incorporated into the LDV Fleet Model. 


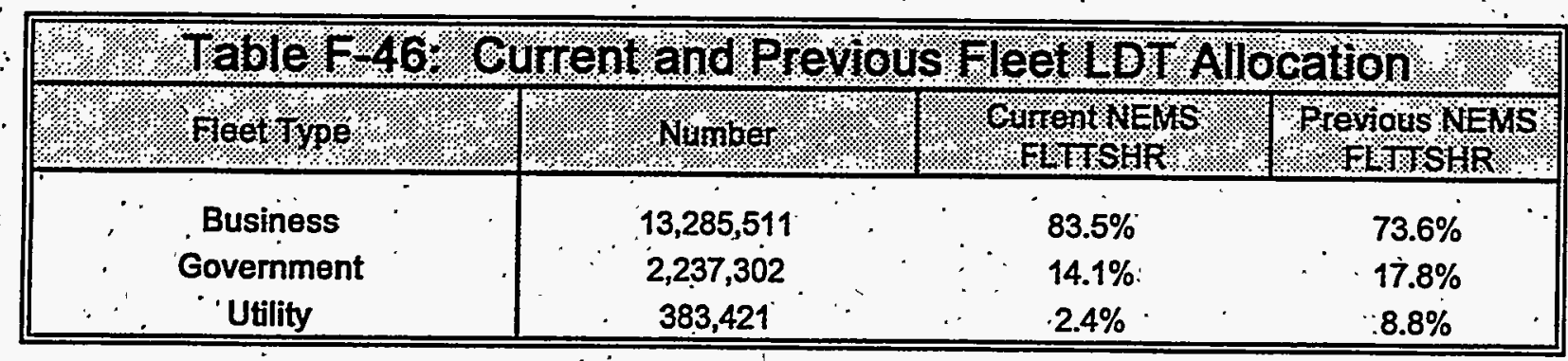

\section{Vehicle Distribution Within Fleets}

Under the provisions of EPACT, purchases of vehicles by fleets meeting certain criteria are affected by the requirement that a proportion be alternatively fueled. The specific conditions under which these provisions are in effect; and the fleet sizes which are affected are not static, but are subject to revision. Obtaining an accurate estimate of the number of automobiles in fleet service is necessary in order to derive a forecast of the purchase of alternative fuel vehicles mandated under EPACT; and the consequent demand for petroleum, electricity, and alternative fuels used for transportation. 'Under the previous model, a fixed proportion of annual automobile and light truck sales (which were exogenously obtained) were assigned to business, utility, and govemment fleets. As the alternative fuel provisions of EPACT attach to fleets at or above a given size, it is important to develop a means of estimating the affected population of vehicles under the current, or any future definition of a "fleet". Due to the dissimilarities of the data available, separate approaches have been developed for light trucks and automobiles, as described below.

\section{Trucks}

The proposed approach uses the fleet-size data from the TIUS survey to derive a functional form for estimating the affected population of LDT's in fleets. The applicability of this approach is constrained by the aggregate nature of the survey, but should serve as a good first approximation. The first step is to look at the distribution of trucks by fleet type; only business and utility fleets are considered as all government vehicles are assumed to be affected by the legislation (and are not represented in TIUS). The number of trucks within each considered fleet type, stratified by fleet size, are tabulated below. These distributions are also graphically depicted on the following pages. It is clear from these figures that business and utility fleets have significantly different size 'characteristics, as is to be expected. Most commercial light trucks exist in fleets of less than 20 vehicles, and are therefore unaffected by EPACT legislation, while the overwhelming majority of utility vehicles are in large fleets. 


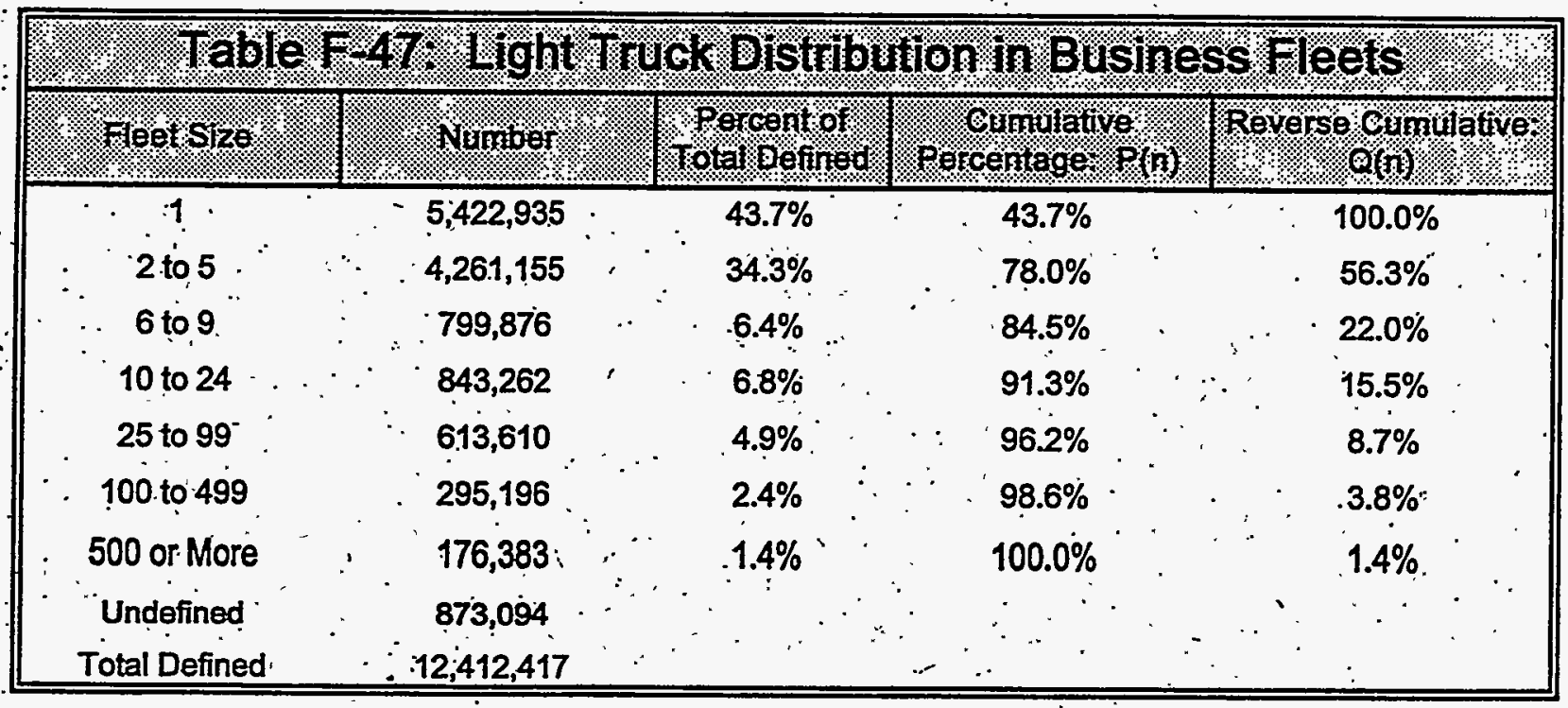

\begin{tabular}{|c|c|c|c|c|}
\hline \multicolumn{5}{|c|}{ (1.: } \\
\hline Heersize & (4., & Torcentof & Percontage & Reverse Gunglative \\
\hline 1 & $\therefore 25,677$ & $6.8 \%$. & $6.8 \%$ & $100.0 \%$ \\
\hline 2 to 5 & 18,573 & $.4 .9 \%$ & $11.8 \%$ & $93.2 \%$ \\
\hline 6 to 9 & 24,296 & $6.5 \%$ & $18.2 \%$ & $88.2 \%$ \\
\hline 10 to 24 & 38,717 & $10.3 \%$ & $28.6 \%$ & $81.8 \%$ \\
\hline 25 to $99^{\circ}$ & $=59,301$ & $15.8 \%$ & $44.3 \%$ & $71.4 \%$ \\
\hline 100 to 499 & 49,294 & $13.1 \%$ & $57.5 \%$ & $55.7 \%$. \\
\hline 500 or More & 159,804 & $42.5 \%$ & $100.0 \%$ & $42.5 \%$ \\
\hline Undefined & ' $\quad 7,759$ & & & $\therefore$ \\
\hline Total Defined & 375,662 & & & \\
\hline
\end{tabular}


Figure F-10: Business Fleet LDT Distribution

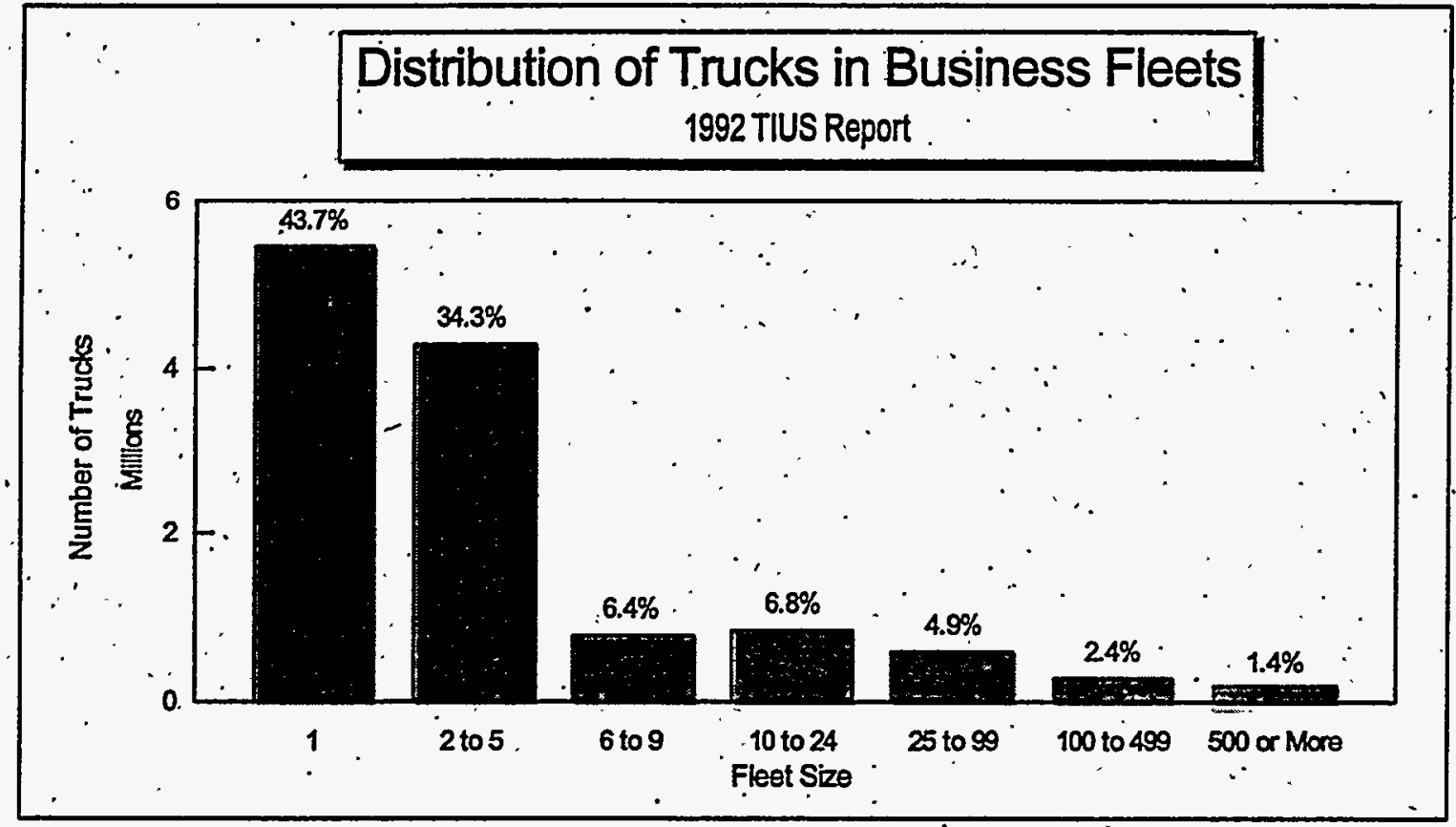

Figure F-11: Utility Fleet LDT Distribution

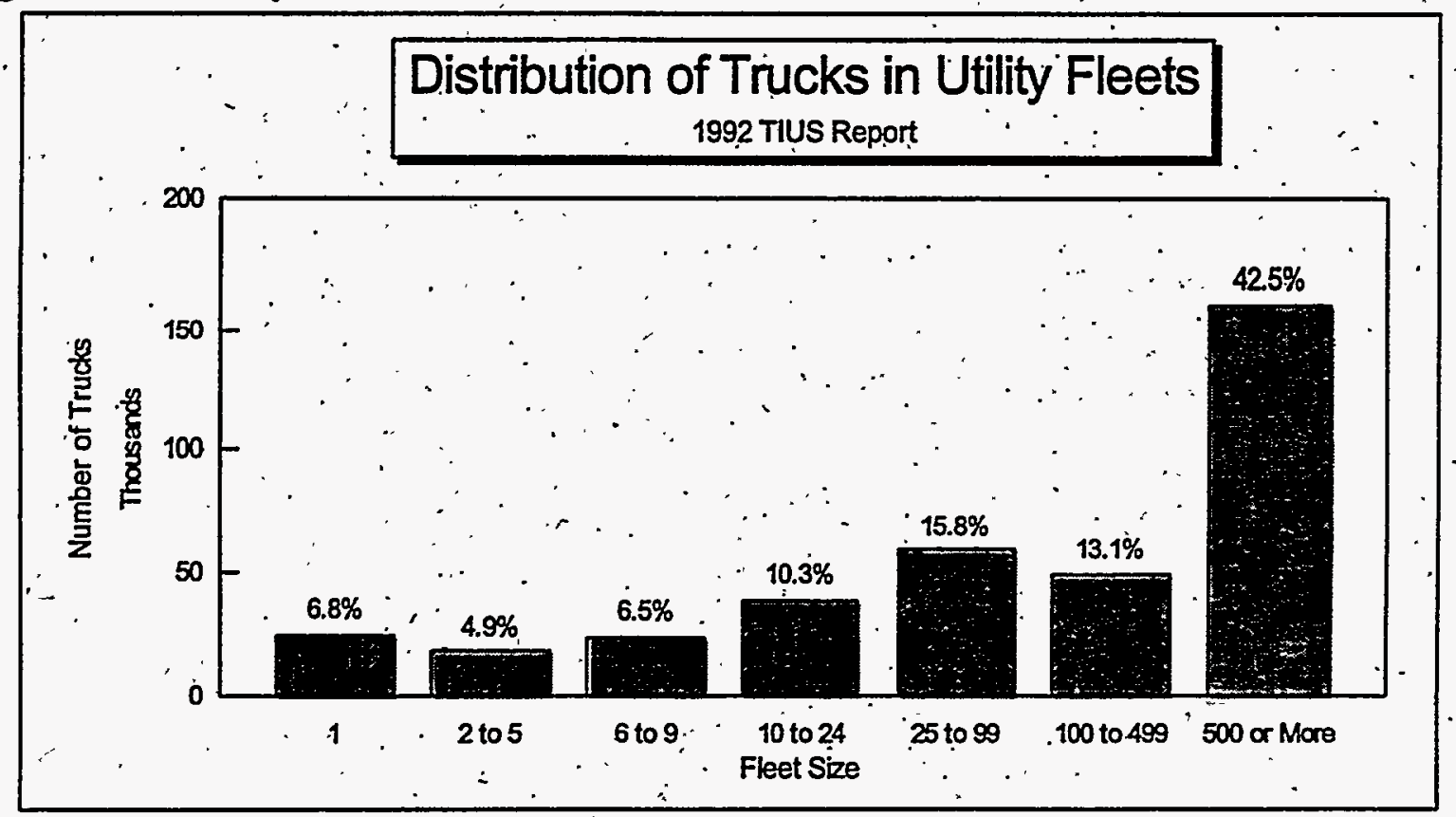

As the strata defined in the TIUS survey do not correspond to the fleet sizes addressed in EPACT, it is necessary to derive a functional form for each distribution. This is accomplished by considering the cumulative distribution of fleet trucks $\mathrm{P}(\mathrm{n})$, or, more accurately, its complement: $\mathrm{Q}(\mathrm{n})$, referred to, for lack of a better term, as the reverse cumulative distribution. This distribution describes the 
number of trucks in fleet sizes greater than or equal to $n$, as depicted below.

Figure F-12: Distribution of LDT's, by Fleet Size

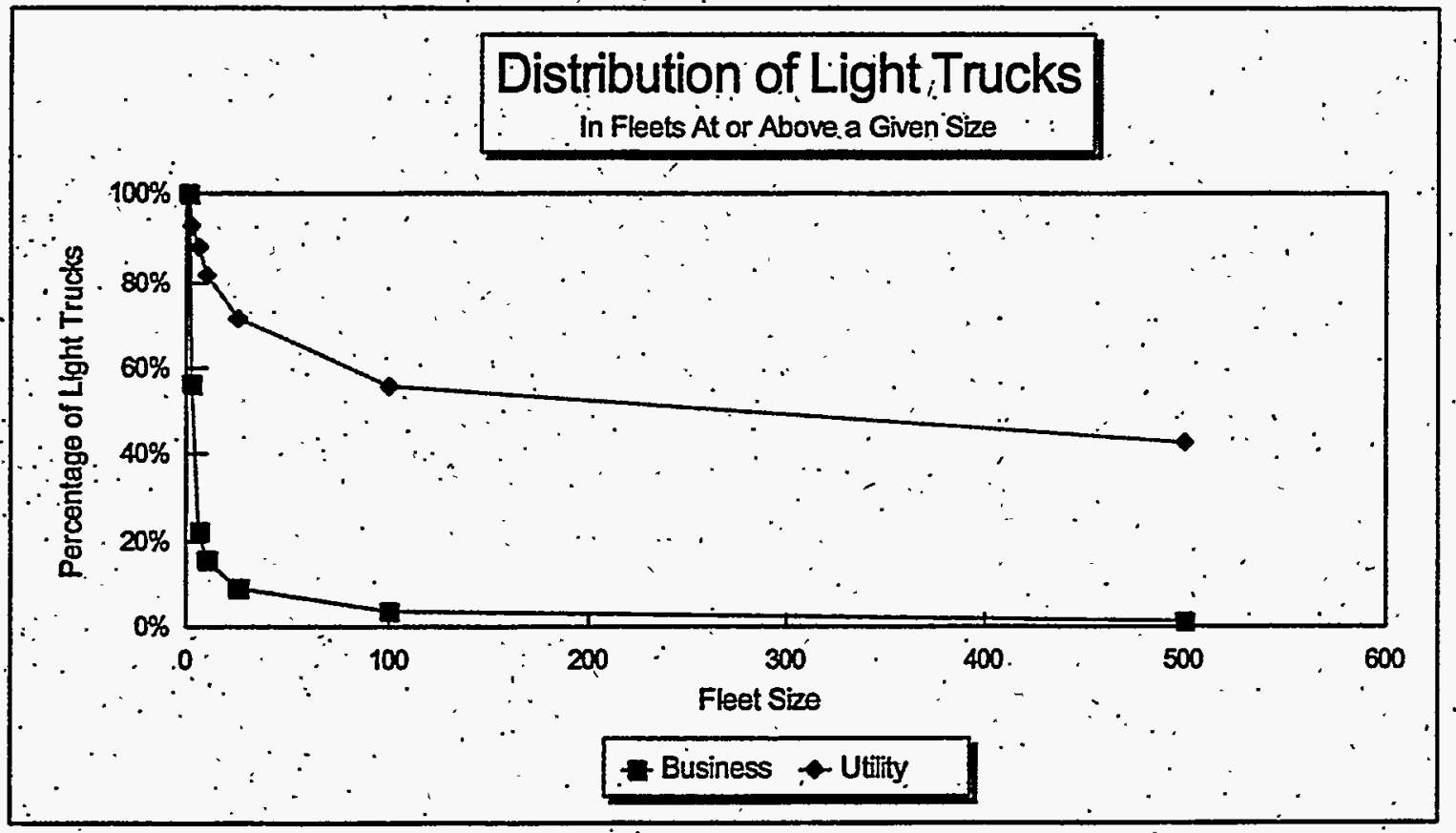

Figure-F-13: Distribution of LDT's, by Fleet Size (Logarithmic Scale)

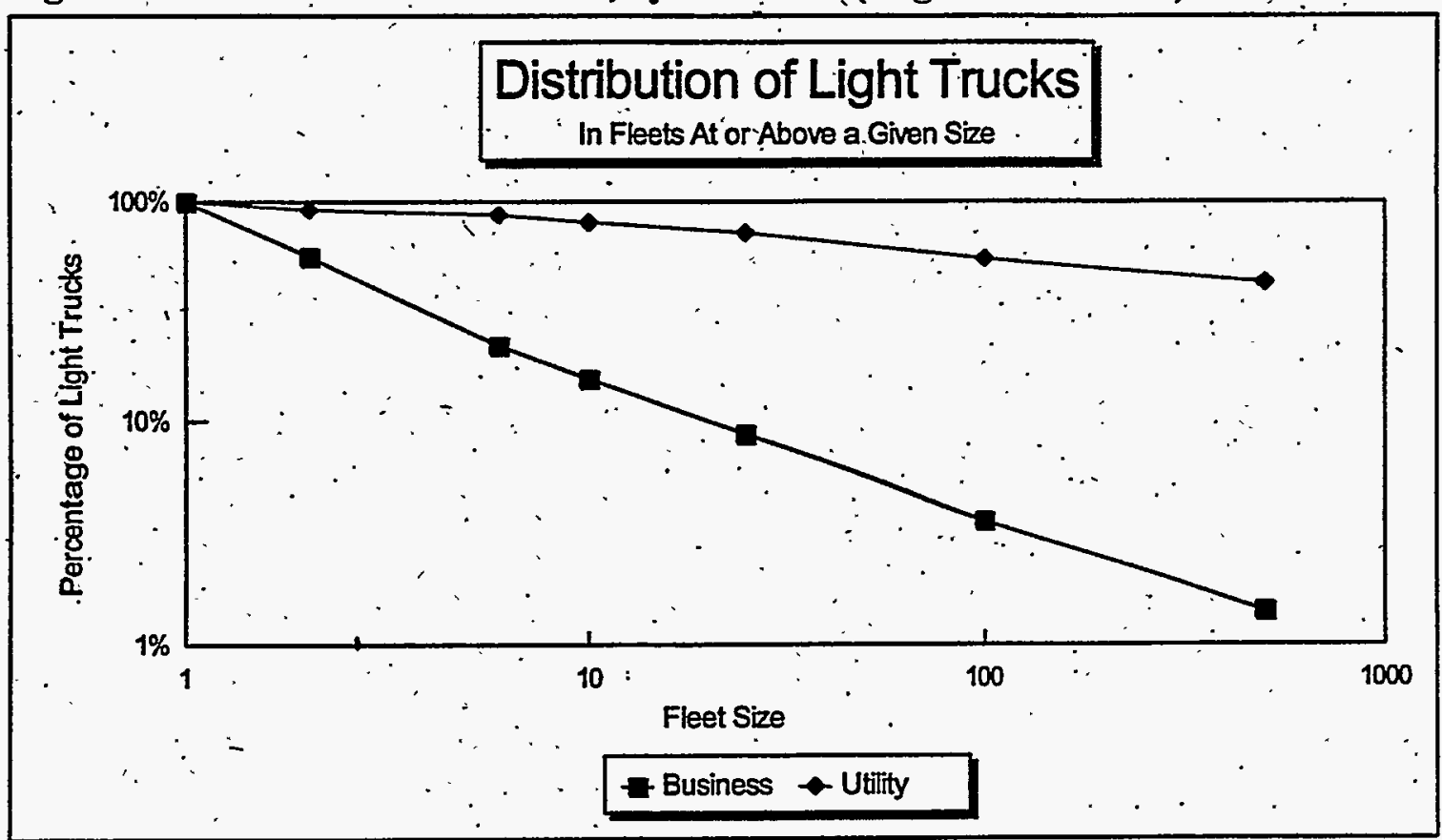


The most straightforward method of estimating a functional form is to transform the data so that it approximates a linear relationship, then use OLS to estimate the coefficients. As the figure above shows, plotting both axes logarithmically produces a reasonable approximation of linearity. This suggests the following form:

$$
\begin{gathered}
\operatorname{In} Q(n)=k \operatorname{Ln}(n) \\
\text { or } \\
\because Q(n)=n^{k}
\end{gathered}
$$

where:

$$
\begin{aligned}
& Q(n)=\text { The reverse cumulative distribution: the percentage of trucks in fleets of size greater than } \\
& \text { or equal to } n .
\end{aligned}
$$

\begin{tabular}{|c|c|c|c|c|}
\hline $1.1 .1 \% .1 .1 \% \mathrm{labe}$ & $49 \%$ gegles & Sion & OUPut $\%$ & 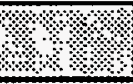 \\
\hline 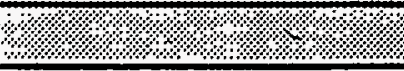 & Business & & \% Utility & 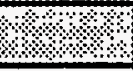 \\
\hline Constant & 0 & & 0 & , \\
\hline Coefficient (k) & -0.747 & $\because$ & -0.111 & \\
\hline Standard Errợ. & 0.020 & & 0.008 & - \\
\hline T-Statistic & -36.63 & & -13.22 & \\
\hline R Squared & 0.988 & & 0.937 & \\
\hline
\end{tabular}

Testing this approach with the data described above provides the results tabulated below. The significance of the coefficients and the high $\mathrm{R}$-squared gives confidence that this formulation will provide a satisfactory means of estimating the affected light truck population in business and utility fleets. A plot of these functions over TIUS data is provided below. 


\section{Figure F-14: Distribution of LDT's (Estimated Functional Form)}

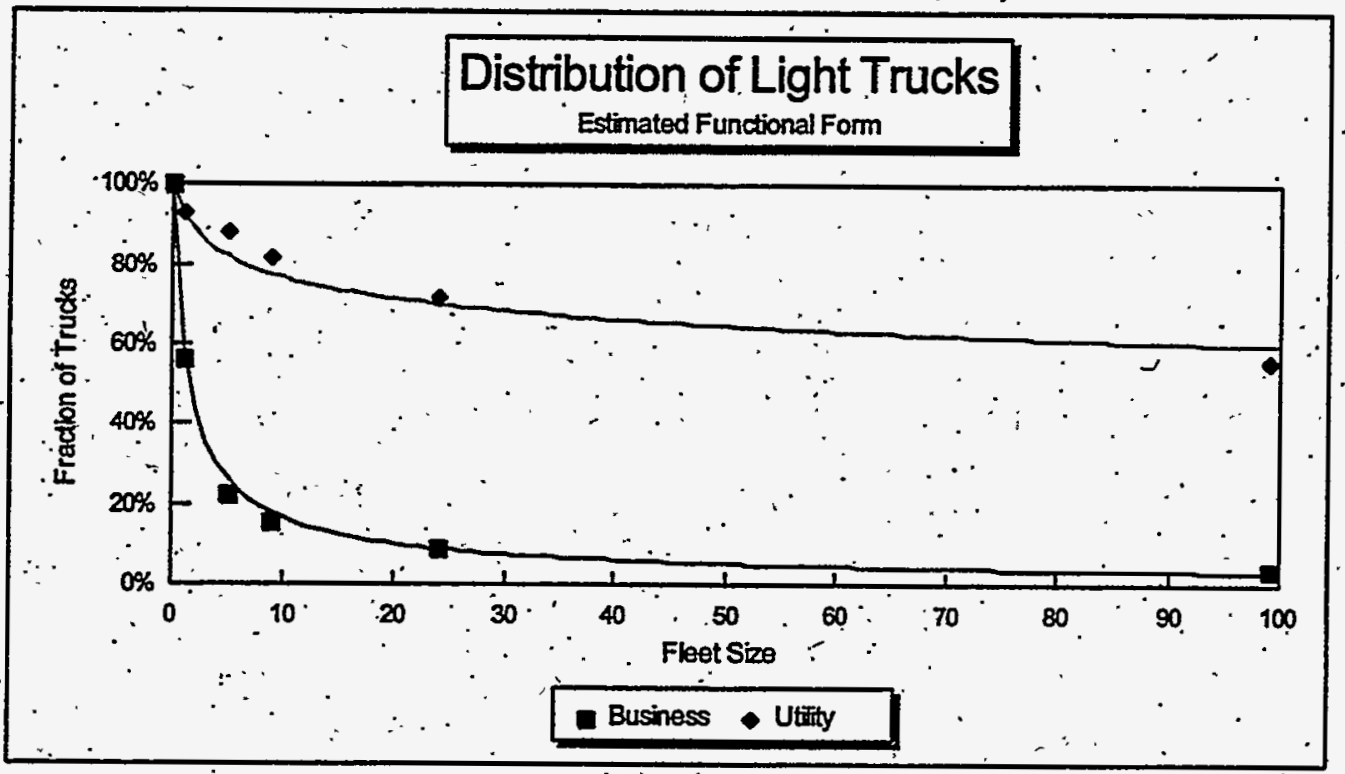

Applying this function permits a stratification of light trucks into three groups: non-fleet $(<20$ vehicles), small fleet (20-50 vehicles) and large fleet ( $>50$ vehicles). The distribution of these percentages, by fleet type, are tabulated below. It should be noted, once again; that publicly-owned vehicles (federal; state, and municipal) are not subject to the fleet-size constraints, and are therefore not similarly stratified. Insofar as different components of the publicly-owned fleet of LTD's have differentacquisition requirements under EPACT, it is suggested that a sales-weighted average of the requirements be used.

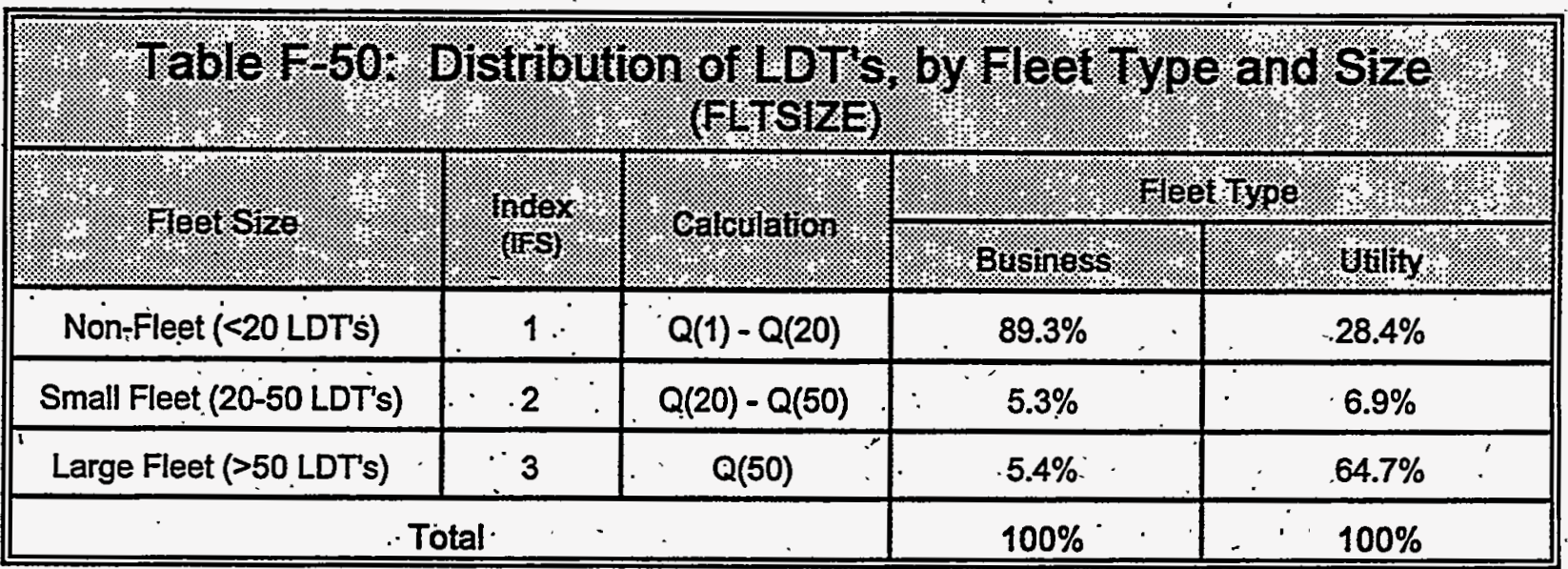




\section{Automobiles}

In a report on the characteristics of fleet.vehicles in the United States, ${ }^{56}$ Oak Ridge Natiional Laboratory notes that no comprehensive nationwide automobile fleet vehicle survey is currently available. This stands in contrast to the abundance of census data available for the analysis of U.S. trick populations, and inhibits the development of a methodology to estimate the number of fleet, vehicles covered by EPACT regulations. The 1992 Automotive Fleet Fact Book, ${ }^{57}$ which provides summary characteristics of fleet vehicles, represents the sole source of data used in constructing the following distribution.

Given the limitations of the data, several assumptions and manipulations are necessary to transform the published data into a form commensurate with the needs of the model. It is first assumed that both Government and Utility fleets are large enough to be affected by EPACT regulations, obviating the need for further analysis of their distributions. It is also assumed that the number of vehicles in business fleets should not include employee-owned, daily rental; or individually-leased vehicles, as these are outside the purview of the legislation. This exclusion is accomplished through the use of the function BFLTFRAC, described above. Aggregating business fleet data and subtracting excluded vehicles results in the distribution provided in the table below. As there are only three data points, this effectively precludes the use of regression analysis to estimate a distribution function for business fleet vehicles. The alternative is to assume the simplest functional form which can be adjusted to approximate the desired distribution. After testing a variety of specifications, the form selected is as follows:

$$
Q(n)=\frac{k_{3}}{\operatorname{Ln}(n)}
$$

where:

$$
\begin{aligned}
\mathrm{Q}(\mathrm{r}) & =\text { The percentage of vehicles in fleets of size greater than or equal to } n \\
\mathrm{k}_{3} & =\text { The constant of proportionality; chosen by normalizing the function to } 1.0 \text { when } n=4 ; \\
& \text { estimated to be } 1.386
\end{aligned}
$$

${ }^{56}$ Fleet Vehicles in the United States: Compósition, Operating Characteristics, and Fueling Practices, Oak Ridge National Laboratory, ORNL-6717, May 1992.

${ }^{57}$ Automotive Fleet Fact Book.1992. Bobit Publishing Company, pp. 16, 20. 


\begin{tabular}{|c|c|}
\hline \multicolumn{2}{|c|}{ Table F 51 . 1992 Bobil Fleet Bata } \\
\hline 7 mieat Typo & $\begin{array}{l}\text { Nomber of Vehicles } \\
\text { (Thousands) }\end{array}$ \\
\hline Business Fleets (by Size) & \\
\hline$>=4$ Vehicles & 5,261 \\
\hline$\nu=10$ Vehicles & 2,820 \\
\hline$>=25$ Vehicles & 2,323 \\
\hline Government Fleets & 504 \\
\hline Utility Fleets & 544 \\
\hline
\end{tabular}

This function is graphically displayed below, along with the original data. Applying this function permits a stratification of business fleet automobiles into three groups: non-fleet ( $<20$ vehicles), small fleet (20-50 vehicles) and large fleet ( $>50$ vehicles). The distribution of these percentages is tabulated below.

\section{Figure F-15: Distribution of Business Fleet Vehicles}

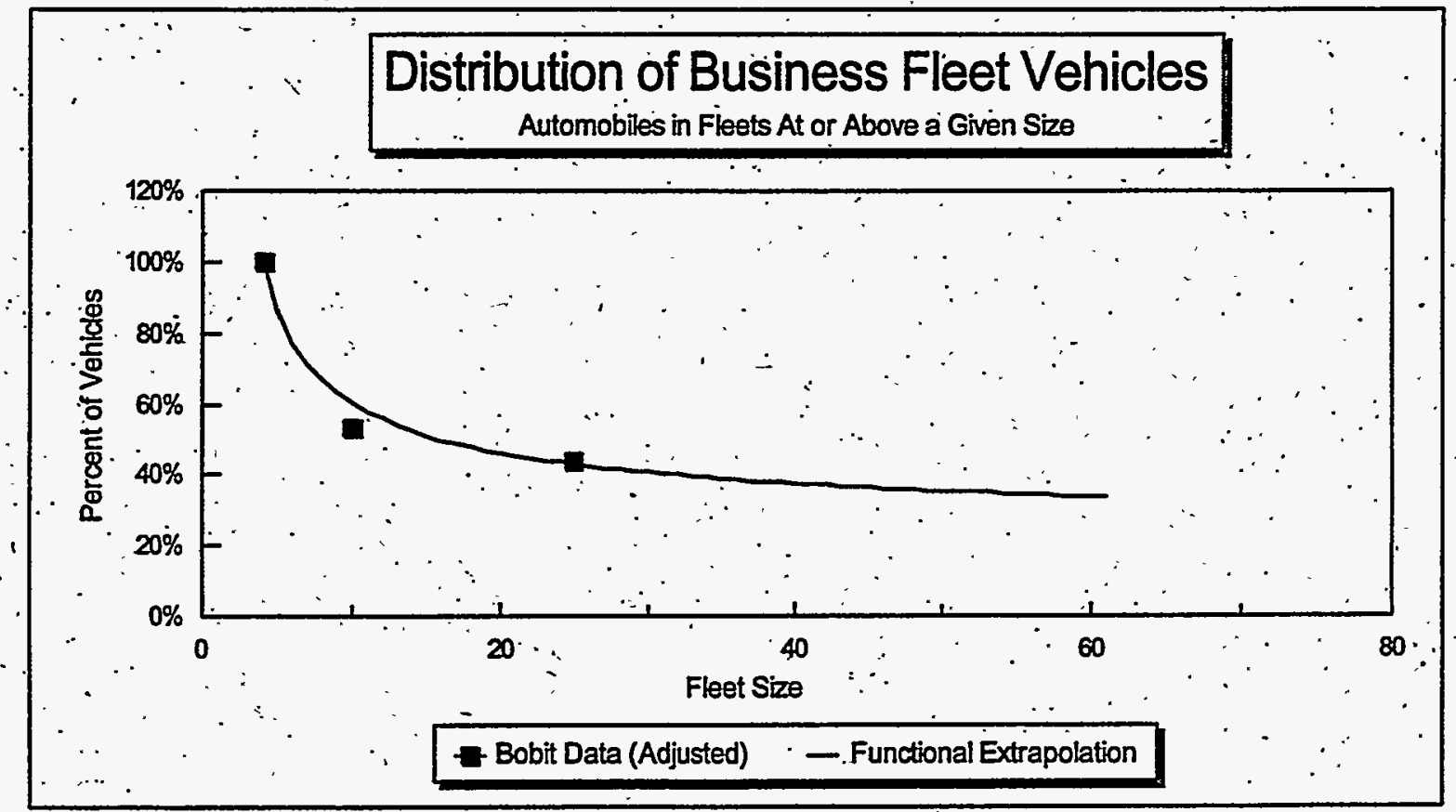




\begin{tabular}{|c|c|c|c|}
\hline \multicolumn{4}{|c|}{ 1.able } \\
\hline \% & $1 \%$ ofest: & Catculation: & $14.6 \%$ Perent. \\
\hline Non-Fleet (<20 Cars) & 1 & $Q(1)-Q(20)$ & $53.7 \%$ \\
\hline Small Fleet (20-50 Cars) : & 2 & $Q(20)-Q(50)$ & $10.8 \%$ \\
\hline Large Fleet (>50 Cars) & 3 & $Q(50)$ & $35.4 \%$ \\
\hline Tota & & & $100 \%$ \\
\hline
\end{tabular}

The incorporation of these modifications will, in all likelihood, not result in significant changes in the output of the NEMS Transportation Model, but will more easily permit the inclusion of users' assumptions and will be able to withstand a higher level of scrutiny of the methodology. 
I
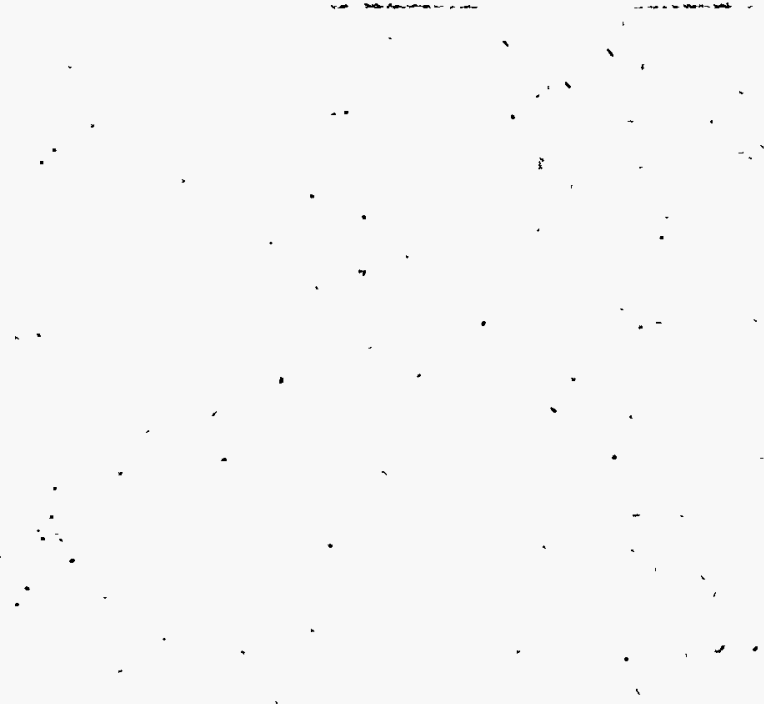


\section{Attachment 5:. Light Commercial Truck Model .}

\section{Data Development for the LCT Model}

The primary source of data for this model is the microdata file of the 1992 Truck Inventory and Use Survey (TIUS), which provides numerous details on truck stock and usage patterns at a high.level of disaggregation. The data derived from this source are used to allocate and sort the summary truck data presented in the Federal Highway Administration's annual publication of highway statistics, which constitute the baseline from which the NEMS forecast is made. TIUS data are also used to distribute estimated sales of truckss, obtained from the Macroeconomic Model, among the affected models according to their weight class. Finally, the TIUS microdata set is used to construct $a$ : characterization of these Light Commercial Trucks, comprising their average annual miles of travel, fuel economy, and distribution among several aggregate industrial groupings chosen for their correspondence with output measures currently being forecast by NEMS. It is expected that projected growth in industrial output will provide a useful proxy for the growth in demand for the services of light commercial trucks. This issue will be addressed later in this section.

\section{Distribution of Truck Stock}

The principal source of confusion and double-counting encountered in the truck models stems from differing definitions of what constitutes a light truck among the data sources used by NEMS. In the past, FHWA's estimate of 2-axle, 4-tire trucks have been interpreted as representing light-duty trucks, less than $8,500 \mathrm{lbs}$, and therefore properly within the purview, of the LDV Module. Likewise, sales estimates from the Macro Model have been assumed to represent only LDT's, and have been similarly assigned. On closer examination, neither of these assumptions can be shown to have been justified.

Using the information derived from TIUS, it is estimated that of the 2-axle, 4-tire trucks, approximately 88 percent of the pickup trucks and 85 percent of the other trucks (vans, panel trucks, etc.) fall into that weight range. The remainder properly belong in the newly-established LCT category. Similarly, sales estimates from the Macro Model have been shown to represent sales of trucks under $14,000 \mathrm{lbs}$, indicating a significant overlap across the LCT weight range and into the medium freight truck category. Using the weight distributions by truck type available from TIUS, a suggested stratification scheme may be proposed. Table F-53, below, presents the TIUS estimates of single-unit truck stock, stratified by axle configuration, body type, and weight. While there are significant discrepancies between FHWA's summary stock figures and those presented below (see Table F-65), it is assumed that the relative distribution of trucks within each grouping is constant, 
and transferrable between samples.

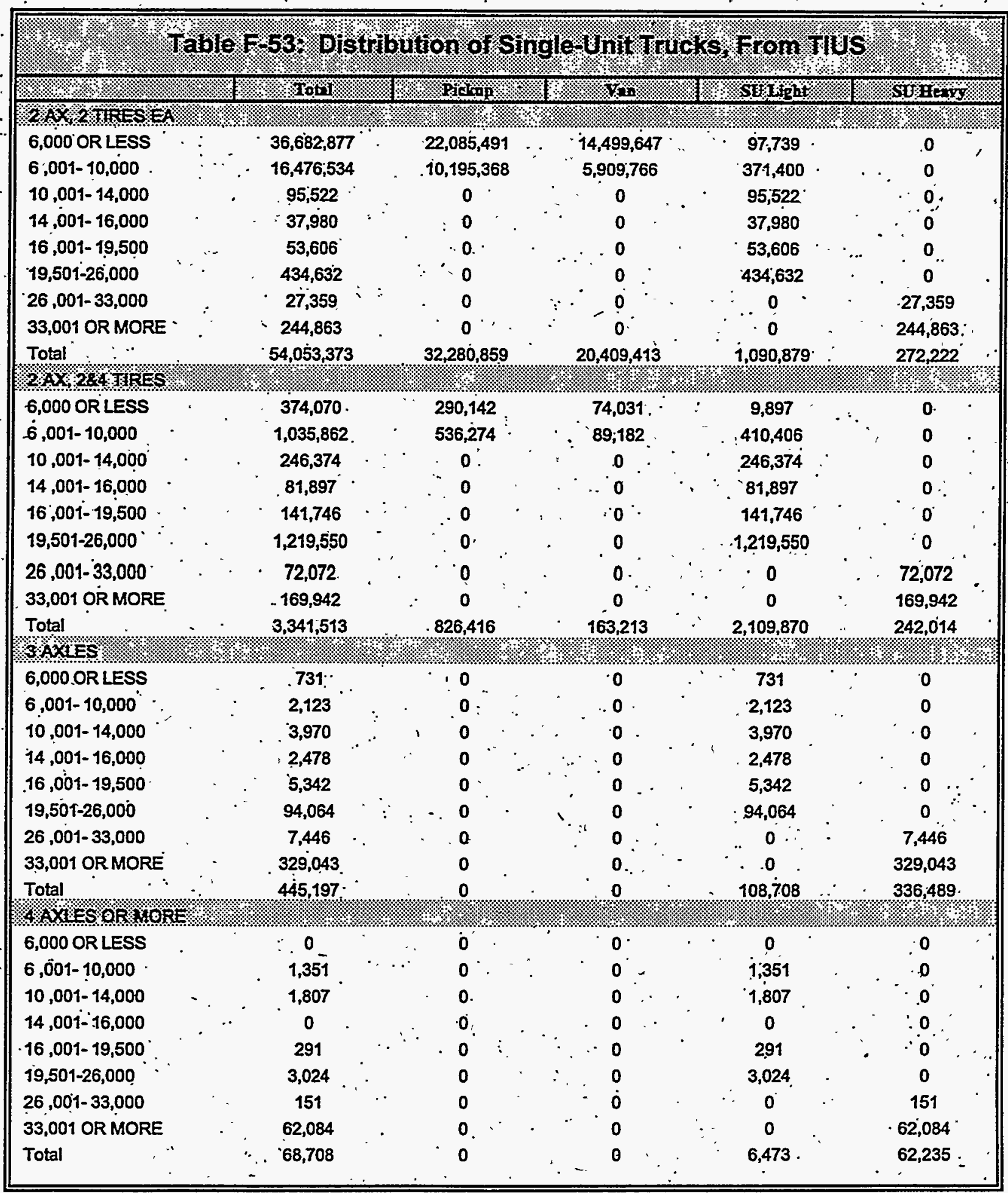

.. The data above can be used to estimate the fraction of single-unit trucks in the FHW.A sample which. 
are less than or equal $10,000 \mathrm{lbs}$., the upper bound of the LCT weight class. Aggregating the sample numbers and calculating the percentages in the relevant groups provides the winnowing factors in the table below.

\begin{tabular}{|c|c|c|c|c|c|c|}
\hline \% & $\%$ Table: & Sro & SHomes & Single. & Hivucks: & \% \\
\hline & AlH. & & Futck 8. & $0,000 \% 405$ & \% & K.6. \\
\hline namber & $2.2 \mathrm{A4T}$ & Wother & Wrak4X & Kotrat & \% 2AkT & Pother \\
\hline Pickups & $32,280,859$ & 826,416 & $32,280,859$ & 826,416 & $100 \%$ & $\therefore 100 \%$ \\
\hline Other & $21,772,514$ & $3,029,002$ & $20,878,552$ & $587,721^{\circ}$ & $95.89 \%$ & $19.40 \%$ \\
\hline Total. & $54,053,373$ & $3,855,418$ & $\begin{array}{c}53,159,41,1 \\
\vdots\end{array}$ & $1,414,137$ & & \\
\hline \%., & AII & & W. & 0,000 . Eos: & ४\% & \\
\hline$\%$ sercent & 1 & OOthen & .\%2A4⿴囗十 & O\#hex & & ४४ \\
\hline $\begin{array}{l}\text { Pickups } \\
\text { Other }\end{array}$ & $\begin{array}{l}59.72 \% \\
40.28 \%\end{array}$ & $\begin{array}{l}21.44 \% \\
78.56 \%\end{array}$ & $\begin{array}{l}60.72 \% \\
39.28 \%\end{array}$ & $\begin{array}{l}58.44 \% \\
41.56 \%\end{array}$ & & \\
\hline
\end{tabular}

Similarly, the distributions in Table F-53 can be aggregated to determine the allocation of truck sales obtained from the Macro Model, first splitting off that fraction between 10,000 and $14,000 \mathrm{lbs}$., and then distributing the remainder between 2-axle, 4-tire trucks and trucks with other axle configurations, as shown below.

\begin{tabular}{|c|c|c|}
\hline ४ै। & Muck Sales rom & 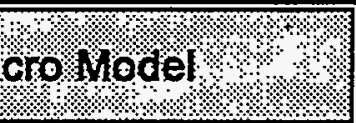 \\
\hline 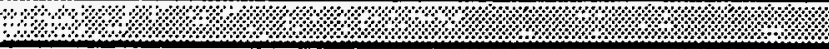 & Total $/ .1$. & Percent + \\
\hline Total SU Trucks $<=14,000$ lbs & $-54,921,221$ & \\
\hline Of Which: $\quad ;$ su Trucks $<=10 ; 000$ lbs. & $54,573,548$ & $99.37 \%$ \\
\hline $\begin{array}{c}\text { Of Which: } \\
\text { 2A4T Trucks }<=10,000 \text { lbs } \\
\text { Other SU Trucks }<=10,000 \text { lbs. }\end{array}$ & $\begin{array}{r}\therefore \quad \\
\quad-1,1414,137\end{array}$ & $\begin{array}{l}97.41 \% \\
2.59 \%\end{array}$ \\
\hline
\end{tabular}


The next step is to determine the fraction of trucks which exceed the $8,500 \mathrm{lb}$. lower bound of the LCT weight category. TIUS, unfortunately, does not provide a breakdown of truck stock along those lines, thus requiring the imputing of the appropriate fractions. After consideration of several options, it has been decided to use a simple linear interpolation of the cumulative share of each truck type between 6,000 and 10,000 lbs. The data and resulting shares are provided in Table F-56, below.

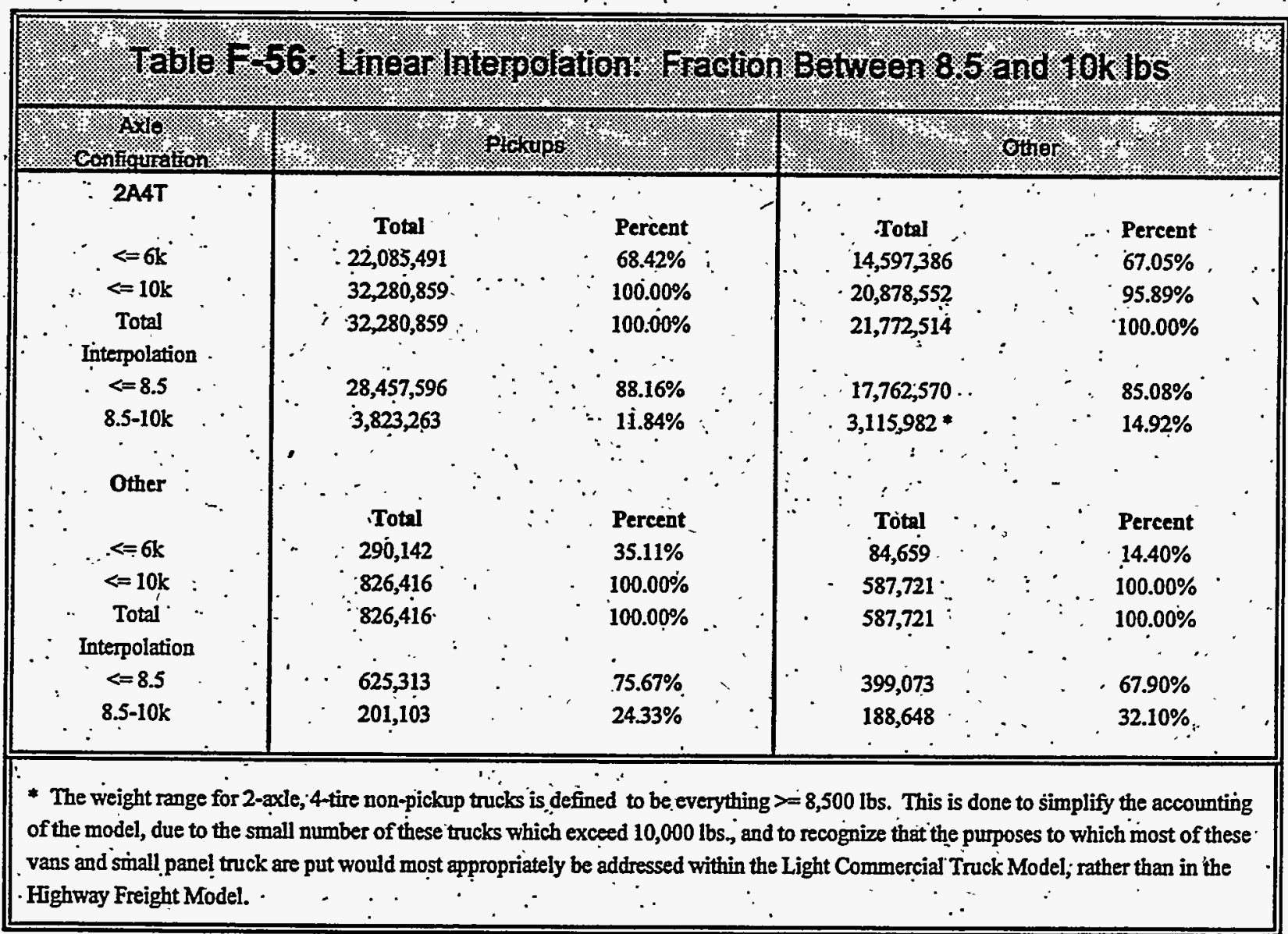

In order to simplify the allocation scheme described above, the distribution of stock and sales are. presented graphically, in Figures F-16 and F-17, below. 
Figure F-16: Distribution of FHWA Single-Unit Truck Stocks

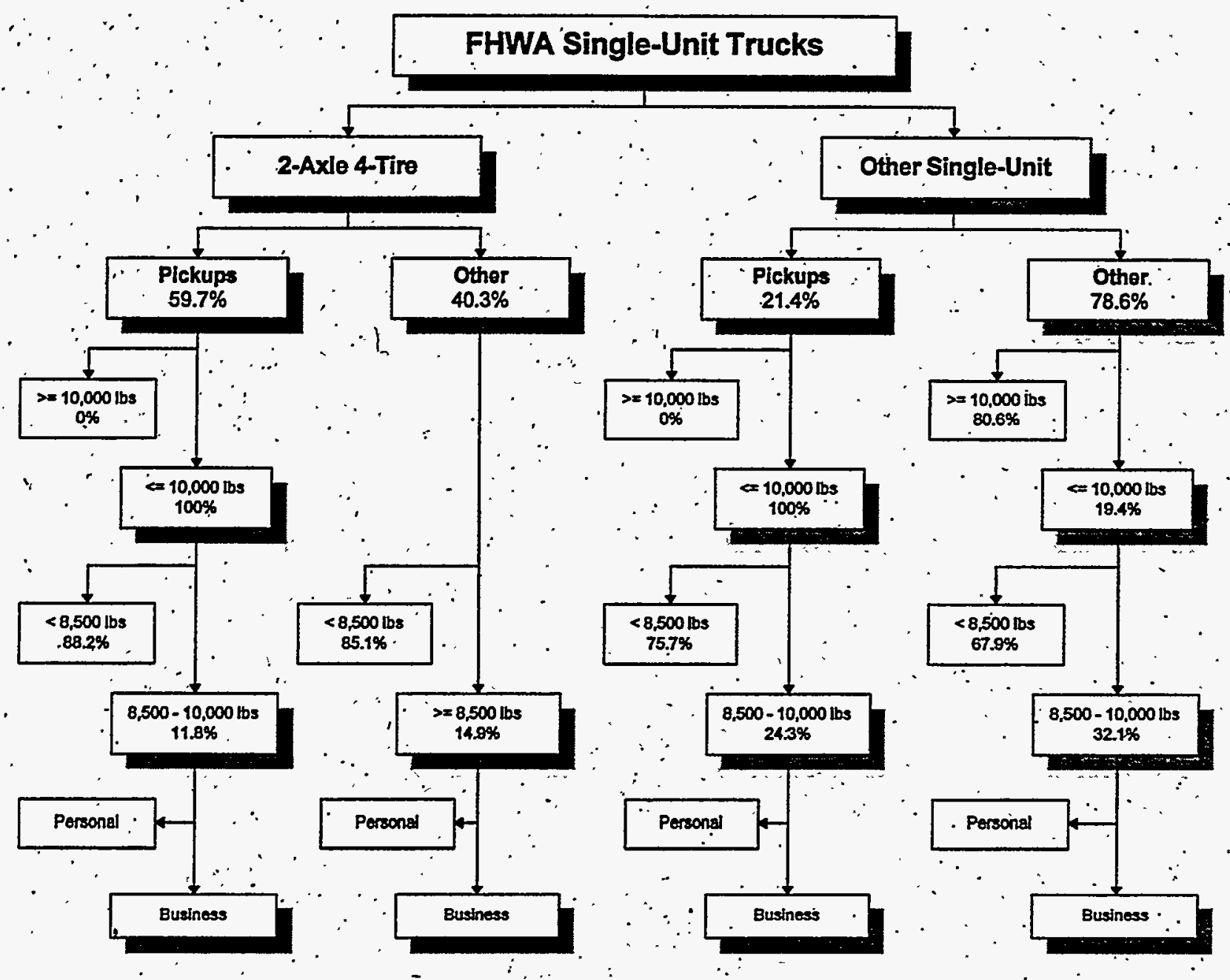


Figure F-17: Distribution of Light Truck Sales

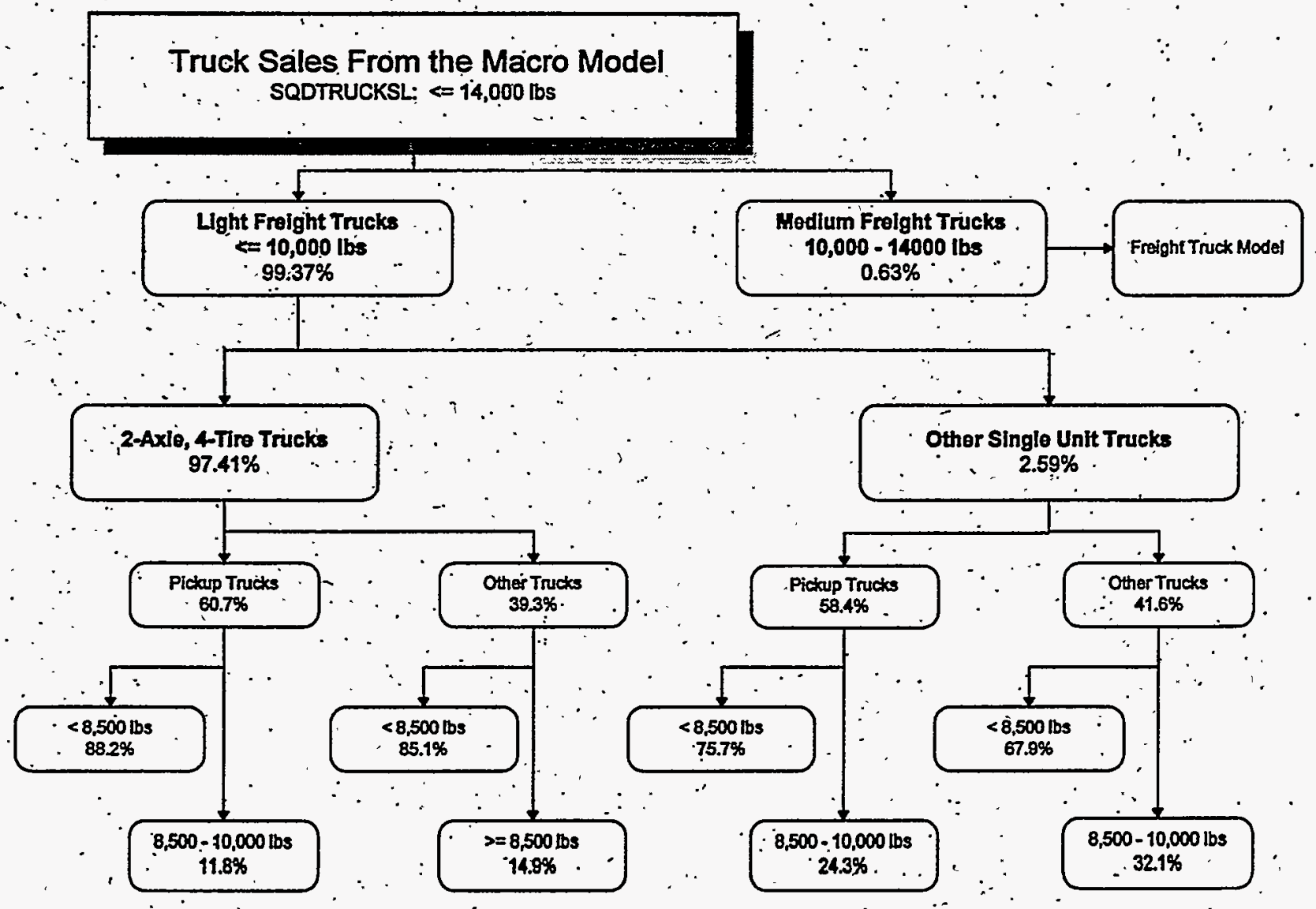




\section{Allocation of Truck Stock Among Industrial Groups.}

In order to develop a forecast of LCT use which is sensitive to economic activity, it is necessary to allocate the trucks according to their major use. TIUS provides an accounting of trucks within sixteen major use categories, not all of which correspond directly with measures of industrial output generated by NEMS. These categories are therefore aggregated into measures which can be addressed within the NEMS structure, as defined below.

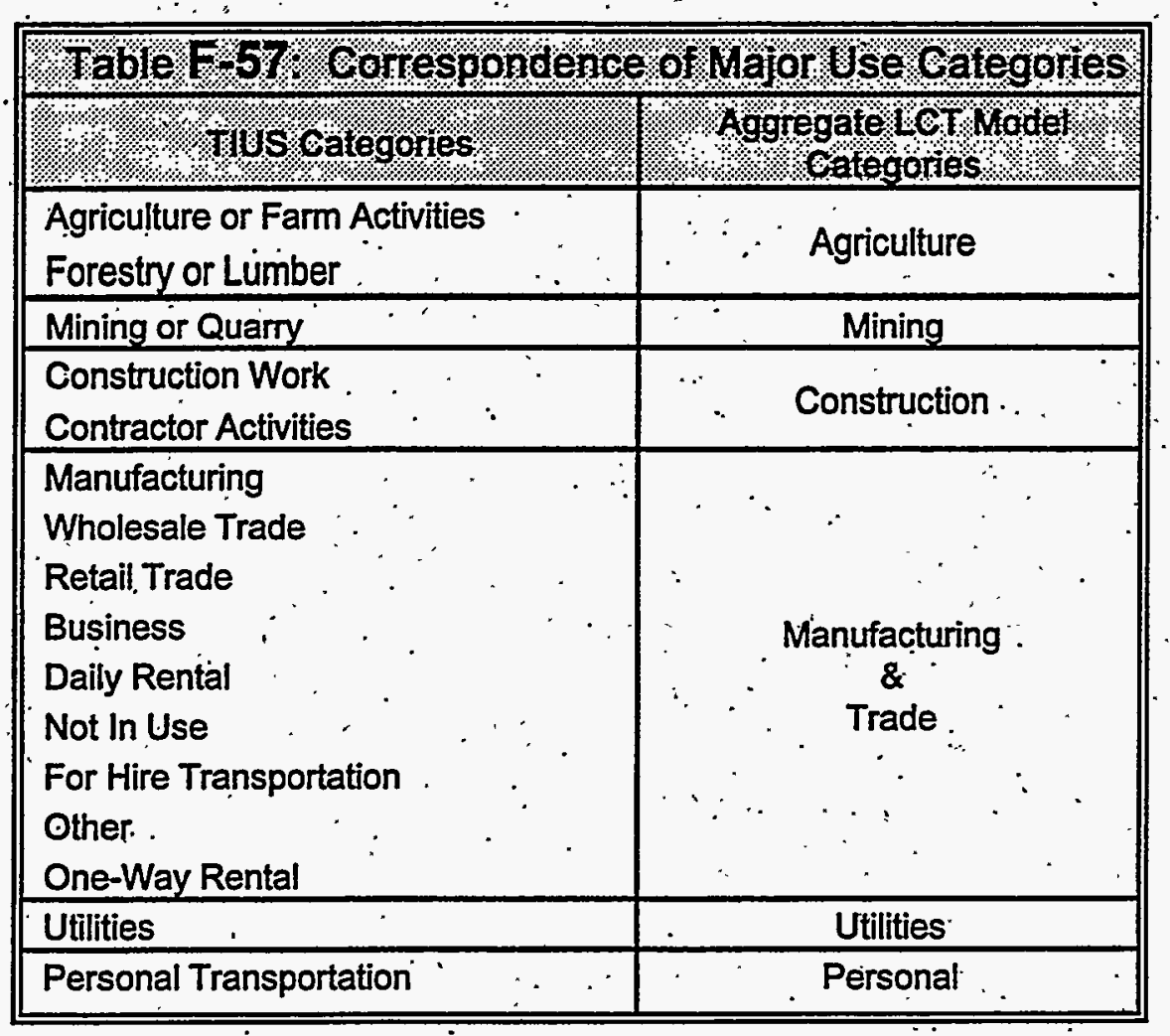

Detailed tables of the distribution of single-unit trucks among both major-use categories are provided in subsequent tables. These data are used to share-out the four types of truck considered by this model. It is assumed that the relative shares of trucks in the 6 to 10 thousand pound weight range is an acceptable proxy for the relative populations of the 8.5 to 10 thousand pound vehicles. The aggregate numbers and the resulting percentages are provided in the following table. It is further assumed that the percentage figures used to allocate the LCT's remain constant, at least until the publication of the next TIUS. These are rather strong assumptions, but appear justified by the paucity of other sources of detailed information about the population and operating characteristics of Light Commercial Trucks. 


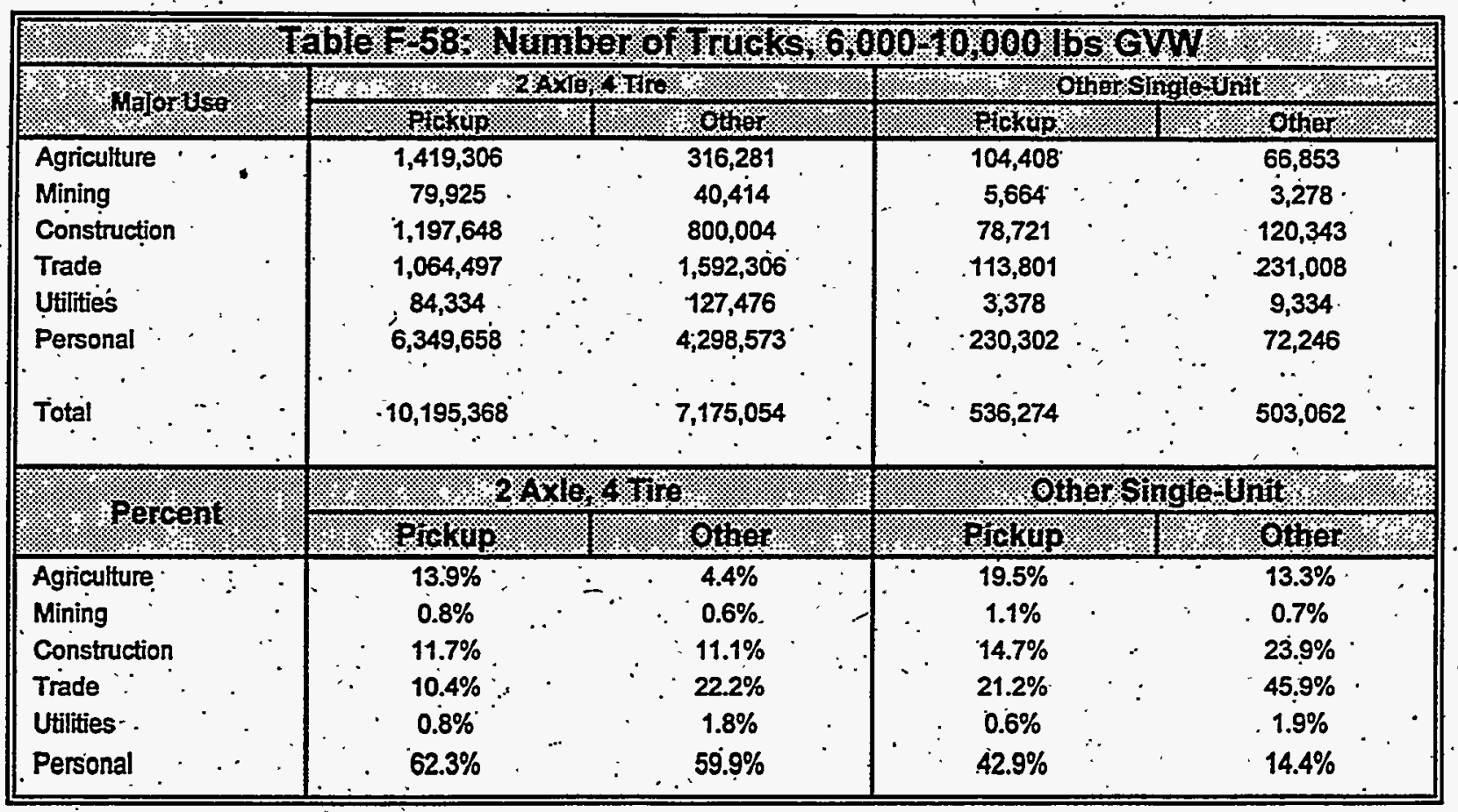

\section{Operating Characteristics}

The operating characteristics of LCT's relevant to forecasting energy demand are the average annual miles per truck driven within each major use category and the corresponding average fuel economy. An extensive sequence of sorting and tabulating procedures has resulted in Table F-59, which provides an estimate of average travel demand for trucks between 6 and 10 thousand pounds. As is done in apportioning trucks among use categories, it is assumed that these driving characteristics are uniform across the weight class, and therefore accurately represent the more narrow LCT category.

\begin{tabular}{|c|c|c|c|c|}
\hline (1. & F59\% & ge A minal wiles & sse & \\
\hline & : & Singlo Unift S S & 108000 & \% \\
\hline Hatar yser. & \% & AXje, 4 - sire & & ati \\
\hline $4+4$ & (1) PICKup & \% & Plakup & Other \\
\hline "Agriculture & 11,920 & 8,569 & 15,197 & 7,054 \\
\hline Mining & 20,231 & 24,871 & 18,520 & 17,786 \\
\hline Construction & 15,909 & 15,195 & 13,043 & 10,074 \\
\hline Trạde & 13,313 & 15,394 & 10,009 & 11,832 \\
\hline Utilities ' & 13,023 . & 13,776 & 9,947 & 9,996 \\
\hline Personal & 9,980 & - $\quad 10,148^{\circ}$ & 8,429 & 5,852 \\
\hline
\end{tabular}


Estimating the average fuel economy of these trucks is considerably more problematic, and requires additional assumptions and calculations. While TIUS requires the operators of larger trucks to explicitly state their average fuel economy, the census form for smaller trucks requires only that operators identify an MPG range in which their trucks operated in the prior year. It is therefore necessary to combine these two sets of survey responses on the most aggregate level, and then use more robust estimation methods to determine the mean characteristics of each group. The aggregate tabulation of trucks according to major use, vehicle type, and fuel economy is provided in tables below. Again, the attributes of 6 to 10 thousand pound trucks are assumed to represent those of the 8.5 to 10 , thousand pound group.

Estimating the average characteristics of these grouped data involves the use of a trimmed mean: first determining the quartiles of each distribution, calculating the interquartile range (IQR), and then estimating the biweighted harmonic mean of the sample. These quartiles are presented in Table F-60. Determining the biweighted mean involves calculating a weighting factor which is a function of an observation's deviation from the median of the sample $\hat{\mathrm{X}}$, as shown below.

$$
\begin{aligned}
& m(x)=\left(1-z^{2}\right)^{2} . \quad|z| \leq 1 \\
& w(x)=0 \quad|z|>1 \\
& \text { where: } \quad z=\frac{\dot{x}-\hat{x}}{3(\text { IQR })}
\end{aligned}
$$

where $w$ is the weighting factor, and X represents the:midpoint of each MPG range. The biweighted mean is then calculated as follows:

$$
\bar{X}=\left[\frac{\sum_{k} N_{k}\left(\frac{1}{X_{k}}\right) w\left(X_{k}\right)}{\sum_{k} N_{k} w\left(X_{k}\right)}\right]^{-t}
$$

where $N_{k}$ is the population of MPG range. $k$. The inverting of the MPG value in the equation, and subsequent inversion of the result is intended to provide an estimate of the harmonic mean of the sample. This results in a first approximation of the fuel economy of LCT's, and is tabulated in Table F-60. These values are subsequently. used to replace the value of the sample median in the calculation of $Z$, above, and the procedure is iterated until the MPG estimates converge. The results 
of this iterative procedure are presented in Table F-61.

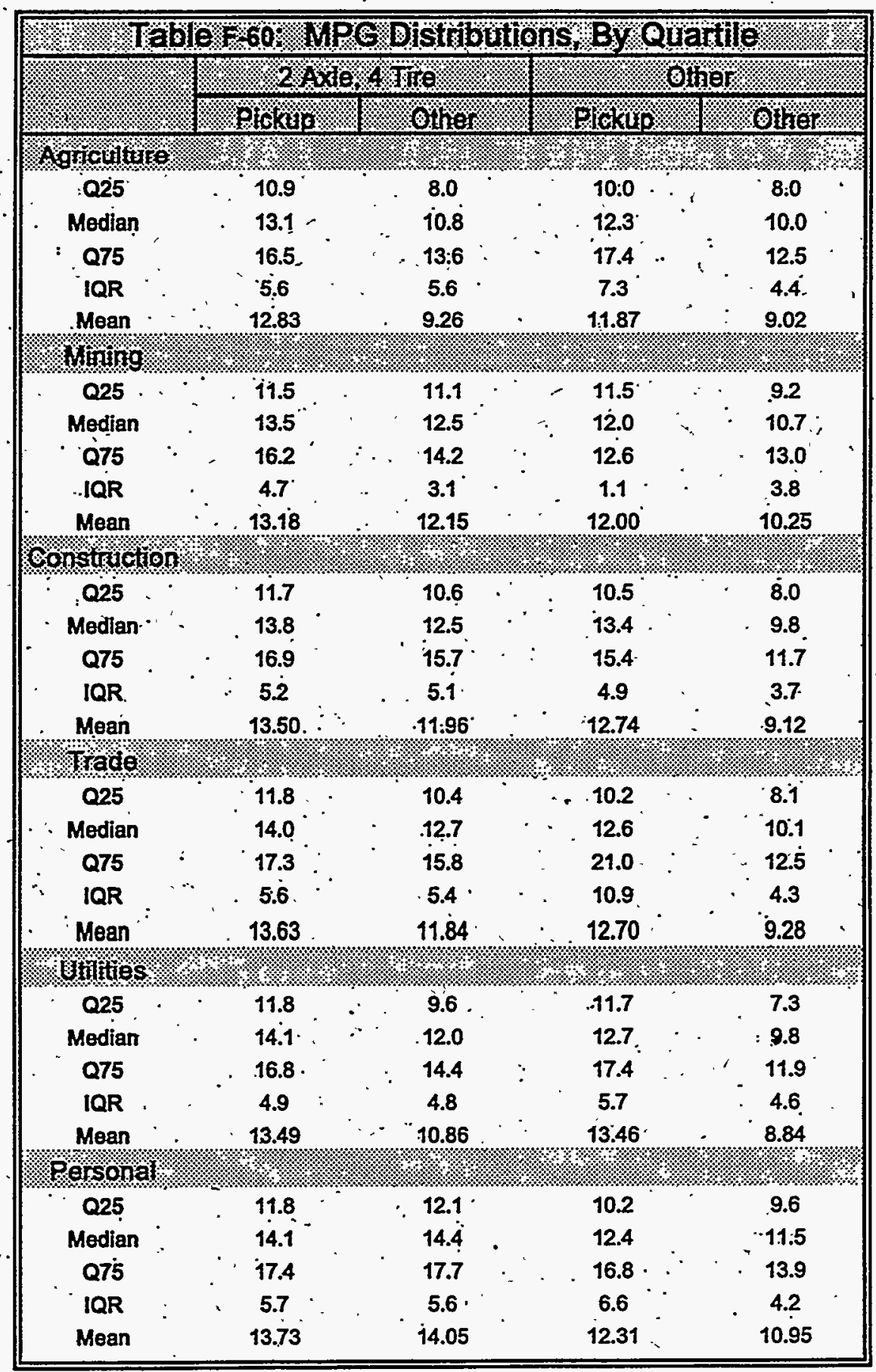




\begin{tabular}{|c|c|c|c|c|c|}
\hline \multirow{3}{*}{ \%\% } & \\
\hline & \multicolumn{5}{|c|}{ 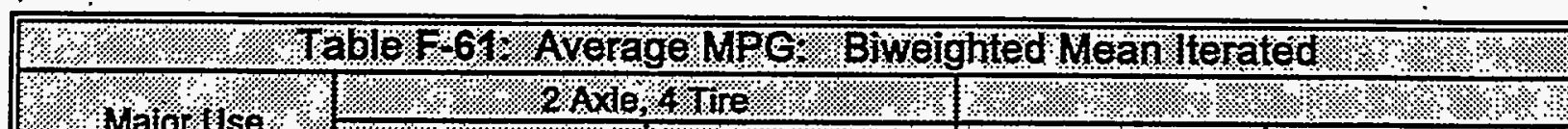 } \\
\hline & \%. \%akup & \%? & \% & \% . Plokup & (6other ${ }^{2}$ \\
\hline Agriculture & 12.77 & e & $\cdot 8.75$ & 11.79 & 8.66 \\
\hline Mining & 13.12: & & 11.92 & $12.00^{\circ}$ & 10.10 \\
\hline Construction & 13.45 & & 11.79 & 12.58 & 8.92 \\
\hline Trade & 13.55 & & 11.57 & 12.71 & 8.98 \\
\hline Utilities & 13.33 & - & 10.25 & 13.57 & $8.65^{\circ}$ \\
\hline Personal & $13: 67$ & . & 13.99 & 12.29 & 10.78 \\
\hline
\end{tabular}

The above tables effectively describe Light Commercial Trucks for the purpose of forecasting their demand for travel and consumption of fuel. In the following section, the FHWA stock numbers will be incorporated, and measures of industrial output will be used to test the responsiveness of the proposed model to variations in economic conditions.

\section{Incorporation of FHWA Baseline Data}

In order to track the activities of LCTs, and derive an estimate of scrappage rates, historical figures from FHWA have been considered. The stock of trucks and their annual miles of travel are presented below. It should be noted that, beginning with the 1994 edition of FHWA's Highway Statistics, a revised definition of 2-axle, 4-tire trucks has been implemented, removing such vehicles as vans'and sport-utility vehicles from the "automobile" category and placing them in the "single-

\begin{tabular}{|c|c|c|c|c|c|c|}
\hline \multicolumn{7}{|c|}{ 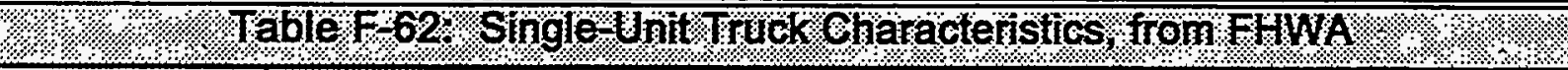 } \\
\hline \multirow[b]{2}{*}{ \%ి. } & \multicolumn{2}{|c|}{ \%., } & \multicolumn{2}{|c|}{ Yo Y Nullons) } & \multicolumn{2}{|c|}{$1 \%$ you per rruck } \\
\hline & $1.2 \mathrm{~A} 4 \mathrm{~T} \%$ & $3 \%$ other & $2+244 T+2$ & Oother & $2 A 4 T$ & \%other \\
\hline 1985 & $46,125,097$ & $3,927,412$ & 490,274 & 46,980 & 10,629 & 11,962 \\
\hline . 1986 & $47,319,902$ & $4,024,842$ & 510,178 & 48,413 & 10,781 & 12,029 \\
\hline 1987 & $48,816,260$ & 3,$883 ; 694$ & 543,615 & 49,537 & 11,136 & 12,755 \\
\hline "1988 & $50,524,830$ & $3,957,319$ & 575,411 & 51,239 & 11,389 & 12,948 \\
\hline 1989 & $51,644,255$ & $4,102,863$ & 596,024 & 52,969 & 11,541 & 12,910 \\
\hline 1990 & $52,932,510$ & $4,243,044$ & 614,491 & 53,443 & 11,609 & $\cdot 12,595$ \\
\hline 1991 & $53,210,253$ & $4,265,307$ & 624,982 & 53,787 & $11 ; 746$ & 12,610 \\
\hline 1992 & $53,844,501$ & $4,316,148$ & 637,049 & 53,691 & 11,831 & 12,440 \\
\hline - 1993 & $.55,710,076$ & $4,526,004$ & 661,546 & 56,781 & 11,875 & 12,546 \\
\hline .1994 & $57,141,967$ & $4,724,608$ & 669,321 & 61,284 & 11,713 & 12,971 . \\
\hline 1995 & $57,897,398$ & $5,203,810$ & 686,977 & 62,706 & 11,865 & 12,050 \\
\hline
\end{tabular}


unit truck" category.

This change in definition has required making incremental adjustments to $2 \mathrm{~A} 4 \mathrm{~T}$ truck stocks in the preceding years. This has been accomplished by considering the change in $2 \mathrm{~A} 4 \mathrm{~T}$ populations for the year 1993-the only overlapping year in which stock numbers under both sets of definitions are provided. The current definition increaseses truck population by 36.2 percent over the prior tabulation; this is therefore considered to be uniform across time, and previous years' stocks have been similarly augmented. The number of miles traveled is also adjusted, through the expedient of assuming that every vehicle transferred from the automobile category travels an average number of miles defined by the overall average for automobiles. The above table represents single-unit trucks of all weight classes. The stratification procedures described in the previous section is subsequently imposed in order to derive an estimate of Light Commercial Truck stock within each truck typé and major-use category: The distribution among truck types is presented below, in Table F-63.

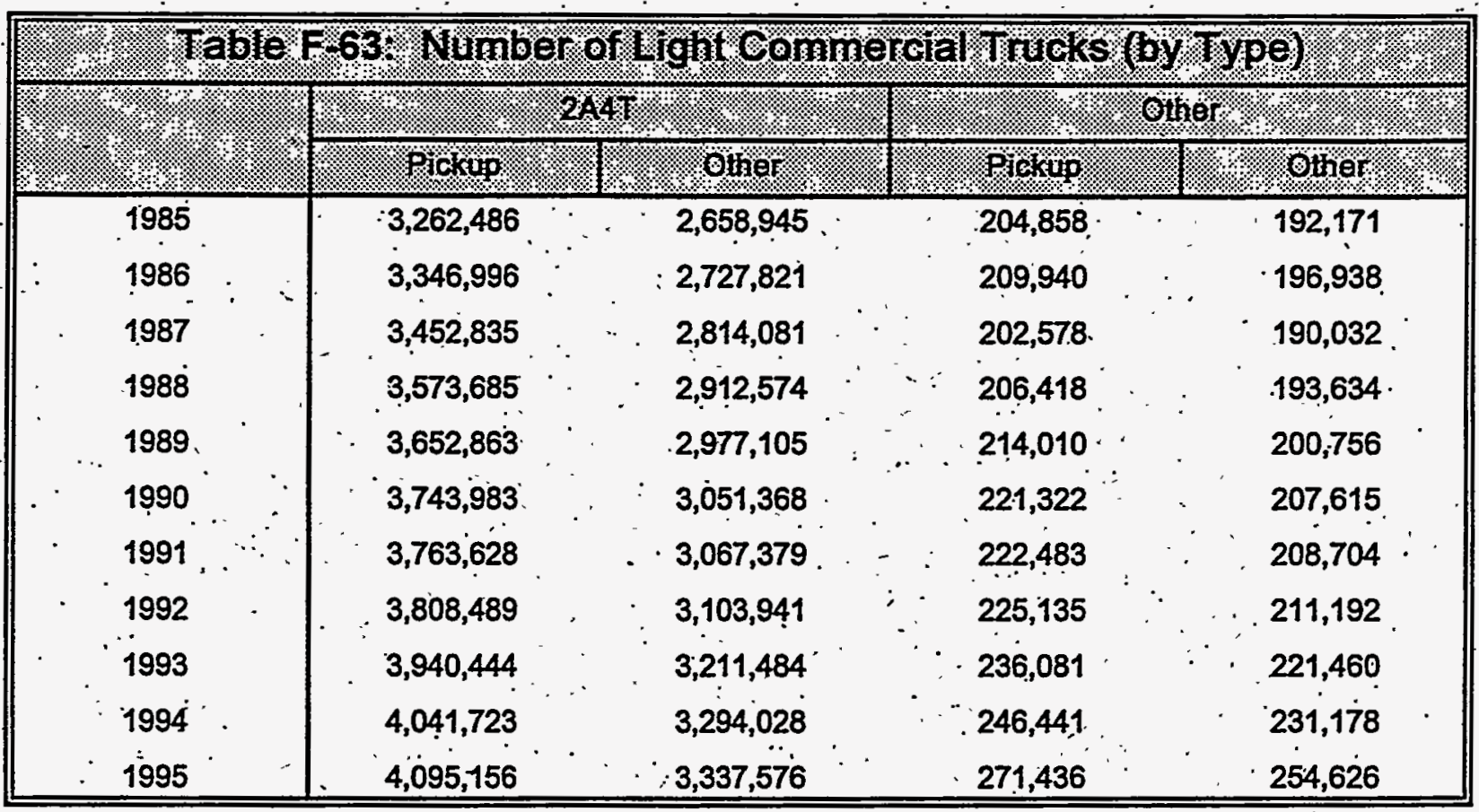

The number of trucks in each year is assumed to represent the net effect of a fixed scrappage rate applied to the previous year's stock, and the allocation of new purchases from the Macro.Model. Because light truck purchases are exogenously supplied, the scrappage rate must be inferred. The table below represents the allocation of new LCT stock by vehicle type. Allocation among majoruse groups is detailed in subsequent tables. A fixed scrappage rate is then calculated for the two classes of single-unit trucks, combining pickups and others, and averaging across the years 1986 to 1994. This results in an average annual scrappage rate of 6.77 percent for 2-axle 4-tire trucks, and 
6.54 percent for other single-unit trucks. This percentage is applied uniformly across the forecast years. The purpose of this exercise is to enable the model to accommodate the incorporation of more fuel-efficient trucks over the course of the forecast.

\begin{tabular}{|c|c|c|c|c|c|c|c|}
\hline \multirow{2}{*}{ ?: } & \multicolumn{4}{|c|}{ \%थ } & & \multicolumn{2}{|c|}{ (1. } \\
\hline & SPCoup & \% & (wouler & & & Pigkup. & Qtre \\
\hline 1985. & 307,831 & & 250,884 & & & 16,192 & 15,189 \\
\hline 1986 & 320,501 & & 261,210 & & & 16,858 & 15,814 \\
\hline 1987 & 323,634 & & 263,763 & & & 17,023 & 15,969 \\
\hline $1988^{\circ}$ & 337,556 & & 275,110 & & & . 17,755 & 16,656 \\
\hline 1989 & $.326,905$ & & 266,430 & & & 17,195 & 16,130 \\
\hline 1990 & 305,929 & & 249,334 & & & 16,092 & 15,095 \\
\hline 1991 & 287,665 . & & 234,449 & & & 15,131 & 14,194 \\
\hline 1992 & $324,25 ?$ & & 264,272 & & & $.17,056$ & 16,000 \\
\hline 1993. & $374,85 ?$ & & 305,511 & & & 19,717 & . 18,496 \\
\hline 1994 & 421,693 & & 343,682 & & & 22,181 & 20,807 \\
\hline $1995^{\circ}$ & 424,944 & & 346,331 & : & & 22,352 & 20,968 \\
\hline
\end{tabular}

\section{Forecasting VMT and MPG}

In order to estimate fuel demand by LCT's, it is necessary to develop a forecast of two elements: the total travel demanded within each major-use group, and the average fuel economy of the trucks. Again, the FHWA data provides little guidance in the allocation of VMT and MPG among light commercial trucks; assumptions based on TIUS stratifications are therefore used. 


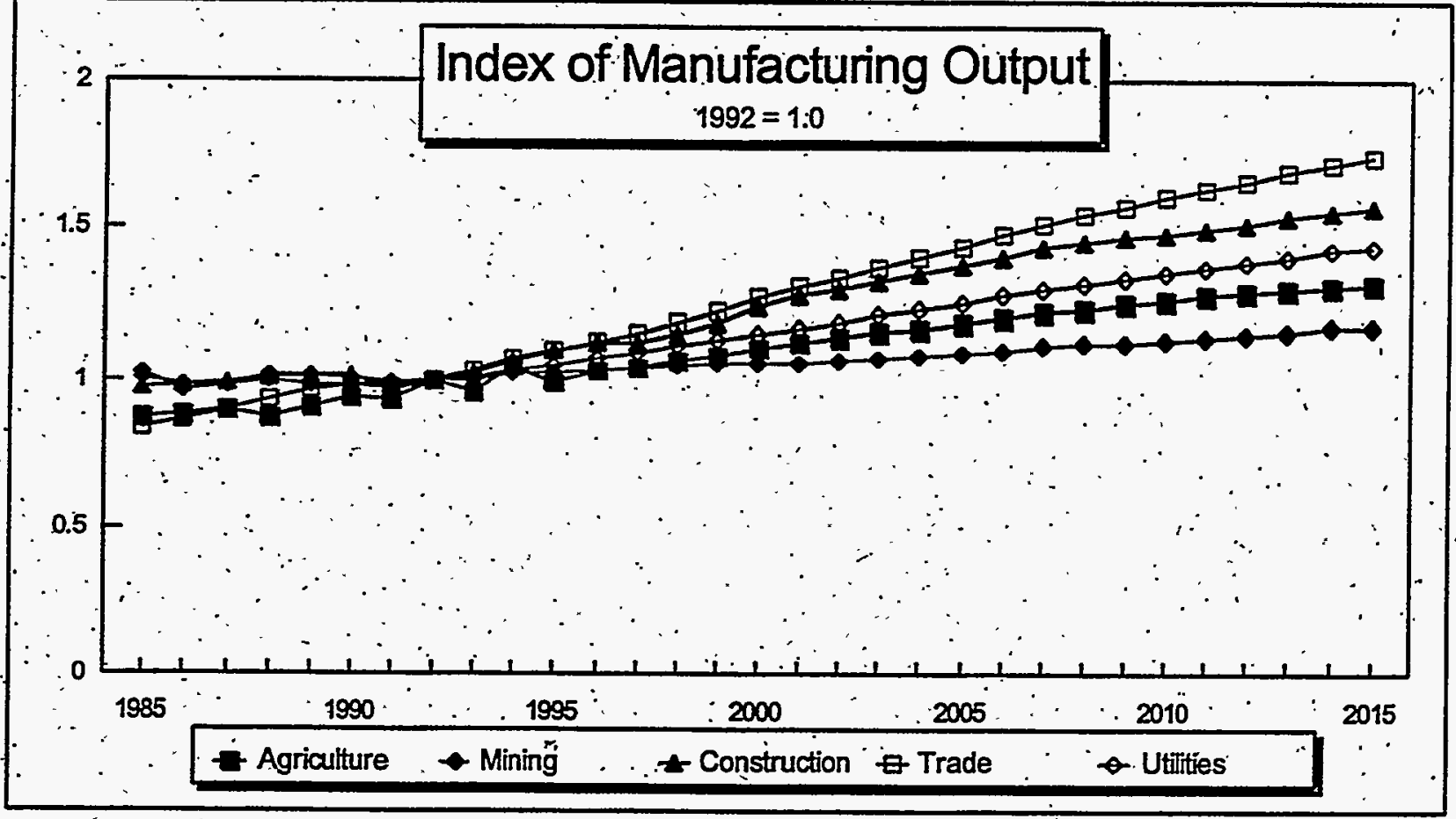

Using the disaggregated FHWA data on the rumber of LCT's in 1992, and the TIUS data on the average number of miles per truck in the same year, a baseline VMT demand for 1992 may be constructed for each industrial group. Each baseline figure is. then multiplied by an index of corresponding macroeconomic output. $(1992=1.0)$; to estimate the growth in VMT for each group. Personal travel is the exception, being adjusted by an index of personal travel from the LDV' Model: The indexed growth in industrial output is depicted in the figure above. The figure on the following page depicts total VMT forecasts by truck type.

Estimates of fuel economy for trucks in each sector are obtained in a similar manner. Absent disaggregate time-trend data on LCT fuel economy, it is assumed that the 1992 TIUS values derived above satisfactorily describe each class of truck. It is further assumed that new trucks acquired after 1992 experience the same proportional change in MPG as do the light-duty trucks as represented in the LDV Model. Each MPG within the LCT Model is therefore adjusted by an index of LDT.fuel economy; with $1992=1.0$. These new, more efficient trucks are incorporated into the previous year's scrappage-adjusted stock using a stock-weighted harmonic average of fuel economies. This is depicted in the aggregate, below, where a VMT-weighted harmonic average was used to combine industrial groups, resulting in a forecast of stock MPG by truck type. 

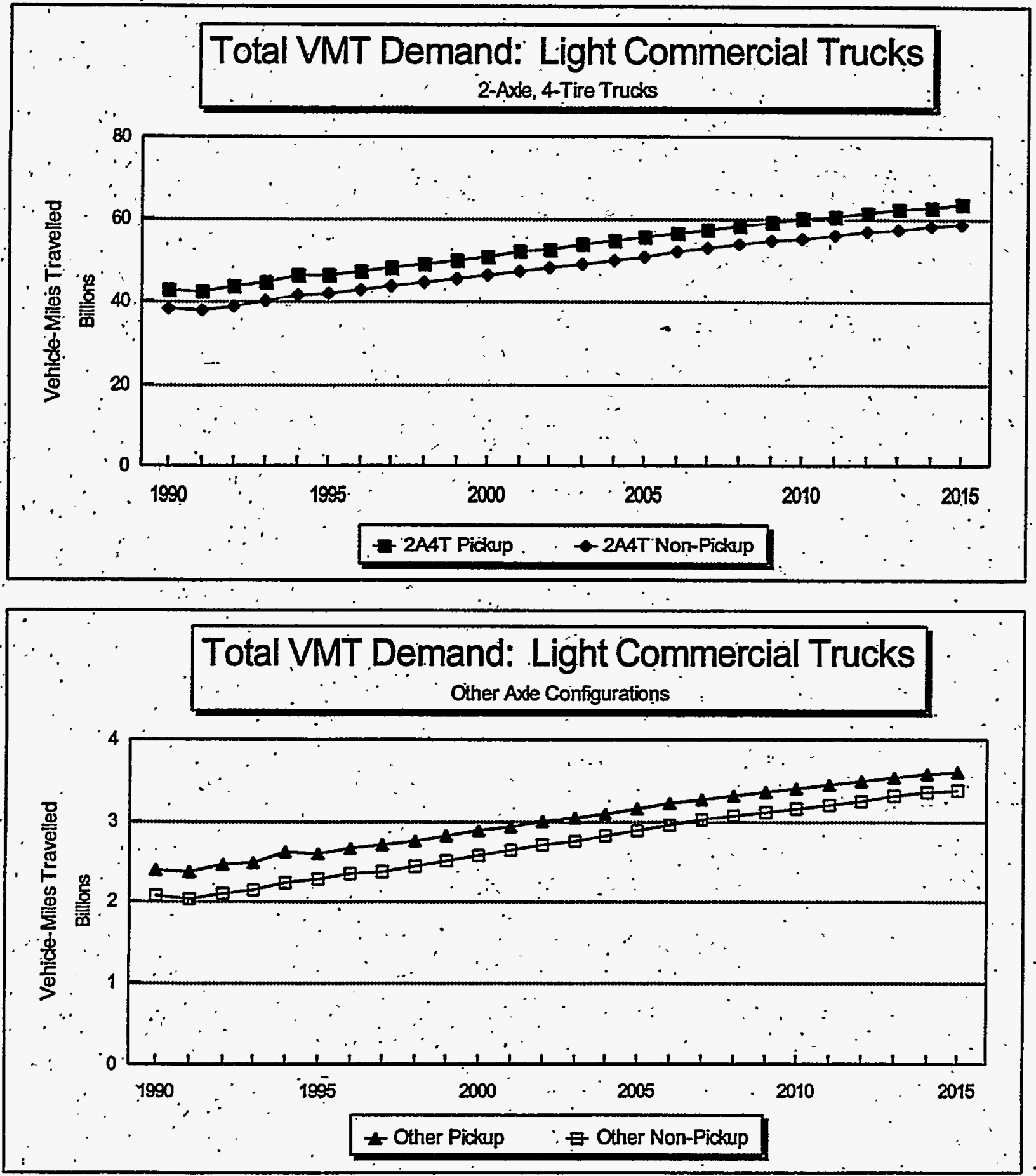
- Figure F-20: Stock Average MPG for Light Commercial Trucks

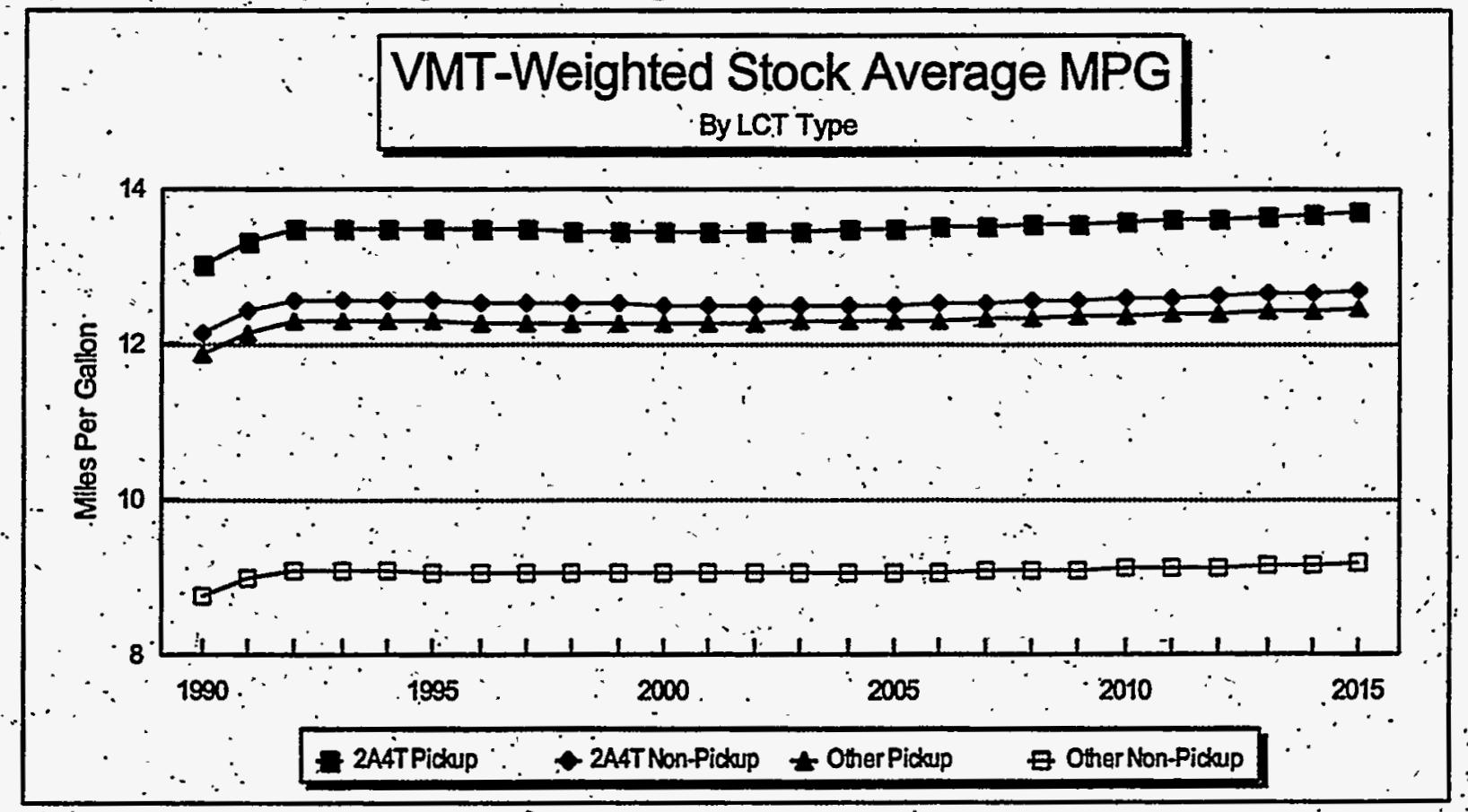

\section{Energy Demand}

Having an estimate of travel demand and fuel economy for each truck type and industrial group, it is a simple step to calculate the energy required to meet this demand. The figures below represent the aggregate demand for energy, by truck type, forLCTs. It is a relatively small, but not negligible, amount; rising from approximately 1-quad in 1.990 to near 2 quads in 2015. The figures on the following page show how this energy demand is distributed among the major-use groups. Personal travel represents roughly half of all energy demand within this class of truck, with much of the remainder being allocated between Construction and Manufacturing \& Trade.

This proposed model provides, by necessity, a rough approximation of the characteristics and performance of a relatively. small category of trucks. Improvéments in the model and the narrowing of assumptions will probably have to wait until the issuance of the next Truck Inventory and Use . Survey, or the provision of more detailed statistics by FHWA. 
Figure F-21: Energy Consumption by Light Commercial Trucks
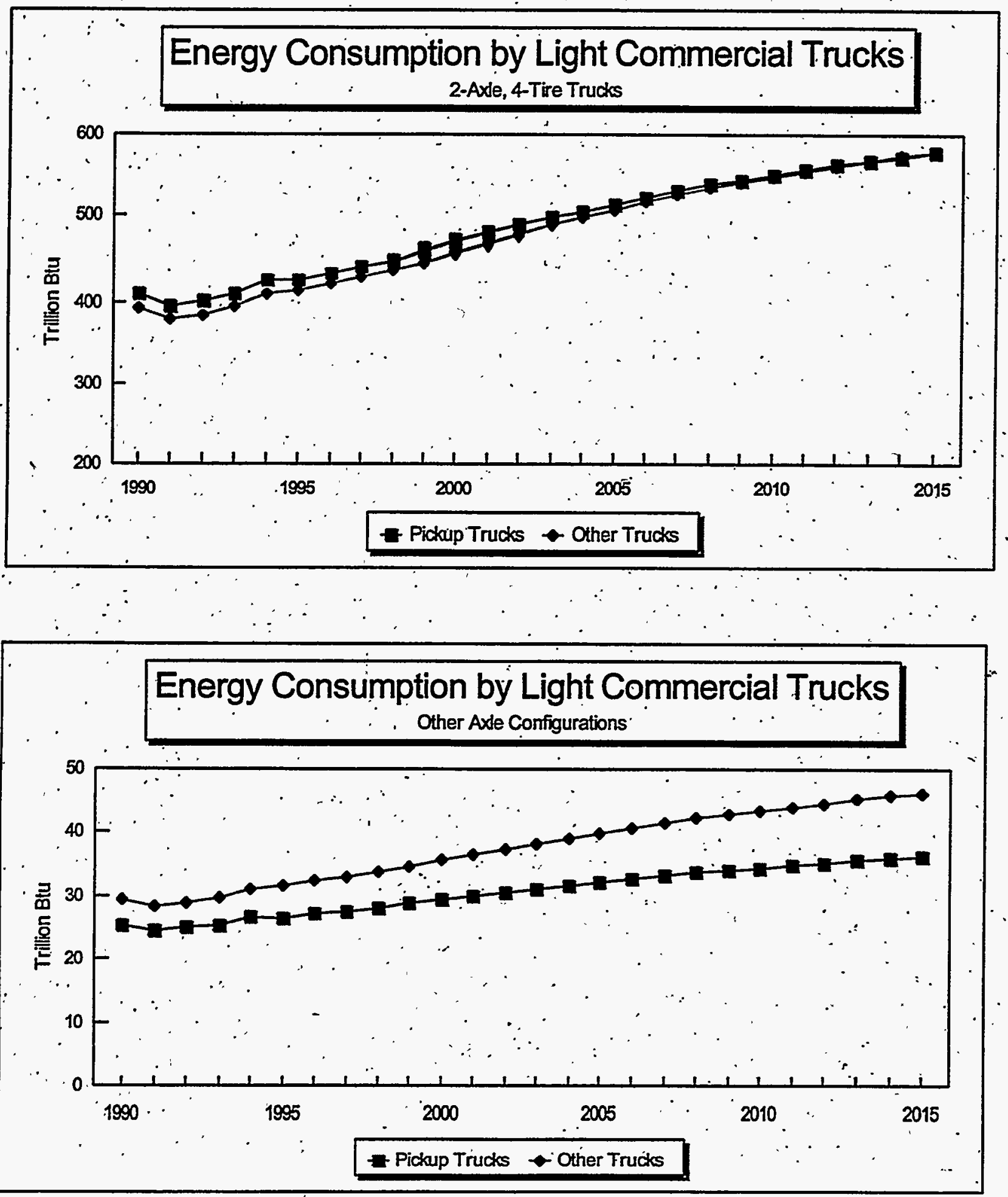


\section{Figure F-22: Components of VMT Demand for LCT's}

\section{Components of VMT Demand}

\section{2-Axde, 4-Tire Trucks}

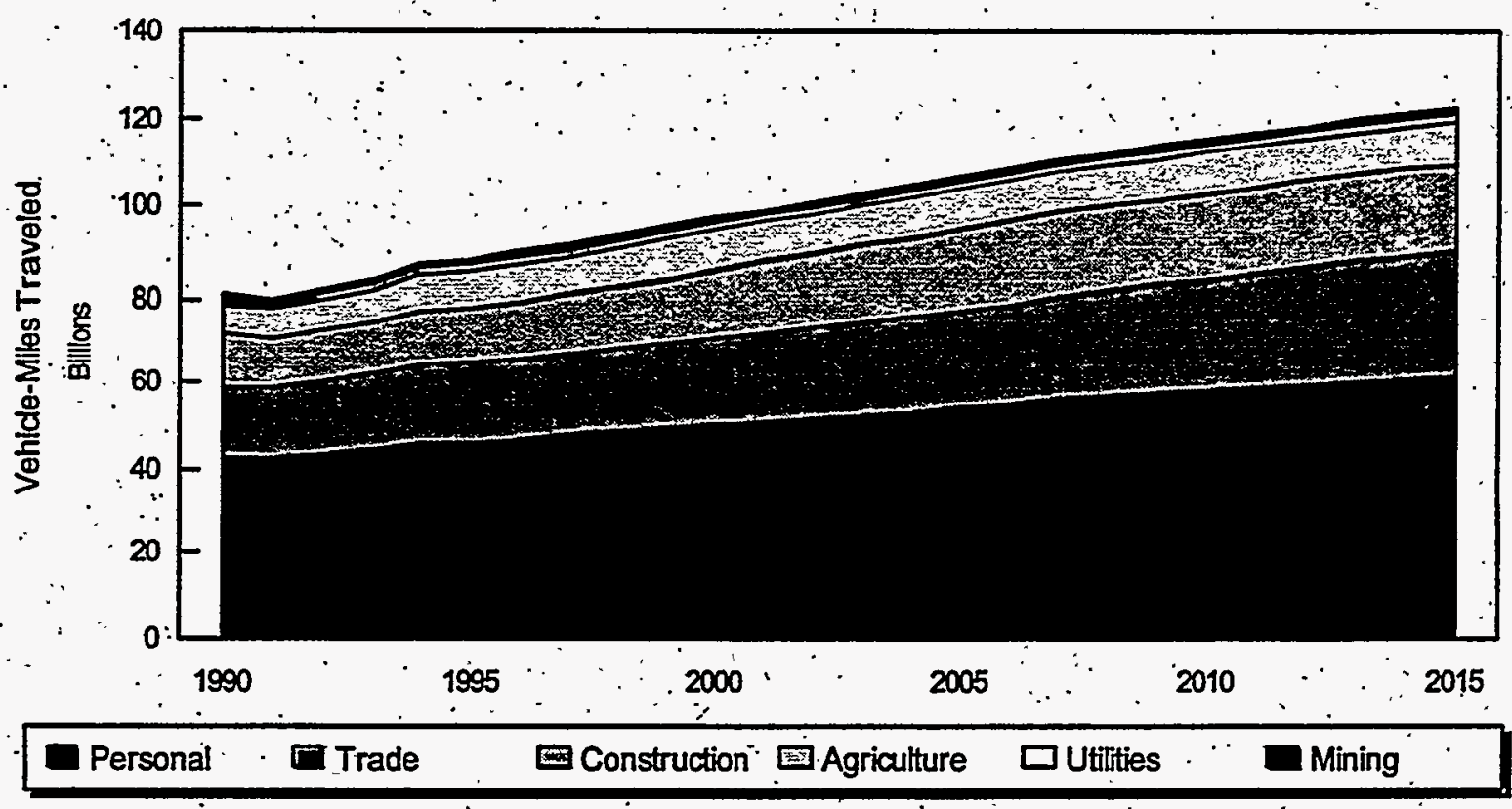

\section{Components of VMT Demand}

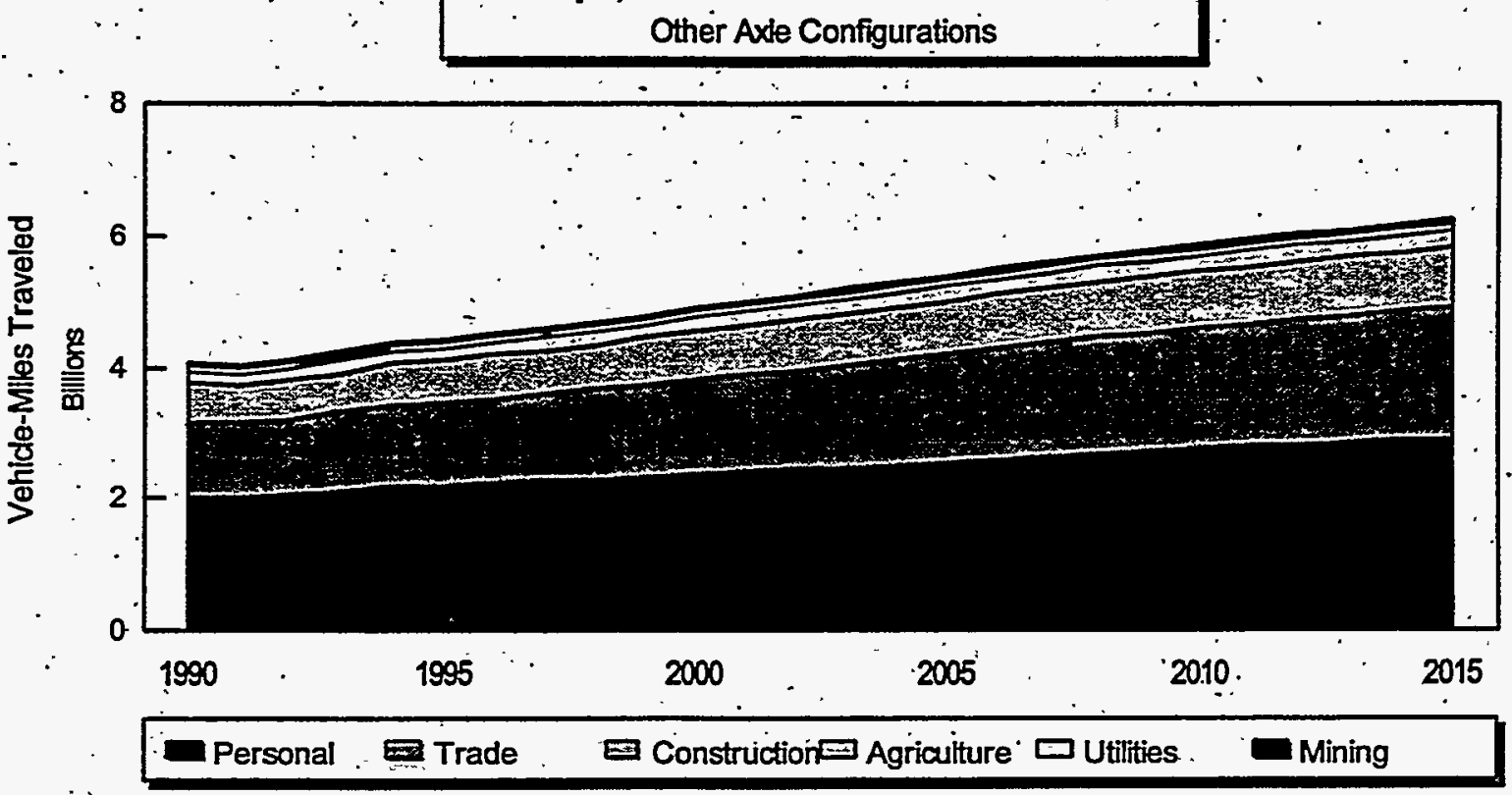




\section{TIUS Estimated Truck Registration Comparison with Federal Highway Administration}

Truck Registration

The Federal Highway Administration (FHWA) estimate of the number of private and commercial trucks registered is based on a calendár year summary report from each state. It reflects differences in truck definitions used by each state for vehicle registration from those used in TIUS.

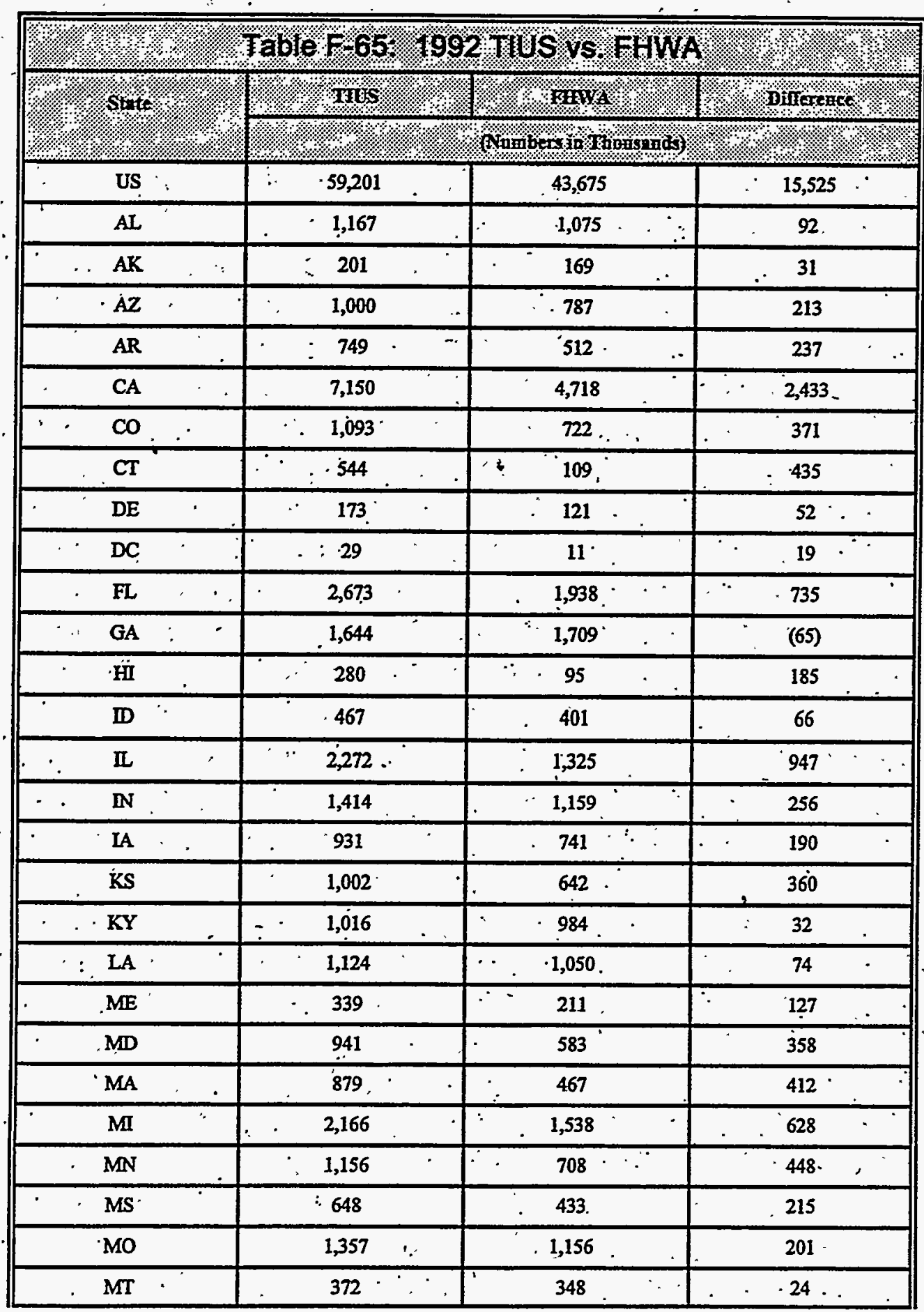




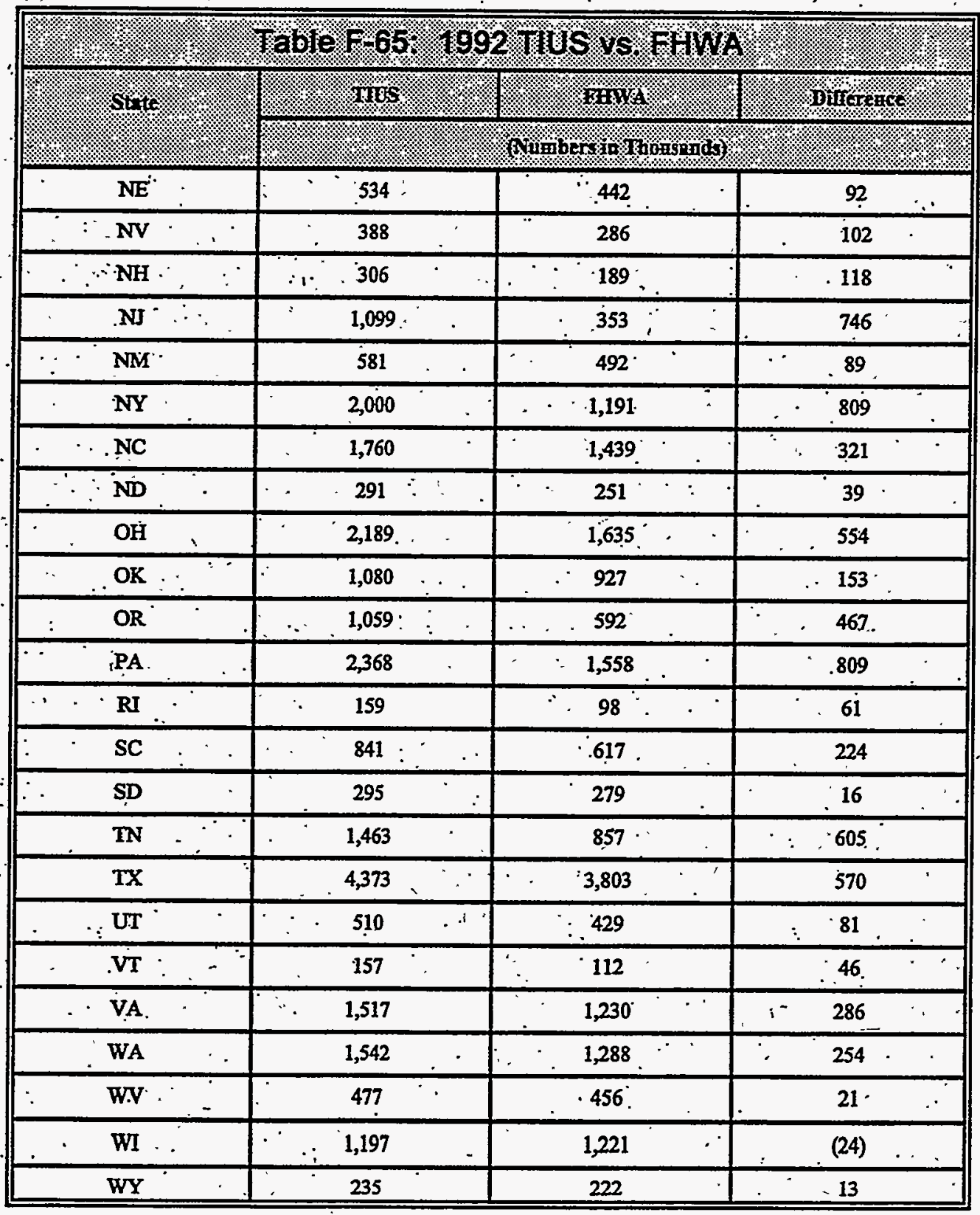




\section{Distribution of Single-Unit Truck Stock}

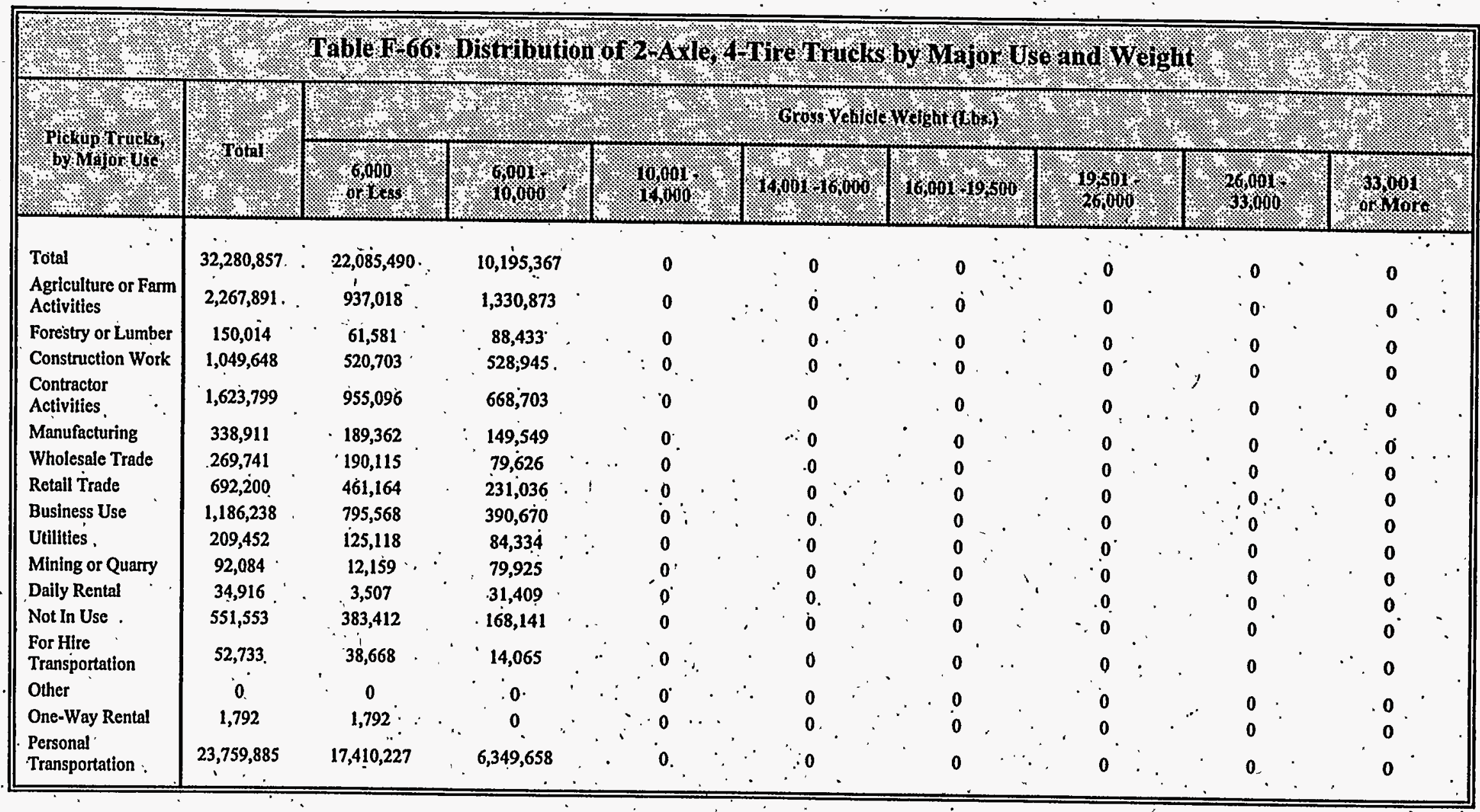




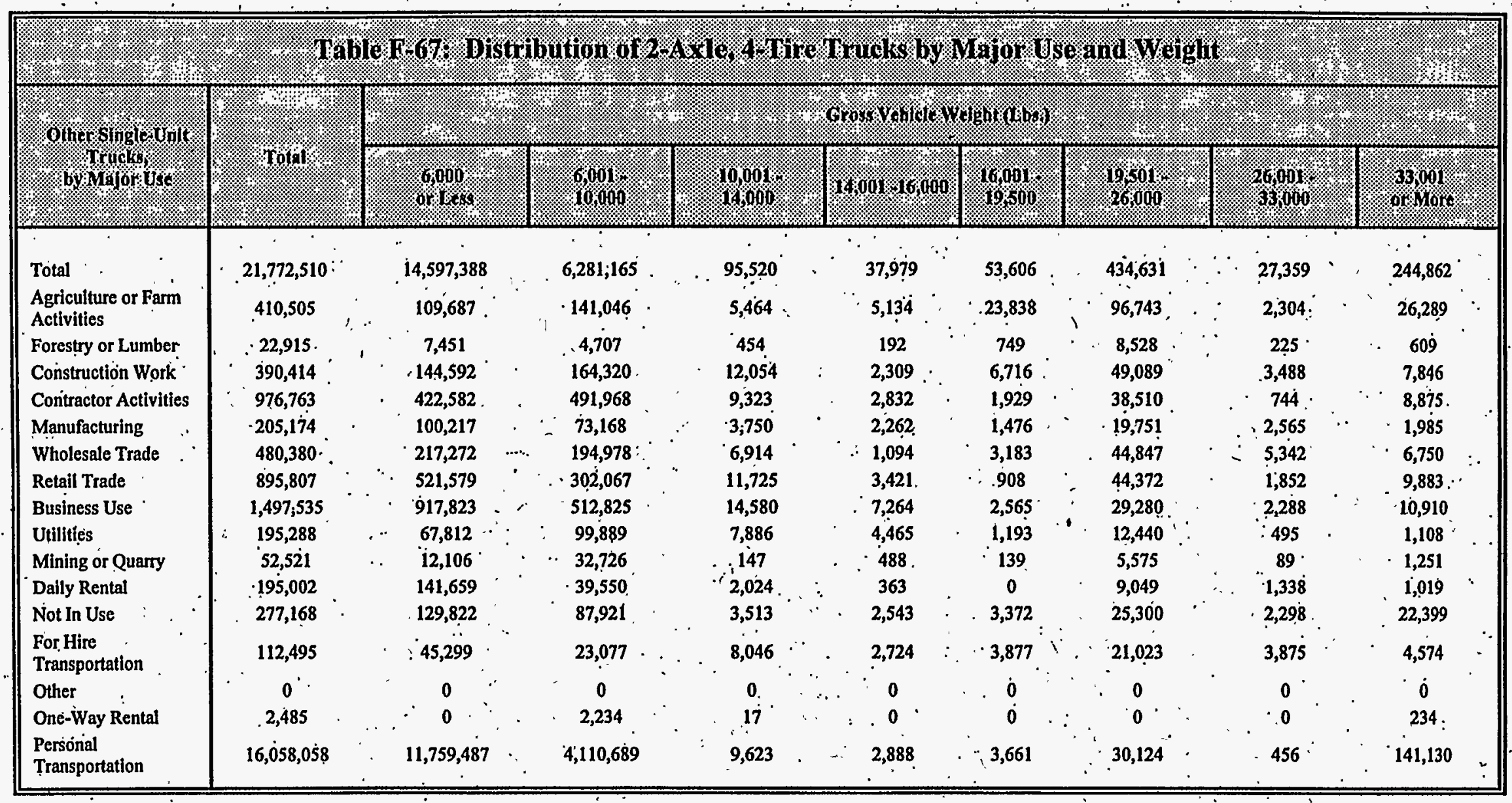




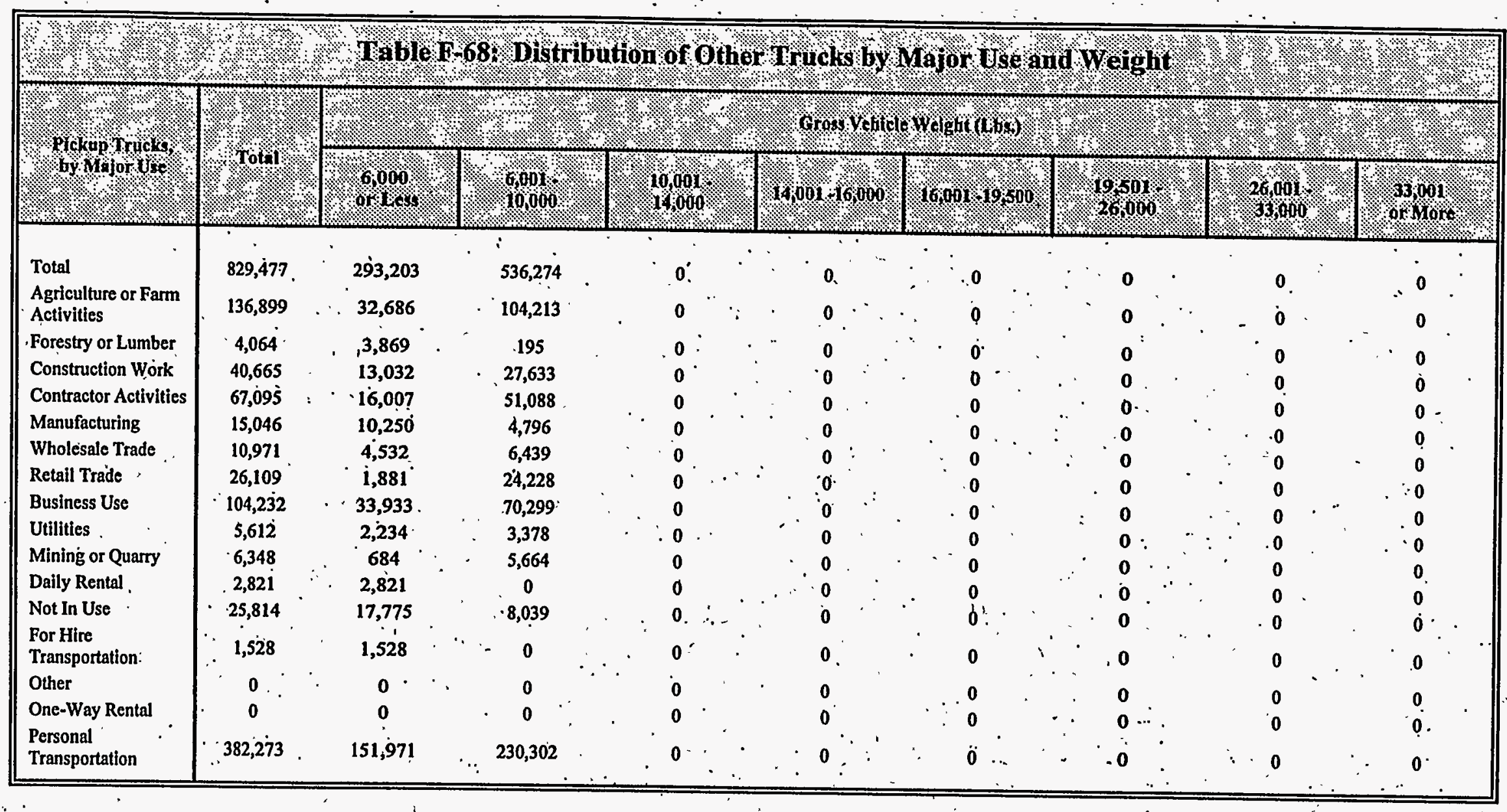




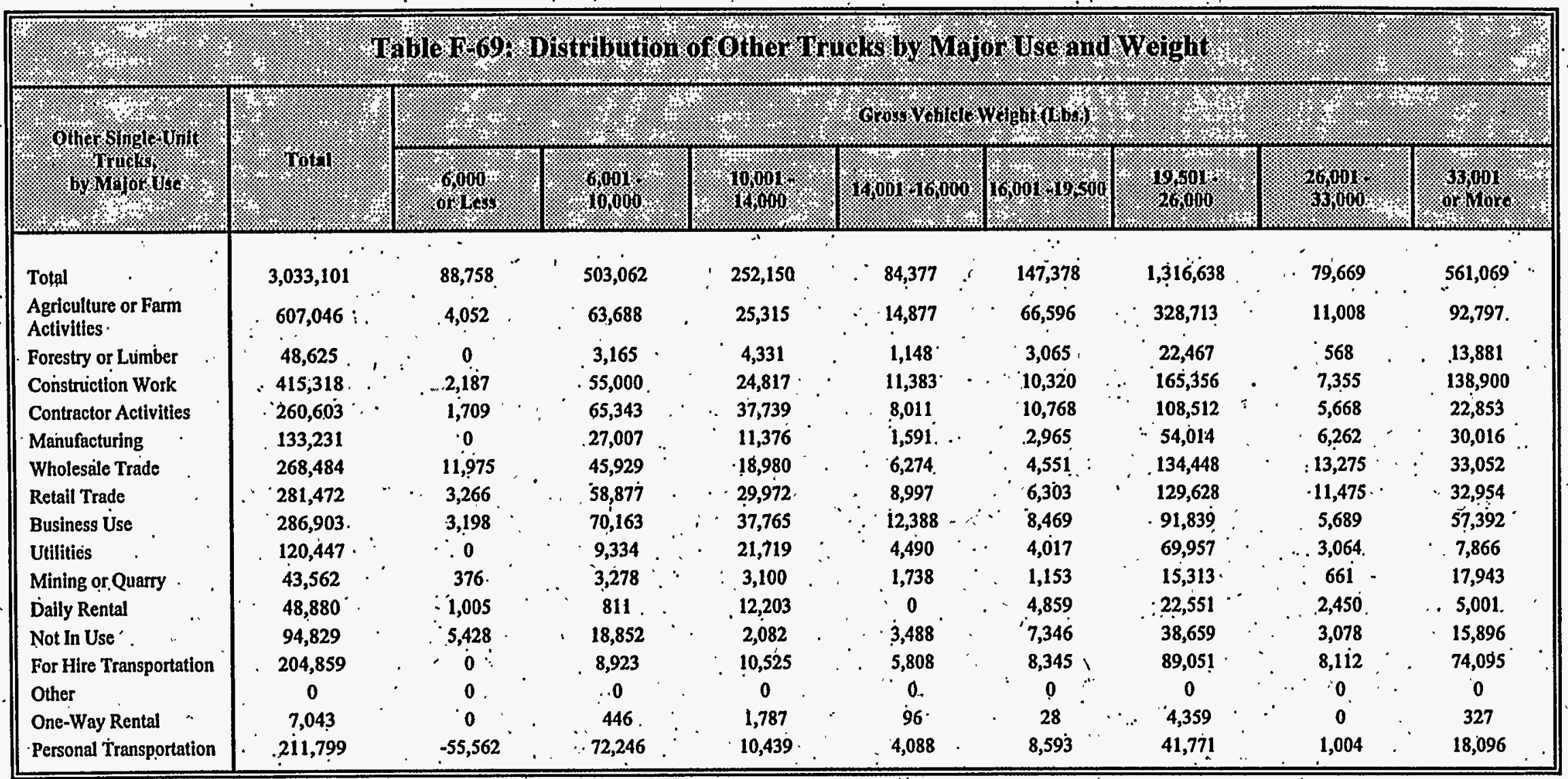




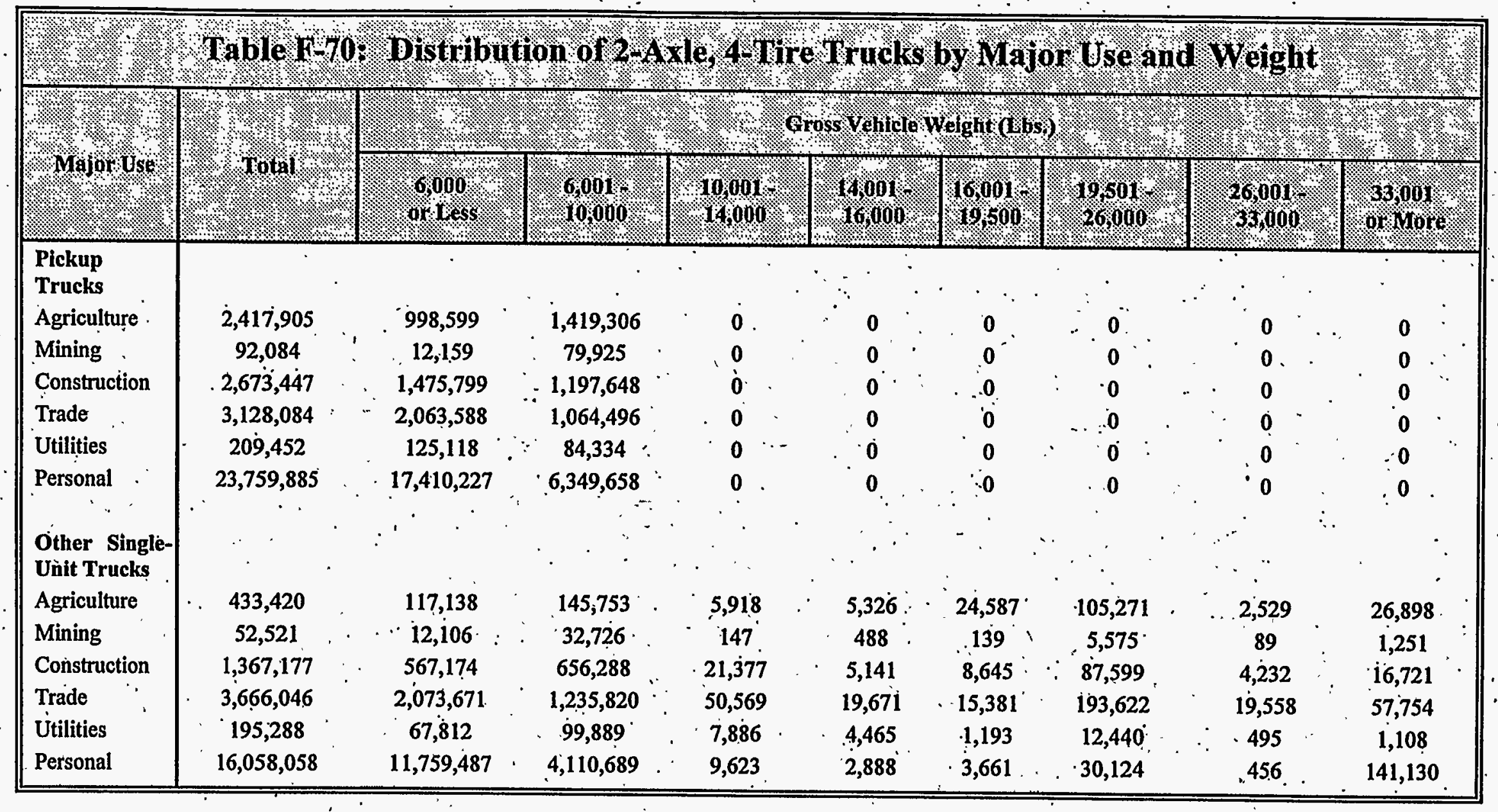




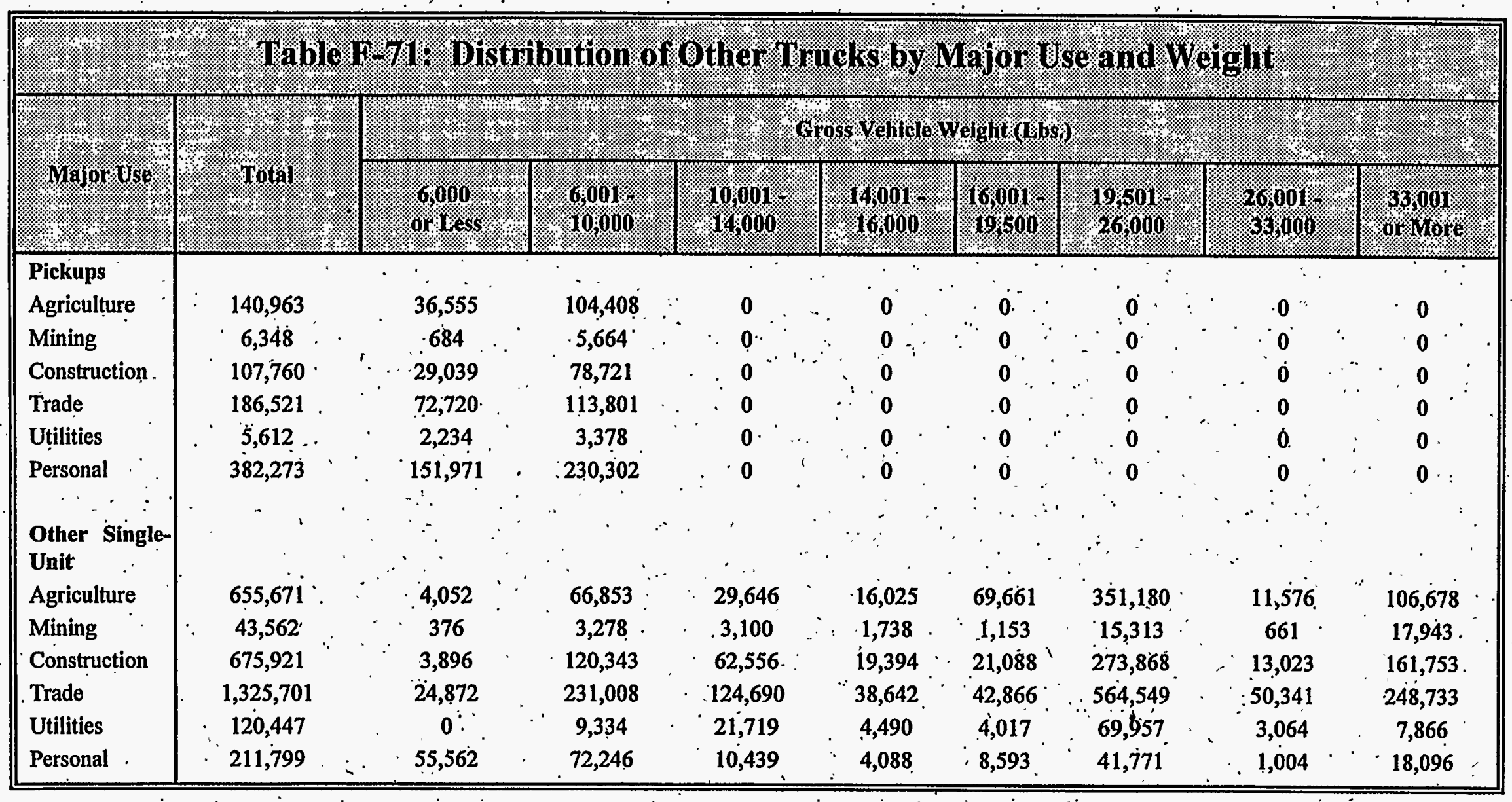




\section{Fuel Economy of Light Commercial Trucks}

\begin{tabular}{|c|c|c|c|c|c|c|c|c|c|c|c|c|}
\hline \multirow{4}{*}{ (3ilessper Gallon } & \multicolumn{12}{|c|}{ 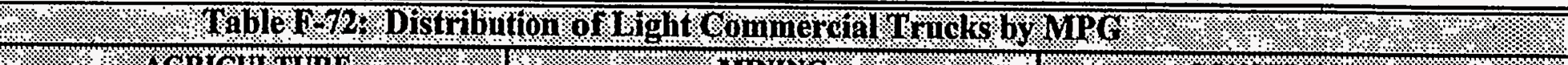 } \\
\hline & \multicolumn{4}{|c|}{ ACKICULUUAL } & \multicolumn{4}{|c|}{ NININC } & \multicolumn{4}{|c|}{ CONSTKUATLO } \\
\hline & \multicolumn{2}{|c|}{$2 \mathrm{Axlo}, 4 \mathrm{nire}$} & \multicolumn{2}{|c|}{ oontion } & \multicolumn{2}{|c|}{ 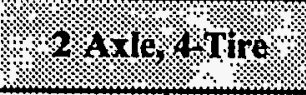 } & \multicolumn{2}{|c|}{$\begin{array}{l}\text { Other \&ile } \\
\text { Cooningurations. }\end{array}$} & \multicolumn{2}{|c|}{ 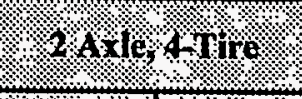 } & \multicolumn{2}{|c|}{ conting uxle } \\
\hline & Plokup & ollier & Prokup & Oather: & Bickun & otion & plekup & oilin & olckup & Olmer & olckup & other \\
\hline Less Than 5 & 0. & 11,586 & 0 & 2,157 & o. & 1,304 & $\mathbf{0}$ & 40 & 0 & 009 & $0^{\circ}$ & 1,695 \\
\hline $6.0-6.9$ & 2,249 & 37,908 & 6,233 & 6,559 & 0 & 1,258 & 0 & 42 & 0 & 22,340 & 493 & 10,669 \\
\hline $.7 .0-7.9$ & 47,422 & 41,985 & 4,863 . & 14,519 & 1,566 & 3,491 & 0 & 629 & 17,069 & $44,871^{\circ}$ & 1,520 & $32 ; 174^{\circ}$ \\
\hline $9,0-10.9$ & 319,048 & 54,325 & 28,961 & 19,405 & 13,148 & 2,970 & 271 & 1,110 . & 171,259 & 150,295 & 23,296 & 34,899. \\
\hline $11.0 \cdot 12.9$ & 321,488 & 54,229 & 18,398 & 8,554 & 20,774 & 13,312 & 5,041 & 632 & 302,322 & 221,162 & 10,420 & 20,910 \\
\hline 13.0 & 266,650 & 33,385 & $.7,596$ & 4,900 & 19,671 & 10,986 & 351 & 309 & 280,306 & 116,567 & 19,477 & 5,652 \\
\hline $15.0 \cdot 20.9$ & 436,552 & $45 ; 033$ & 31,111 & 8,924 & $.24,496$ & 5,073 & 0 & 514 & 392,149 & 189,693 & 23,516 & 9,598 \\
\hline $21.0-24.9$ & 20,643 & 1,557 & 7,246 & 0. & 271 & 0 & 0 & 0 & 25,983 & $22,077^{\circ}$ & 0: & 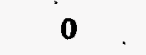 \\
\hline $25.0 \div 29.9$ & 4,195 & 150 & o & 174 & $\dot{0}$ & $\mathbf{0}$ & 0 & 0 & 2,343 . & 19. & 0 & $0^{\circ}$ \\
\hline 30 Or More & 1,060 & 666 & 0 & $\because 0$ & 0 & 0 & 0 & 0 & 218 & 1,914 & 0 & $\mathbf{0}$ \\
\hline
\end{tabular}




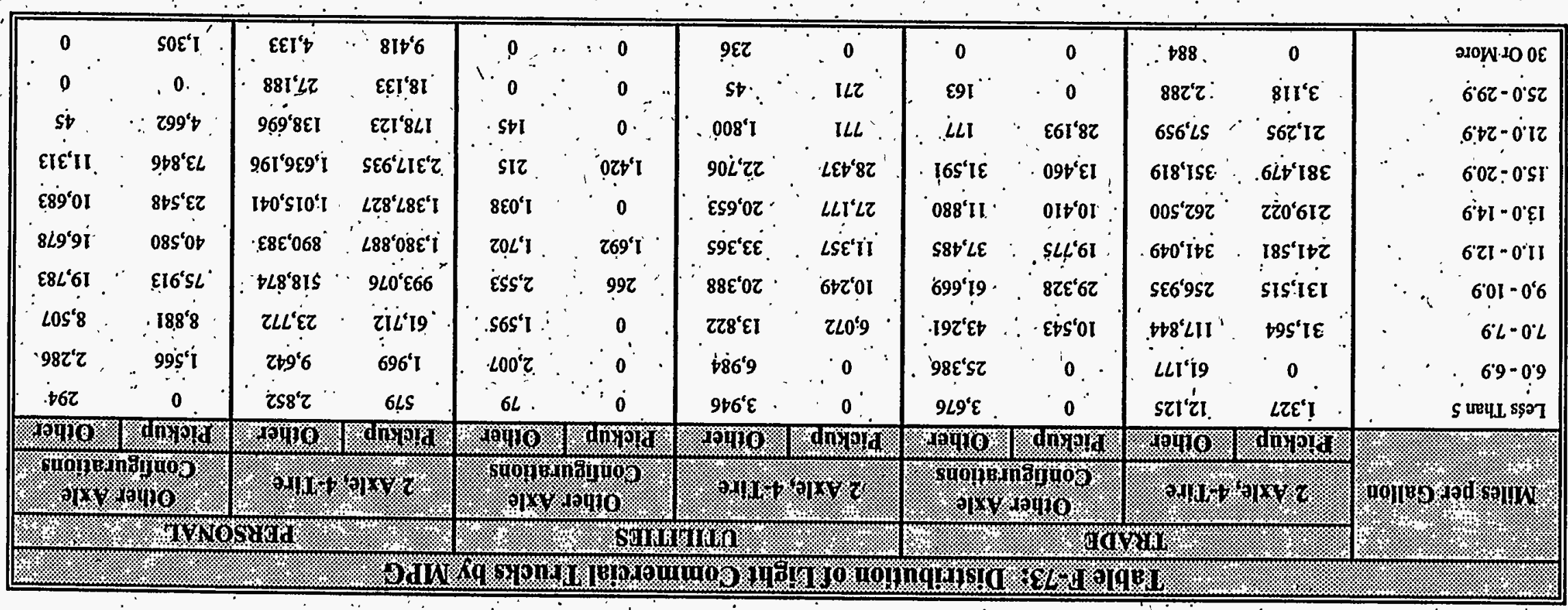


Major-Use Distribution of LCT's

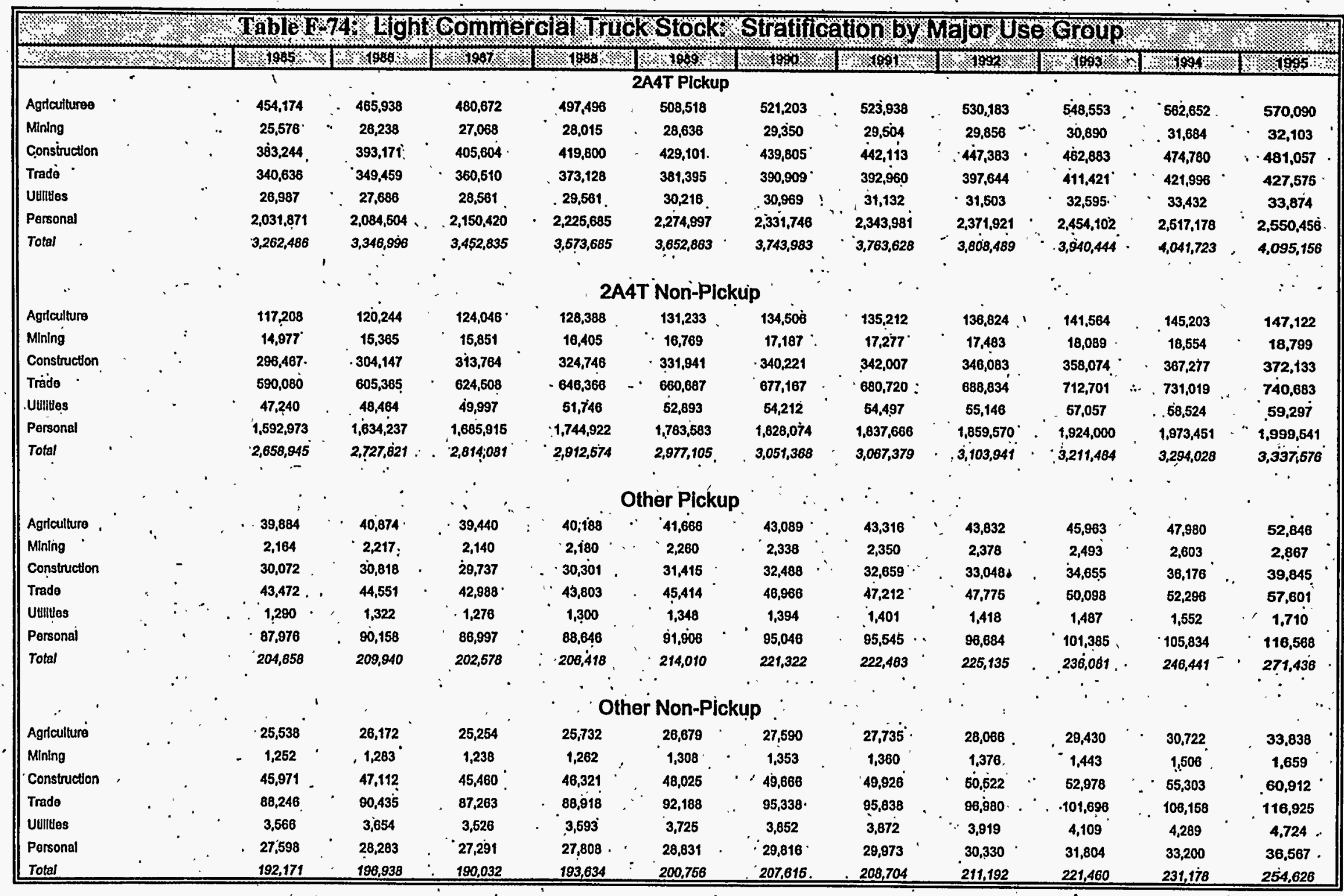

Natlonal Energy Modeling System

Transportatlon Model Demand Sector Documentation Report 


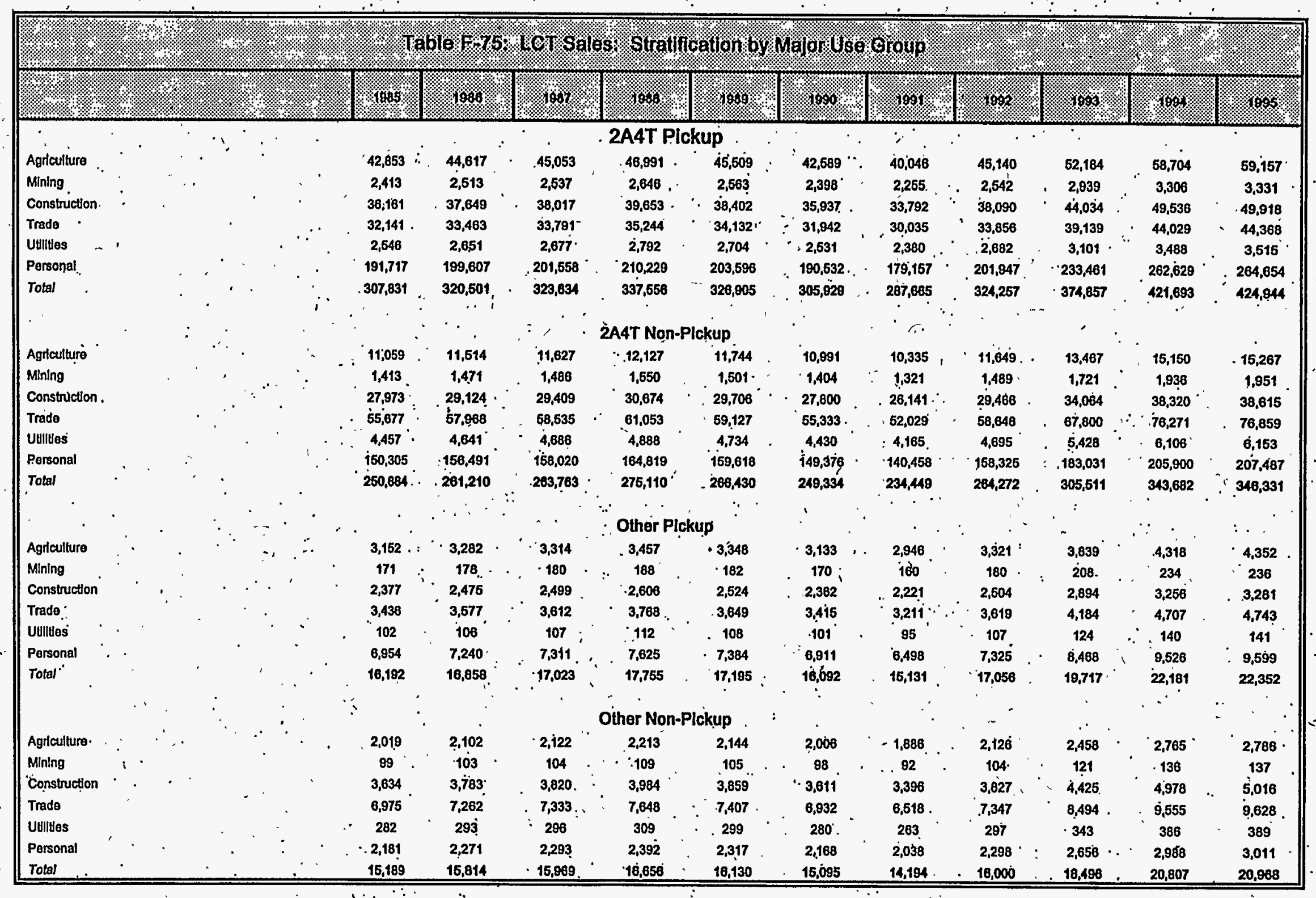

F-160

National Energy Modeling Systom

Transportation Model Demand Sector Docuriontation Roport 


\section{Attachment 6: Air Travel Module}

\section{Derivation of Demographic Adjustment Factors}

It is expected that the "personal travel" segment of commercial passenger traffic will be more sensitive to air fares than the "business travel" segment. . It is also likely that the volume of discretionary travel will be more influenced by public perceptions of airline safety, convenience, and quality of service. One way of quantifying this effect is in a stratified measure of the "propensity to fly":which, in its most rudimentary form; associates with each age group and gender a static value obtained from a survey of travelers. ${ }^{58}$. The propensity to fly is considered to be the product of the percentage of a given population segment to have flown in the previous year, and the average number of flights taken by the travelers. This translates into the number of trips per capita associated with that population cohort. These values are subsequently used to modulate forecasts produced by the conventional model as follows:

$$
A R P M_{T}=D I_{T} \cdot R P M_{D, P, T}
$$

where:

$$
\begin{aligned}
A R P M_{\mathrm{T}} & =\text { Adjusted personal-travel revenue passenger miles in year } \mathrm{t} \\
\mathrm{DI}_{\mathrm{T}} & =\text { Demographic index in year } \mathrm{t} \\
\mathrm{RPM}_{\mathrm{DPT}} & =\text { Unadjusted forecastt of domestic personal } \mathrm{RPM} \text { in year } \mathrm{t}
\end{aligned}
$$

and:

$$
D I_{\tau}=\left[\frac{\sum_{1} P O P_{1, \tau} \cdot P R O F L Y_{1, \tau}}{\sum_{T} P O P_{1, \tau}:}\right] \div\left[\frac{\sum_{1, P O P_{1,0} \cdot P R O F L Y_{1,0}}}{\sum_{T} P O P_{1,0}}\right]
$$

where:

$\mathrm{POP}_{\mathrm{L}, \mathrm{T}}=$ The population of the $\mathrm{I}^{\mathrm{H}}$ cohort in year $\mathrm{T}$.

$\mathrm{POP}_{\mathrm{I}, 0}=$ The population of the $\mathrm{I}^{\text {th }}$ cohort in the base year.

PROFLY $Y_{L T}=$ The propensity to fly for the $I^{\text {th }}$ cohort.

The following describes the assumptions and data manipulations undertaken to develop age- and

st This adjustment algorithm has been adapted from that provided in Appendix A of Forecasting Civil Aviation Activity: Methods and Approaches, Transportation Research Circular Number 372, Transportation Research Board; June 1991. 
gender-specific demographic adjustments to forecasts of personal travel: The use of these factors is predicated on the static nature of the public's propensity to 'fly (PROFLY $\mathrm{Y}_{\mathrm{LT}}=$ PROFLY $_{\mathrm{LO}}$ ), absent sufficient time series data to reflect and predict changing trends.

- The ATA travel survey provides the percentage of each age group which has flown in the previous year $\left(\pi_{A}\right)$, as well as the fraction of men and women of all age groups who have flown $\left(\pi_{\mathrm{M}}\right.$ $\left.\pi_{\mathrm{W}}\right)$. The first step is to derive an estimate of the percentage of each age group and sex which has flown:

Given that $\mathrm{N}_{\mathrm{M}}$ and $\mathrm{N}_{\mathrm{W}}$ represent the total number of men and women, respectively, the percent of the flying population that are of each gender can be represented as follows:

$$
\ddot{P}_{M}=\frac{\pi_{M} N_{M}}{\pi_{M} N_{M}+\pi_{W} N_{W}} ; P_{W}=1-P_{M}
$$

Using the 1990 Census numbers, ${ }^{\prime}{ }_{M}=0.53$ and $P_{W}=0.47$. In other words, 53 percent of people who took at least one air trip in the previous year were male.

E It is assumed that this gender ratio is constant across age groups and time. This ratio is used to estimate the percentage of the population by gender and age group which has flown in the previous year. The equation for males is as follows:

$$
\pi_{M, A}=\frac{P_{M} \cdot \pi_{A} N_{A}}{N_{M, A}}
$$

In order to determine the number of trips per capita for male and female cohorts, further assumptions are.necessary.

According to the ATA survey, male travelers flew more than female travelers; the ratio of male to female trips per capita is 1.72 , i.e:

$$
\frac{T_{M}}{N_{M}}=1.72 \frac{T_{W}}{N_{W}}
$$

where $T_{M}$ and $T_{W}$ represent the total number of trips by male and female travellers, respectively. 
- In each age group, the number of average trips per capita is reported. It is assumed that the male/female travel ratio holds across age groups, which enables the subsequent division of each figure into two gender-specific figures.

For each age group, the number of trips per capita (TPC) is expressed as:

$$
\frac{\dot{T}_{M, A}+T_{W, A}}{N_{M, A}+N_{W, A}}=T_{P C}
$$

From above:

$$
T_{M, A}=1.72\left(\frac{T_{W, A} N_{M, A}}{N_{W, A}}\right)
$$

Substituting, and rearranging:

$$
T_{W, A}\left(1+1.72\left(\frac{N_{M, A}}{N_{W, A}}\right)\right)=\operatorname{TPC}_{A}\left(N_{M, A}+N_{W, A}\right)
$$

which leads to the trips per capita for women, by age group:

$$
\frac{T_{W, A}}{N_{W, A}}=\operatorname{TPC}_{A}\left[\frac{N_{M, A}+N_{W, A}}{N_{W, A}+1.72 N_{M, A}}\right]
$$

The resulting figures are tabulated, and a graph of the demographic index through the year 2040 is provided on the following page. 


\section{Table F-76. ATA 1990 Air Travel Survey Data}

\begin{tabular}{|c|c|c|c|c|c|c|c|c|}
\hline \multirow{2}{*}{ 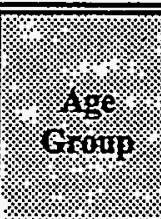 } & \multicolumn{2}{|c|}{ (1990 popplation } & \multicolumn{2}{|c|}{ 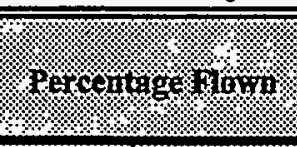 } & \multicolumn{2}{|c|}{ 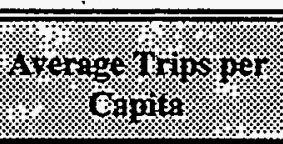 } & \multicolumn{2}{|c|}{ Pronsin } \\
\hline & Male & fourale. & 19ati & ferminge & thal & menia & 14le: & remate \\
\hline 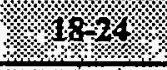 & 13,215 & 12,925 & 0.31 & 0.29 . & 3.29 & · 1.91 & 1.03 & 0.55 \\
\hline 25.34 & 22,078 & 21,848 & 0.37 & 0.33 & 4.88 & 2.83 & 1.80 & 0.94 \\
\hline $35 \%$ & 18,193 & $19 ; 112$ & 0.38 & 0.32 & 5.18 & 3.03 & $1.97^{\circ}$ & 0.97 \\
\hline 145.54 & 12,406 & 13,081 & 0.39 & 0.33 & 4.82 . & 2.81 & .1 .89 & 0.93 \\
\hline $85-6$. & 10,103 & 11,260 & $0.33^{\circ}$ & 0.26 & $4: 17$ & 2.45 & 1.36 & 0.63 \\
\hline $65 \%$ & 12,853 & 18,706 & 0.31 & $0: 19$ & 4.28 & .2 .52 & 1.34 & 0.48 \\
\hline
\end{tabular}

Figure F-23. Demographic Adjustment Index for Personal Air Travel: 1980-2040

\section{Demographic Index}

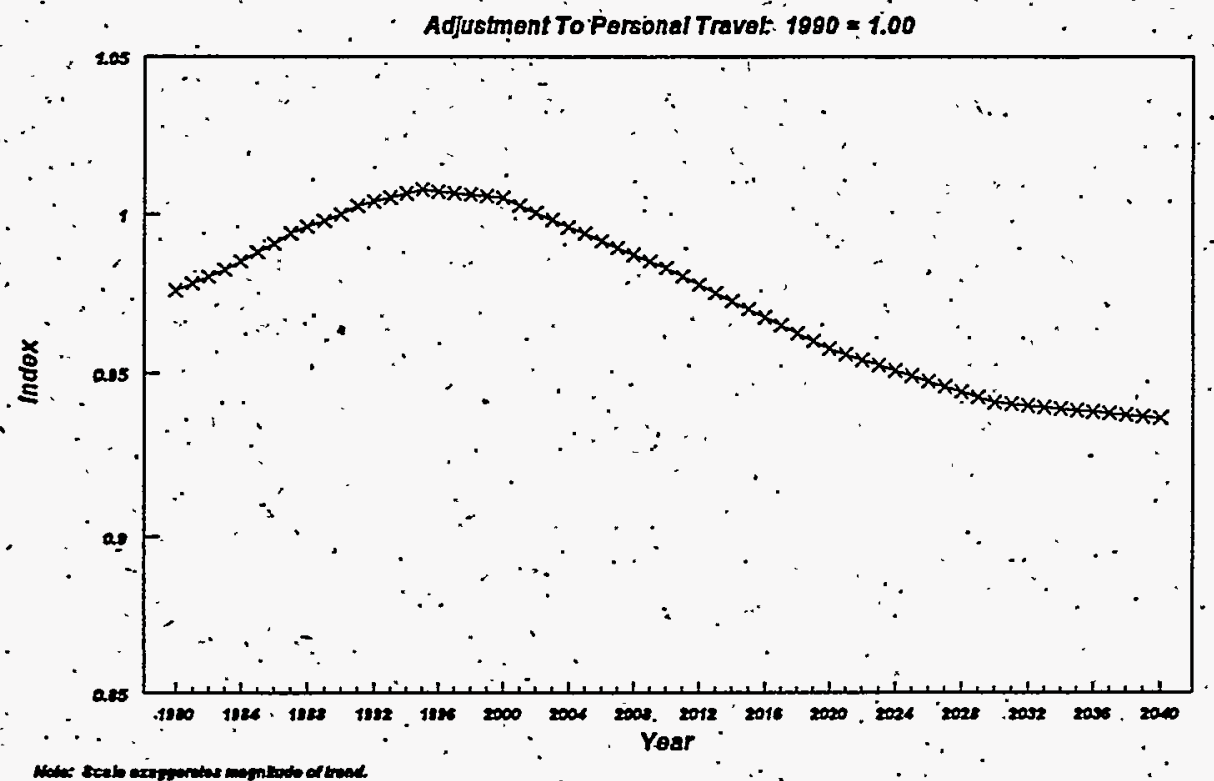

Sources:

Population Data: U.S. Department of Commerce, Bureau of the Census, Projections of the Population of the United States by Age, Sex, and Race: 1988 to 2080. Population. Estimates and Projections, Series P-25, No. 1018.

Percentage Flown \& Trips per Capita: ATA, Air Travel Survey, 1990. 


\title{
Attachment 7: Vehicle Emissions Module
}

\author{
Derivation of Emission Factors
}

\section{INTRODUCTION}

This report provides EPA emission factors to be used in the transportation vehicle emission solution algorithm, which is outlined in the Transportation Sector Component Design Report (TSCDR) section on emissions. This algorithm is as follows:

$$
\text { EMISS }_{\mathrm{IE}, \mathrm{MM}, \mathbb{R}, \mathrm{T}}=E F A C T_{\mathrm{IE}, \mathrm{M}, \mathbb{R}, \mathrm{T}} * U_{\mathrm{MM}, \mathrm{R}, \mathrm{T}}
$$

where EMISS is total emissions of pollutant IP by mode IM, in region $\mathrm{IR}$, and time T, EFACT is an emission factor based on technology, fuel and vintage weights; and $U$ is a measure of annual vehicle activity (vehicle-miles-traveled or fuel consumption in gallons).

The TSCDR specifies modal emission factors for $\mathrm{SO}_{x} \mathrm{NO}_{x}$ carbon, $\mathrm{CO}, \mathrm{CO}_{2}$ and VOCs, and calls for emissions to be calculated for the following six transportation modes:

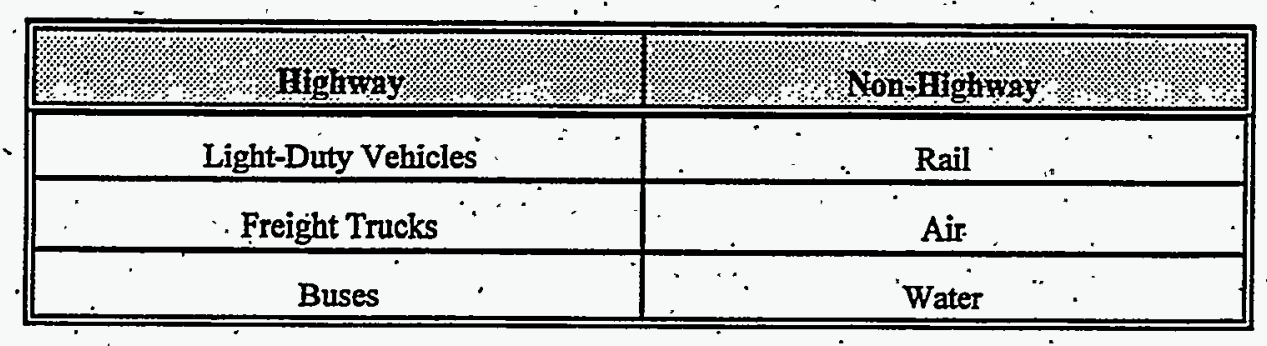

A number of these transportation modes have subcomponent modes that are to be handled in a separate TERF "Miscellaneous End-Use Component" module. These subcomponent modes include - military aircraft, recreational boating, passenger rail, and buses. This report also provides the emission factors for these miscellaneous transportation energy end-use categories, as well as for alternative fuel vehicles (AFVs).

Pollutant emission factors are not reported for certain transportation vehicles. Reasons for the exclusion of these emission factors include one or more of the following: 
the lack of adequate EPA emissions testing results for the production of reliable fleet-average emission rates,

the quantities of a pollutant generated a vehicle type are not significant,

the pollutant is not regulated by the EPA (for example, only, aircraft $\mathrm{HC}$ and smoke emissions are currently regulated).

Such instances of nonreported emission factors are documented in the relevant transportation mode sections of this report.

\section{HIGHWAY MOBILE SOURCE EMISSION FACTORS}

\section{Highway Source Emission Factor Information Sources}

Emission factors and the accompanying calculation procedures used for virtually. all federal and state mobile source emission inventory studies come from the following EPA source documents:

Cómpilation of Air Pollutant Emission Factors - Volume II: Mobile Sources (AP-42, Fourth Edition; September 1985)

Supplement $A$ to $A P-42$ Volume II, January 1991.

User's Guide to MOBILE4.1, EPA-A-AEB-91-01 (EPA Office of Mobile Sources, Emission Control Technology Division, July 1991).

Interim Guidance for the Preparation of Mobile Source Emission Inventories, Attachments A through J (This EPA memorandum supersedes the mobile source emission inventory preparation instructions contained in Procedures for Emission Inventory Preparation - Volume IV; Mobile Sources, which is currently being revised)

Procedures for Emission Inventory Preparation - Volume IV, Mobile Sources, EPA-450/4-81-26d (revised), (July 1992). 
The document, Compilation of Air Pollutant Emission Factors - Volume II, reports all data and emission factor calculation algorithms for both highway and off-highway emission sources. Supplement A to AP-42 presents updated emissions factor information for highway sources based on the results of additional vehicle test data obtained subsequent to the publication of the original AP-42 Air Pollutant Emission. Factor compilation document, as well as methodological modifications reflecting calculation refinements and new emission regulations. Both EPA data source documents categorize highway mobile sources into eight types: light-duty gasoline vehicles (LDGVs), light-duty gasoline-powered trucks with a gross vehicle weight rating of less than or equal to 6,000 lbs (LDGT1s), light-duty gasoline-powered trucks with a gross vehicle weight rating greater than 6,000 lbs (LDGT2s), heavy-duty gasoline-powered vehicles (HDGVs), light-duty diesel: powered vehicles (LDDVs), light-duty diesel-powered trucks (LDDTs), heavy-duty diesel-powered vehicles. (HDDVs), and motorcycles. The EPA document, Procedures for Emission Inventory. Preparation -Volume IV, Mobile Sources, provides the most up-to-date instructions for all state and local agencies involved in the preparation of mobile source inventories. The EPA makes frequent mention of the fact that a number of emission rate studies are ongoing. Therefore, frequent monitoring of the status of EPA analytical studies is suggested in order to ensure that TERF emission factors reflect the latest available emission testing and methodological information.

Highway mobile source emission factor calculation routines, outlined in the above EPA documents, are incorporated into E'PA's MOBLE model, which estimates hydrocarbon, carbon monoxide, and oxides of nitrogen emission factors for gasoline and diesel-powered vehicles. The most recent version of the mobile emissions model, MOBILE4.1, was released in 1991 for the express purpose. of preparing all 1990 base year emission inventories mandated by the CAAA for all areas exclusive of California and to prepare CAAA-mandated carbon monoxide emissions inventory projections. However, MOBILE4.1 does not incorporate the effects of other CAAA provisions, such as the Tier I exhaust emissions standards for light-duty. vehicles and light-duty trucks. Revisions to the MOBILE4.1 model to reflect CAAA provisions for NMHC and $\mathrm{NO}_{\mathrm{x}}$ and additional test data are being discussed and planned for incorporation into the new MOBLE5 model. The EPA is currently seeking recommendations through a series of public workshops, and expects to release MOBILE5 in the fall of 1992. Appendix E.EM.B provides an excerpt from an EPA letter handout (dated March $5,1992)$ that outlines potential MOBILE5 revisions.

Highway source emission factors for California are calculated through the use of the California Air Resources Board's own emission factor model, EMFAC. The most recent version of this model is EMFACTEP, which incorporates the most recent California vehicle and fuel standards. All EMFAC model versions are variants of EPA's MOBILE model, and have been customized to serve the 
emission calculation needs of the CARB. EPA's Office of Mobile Sources is currently examining $\mathrm{CA} \underset{\mathrm{R} B}{\mathrm{~B}}$ in-use test data for vehicles certified to meet California's $0.7 \mathrm{gpm} \mathrm{NO}$ emission standard. Emission rate equations for reflecting the effects of California's low-emitting vehicle (LEV) program and inspection/maintenance credits are also being considered for inclusion in MOBILE model updates.

The California Air Resources Board uses a separate computer model to assimilate emission test data and calculate basic emission rates. This model, CCLIFAC, uses the CARB's.In-Use Surveillance Program and the Inspection/Maintenance Project databases (along with EPA data) to derive the basic emission factors. The basic emission factors serve as the inputs to EMFAC, which subsequently applies emission correction factors to produce final emission factors. This report lists the California highway emission factors along with the EPA national emission factors.

\section{The EPA Procedure for Calculating Mobile Source Emissions Factors}

\section{Methodology:Overview}

Federal and state agency-developed emission factors for each vehicle type are derived from a fourstep process 5 :

First, "basic exhaust emission factors", or BEFs, are estimated according to rigid federal testing procedures ${ }^{60}$.

Second the BEFs are adjusted with a series of multiplicative and additive correction factors that account for testing condition variances in ambient temperature and operating mode, as well as expected emission contxl device tampering rates.

Third the BEFs are further adjusted with a composite correction factor that reflects/actual vehicle characteristics and driver operating practices (For the hydrocarbon BEF, separate emission factors for evaporative and running losses are added. In addition, the hydrocarbon

59 All emission rate equations and data referenced in this section come from EPA's AP-42 document and accompanying supplements, or the MOBILE4.1 model documentation, unless otherwise noted.

${ }^{60}$ Exhaust and evaporative emissions testing procedures for light-duty gasoline and diesel-powered vehicles are stipulated in the Code of Federal Regulations, 40 CFR Part 86, Subpart B, July 1, 1989. Testing procedures for heavy-duty gasoline and dieselpowered vehicles are stipulated in 40 CFR Part 86, Subpart N, July 1, 1989. 
and carbon monoxide BEFs are adjusted for fuel volatility.). A number of these correction factors are not included in the emission factor calculations for diesel-powered vehicles and trucks due primarily to a lack of reliable data.

Fourth; consolidated BEFs are derived by weighting the adjusted BEFs according to the fraction of total miles driven for each model year, and then summing over the 25 historical model years that constitute the in-use vehicle fleet for each calendar year. ${ }^{61}$ The equations for the consolidated emission factors are as follows:

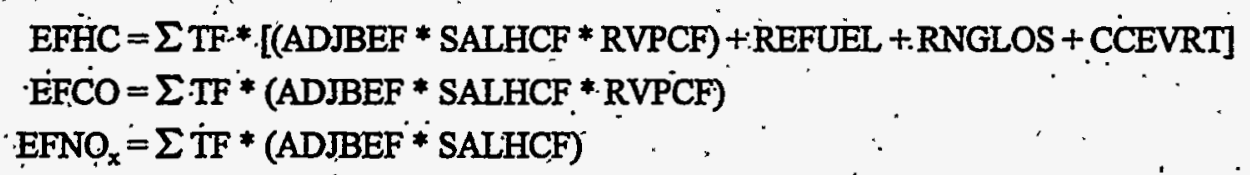

where:

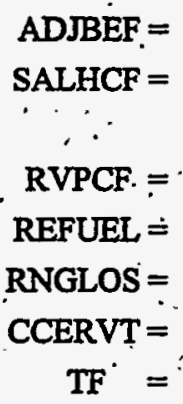

Adjusted basic exhaust èmission factor in grams per mile,

Composite speed, air conditioning, extra load, and trailer towing correction factor,

Fuel volatility correction factor,

Refueling hydrocarbon emission factor ( $g /$ mile),

Ruinning loss hydrocarbon emission factor ( $\mathrm{g} / \mathrm{mile}$ ),

Crankcase and evaporative hydrocarbon emission factor (g/mile),

Fraction of total miles driven

(Summation occurs over 25 model years $i$, from $\mathrm{n}-24$ to $\mathrm{n}$; where $n$ is the calendar year)

\section{Methodology Details}

Federal Test Procedures. The federal test procedures calculate basic exhaust and evaporative emissions for each vehicle model under specified ambient temperature and humidity levels, average speed and idle time, vehicle-miles-traveled (VMT), percent of VMT in cold-start, hot-start; and: stabilized operations, trip length, and fuel volatility. ${ }^{62}$ The gathering of exhaust emissions data is. accomplished with three test segments. For Segment No. 1 (cold-start test), emissions for the first.

\footnotetext{
61 The number of model years for the in-use fleet was expanded from 20 to 25 with the release of MOBILE4.1 (see User's Guide to MOBILE4.1, Sec. 1.1.4.).

62 The measure of volatility is Reid Vapor Pressure. Vapor pressure mieasures the level of surface pressure in pounds per square inch (psi) required to keep a liquid from vaporizing. Vehicles are tested at a certified RVP of 9.0 psi.
} 
505 seconds after engine start-up are collected. For Segment No. 2 (stäbilized test), emissions are collected for the next 870 seconds. Finally, for Segment No. 3 (hot-start test), the engine is turned off for a ten-minute duration, and is restarted and run for an additional 505 seconds with emissions being collected. The EPA conducts the test cycles at both low and high altitude locations.

Basic Emission Rates. The basic emission rate is calculated by a two-step formula based on the assumption that emission rates increase linearly with respect to accumulated vehicle mileage. First, a zero-mile emission level is obtained from the in-use vehicle testing results for a specific model year and pollutant. Added to this basic emission rate is an adjustment that reflects the culmulative mileage for the model year vehicle and a per-10,000 mile emission deterioration rate. The two step formula accounts for vehicles with cumulative mileage of less than 50,000 , and vehicles with mileage in excess of 50,000. The following example shows the equations and calculations used to obtain basic carbon monoxide emission rates for light-duty vehicles with a 1990 model year.

\section{Example 1: Calculating Carbon Monoxide Bäse Emission Rates}

\section{BER Two-Step Formula}

BER

$=\mathrm{ZML}+(\mathrm{DR} 1 * \mathrm{M})$

$=\mathrm{ZML}+(\mathrm{DR} 1 * 5)+(\mathrm{DR} 2 *(\mathrm{M}-5)$

for $M \leq 50,000$ Miles

for $M \leq 50,000$ Miles

where
$\mathrm{ZML}=$
Zero-mile emission level in gpm
$\mathrm{DR} 1=$
Emission deterioration rate for vehicles with less than or equal
DRि $=$ to 50,000 miles, in gpm per 10,000 miles Emission deterioration rate for vehicles with more than
$\mathbf{M}=$ 50,000 miles, in gpm per 10,000 miles
Model year cumulative mileage divided by 10,000 miles

\section{Assumptions:}

(1) CO emissions are for light-duty gasoline-powered vehicles with a 1990 model year

(2) Tests conducted at low altitude

(3). Calculate emission levels at cumulative mileage intervals of 50,000 and 100,000 miles.

\$0,000 Mile Emission Level:

$\mathrm{BER}=2.813+(0.769 * 5)=6.658$ grams per mile $\mathrm{CO}$

100,000 Mile Emission Level:

$\mathrm{BER}=2.813+(0.769 * 5)+(0.961 *(10-5))=11.463$ grams per mile $\mathrm{CO}$ 
Data Source: U.S. Environmental Protection Agency Office of Mobile Sources, Supplement $A$, Compilation of Air Pollutant Emission Factors, Volume.II - Mobile Sources (ÄP-42), January 1991.

-Basic Emission Factor Adjustments. The basic emission factors are adjusted with a series of general and pollutant-specific correction factors to account for ambient and vehicle operation characteristics that differ from the standardized federal testing conditions. The adjusted BER: equations are as follows:

$$
\begin{aligned}
& \mathrm{ADJBEF}_{\mathrm{HC}}=\{[(B E R * \text { OMTCF })-\mathrm{OFFMTH}] * \text { PCLEFT }\}+\text { OMTTAM } \\
& \text { ADJBEF } C O=(B E R * \text { OMTCF * PCLEFT })+O F F C O+\text { OMTTAM } \\
& \mathrm{ADJBEF}_{\mathrm{NO}}=\left(\mathrm{BER}^{*} \text {. OMTCF }\right)+\mathrm{OMTTAM}
\end{aligned}
$$


The equation terms are described below:

Temperature/Operating-Mode Correction Factor (OMTCF) - This multiplicative correction factor accounts for the observation that vehicles produce a smaller quantity of emissions as they move from cold-start to stabilized and hot-start operating modes. The OMTCF is expressed as a sum of VMT-weighted linear functions of the fleet cumulative mileage for each model year, adjusted for (1) the emissions contribution attributable to each operating mode (represented as intercept and slope coefficients of the linear functions), and (2) a previously estimated temperature correction factor for each model year, pollutant, test segment, and ambient-temperature (not applicable to diesel-powered vehicles and trucks): As with the basic emission rate formula, OMTCFs are calculated with a two-stage formula to reflect emissions deterioration for vehicles with cumulative mileage greater than 50,000 miles:

\section{OMTCF $=($ TERM1 + TERM2 + TERM3 $) /$ DENOM}

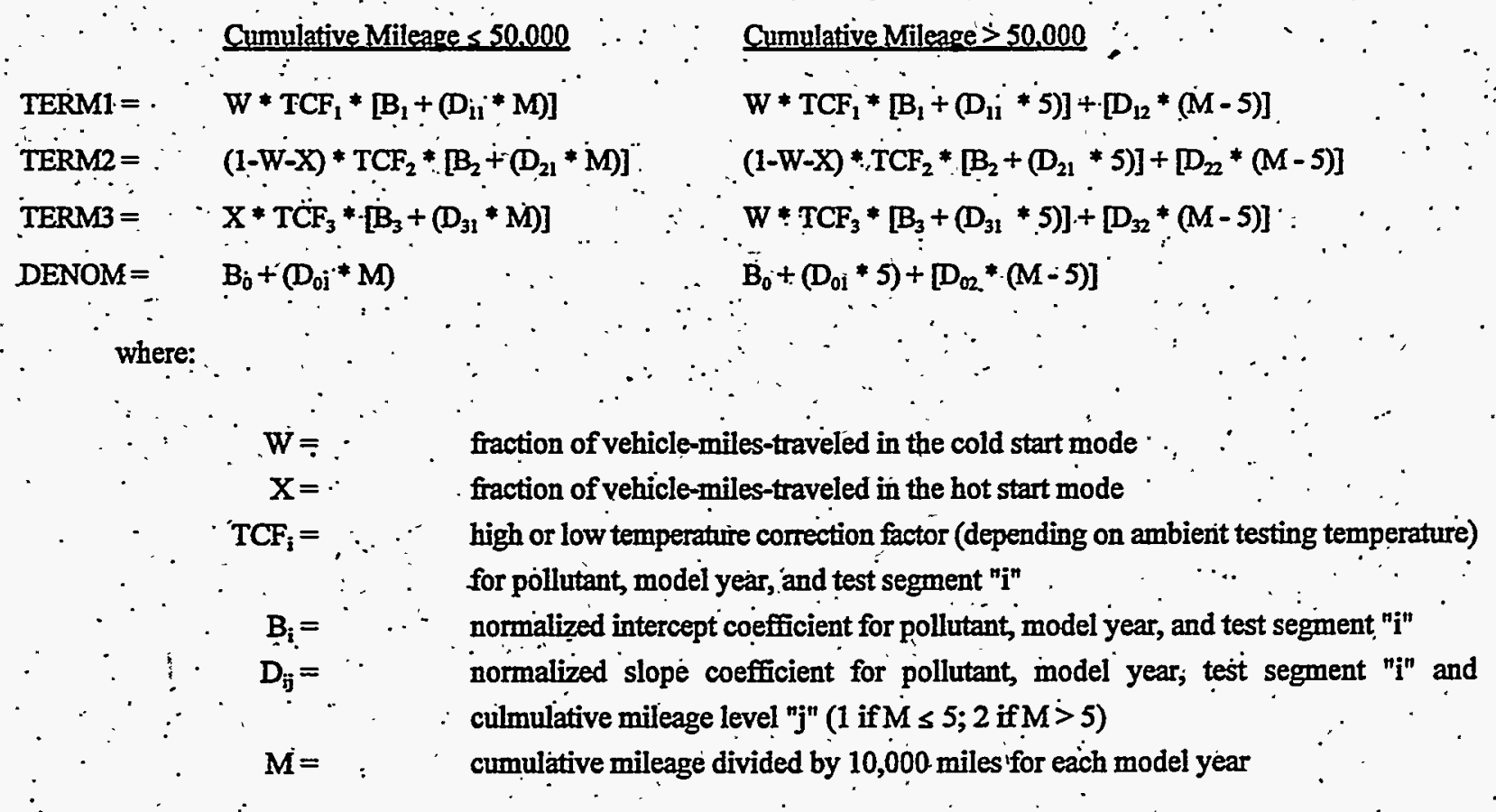

The low temperature correction factor is applied when the ambient temperature is lower than the reference test temperature of $75^{\circ} \mathrm{F}$. For all pollutants, test segments, and model years, except segment 1 (cold start) CO emissions for model years from 1980 and later, a simple 
exponential model is used ${ }^{63}$ In the case of cold start carbon monoxide OMTCFs for model years 1980 and later, two additional calculation steps are necessary. First, $\mathrm{TCF}_{1}$ is removed from the TERM1 equation in order to eliminate the temperature correction related to the cold start mode. Second; an alternative additive version of the low temperature correction factor is calculated, the "CO offset" (OFFCO), which adjusts the cold start emissions for higher $\mathrm{CO}$ produced during the cold start mode. The $\mathrm{CO}$ offset is multiplied by the percent of VMT in the cold start mode (the "W" term) and adjusted for fuel volatility if the temperature is greater than $40^{\circ} \mathrm{F}$. The $\mathrm{CO}$ offset term is then added to the basic $\mathrm{CO}$ exhaust emission rate factor:

'The high temperature correction factor equation for pre-1980 model years, applied when the ambient temperature is higher than $75^{\circ} \mathrm{F}$, is similar to that of the low temperature correction factor. For post-1979 model years, an alternative correction factor is used that incorporates a fuel volatility correction component. The combined high temperature/fuel volatility correction factor model is:

$$
\text { TRCF }=\mathrm{e}^{\left\{[\mathrm{A} *(\operatorname{RVP}-9.0)]+\left[\mathrm{B}^{*}(\mathrm{~T}-75.0)\right]+\left[\mathrm{C}^{*}(\mathrm{RVP}-9.0)\right] *(\mathrm{~T}-75.0)\right\}}
$$

where $\mathrm{RVP}$ is the fuel volatility level in psi RVP, T is the ambient temperature, and $A, B$, and $\mathrm{C}$ are estimated coefficients.

Tampering Offset (TAMPOFF) - A tampering and misfueling offset (in grams per.mile) is added to the basic emission rate to reflect the assumption that a certain fraction of flHxt vehicles have had emission control components disabled or fueling components damaged. Such tampering and misfueling occurrences increase exhaust and evaporative emissions. Tampering/misfueling types tracked by the EPA include air pump disablement, catalyst removal, EGR system disablement, filler neck damage, fül tank misfueled, combined filler neck damage and fuel tank misfueled, PCV system disablement, canister disconnection, and combined canister and fuel cap removal.

The EPA has conducted nationwide tampering/misfueling surveys since 1978, and data for surveys completed in 1984, 1985, and 1986 have been incorporated into the Tampering

${ }^{63}$ The equation is: $\mathrm{TCF}_{\mathrm{bew}}=\operatorname{EXP}\left[\mathrm{TC}_{\mathrm{ibp}} \bullet(\mathrm{T}: 75.0)\right]$, where $\mathrm{TC}_{\mathrm{ibp}}$ is a coefficient for model year $i$, pollutant $p$, and test segment $b$, at the ambient reference temperature of 75 degrees Fahrenheit; and $T$ is the ambient temperature. 
Offset calculation methodology ${ }^{64}$ The TAMPOFF is applied to only four vehicle types due to the lack of comprehensive data: light-duty gas-powered vehicles, light-duty gas-powered trucks (both weight categories I and II), and heavy-duty gas-powered vehiclès. The TAMPOFFs for each tampering type are calculated with the following equation for calendar year ${ }_{n}: \cdots$

$$
\text { TAMPOFF }=\text { TAMP }_{\text {ipm. }} * \text { PEQUIP }_{\text {im }} * \text { RATE }_{\text {im }}
$$

where:

$$
\begin{gathered}
\text { TAMP }_{\text {pm }}= \\
\because \\
\text { PEQUIP } \\
\text { im } \\
\text { RATE }_{\text {im }}=
\end{gathered}
$$

incremental increase in emissions from tampered vehicles for model year $i$, pollutant $p$, and tampering type $\ddot{m}$, percent of the model-year $i$ vehicles that are equipped with item $m$ that can be tampered, percent of model-year $i$ vehicles with equipment $m$ that has been tampered with.

The term, TAMP, is derived from linear regression equations with cumulative mileage in 10,000 -mile increments serving as the regressor or explanatory variable (the regression intercept is interpreted as the zero-mileage emission rate). The regressions yield deterioration rates up to 50,000 cumulative mileage, with mileage in the 50,000 to 130,000 . range handled with an additional adjustment factor representing each tampering-type/vehicletype combination.

The tampering-type emissions offsets are combined to form an overall composite offset with each tampering-type offset adjusted with the applicable temperature correction factor (TCF), and weighted according to the percent of accumulated vehicle-miles-traveled in cold start, stabilized, and hot start modes. The tampering offset is not applicable to diesel-powered vehicles and trucks.

\section{Inspection and Maintenance (I/M) Program Exhaust Emission Benefit (PCLEFT) -}

This optional emissions rate adjustment factor accounts for the hydrocarbon and $\mathrm{CO}$ emissions reduction benefits attributable to inspection/maintenance programs. The emission rate I/M credits are estimated using a separate EPA model, TECH IV+; which is currently

\footnotetext{
- ${ }^{64}$ Source: Compilation of Air Pollutant Emission Factors, Volume 2-Mobile Sources, Supplement A, Appendix E, p. E-1. Additional survey results gathered after the publication of this document are also included in the offset estimation equations.
} 
being updated into a.TECH 5 version that will include a $\mathrm{NO}_{x}$ benefit submodel and other revisions reflecting new I/M program data ${ }^{65} \mathrm{I} / \mathrm{M}$ program parameters for the TECH model include program start year, stringency level, first/last model years of vehicle subject to. program requirements, waiver rates, compliance rates, program type, inspection frequency, vehicle type, test type, and availability of alternative $\mathrm{I} / \mathrm{M}$ credits for certain technology groups: The I/M program emissions benefit is not applicable to diesel-powered vehicles and all truck types.

Methane Offset (OFFMTH) - This grams-per-mile offset is used to adjust the hydrocarbọn basic emission rate when nonmethane $\mathrm{HC}$ emissions are estimated. Model-year offsets are calculated for each of the three test segments.

The BEFs are further adjusted by a composite speed, air conditioning; extra load, and trailer towing correction factor (SALHCF), with the following form:

$$
\mathrm{SALHCF}_{\mathrm{HC}, \mathrm{CO}}=\mathrm{SCF} * \mathrm{ACCF} * \mathrm{XLCF} * \mathrm{TWCF}
$$

and

$$
\mathrm{SALHCF}_{\mathrm{NO} \mathrm{x}}=\mathrm{SCF}^{*} \mathrm{ACCF} * \mathrm{XLCF} * \mathrm{TWCF}^{*} \mathrm{HCF}
$$

Each of the equation terms are described belòw.

Speed Correction Factor (SCF) - Federal test procedures call for the collection of basic exhaust emissions at an average speed of 19.6 miles per hour. To account for higher and lower average speeds exhibited by in-use vehicles, correction factors for three speed ranges were calculated using linear regression. ${ }^{66}$ The ranges are low speeds ( 2.5 to $19.6 \mathrm{mph}$ ), moderate speeds (19.6 to $48 \mathrm{mph}$ ), and high speeds. (48 to $65 \mathrm{mph}$ ). The speed correction factors are delineated by model year group, technology, pollutant, and emission level (i.e., normal vs high emitters), but are weighted and combined into one basic speed correction factor applied to base emission rates.

\footnotetext{
.65 The only $\mathrm{NO}_{x}$ reduction benefit currently modeled is from a reduction in tampering rates resulting from I/M programs. EPA analysis of transient $\mathrm{I} M \mathrm{M}$ test (IM240) data indicates that additional emissions reductions result from $\mathrm{NO}_{\mathrm{x}}$ cutpoint $\mathrm{I} / \mathrm{M}$ programs. (See Appendix E.EM.C, List of Potential Revisions for MOBILE5; Item No. 3-5.)

66 The speed correction factors are normalized to the speed associated with a weighted sum of the cold start and hot start mode VMT fractions. The SCFs were derived from multiplicative linear regression equations.
} 
Air Conditioning Correction Factor (ACCF) - The air conditioning correction accountș for the impact of air conditioner operations on pollutant emission types at various ambient temperatures for each model year.(This factor is not applicable to heavy-duty gas-powered vehicles, light-duty diesel-powered vehicles, light-duty diesel-powered trucks, and heavyduty diesel-powered vehicles). The correction factor is expressed as a linear relationship to temperature, adjusted with a multiplicative factor that reflects the fraction of $\mathrm{AC}$ units in use. The air conditioning correction factor equation has the following form:

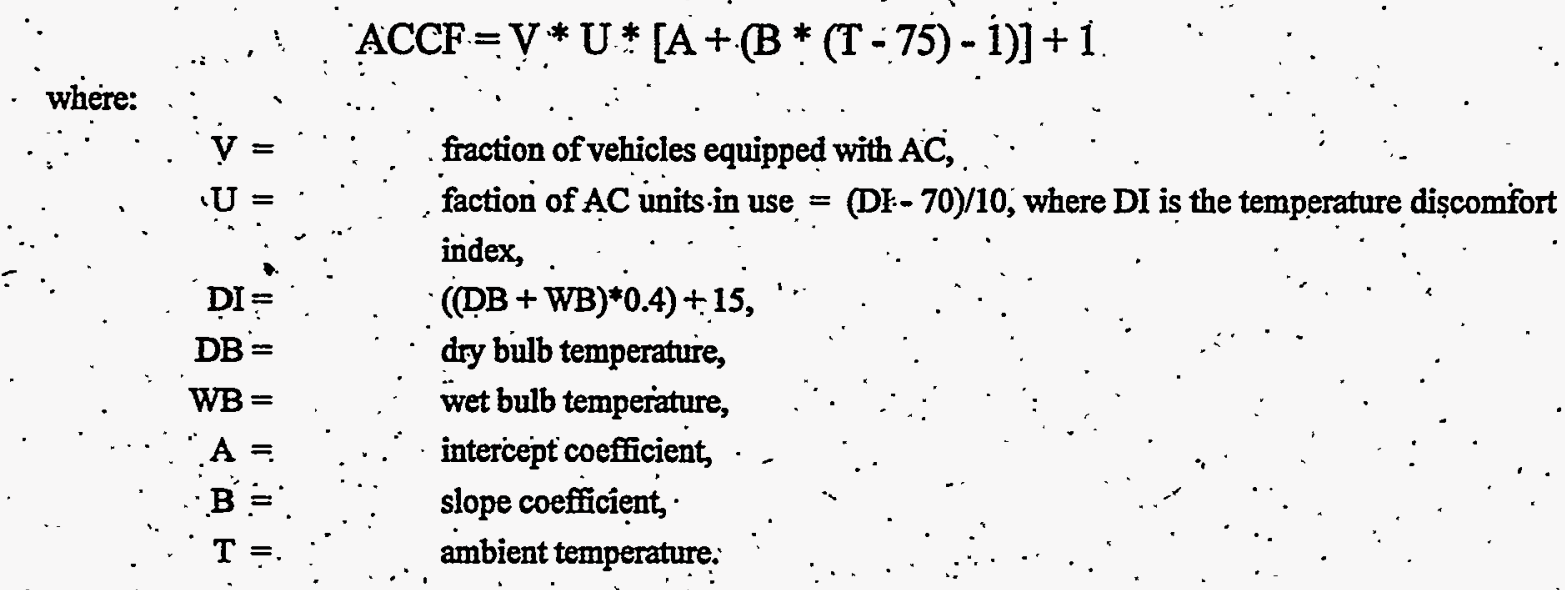

Extra Loàd Correction Factor (XLCF) - This correction factor incorporates the impacts on emissions of an increase of 500 pounds to the test standard vehicle weight, which includes a driver and one passenger. (This factor is not applicable to heavy-duty gas-powered vehicles, light-duty diesel-powered vehicles, light-duty diesel-powered trucks, and heavyduty diesel-powered vehicles). The extra load correction factor equation is:

$$
X I C F=\left[\left(X I^{\prime} C-1.0\right) * U\right]+1.0
$$

where XILC is a factor coefficient for each model year and pollutant, ${ }^{67}$ and $U$ is the fraction of vehicle-miles-traveled with the extra loạd.

Trailer Towing Correction Factor (TWCF)- The trailer towing correction factor, which accounts for the effect on emissions of an extra trailer weight of 1,000 pounds, is calculated with an equation that is identical in structure to that used for calculating the extra load

\footnotetext{
67 For example, XIC varies from 1.0786 to 1.0455 for low altitude light-duty gas-powered vehicles, depending on the model year. The XLC range for $\mathrm{CO}$ is 1.3058 to 1.1347 , and the range for $\mathrm{NO}_{x}$ is 1.0719 to 0.9535 .
} 
correction factor:

$$
\mathrm{TTCF}=[(\mathrm{TTC}-1.0) * \mathrm{U}]+1.0
$$

where TTC is a factor coefficient for each model year and pollutant, ${ }^{68}$.and $\dot{U}$ is the fraction of vehicle-miles-traveled with the extra trailer load.

This factor is not applicable to heavy-duty gas-powered vehicles, light-duty diesel-pówered vehicles, light-duty diesel-powered trucks, and heavy-duty diesel-powerëd vehicles.

NO $\mathrm{x}_{\mathrm{x}}$ Humidity Correction Factor $(\mathrm{HCF})-\mathrm{NO}_{\mathrm{x}}$ emission factors are normalized to 75 'grains of water per pound of dry air. To achieve this normalization given various humidity levels, a multiplicative correction factor is applied to the composite $\mathrm{NO}_{x}$ SALHCF. The following HCF equation is applicable for all model years:

$$
\mathrm{HCF}=1.0-0.0038 *(\mathrm{H}-75.0)
$$

where $\dot{H}=$ humidity level in grains of water/lb. dry air. This humidity correction factor is not applicable to heavy-duty diesel-powered trucks.

Data obtained from monitoring emissions at different Reid Vapor Pressure levels shows that hydrocarbon and $\mathrm{CO}$ emissions increase as volatility increases. For exhaust emissions at fuel . volatility levels different from the test certification RVP of $9.0 \mathrm{psi}$; and when the ambient temperature is greater than $40^{\circ} \mathrm{F}$, a fuel volatility correction factor (RVPCF) is applied to the basic hydrocarbon and $\mathrm{CO}$ emission factors.

There are three fuel volatility correction factor equations, with the selection based on vehicle model year and ambient temperature.- For model years 1971 through 1979 (and at all temperatures), the RVPCFs for hydrocarbons and $\mathrm{CO}$ are based on a simple linear extrapolation model ${ }^{69}$ :

$$
\begin{aligned}
& \mathrm{RVPCF}_{\mathrm{HC}}=(0.56222+0.012512 * \mathrm{RVP}) / 0.67483 \\
& \mathrm{RVPCF}_{\mathrm{CO}}=(7.1656+0.33413 * \mathrm{RVP}) / 10.17277
\end{aligned}
$$

\footnotetext{
6s For example, TTC varies from 1.7288 to 1.2614 for low altitude light-duty gas-powered vehicles, depending on the model year. -The TTC range for $\mathrm{CO}$ is 1.8940 to 3.9722 , and the range for $\mathrm{NO}_{\mathrm{x}}$ is 1.1184 to 1.3875 .
}

69 The denominator value represents the numerator evaluated at the certification Reid Vapor Pressure of 9 psi. 
For post- 1979 model years and at a temperature greater than $75^{\circ} \mathrm{F}$, the RVPCF is incorporated with the high temperature correction factor discussed in the Temperature/Operating-Mode Correction Factor (OMTCF) section.

For post-1979 model years and at a temperature in the $40^{\circ} \mathrm{F}$ to $75^{\circ} \mathrm{F}$ range, a two-step correction procedure is used. First, a RVP correction factor evaluated at $75^{\circ} \mathrm{F}$ is obtained using the combined high temperature/fuel volatility model. The resulting RVPCF is then used as an input to the following equation:

$$
\mathrm{RVPCF}==1.0+\left\{\left[\left(\mathrm{RVPCF}_{75^{\circ} \mathrm{F}}-1.0\right) *[(\mathrm{~T}-40.0) / 35.0)\right]\right\}
$$

where $T$ is the ambient temperature in the range of $40^{\circ} \mathrm{F}$ to $75^{\circ} \mathrm{F}$.

The post-1979 model year fuel volatility correction factors are also disaggregated based on test segment and fuel delivery system (carbureted, throttle-body fuel injection, and multi-point fuel injection).

Evaporative Emissions Factors. In addition to the basic exhaust emission factors for hydrocarbons, evaporative emissions from carburetion and fiel tank systems must be included in the consolidated hydrocarbon emission factors. The EPA models five types of $\mathrm{HC}$ evaporative emissions: crankcáse, hot soak (evaporative emissions occurring after a trip), diurnal (release of fuel vapors due to an expansion of the air-fuel mixture in a partially filled fuel tank when the ambient temperature increases), running loss (emission generated during vehicle operation), and refueling. (displacement of fuel vapor from the tank during refueling, and spillage). Evaporative emission factors are not applicable to diesel-powered vehicles and trucks.

Crankcase, hot soak, and diurnal emissions (CCERVT) are calculated with one equation:

$$
\text { CCERVT }=\left[(H S+T A M P H S) * \mathrm{TPD}_{\mathrm{j}}\right]+\left[(\mathrm{DI}+\mathrm{TAMPDI}) / \mathrm{MPD}_{\mathrm{j}}\right]+(\mathrm{CC}+\mathrm{TAMPCC})
$$

where:

$$
\begin{array}{ccc}
\text { HS }= & \begin{array}{l}
\text { Hot soak emission rates in grams per trip, corrected for temperature } \\
\text { TAMPHS }=
\end{array} & \begin{array}{l}
\text { Excess hot soak emission rates due to tampering, corrected for RVP } \\
\text { fuel volatility, }
\end{array} \\
\mathrm{TPD}_{\mathrm{j}}= & \begin{array}{l}
\text { Trips per day for age } \mathrm{j} \text { vehicles, } \\
\mathrm{DI}=
\end{array} & \begin{array}{l}
\text { Diumal emission rates in grams, corrected for temperature and fuel } \\
\text { volatility, }
\end{array}
\end{array}
$$




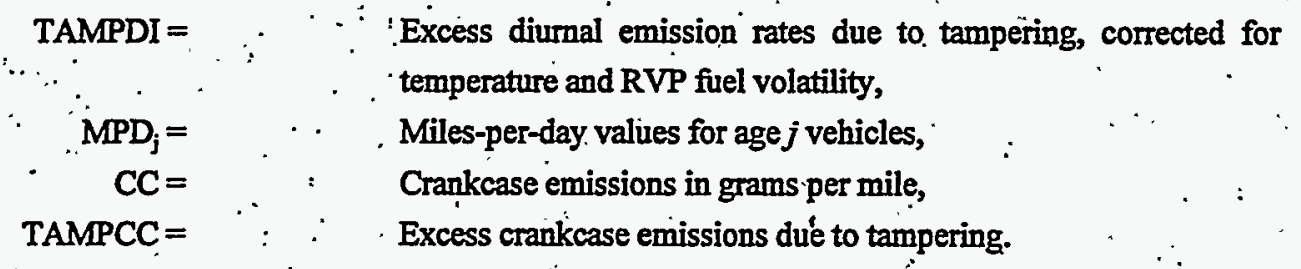

Running loss emissions (RNGLOS) are calculated in a similar manner: loss emission rates in grams per mile are corrected for temperature and RVP fuel volatility (RULOSS), and then are added to the excess running loss emissions ascribed to tampering (TAMPRL).

Refueling loss emissions (REFUEL) are calculated by adding together the displacement fueling 'losses corrected for.RVP fuel volatility (DISP) and an average spillage,rate-(SPILL), both measured in grams per gallon. This figure is divided by the road fuel economy rate (ROADFE), measured in gallons per mile.

All evaporative emission factor components are modeled as a function of the ambient temperature and fuel volatility. Running losses are modeled with two additional variables - average speed and trip duration. Refueling losses are modeled with one additional variable, defined as the temperature difference between the dispensed fuel and the residual tank fuel. EPA has also recently incorporated into its modeling the results of inspection/maintenance program testing for fuel/evaporative control system leaks and the capability of the carbon canister to properly purge vapors. The impact of "pressure and purge" problems on hot soak, diumal, and running loss emission rates are reflected in MOBILE4.1.70

Calculation of Travel Weighting Fractions. After emission factor corrections have been applied to the basic exhaust emission factors, and hydrocarbon evaporative and exhaust emission factor components have been added together, travel weighting fractions (TFs) are applied for deriving the final consolidated emission fáctors.

The TFs represent model-year proportions of total vehicle-miles-traveled for each vehicle type. They are calculated with the use of an annual mileage accumulation rate distribution, a registration distribution $^{71}$, and a diesel sales distribution (applicable to all vehicle types except heavy-duty gas-"

${ }^{70}$ User's Guide to MOBILE4.1, Sec. 1.1.6, p. 1-12.

7 The EPA collects July 1 registration data, which is adjusted to reflect registration activity as of January 1. Vehicle sales are assumed to be uniform throughout the year. 
powered vehicles and heavy-duty gas-powered trucks).

Example 2 shows the calculation of a consolidated hydrocarbon emission factor for model-year 1988 light-duty gasoline-powered vehicles.

\section{Example 2: Calculating a Consolidated Hydrocarbon Emission Factor for Light-Duty Gasoline Powered Vehicles.}

\section{Assumptions:}

(8) : $:$ Basic HC emission factors are adjusted for the effects of tampering. (9) , Methane is included in HC calculations.

HC emissions are for light-duty gasoline-powered vehicles with a 1988 evaluation calendar year, 20-model-year vehicle window, with testing conducted at low altitude.

Daily minimum and maximum ambient temperatures are $60^{\circ} \mathrm{F}$ and $80^{\circ} \mathrm{F}$, respectively.

All conditions match the basic federal test conditions (i.e., air conditioning, extra load, trailer ${ }^{*}$ towing, humidity levels, and other basic exhaust emission correction factors have no affect on : the calculations, and are therefore set to 1.0 ).

No inspection/maintenance or anti-tampering programs are assumed:

Certification fuel volatility of $9.0 \mathrm{psi}$ is assumed.

Total HC emissions are calculated at an average speed of 30 miles per hour.

Percentages of vehicle-miles-traveled in the cold start, stabilized, and hot start operating modes

\section{Consolidated Emission Factor Equation}

\section{CONBEFHC $=\sum_{\text {TF }_{i}} *$ [(BEF $*$ SALHCF $)+$ REFUEL + RNGLOS + CCEVERT]}

where:

CONBEFHC $_{n}=$ Consolidated Hydrocarbon Emission Factor for calendar year $n$,

$\mathrm{TF}_{i}=$.Travel Weighting Fraction for Model Year $i$,

$B E F=$ Adjusted. Hydrocarbon Exhaust Emission Factor," SAIHCF= Speed Correction Factor,

REFUEL=Refueling HC Emission Factor,

RNGLOS= Rumning Loss HC Emission Factor,

CCEVERT $=$ Crankcase and Evaporative HC Emission Factor. 
Data Table

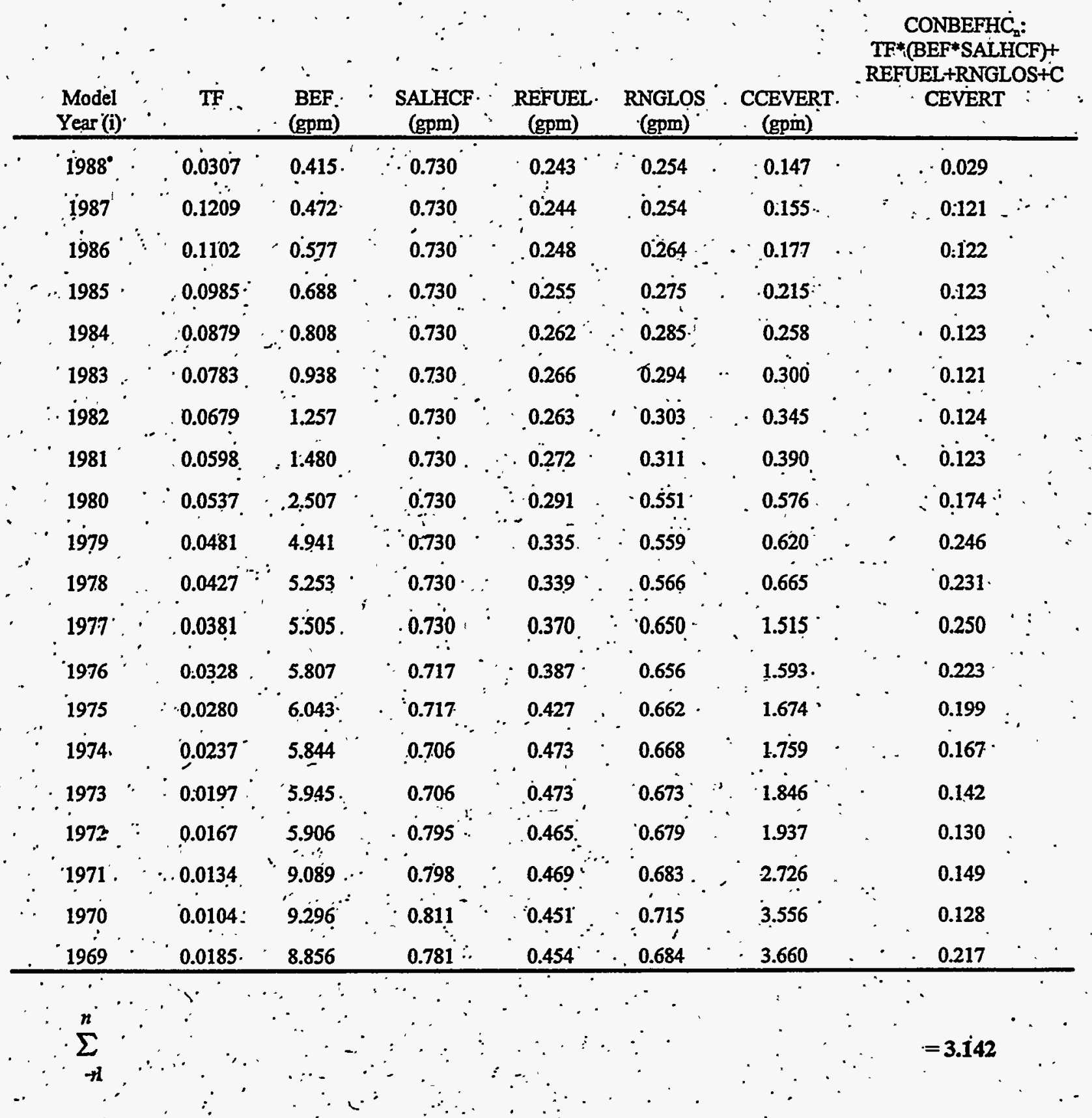

Data Source: U.S. Environmental Protection Agency Office of Mobile Sources, Supplement A, Compilation of Air Pollutant Emission Factors, Volume II - Mobile Sources (AP-42), January 1991, Appendix G. 


\section{DAC Highway: Mobile Source Emissions Factor Methodology}

\section{Carbon Monoxide, Volatile Organic Compound, and Nitrogen Oxide}

\section{Emission Factors: Conventional Vehicles}

DAC calculated $\mathrm{VOC}, \mathrm{CO}$, and $\mathrm{NO}_{\mathrm{x}}$ emission factors for highway sources using a two-step methodology. First, MOBILE4.1 model runs were conducted to obtain baseline emission factor forecasts. Second, off-line adjustments to the baseline emission factor forecasts were made to reflect the new CAAA regulations that have not been incorporated into the MOBILE4.1 solution algorithms. Table F-77 provides the adjusted MOBLE4.1 emission factors for conventional vehicle types. ${ }^{72}$. The vehicle types consist of LDGVs, LDGTs (combined Class 1 and 2), HDGVs, LDDVs, LDDTs, and HDDVs: Table F-7.8 provides the EPA definitions for each of the vehicle-type çategories:-

Emission factors for heavy-duty diesei-powered vehicles (HDDVs) should be used for dieselpowered buses: This is recommended by the EPA, which cites the similarities between the two vehicles types as well as the lack of comprehensive emission testing for buses (note that the EPA bus emission factors are reported in grams per mile as opposed to the TERF lbs./1,000 gal. specification):. Efforts at improving the EPA bus emission data base are ongoing because of concern that the HDDV emission factors do not accurately reflect in-use characteristics of buses in urban areas.

A complication results in trying to combine the EPA vehicle-type emission factors into the freight truck category designated in the TSCDR As shown in Table F-78, the EPA vehicle-type categories for-heavy-duty vehicles and trucks do not correspond to the weight categories used by either the TIUS or the FHWA Highway statistics report. The EPA uses a weight cut-off of 8,500 pounds GVW for its heavy-duty classifications. Trucks with an average weight greater than 10,000 pounds are classified as medium, light-heavy, or heavy-heavy by the TIUS. There is no weighting method that proves satisfactory for normalizing the EPA emission factors to the FHWA weight categories. Therefore, we recommend that the EPA emission factors for gasoline and diesel heavy-duty vehicles - (HDGVs and HDDVs) be used as the TERF freight truck emission factors:

i2 Five-year interval forecasts were interpolated to produce year-to-year emission factors. 
Table F-77. Adjusted MOBILE4.1 Emission Factors

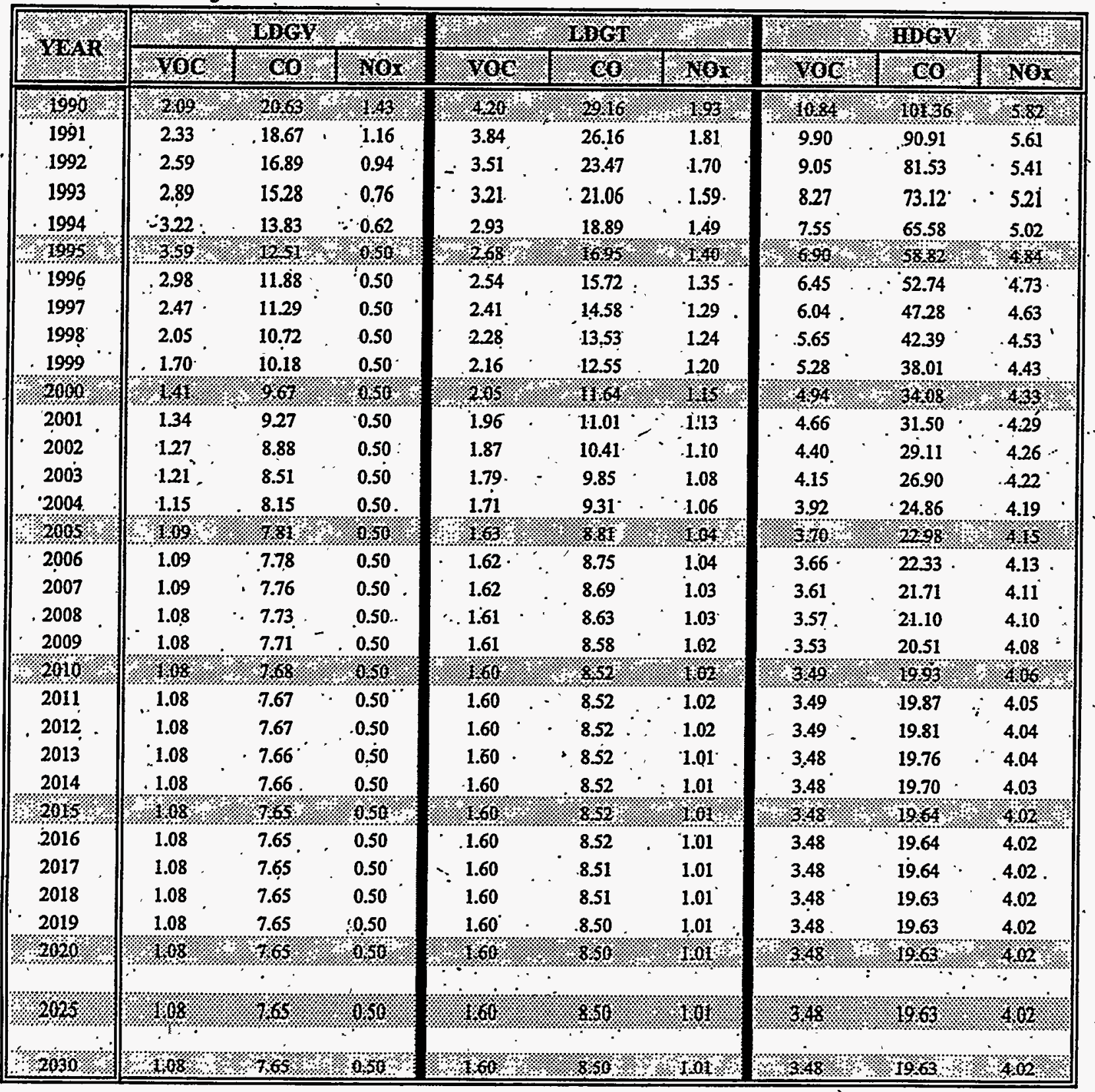

Adjustment notation:

(1) LDGV's: Adjust VOC downward by $0.14 \mathrm{gpm}$ for 1995 through 2030 to reflect decrease in exhause emission standard from $0.39 \mathrm{gpm}$ to $0.25 \mathrm{gpm}$.

(2) LDGVS: Assume $\mathrm{NO}_{\mathrm{x}}$ emissions of $0.50 \mathrm{gpm}$ beginning in 1995 and forward to reflect new/in-use standard fo $0.40 \mathrm{gpm}$ and $0.6 \mathrm{gpm} 100,000$-mile certification standard.

(3) LDGV's: CO emission factors include new cold temperature standards.

(4) LDDV's: MOBLE4.1 emission factors are below standards; therefore no adjustments to IDDV emission factors are necessary.

(5) . HDDV's: MOBILE4.1 incorporates $1994 \mathrm{HC}$ and CO standards. $\mathrm{NO}_{\mathrm{x}}$ standard was lowered, but MOBILE4.1 produces forcast emission factors at about the same level as the standards. 
Table F-77 (Continued)

\begin{tabular}{|c|c|c|c|c|c|c|c|c|c|}
\hline \multirow{2}{*}{ 16. } & \multicolumn{3}{|c|}{$1001 \%$} & \multicolumn{3}{|c|}{ 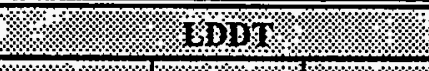 } & \multicolumn{3}{|c|}{ RDDV. } \\
\hline & 1000 & 160 & $110 \times$ & 1000. & 00 & $110 \times$ & Yod & 100 & $810 x$ \\
\hline 990 & $\%$ & 66 & $\sqrt{2.59}:$ & 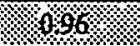 & $\times 90$ & $187 \%$ & $28 \%$ & $13 \% 4$ & $3 / 1945$ \\
\hline 1991 & 0.72 & 1.68 & . 1.63 & 0.97 & 1.91 & 1.86 & 2.73 & 12.75 & $\therefore \quad 17.72$ \\
\hline 1992 & 0.73 & 1.70 & 1.64 & 0.98 & 1.91 & $1: 85$ & 2.62 & 12.49 & 16.14 \\
\hline 1993 & 0.74 & 1.71 & · 1.64 & 1.00 & .1 .92$. & 1.85 & $2.52^{\circ}$ & $12.22^{\circ}$ & 14.70 \\
\hline $1994^{\circ}$ & 0.75 & $=1.73$ & $1.65^{\circ}$ & $1.01=$ & 1.92 & 1.84 & 2.42 & 11.96 & 13.39 \\
\hline$\frac{9995}{99}=$ & $10 \%$ & 64.4 & (:) & 102 & 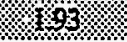 & 1883 & 28 & 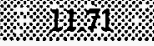 & $228 \%$ \\
\hline 1996 & 0.74 & 1.71 & - 1.59 & 0.98 & 1.89 & 1.76 & 2.28 & $11.61^{\circ}$ & 11.56 \\
\hline 1997 & 0.71 & 1.68 & 1.53 & 0.94 & 1.85 & $1.699^{\circ}$ & 2.25 & 11.51 & 10.94 \\
\hline 1998 & 0.69 . & 1.65 & 1.48 . & 0.91 & 1.81 & 1.62 & 2.22 & -11.41 & 10.37 \\
\hline 1999 & 0.67 & 1.63 & 1.42 & 0.87 & 1.78 & 1.56 & .2 .18 & 11.31 & .9 .82 \\
\hline $2006 \%$ & $0,6 \%$ & 260 & $437 \%$ & 0084 & $1 \%$ & 160 & 2015. & $x .1$ & $830 \%$ \\
\hline $2001^{\circ}$ & 0.62 & $1.57^{\circ}$ & 1.32 . & 0.80 & $\cdot 1: 70$ & $1: 44$ & 2.14 & 11.18 & 9.11 \\
\hline 2002 . & 0.59 & 1.53 & .27 & 0.76 . & 1.66 & i. 39 & .2 .13 & 11.16 & 892 \\
\hline 2003 & 0.57 & 1.50 & 1.22 & 0.73 & 1.62 & 1.33 & 2.13 & $11: 13$ & 8.73 \\
\hline $2004^{\circ}$ & 0.54 & 1.47 & 1.17 & 0.69 & 1.59 & 1.28 & 2.12 & 11.11 & 8.55 \\
\hline 12005 & 632 & 4.4 & xis. & 0.66 & $45 \%$ & 123 & 211 & 11808 & 837. \\
\hline 2006 & 0.52 & 1.44 & $1.12 ：$ & 0.66 & 1.55 & 1.22 & 2.11 & 11.07 & 8.32 \\
\hline $2007 \because$ & 0.51 & 1.43 & 1.11 & 0.66 & 1.55 & 1.21 & 2.11 & $11.07 \ldots$ & $8.27^{\circ}$ \\
\hline 2008 & 0.51 & -1.43 & 1.09 . & 0.65 & 1.54 & 1.21 & 2.10 . & 11.06 & 8.21 \\
\hline 2009 & 0.50 & 1.42 & $1.08^{\prime}$ & 0.65 & 1.54 & 120 & 2.10 & 11.06 & 8.16 \\
\hline $20+0=$ & $850 \%$ & 1242 & \%ot & 806 & $8.5 \%$ & 10 & $20 \%$ & 180 & 81 \\
\hline 2011 & 0.50 & 1.42 & 1.07 & 0.65 & 1.54 & 1.19 & 2.10 & 11.05 & 8.10 \\
\hline 2012 & 0.51 & $1: 43$ & .08 & 0.65 & $.1 .54^{\circ}$ & 1.19 & 2.10 & 11.05 & $8.09^{\prime}$ \\
\hline 2013 & 0.51 & 1.43 & \%. 1.08 & 0.66 & 1.54 & 1.19 & 2.10 & 11.04 & 8.07 \\
\hline 2014 & 0.52 & 1.44 & 1.09 & 0.66 & 1.54 & 1.19 & 2.10 & 11.04 & 8.06 \\
\hline 22015 & $855 \%$ & 184 & 109 & 0666 & (1. & 1/.9. & 210 & 1100 & $805 \%$ \\
\hline 2016 & 0.52 & 1.44 & 1.09 & 0.66 & 1.54 & 1.19 & 2.10 & $11: 04$ & 8.05 \\
\hline 2017 & 0.52 & 1.44 & 1.09 & 0.67 & 1.55 & 1.20 & 2.10 & 11.04 & 8.05 \\
\hline 2018 & 0.52 & 1.44 & 1.09 & $0.67^{\circ}$ & $1.55^{\circ}$ & 1.20 & 2.10 & 11.04 & 8.05 \\
\hline .2019 & 0.52 & 1.44 & 1.09 & 0.68 & 1.56 & 1.21 & 2.10 & 11.04 & 8.05 \\
\hline $2020 \%$ & 0.52 & 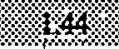 & 809 & 0,68 & \% & Q2i. & 416 & 41,04 & $805 \%$ \\
\hline & & & $+\ldots$ & $\therefore$ & & & & & \\
\hline 12025 & $80 \leqslant 2$. & 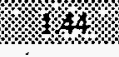 & U. & 8.68 & 136 & 121 & 210 & $110 \%$ & $805 \%$ \\
\hline & & & & & & & & & \\
\hline 203.0. & $80.5 x$ & 444 & 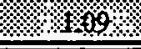 & 0.68. & 3.66 & 121 & $2.10 \%$ & 4040 & $8.8: 05$. \\
\hline
\end{tabular}

Adjustment notation:

(1) LDGV's: Adjust VOC downward by $0.14 \mathrm{gpm}$ for 1995 through 2030 to reflect decrease in exhause emission

(2). LDGV'S: Assume $\mathrm{NO}_{x}$ emissions of 0.50 gpm begining in 1995 and forward to reflect new/in-use standard fo $0.40 \mathrm{gpm}$ and $0.6 \mathrm{gpm} 100,000$-mile certification standard.

(3) LDGV's: CO emission factors include new cold temperature standards.

(4) LDDV's: MOBLE4.1 emission factors are below standards; therefore no adjustments to LDDV emission factors are necessary.

(5) HDDV's: MOBLE4.1 incorporates $1994 \mathrm{HC}$ and CO standards. $\mathrm{NO}_{\mathrm{x}}$ standard was lowered, but MOBILE4.1 produces forcast emission factors at about the same level as the standards. 
Table F-78: EPA Highway. Vehicle Classification Categories and Definitions

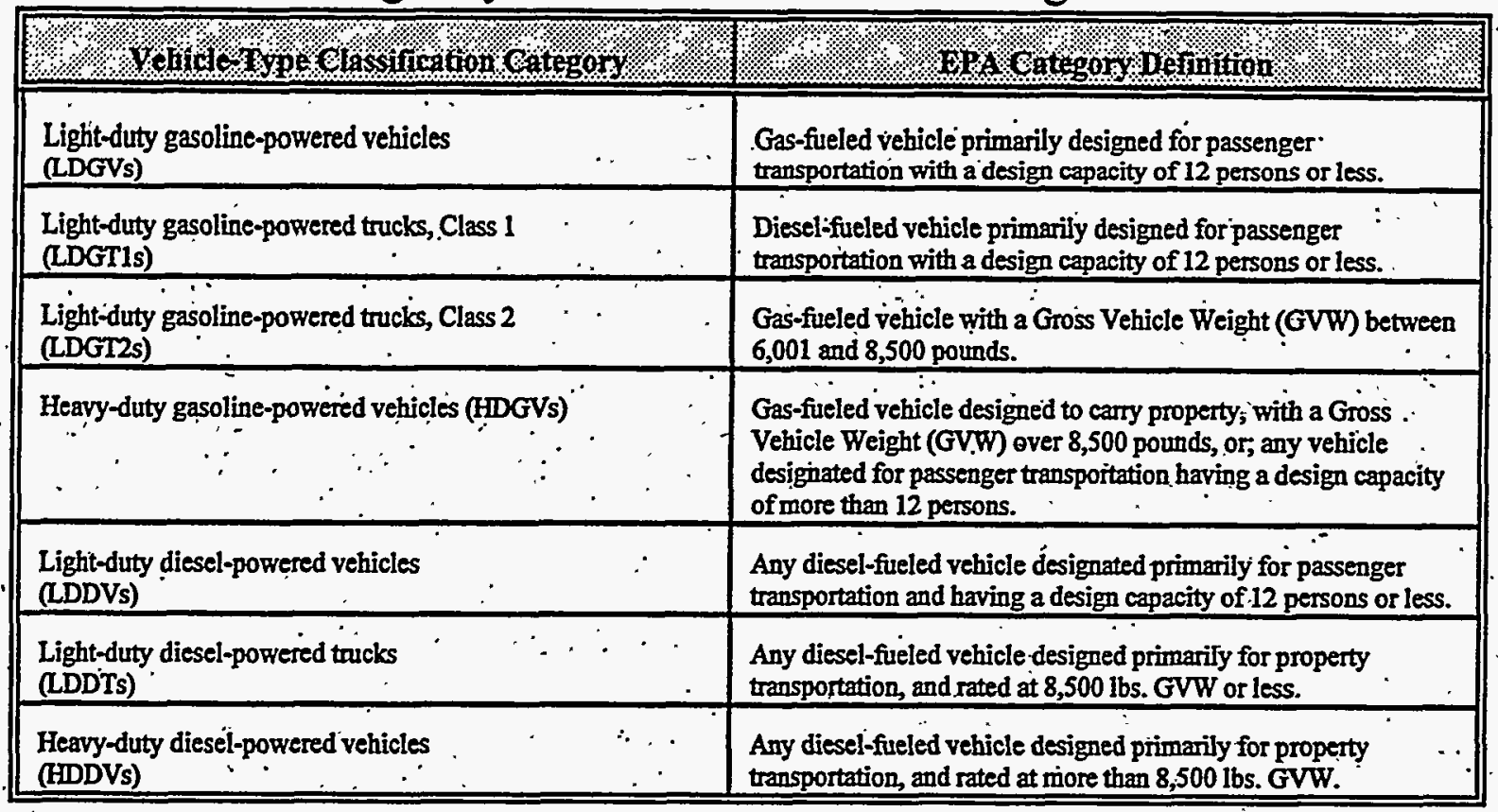

Source: U.S. Environmental Protection Agency, Supplement A to AP-42. Volume II, January 1991.

DAC obtained the MOBILEA.1 model from the EPA, and used the model to calculate national CO, $\mathrm{NO}_{\mathrm{x}}$, and VOC emission factors to the year 2020 (the last MOBILE4.1 forecast year) using a scenario-based input data set. EPA.staff make the assumption that emission factors remain relatively stable after $2010 .^{73}$ Therefore, emission factors for 2020 are used for the subsequent forecast years. As already noted, the MOBILE4:1 emission factors do not reflect many new CAAA standards that should affect emission rates after 1993. Post hoc adjustments need to be made to account for new vehicle standards, in-usé standards, and other CAAÄ emission control requirements if the forecasted emission factors exceed the standards in any year. It is important to note that any emission factor adjustments are based on gross assumptions, with the resulting emission factors considered to be interim in nature.

The MOBILE4.1 input data set consists of a series of user-specified control flags, data inputs common to all emission scenarios, and data inputs specific to an individual scenario. In addition to regulating program execution and input/output stream formatting, the control flags determine model actions such as the use of emission control device tampering rates, average vehicle speed selection, mileage accumulation rate selection, VMT mix selection, I/M program impact, ambient temperature selection; and many other factors. Control flags specifying EPA default values and national averages were included to the maximum extent.

73 Personal communication with Lois Platte, EPA Motor Vèhicle Emission Laboratory, Ann Arbor, Michigan, June 26, 1992. 
The greatest difficulty in developing the MÖBILEA.1 data.set was accounting for the impact of inspection/maintenance programs. MOBILEA.1 was not designed with the capability for estimating national average I/M program impacts. The I/M program data set record must be specified according to local IM program attributes. Such program attributes are highly customized to met localespecific implementation needs, and therefore cannot be formulated into a national average $I / M$ program. Further complications result from the fact that:I/M programs are not required nor implemented in many areas of the country, and new EPA regulations have resulted in greater complexity for existing and planned programs.

To account for the effects of $\mathrm{I} / \mathrm{M}$ and anti-tampering programs on emission factors, a model-run interpolation method was used. Inspection and maintenance programs are required for 162 ozone areas based on CAAA regulations. A data set was created that included parameters and data for an "enhanced".I/M model program (required for serious, severe, and extreme ozone nonattainment areas) as outlined in the EPA's Notice of Proposed Rulemaking. ${ }^{74}$ An enhanced I/M program includes annual centralized testing for light-duty vehicles and trucks, and include such tests as the transient IM240 exhaust emission test, the transient purge test, the pressure test, the two-speed exhaust test, and the idle exhaust test. The EPA estimates that such an I/M program could reduce vehicle VOC emissions by 28 percent, $\mathrm{CO}$ emissions by 30 percent, and $\mathrm{NO}_{\mathrm{x}}$ emissions by 9 percent. ${ }^{75}$

A MOBLE4.1 emission factor based on national imposition of enhanced I/M programs is assumed to represent an upper bound for vehicle emissions. To account for areas that have no IM and antitampering programs, a MOBILE4.1 data set was created that excluded operating $I / M$ and antitampering programs. Separate sets of emișion factors were generated from MOBLIE4.1 model runs employing each data set. Composite emission factors were derived by taking the arithmetic average of the two emission factor sets. Ideally, the composite emission factor set should be calculated as a.weighted average, using vehicle mileage data for each type of ozone nonattainment area and I/M program type. Such a procedure is complex and time-consuming (and perhaps not doable because of the flexibility afforded to the states for choosing I/M program elements), and could not be attempted given the resources available for this subtask. The simple arithmetic average approach, while producing somewhat arbitrary results, is superior to assuming a universally-applied I/M program for all areas of the country. Such an assumption yields overly-optimistic emission factor

\footnotetext{
- 74 EPA Notice of Proposed Rulemaking; "Vehicle Inspection and Maintenance Requirements for State Implementation Plańs," 40. CFR Part 51, July 9, 1992.

75 Ibid., section II.
} 
reductions.

\section{Sulfur. Dioxide and Carbon Dioxide Emission Factors: Conventional Vehicles}

The EPA does not regularly monitor and report carbon dioxide and sulfur dioxide emissions for highway mobile sources. The relatively small amounts of $\mathrm{SO}_{2}$ emitted by trucks and cars are quickly converted to sulfuric acid; and therefore do not represent a significant air pollution hazard. Although the EPA produced $\mathrm{SO}_{2}$ measurement procedures in the early 1980 's, the Agency has not published $\mathrm{SO}_{2}$ emission factors. ${ }^{76}$

The $\mathrm{SO}_{2}$ and $\mathrm{CO}_{2}$ emission factors to be used in TERF' come from the Argonne National Laboratory's Transportation Energy and Emissions model (TEEMS). Table F-79 provides the emission factors produced for the DOE Office of Environmental Analysis as part of data input to the NESEAM model:? These emission factors include the effects of CAAA'emission standards, and: are forecasted to the year 2030 .

The TEEMS/NEASAM emission factors were reported in pounds of emissions per million Btu. To convert the emission factors to a grams-per-mile equivalent, the following formula:was used:

$$
\mathrm{EF}_{\mathrm{gpm}}=\mathrm{EF}_{\mathrm{ppBt}} \times 57.9549 / \mathrm{MPG}_{c}
$$

where:

$$
\begin{aligned}
\mathrm{EF}_{\mathrm{gpm}} & =\text { Emission factor in grams permile, } \\
\mathrm{EF}_{\mathrm{pPB}} & =\text { TEEMS emission factor in pounds.per million Btu, } \\
\mathrm{MPG} & =\mathrm{TEEMS} \text { forecasted fuel economy for category c vehicles in gallons per mile, }
\end{aligned}
$$

The TEEMS model does not report $\mathrm{CO}_{2}$ emission factors for heavy-duty diesel trucks and heavyduty gasoline vẻhicles.

\footnotetext{
${ }^{76}$ Personal communication with Penny Carey, EPA Motor Vehicle Emissions Laboratory, Ann Arbor, Michigan, August 4, 1992.

- $\quad \pi$. See, Decision Analysis Corporation, Mobile Source Air Emissions Regulations and Inventories, Draft Report, (Prepared for the EIA Energy Demand Analysis Branch under Contract No. DE-AC01-92EI21946, July 15, 1992).
} 
Table F-79. LDV Sulfur Dioxide and Carbon Dioxide Emission Factors

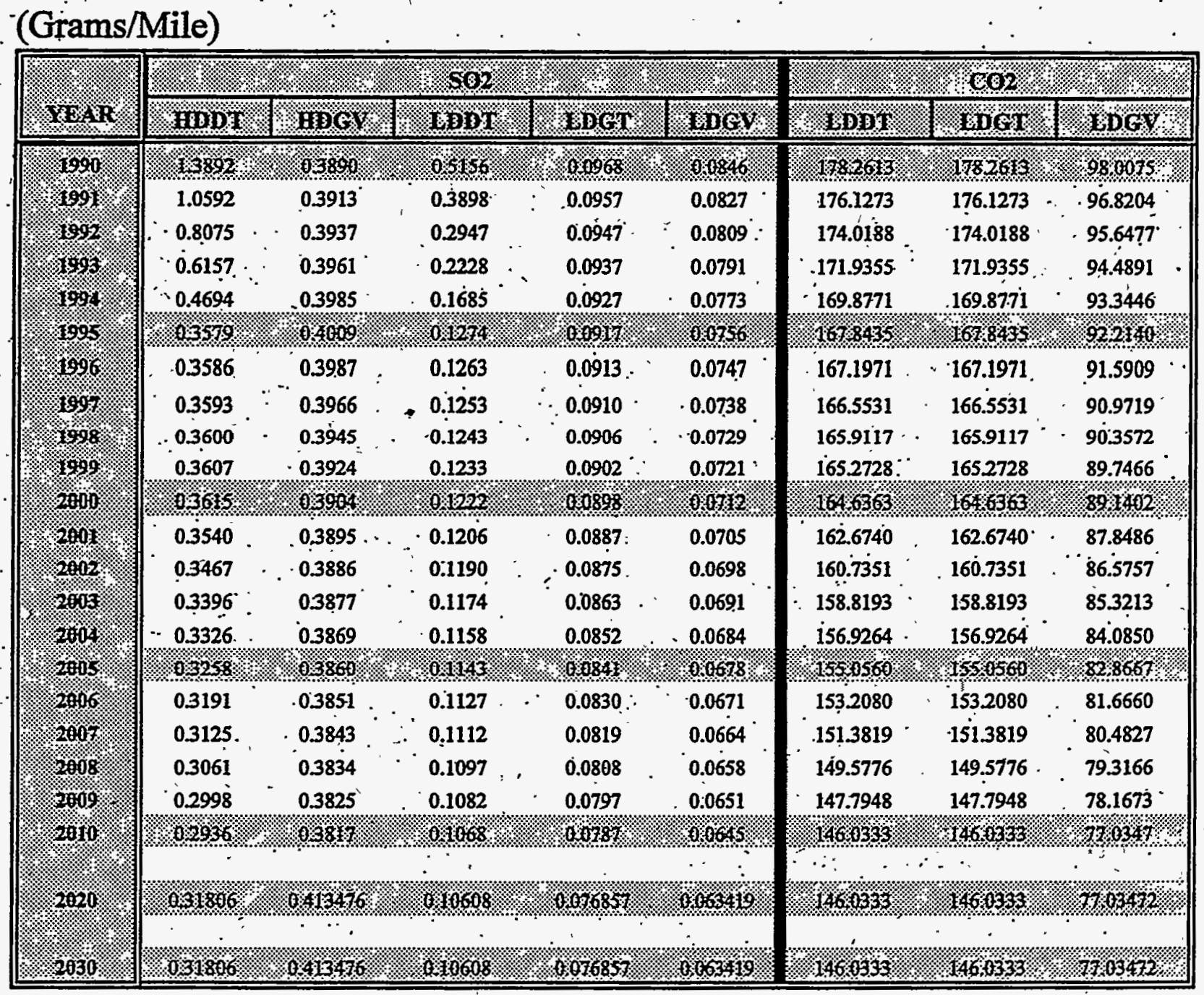

Source: Argonne National Laboratory Transportation Energy and Emissions Modeling System (TEEMS), Model run ANL$90 \mathrm{~N}$. 


\section{Total Carbon Emission Factors: Conventional Vehicles}

The calculation of total carbon emission factors for gasoline and diesel fuels is straightforward. The following formulae are used to produce carbon emission factors in grams per mile:

$$
\begin{aligned}
& \text { CarbonEF } \\
& \text { CarbonEF }=0.866 *(2791.0 / \mathrm{MPG}) \\
& \text { diesel }
\end{aligned}
$$

The constant values of 0.886 and 0.858 are the carbon mass fractions of gasoline and diesel, respectively. ${ }^{28}$ The constant values of 2791 and 3192 are the densities for gasoline and diesel fuel, and were obtained from EIA's 1989 International Energy Annual (February 1991). ${ }^{79}$ To obtain the carbon emission factors, the endogenously calculated TERF miles-per-gallon estimates (MPG) will need to be passed to the emissions module. As currently configured, MPG forecasts will be determined using the Argonne National Laboratory TEEMS methodology, which uses lagged MPG and other economic variables.

Ứsing Argonne's ANL-90N TEEMS run as an example, automobile and diesel freight truck carbon emission factors for 1990, 1995, 2005 and 2010 are shown below (MPG figures are in parentheses).

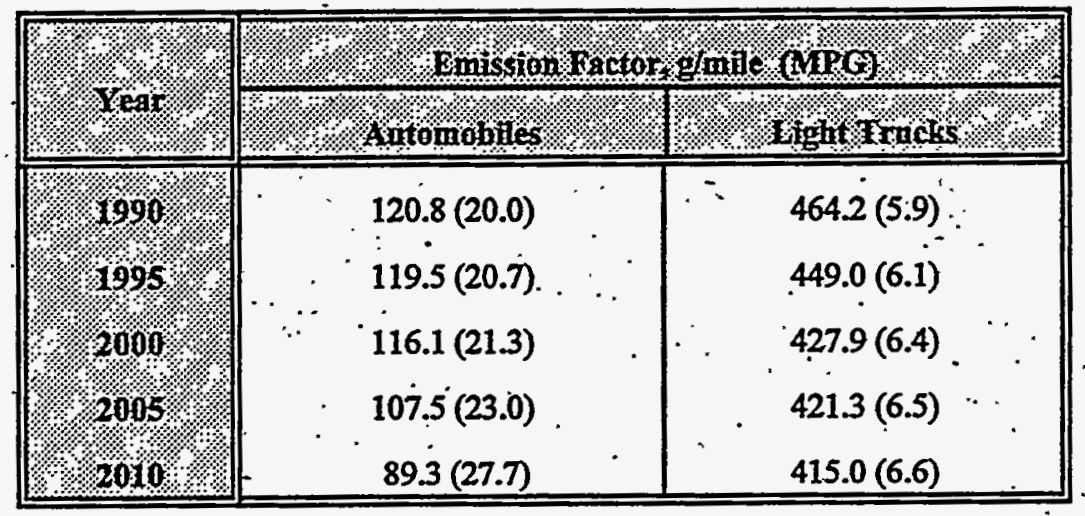

- 78 This value is reported by the EPA. See, Frank Black, 3rd U.S. - Dutch International Symposium, "Atmospheric Ozone Research and Its Policy Implications" (May 9-13, 1988, Nijmegen, the Netherlands), or the DeluchilArgonne greenhouse gas study.

79 Appendix F, Volume, Weight, and Monetary Conversions, p. 149. 


\section{Emission Factors: Alternative Fuel Vehicles}

The calculation of emission factors for alternative fuel vehicles (AFVs) is subjective in nature, and depends on emissions data from test vehicles and the likely capability of AFVs to meet new CAAA clean-fuel vehicle emission standards. Emission factors for- $\mathrm{NMHC}, \mathrm{CO}, \mathrm{NO}_{\mathrm{x}}$, and $\mathrm{CQ}$. were provided to Argonne National Laboratory in a greenhouse gas emission study conducted jointly by the Institute of Transportation Studies at the University of Califomia-Davis, and the Center for Energy and Environmental Studies at Princeton University. Table F-80 lists these AFV emission factors for light-duty. vehicles (LDV's) and heavy-duty vehicles, such as freight trucks and buses (HDV's), powered by the following fuels: methanol (100\%), compressed natural gas, hydrogen, ethanol (100\%), and liquid petroleum gas (LPG). Electric vehicles are considered to emit no. pollutants other than a small quantity of chloroflùorocarbons.(CFCs).

Table-F-80. Lifetime Average Emission Factors for Alternative Fuel Vehicles (Grams per Mile)

\begin{tabular}{|c|c|c|c|c|c|c|c|c|c|c|}
\hline \multirow{2}{*}{ 1/ } & \multicolumn{2}{|c|}{ (1) Nethondr. } & \multicolumn{2}{|c|}{ 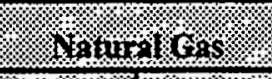 } & \multicolumn{2}{|c|}{ a disogen } & \multicolumn{2}{|c|}{ 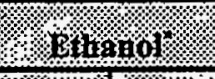 } & \multicolumn{2}{|c|}{$\mathrm{SPO}_{\mathrm{P}} /}$. \\
\hline & 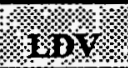 & $10101 \%$ & $18 \mathrm{BH}$ & nol & $\mathrm{Lin}$ & aby & (16) & 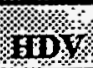 & 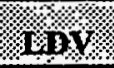 & $\mathrm{ELO}$ \\
\hline IIIIE. & $\cdot 0.56$ & 4.86 & 0.22 & 0.60 & 0.04 & 0.04 & 0.38 & 4.42 & 0.22 & 1.80 \\
\hline 6o & 7.21 & 13.00 & 3.60 & 7.00 & 0.70 & 0.10 & $7.21^{\circ}$ & 13.00 & 5.50 & 9.00 \\
\hline 100 & -0.45 & 8.05 & 0.45 & 8.05 & 0.45 & 8.05 & 0.45 & $8.05^{\circ}$ & .0 .45 & 8.05 \\
\hline $\mathrm{Cos}_{2}$ & $214.64^{\circ}$ & 1495.41 & 195.51 & 1463.94 & 0.00 & 0.00 & 0.00 & 0.00 & 226.72 & 1695.56 \\
\hline
\end{tabular}

Emission factors are for M100 (100\% methanol) and 100\% ethanol fuels.

\footnotetext{
so Mark A.DeLuchi, University of California Institute of Transportation Studies, Emissions of Greenhouse Gases From the Use of Transportation Fuels and Electricity (for the Argonne National Laboratọry Center for Transportation Research, June 26, 1991).
} 


\section{OFF-HIGHWAY SOURCES EMISSIONS FACTORS}

\section{Off-Highway Mobile Source Emission Factor Information Sources}

The following documents were used to compile off-highway emission factors or supply background information on emission factor calculation methods:

Compilation of Air Pollutant Emission Factors - Volume II: Mobile Sources (AP-42, Fourth Edition, September 1985)

Nonroad Engine and Vehicle Emission Study-Report, EPA 460/3-91-02 (Noỵembệ 1991)

Interim Guidance for the Preparation of Mobile Source Emission Inventories, Attachments A through J.(This EPA memorandum supersedes the mobile source emission inventory preparation instructions contained in Procedures for Emission Inventory Preparation - Volume IV, Mobile Sources, which is currently being revised)

Procedures for Emission Inventory Preparation - Volume IV, Mobile Sources, EPA-450/4-81-026d (revised), (July 1992).

The document, Compilation of Air Pollutant Emission Factors - Volume II, reports all data and emission factor calculation algorithms for both highway and off-highway emission sources. Section II outlines the emission calculation methodologies for off-highway mobile sources, including aircraft, railroad locomotives, inboard-powered vessels, outboard-powered vessels, small general utility engines, agricultural equipment, heavy duty construction equipment, and snowmobiles. The EPA is planning to issue an updated version of the AP-42 document, although no estimate has been given as to the release date. The EPA's Nonroad Engine and Vehicle Emission Study, which was mandated as part of CAAA Section 213(a), provides new or updated emission inventory data and emission factors for ten nonroad equipment categories including commercial marine vessels, which 
: is one of the transport modes to be modeled in TERF. ${ }^{81}$ The Nonroad Emission study targeted 24 nonattainment-areas as well as national totals. The document, Procedures for Emission Inventory Preparation - Volume IV, Möbile Sources, provides state and local agencies with detailed guidance 'on the preparation of highway and off-highway mobile source emission inventories. The offhighway emission factors contained in this section were derived either directly from the inventory preparation procedure report, or were calculated using data tables contained therein.

\section{Railroad Locomotive Emission Factors}

Table F-81 lists the railioad locomotive emission factors to be incorporated into the TERF model. Emission factors for $\mathrm{CO}, \mathrm{NO}_{x}, \mathrm{SO}_{2}$ and $\mathrm{HC}$ are included. ${ }^{82}$. Note that the EPA does not measure separately the volatile component of total hydrocarbons. Also, no distinction is made between freight and passenger locomotives because both travel modes use the same locomotive technology types: These emission factors are reported in the July 1992 edition of Procedures for 'Emission Inventory Preparation - Volume $W$, Mobile Sources. They are considered default values for fleetaverage line haul locomotives. ${ }^{83}$ Line haul locomotives represent the largest' segment of the locomotive population, and include all locomotives used for freight and passenger service. As of mid-1991, 9,708 line haul locomotives were in service. ${ }^{84}$ Yard locomotives are used for moving railcars within a rail switchyard, and are considered a negligible source of emissions. As of mid$1991,4,589$ yard locomotives were in service. ${ }^{85}$ :

The emission factors represent an average of emission factors for five diesel engine configuration types: 2-stroke supercharged switch locomotive, 4-stroke switch locomotive, 2-stoke super-charged road servicelocomotive, 2-stroke turbocharged road service locomotive, and 4-stroke road service locomotive. The emission factors are based on duty cycle testing and average fuel consumption

11 The other nine equipment categories are lawn and garden equipment, airport service equipment, recreational vehicles, recreational marine equipment, light commercial equipment, industrial equipment, construction equipment, agricultural equipment, and logging equipment.

82 Source: EPA Office of Mobile Sources, Locomotive Emission Factors.for Inventory Guidance Document (June 1991).

83 The EPA also outlines a methodology for calculating more detailed locomotive emissions for areas that are expected to deviate significantly from the national average. The methodology is called the roster tailoring method, and uses emissions data from individual locomotive makes and models.

84. Interim Guidance for the Preparation of Mobile Source Emission Inventories, Attachment J, Emissions from Railroads (EPA Office of Mobile Sources, February 15, 1992), Appendix 6-5, p. 6-23.

ss Ibid p. 6-23. 
rates. A duty cycle consists of the operating time in eight throttle notch settings.plus idle and dynamic braking. The fuel consumption rate of a locomotive is determined by the throttle notch position - the higher the notch, the higher the fuel consumption, and vice versa. Therefore, fuel consumption is proportional to the amount of time the locomotive spends in each throttle notch - position. ${ }^{86}$. The locomotive emission factors apply to all three Interstate Commerce Commission (ICC) railroad classes: Class I - annual revenues greater than \$93.5 million; Class II - annual revenues greater than $\$ 18.7$ million but less than $\$ 93.5$ million; Class III -annual revenues less than \$18.7.million.

\section{Table F-81. TRAN Locomotive Emission Factors}

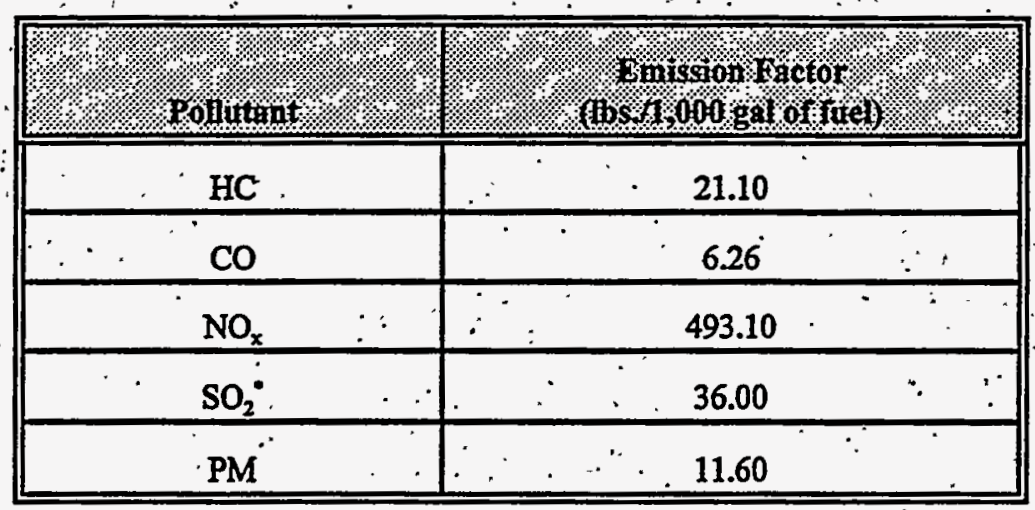

Based on fuel sulfur content of 0.25 percent by weight.

\section{Look-Ahead Issues Concerning Locomotive Emission Factors}

In terms of specifying future-year locomotive emission factors given CAAA requirements, the emission factors in Table F-81 are to be used for all forecast years. Section 213 of the Amended Act requires the EPA to promulgate emission standards for new locomotives by November 1995. These new standards are to be designed to obtain the greatest degree of emission reduction achievable, with due consideration given to compliance cost, energy consumption; safety and noise. ${ }^{87}$ New emisșion factors would be based on testing of the applicable locomotive emission reduction technologies that would be manufactured to comply with new standards. Given the large uncertainty over the prospective emission standards and technologies, as well as the low stock turnover of locomotive

\footnotetext{
${ }^{86}$ Ibid, p. 6-13.

${ }^{87}$ CAAA, sec. 213 (a)(5), 104 STAT 2501.
} 
engines, there is no justification for assigning alternative emission factors to the forecast interval.

\section{Aircraft Emission Factors}

\section{Overview of the EPA Aircraft Emissions Inventory Methodology}

The EPA bases its aircraft emission factors on five operating modes that together consist of the landing and takeoff (LTO) cycle: The first operating mode is the approach, in which the aircraft makes its airport approach after the descent from crüising altitude. The second operating mode is taxi/idle-in, where the aircraft lands and taxis to the gate. The third mode is taxi/idle-out, in which the aircraft taxis back out to the runway for subsequent takeoff. ${ }^{88}$. The fourth mode is takeoff, in which the aircraft attains liftoff speed and becomes airborne. The fifth mode is termed the climbout, and represents the aircraft's accent to cruising altitude. Most aircraft go through a similar sequence during an LTO cycle.

During each operation mode the aircraft engines operate at a fairly standard power setting for a given aircraft category, The power setting results in a certain rate of fuel flow (expressed in pounds per minute) for the operating mode. Total emissions from the aircraft engine are thus determined by the amount of time that an aircraft engine spends in each operation mode (termed the "Time-in Mode"), the fuel consumption rate, and the engine-specific emission factors for each operating mode, expressed in pounds of emissions per 1,000 pounds of fuel consumed.

The EPA aircraft emission factors and inventory preparation procedures are site-specific; they are highly dependent on local airport and aircraft population data. Generally, the emissions inventory is prepared using the following steps: (1) identify airports to be included in the inventory area, (2) determine the mixing height ${ }^{89}$ to be applied to the LTO cycle (a standard default value of 3,000 feet is assumed); (3) define the aircraft fleet population for each aircraft category across all airports, (4) determine the number of LTOs for each aircraft category, (5) select emission factors for each aircraft category, (6) estimate a time-in-mode for each aircraft category at each airport, and (7) calculate an inventory based on the airport activity, time-in-mode, and emission factors.

\footnotetext{
${ }^{85}$ Both Taxi/idle operating modes are highly variable, and depend on such factors as airport size and layout, the amount of ground congestion, airport-specific operational procedures, time of day, and seasonal travel activity.

'89 The height of the mixing zone - that portion of the atmosphere where aircraft emissions affect ground level pollutant concentrations - influences the time-in-mode for approach and climbout operation modes, and is particularly significant when calculating $\mathrm{NO}_{\mathbf{x}}$ emissions:
} 


\section{EPA Aircraft Categorization.}

The EPA categorizes aircraft by the type of use: commercial, general aviation, and military. Commercial aircraft include those used for scheduled service transporting passengers, freight, or both. Air taxis also fly scheduled service carrying passengers and/or freight, but usually are smaller. aircraft and operate on a more limited basis than the commercial carriers. Business aircraft support business travel, usually on an unscheduled basis, and general aviation includes most other nonmilitary:aircraft used for recreational flying, personal transportation, and various other activities.

The EPA combines business aircraft with general aviation aircraft because of their similar size, use frequency, and operating profiles. Similarly, air taxis are treated much like the general aviation category because they are typically the same types of aircraft. Military aircraft cover a wide range of sizes, usès, and operating missions. While they often are similar to civil aircraft, they are handled separately because they typically operate exclusively out of military air bases and frequently have distinctive flight profiles. Helicopters, or rotary wing aircraft, can be found in each of the categories. - Their operation is distinct because they do not always operate from an airport but may land and takeoff from a heliport at a hospital, police station, or similarly dispersed location. Military rotorcraft are included in the military category and non-military rotorcraft are included in the general aviation category since information on size and number are usually found in common sources. However, they are combined into a single group for calculating emissions since their flight profiles are similar.

Commercial aircraft typically are the largest source of aircraft emissions. Although they make up less than half of all aircraft in operation around a metropolitan area, their emissions usually represent a large fraction of the total because of their size and operating frequency. This would not hold true for a city with a disproportionate amount of military activity, or a city with no major civil airports.

\section{Aircraft Emissions Characteristics}

The EPA views $\mathrm{HC}, \mathrm{CO}, \mathrm{NO}_{x}, \mathrm{SO}_{2}$, and $\mathrm{PM}_{10}$ as the significant aircraft pollutants. However, only. 
HC emissions and smoke production are currently regulated. ${ }^{90}$ For a single LTO cycle, aircraft emissions vary considerably.depending on the category of aircraft and the aircraft's flight profile. Emission rates for $\mathrm{HC}$ and $\mathrm{CO}$ are high during the taxi/idle phases when aircraft engines are at low power and operate at suboptimum efficiency. The emission rates fall as the aircraft moves into the higher power operating modes of the LTO cycle. Conversely, $\mathrm{NO}_{\mathrm{x}}$ emissions are low when engine power and combustion temperature are low, but increase as the power level is increased and combustion temperature rises: Therefore the takeoff and climbout modes have the highest $\mathrm{NO}_{x}$ emission rates.

Sulfur dioxide emission rates are highest during the takeoff and climbout operation modes when fuel consumption rates are high. Sulfur emissions typically are not measured when aircraft engines are tested. Therefore, the EPA uses a default emission factor of 0.54 pounds $\mathrm{SO}_{2}$ per 1,000 pounds of fuel for all engine types. (EPA assumes that all sulfur in the fuel combines with oxygen during combustion to form $\mathrm{SO}_{2}$. Nationally, the sulfur content of fuel remains fairly constant from year to year at about $0: 05 \%$ by weight for commercial jet fuel, $0.025 \%$ by weight for military fuel, and $0.006 \%$ by weight for aviation gasoline. These national sulfur content figures are used by the EPA for estimating the $\mathrm{SO}_{2}$ default emission factors.

Particulate emission characteristics are similar to that of $\mathrm{HC}$ and $\mathrm{CO}$ in that emission rates are higher at low power rates than at high power rates because of greater combustion efficiency at a higher - engine power. However; particulate emissions are highest during takeoff and climbout due to the greater fuel flow rate. The EPA does not report emission factors for particulates except for a small number of engine models, citing the difficulty in estimating PM emissions. ${ }^{91}$. Direct measurement of particulate emissions from aircraft engines typically are not available from manufacturers, although emission of visible smoke is reported as part of the engine certification procedure.92 The inventory preparation procedure dociument reports emission factors for only one civil aircraft engine model: This engine model is used in a number of European-built aircraft, and is not representative of the total aircraft fleet.

\footnotetext{
90 EPA established standards for aircraft HC emissions in 1984, which included the establishment of standard procedures for engine certification and emissions testing. The standard applies to jet engines with an engine thrust of over 6,000 pounds. The EPA reports that many older in-service engines exceed the standards. New engine designs produced since the standards went into.effect have HC emissions lower than the standards, but the design changes made to reduce the HC emissionş resulted in small increases in $\mathrm{NO}_{\mathrm{x}}$ emissions.
}

91 Procedures for Emission Imventory Preparation, Vol $N$, page 149.

92 Ibid., p. 149. 


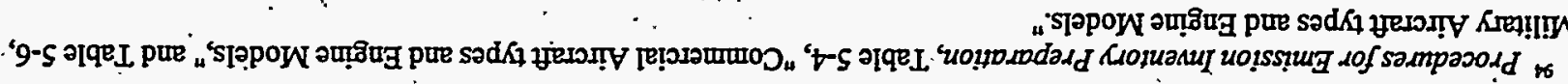

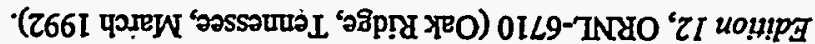

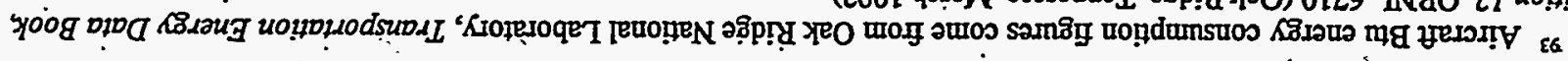

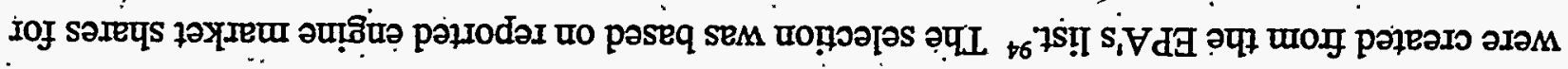

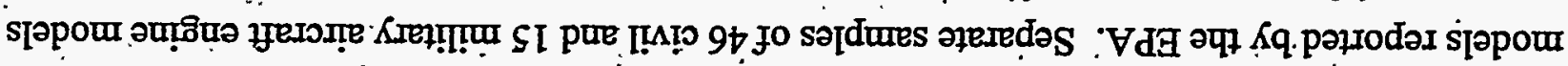

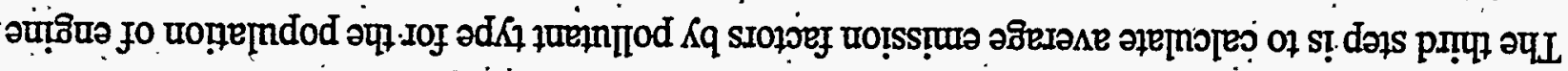

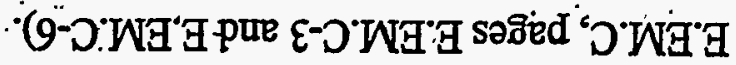

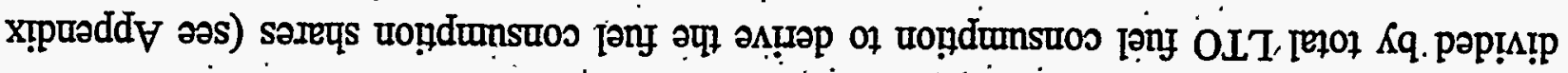

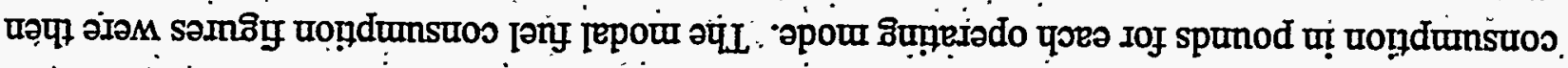

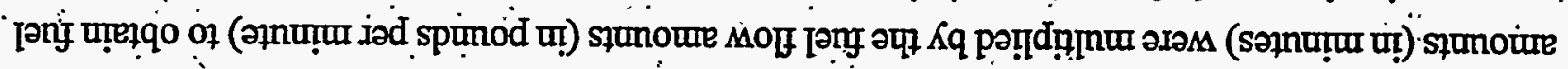

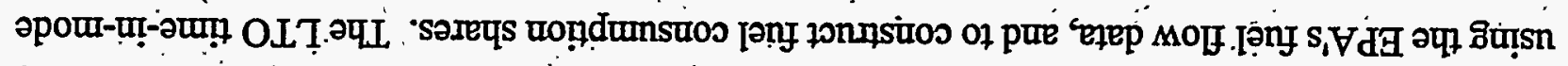

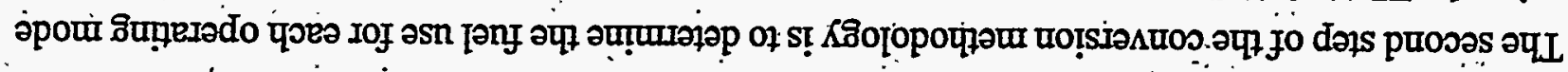

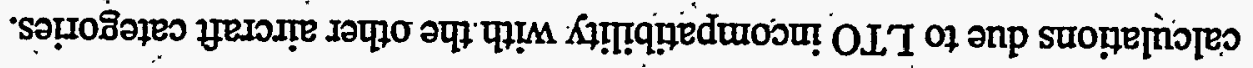

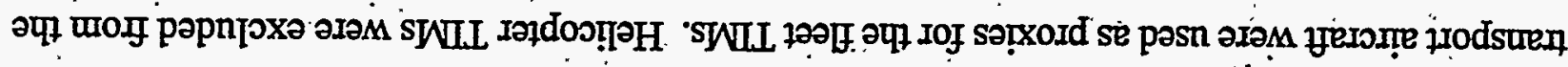

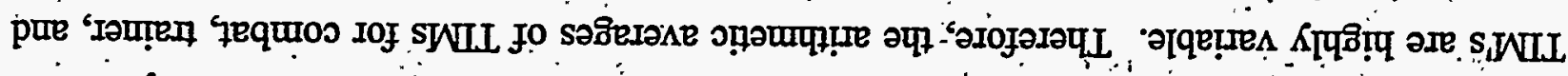

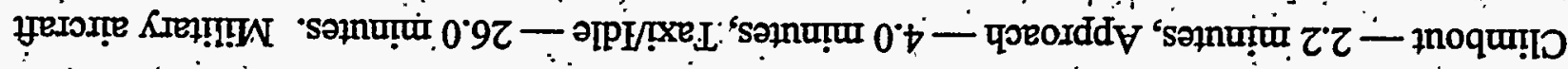

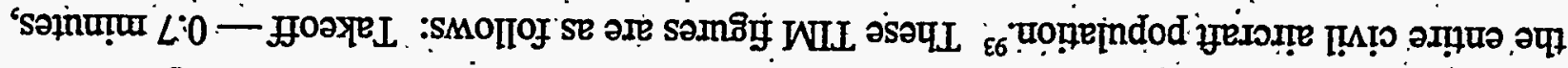

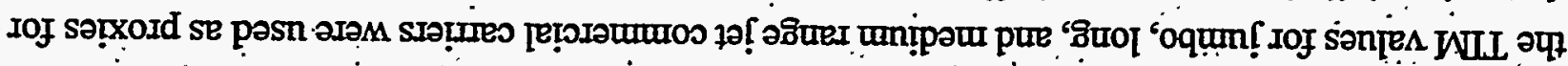

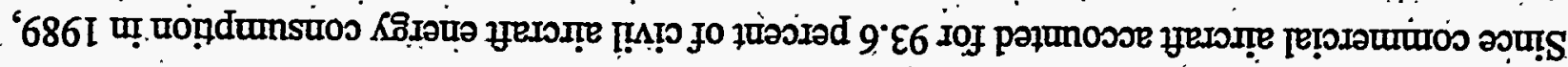

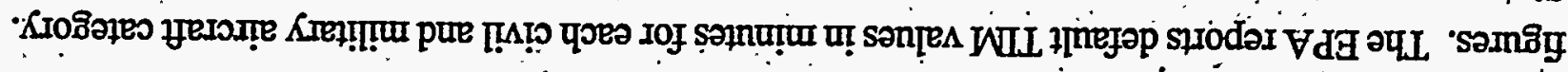

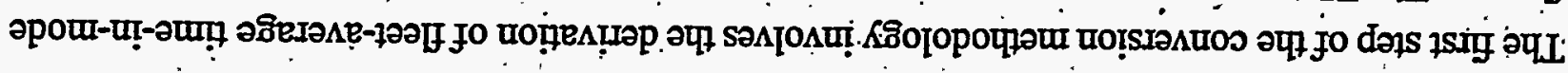

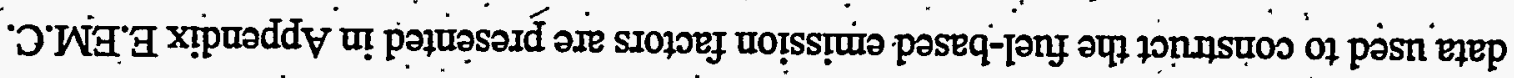

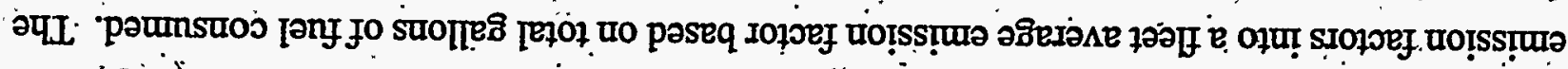

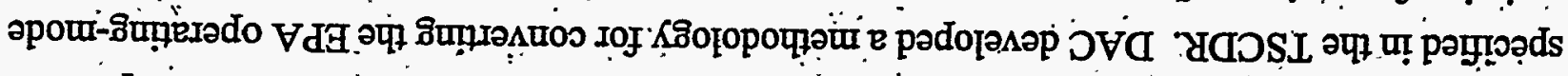

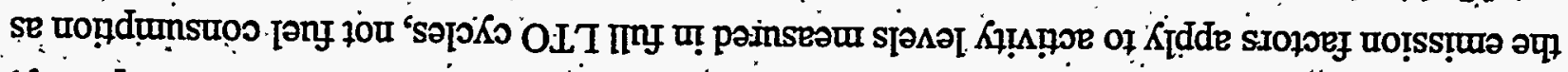
"Кㅁ

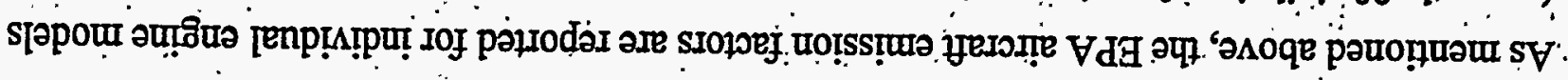

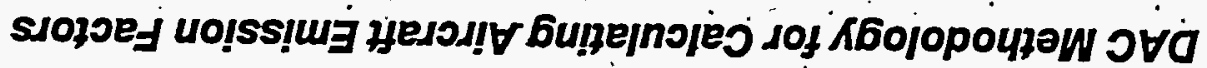


each aircraft model, with aircraft models chosen based on a proportional representation of the commercial, general and military aircraft categories. The sample engine-model emission factors were aggregated by calculating the arithmetic average of reported pollutant emission factors. ${ }^{95}$. (see Appendix.E.EM.C, pages E.EM.C-1, E.EM.C-2, E.EM.C-4, and E.EM.C-5). Since the $\mathrm{SO}_{2}$ emission factor is the same for each operation mode, this methodology is not applicable for $\mathrm{SO}_{2}$. emission rate estimation.

The fourth step is to calculate the weighted fieet-average emission factors for $\mathrm{HC}, \mathrm{CO}$, and $\mathrm{NO}_{\mathrm{x}}$ by multiplying the aggregated engine sample emission factors by the fuel consumption shares calculated in step 2. 'Two further calculations are necessary to produce emission factors that correspond to' TSCDR specifications. First the emission factors must be converted into gallons-of-fuel equivalents. A conversion factor of 6.2 pounds per gallon was used. Second, the total $\mathrm{HC}$ emission factors must be adjusted to produce volatile organic compound (VOC) emission factors. The following EPA adjustment factors, applicable to turbine engines, were used:

$$
\begin{aligned}
\text { VOC }_{\text {COMMERCAL }} & =\text { THC }_{\text {COMAMERCAAL }} \times 1.0947 \\
\text { VOC } & =\text { THITIARY }_{\text {MIITARY }} \times 1.1046
\end{aligned}
$$

Table F-82 presents the aircraft emissions factors for $\mathrm{HC}, \mathrm{VOC}, \mathrm{CO}, \mathrm{NO}_{\mathrm{x}}$, and $\mathrm{SO}_{2} \cdot{ }^{96}$

\begin{tabular}{|c|c|c|}
\hline \multirow{2}{*}{ lon } & \multicolumn{2}{|c|}{ 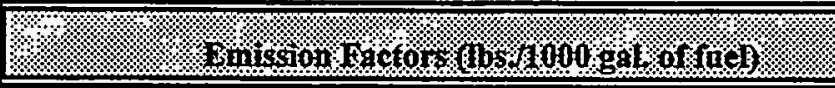 } \\
\hline & Comimerctin 1 frexaft & 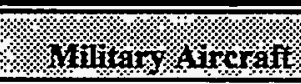 \\
\hline 110 & 37.82 & 75.54 \\
\hline 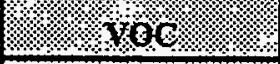 & 41.40 & 83.44 \\
\hline 1. & 101.97 & 330.17 \\
\hline $1 \%, 1.1 \% 0_{x}$ & $\therefore \quad 79.04$ & $58.15^{\circ}$ \\
\hline L & 3.35 & $\therefore$ \\
\hline
\end{tabular}

\section{Table F-82. Aircraft Emission Factors}

.95 Ibid., Table 5-4,"Modal Emission Rates."

is Source: Appendix E.EM.C, page E.EM.C-3;

Notes: Commercial and military VOC emission factors calculated by multiplying Appendix E.EM.C HC values by 1.0947 and 1.1046 , respectively.

$\mathrm{SO}_{2}$ emission factors calculated by dividing the EPA standard value of 0.54 pounds per 1,000 gallons by 6.2 . 


\section{Look-Ahead Isssues Concerning Aircraft Emission Factors}

Among the factors expected to influence aircraft emission rates in a forecasting context are the following:
new aircraft engine designs, airport noise regulations; an increase in airport congestion problems

Aircraft with cleaner and more energy-efficient engine designs are expected to continue to slowly penetrate the world aircraft fleet population. Since there is a significant engineering and development leadtime for producing new aircraft engines, most of the commercial aircraft to be added to the fleet in the next five to seven years will be powered by engines currently monitored by the EPA. ${ }^{97}$ Given the 12-year average service life for commercial aircraft engines, the newer generation of aircraft engines are not expected to make a significant impact on national emission levels until 2010. However, a possible catalyst for an increased rate of new aircraft engine market penetration is the recent enactment of national airport noise regulations; which require the phase-out of loud aircraft by 2000 . Airlines are expected to upgrade their fleets with quieter and cleaner engines once the industry formulates compliance plans. The extent of the emission rate impact of such fleet upgrading is unknown at this time.

Acting as a counterweight on the downward pressure on emission rates caused by stock turnover and new regulations is the growth in air travel combined with limited excess capacity at many airports. Air travel has experienced strong growth over the past several years, and this growth is expected to continue for the foreseeable future. The primary capacity squeeze will be felt at small feeder airports and regional hubs. Increased congestion at capacity-constrained airports will increase taxi/idle times, resulting in increased emissions per LTO:

Given these offsetting impacts on aircraft emissions, the emission factors listed in.Table F-82 should be satisfactory for estimating future aircraft emission levels.

97 Ibid., p. 208. 


\section{Waterborne Vessel Emission Factors}

\section{Commercial Vessels}

Table F-83 provides the EPA emission factors for domestic commercial motorships. These emission factors are reported in the AP-42 document. The emission factors are based on Army Corps of Engineers waterway classification categories, which are defined as follows:

River - All waterborne traffic between ports or landings wherein the entire movement takes place on inland waterways.

Great Lakes - All waterborne traffic between United States ports on the Great Lakes.

Coastal - All domestic traffic receiving a carriage over the ocean or between the Great Lakes ports and seacoast ports when having a carriage over the ocean.

To derived an average emission factor for all three. waterway category vessels, a weighted-average methodology was applied whereby shipment tonnage and average length-of-haul data from the Army Corps of Engineers were used to construct emission factor weights.". Table F-83 provides more details on the weighting methodology.

The EPA Nonroad Engine and Vehicle Emission Study Report provides emission factors for two additional-vessel categories: ocean-going steamships and harbor/fishing vessels: ${ }^{99}$ These emission factors are based on engine sizes and operating mode (hoteling, cruisẹ, and full power), and are not compatible with the emission factors provided in Table F-83. Because of the small emissions contribution of these vessels to the overall waterborne vessel total, they are not included in the composite waterbome vessel emission factors. For reference purposes, Appendix E.EM.D provides the ocean-going and harbor/fishing vessel emission factor tables from the Nonroad Engine and Vehicle report.

98 U.S. Army Corps of Engineers, Waterborne Commerce of the United States, Callendar Year 1989 (Waterbome Statistics Center, New Orleans, LA, 1991), Part 5: National Summaries, pp. 32, 93. .

\footnotetext{
99 These emission factors were compiled and provided to the EPA in a Booz Allen \& Hamilton report, Commercial Marine Vessel Contributions to Emission Inveritories (Los Angeles, CA, October 7., 1991).
} 
Table F-83. Commercial Vessel Emission Factors ${ }^{100}$ (Pounds per 1,000 gallons of fuel)

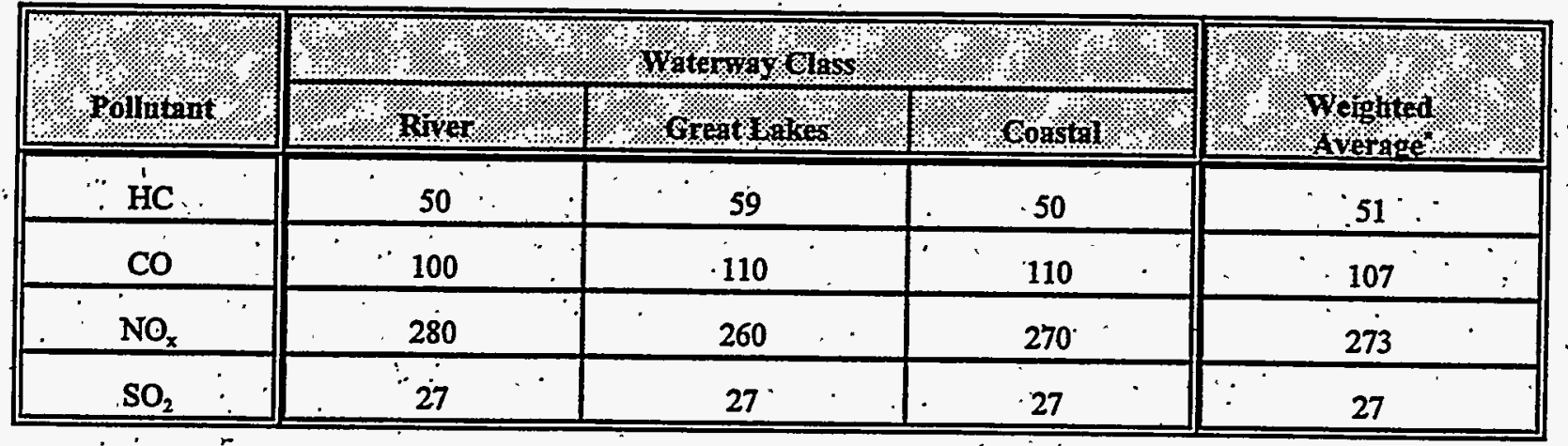

- Average emission factors calculated by multiplying pollutant emission factors for each waterway class by shipment mileage weights and then summing the weighted emission factor values. The shipment weights are as follows: River -0.34 Great Lakes - 0.07, Coastal - 0.59. Shipment mileage weights were derived by multiplying.tons shipped by the average length-of-haul per ton shipped for each waterway class.

\section{Recreational Vessels}

Table F-84 provides $\mathrm{HC}, \mathrm{CO}$, and $\mathrm{NO}_{x}$ emission factors for recreational marine vessels. These emission factors come from the EPA Nonroad Engine and Vehicle Emission Study Report. The EPA classifies and reports emission factors for the following vehicle/engine types:

- vessels with inboard engines (4-stroke)

- vessels with outboard engines (2-stroke)

- vessels with sterndrive engines (4-stroke)

- sailboats with auxiliary outboard engines (diesel)

- sailboats with auxiliary inboard engines (diesel)

When the AP-42 document was compiled, emission testing data was not available for recreational marine vessels. The EPA used coast guard diesel engine and automotive engine emission data to compute in-board emission factors based on the duty-cycle for engines classified as large out-boards. Out-board emission factors were derived from data supplied to the EPA by the Southwest Research Institute.

100 'U.S. Environmental Protection Agency, Compilation of Air Pollutant Emission Factors, Volume II: Mobile Sources, AP-42, PB-87-205266 (EPA' Office of Mobile Sources; September 1985), Part II, Off-Highway Mobile Sources, Täble II-3.1. .

U.S. Army Corps of Engineers, Waterborne Commerce of the United States, Calendar-Year 1989 (Waterbome Statistics Center, New Orleans, LA, 1991), Part 5: National Summaries, pp. 32, 93. 
For the Nonroad Engine and Vehicle report, outboard engine emission factors were derived from test data supplied to EPA by the National Marine Manufacturers Association, which tested 25 two-stroke and three four-stroke outboard engines. For four-stroke outboards, emission factors recommended by the Southwest Research Institute were used for particulate matter emissions. ${ }^{10 i}$. Since no data were available for 2-stroke outboard engine, particulate matter emissions, EPA used emission factors from the CARB Technical Support Document for utility and lawn/garden equipment as approximations. For inboard/sterndrive gasoline engines, the EPA derived emission factors on the basis of test data on three 4-stroke gasoline marine inboard/sterndrive engines supplied by NMMA. The particulate emission factor used was 1.64 pounds per 1,00,0 gallons of fuel. The EPA used NMMA tèst dáta for a small diesel sailboat inboard and three large diesel inboard engines as the basis for calculating emission factors for inboard diesel engines.

As with the commercial marine vessels, vessel/engine type emission factors must be weighted according to an activity or population level indicator and summed to obtain an average emission factor for the total recreational marine vessel population. Engine population data for each vessel/engine-type class was used to construct the weights. Boat population figures were gathered from local boat registration data bases, and were subsequently adjusted to obtain engine population estimates. Energy and Environmental Analysis developed the engine number derivation methodology for the EPA.

Table F-84. Recreational Marine Vessel Emission Factors ${ }^{102}$ (Pounds per 1,000 gallons of fuèl)

\begin{tabular}{|c|c|c|c|c|c|}
\hline \multirow{2}{*}{ (I) } & \multicolumn{4}{|c|}{ 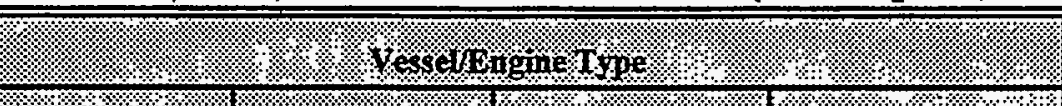 } & \multirow[b]{2}{*}{ Werghted } \\
\hline & $\begin{array}{l}\text { Outhonis } \\
2 \text { Strole }\end{array}$ & 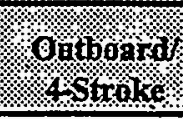 & Sterniniviel & sainhourat & \\
\hline 1he & $1610 \%$ & 190 & $\therefore \quad 160$ & 50 & 1233 \\
\hline (3. & $2990^{\circ}$ & 3130 & 2680 & 80 & 2884 \\
\hline no. & 20 & 150 & 100 & 380 & 44 \\
\hline
\end{tabular}

Weights for each vesselengine-type category were constructed from the following engine population figures: Outboard/2-Stroke - 8,204,304, Outboard/4-Stroke - 41,228, Sterndrive/4-Stroke - 2,713,420, Sailboat/Diesel-Aux. $114,502$.

101 U.S. Environmental Protection Agency, Designation of Areas for Air Quality Planning Purposes, 40 CFR Part 81, Final Rule, -Washington, D.C.; Office of Air and Radiation, November 6, 1991.

${ }_{102}$ U:S. Environmental Protection Agency, Nonroad Engine and Vehicle Emission Study - Report, EPA 460/3-91-02 (EPA Office of Mobile Sources, November 1991), Table 2-03, Appendix I, Table I-11. 
Table F-85. Ocean-Going Commercial Vessel Emission Factors

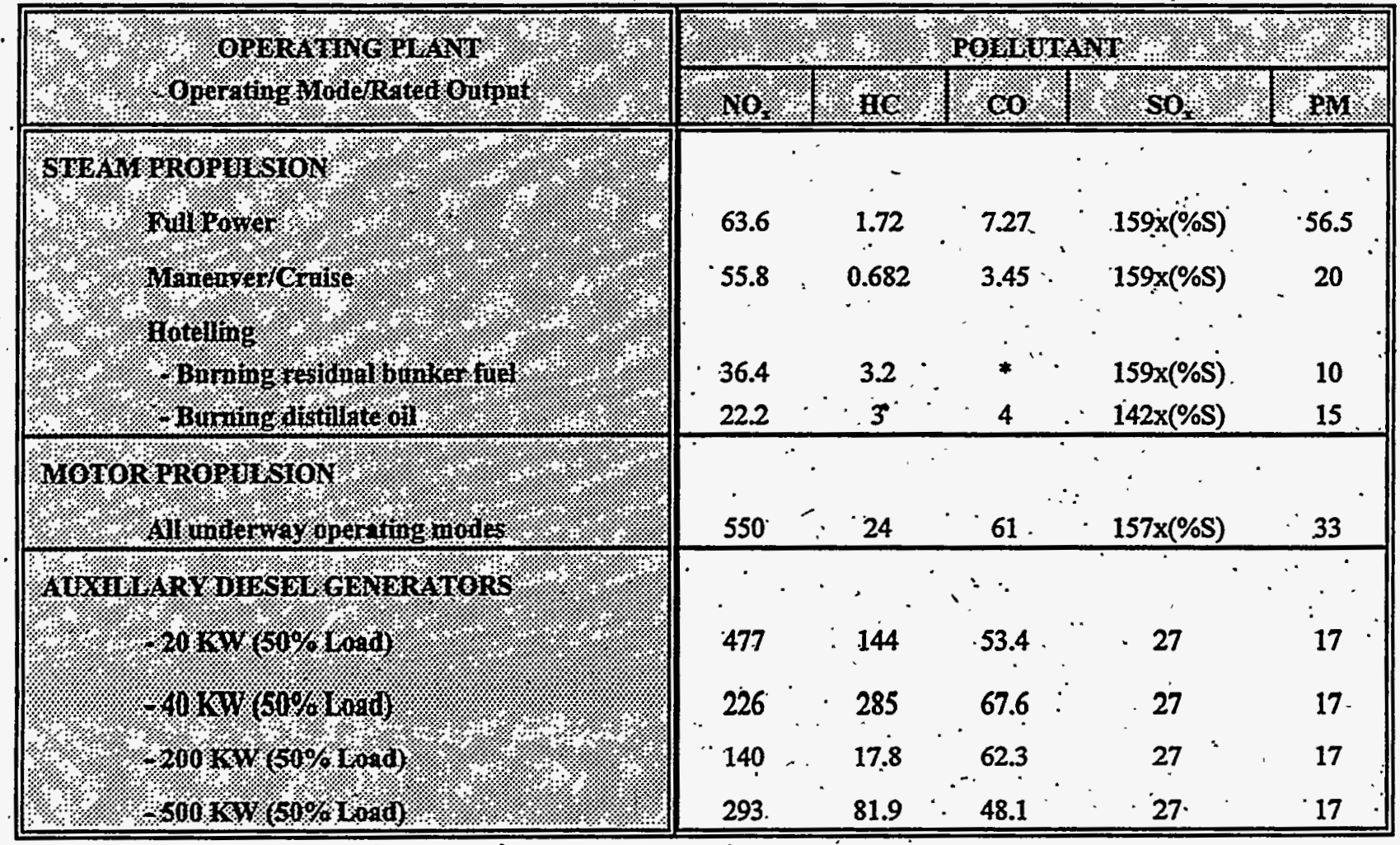

Notes: . 1) Emissions factors showing an asterisk $\left(^{*}\right)$ are considered negligible for these operating modes.

2) Average sulfur concentrations used are 0:8 percent for marine diesel, and 2.0 percent for bunker fuel oil.

Sources: 1) U.S. Environmental Protection Agency. Compilation of Air Póllutant Emission Factors, 1985.

2) U.S. Department of Transportation, Port Vessel Emissions Model, 1986. .

3) California Air Resources Board, Report to the California Legislature on Air pollutant Emissions from Marine Vessels. 
Table F-86, Harbor and Fishing Vessel Emission Factors

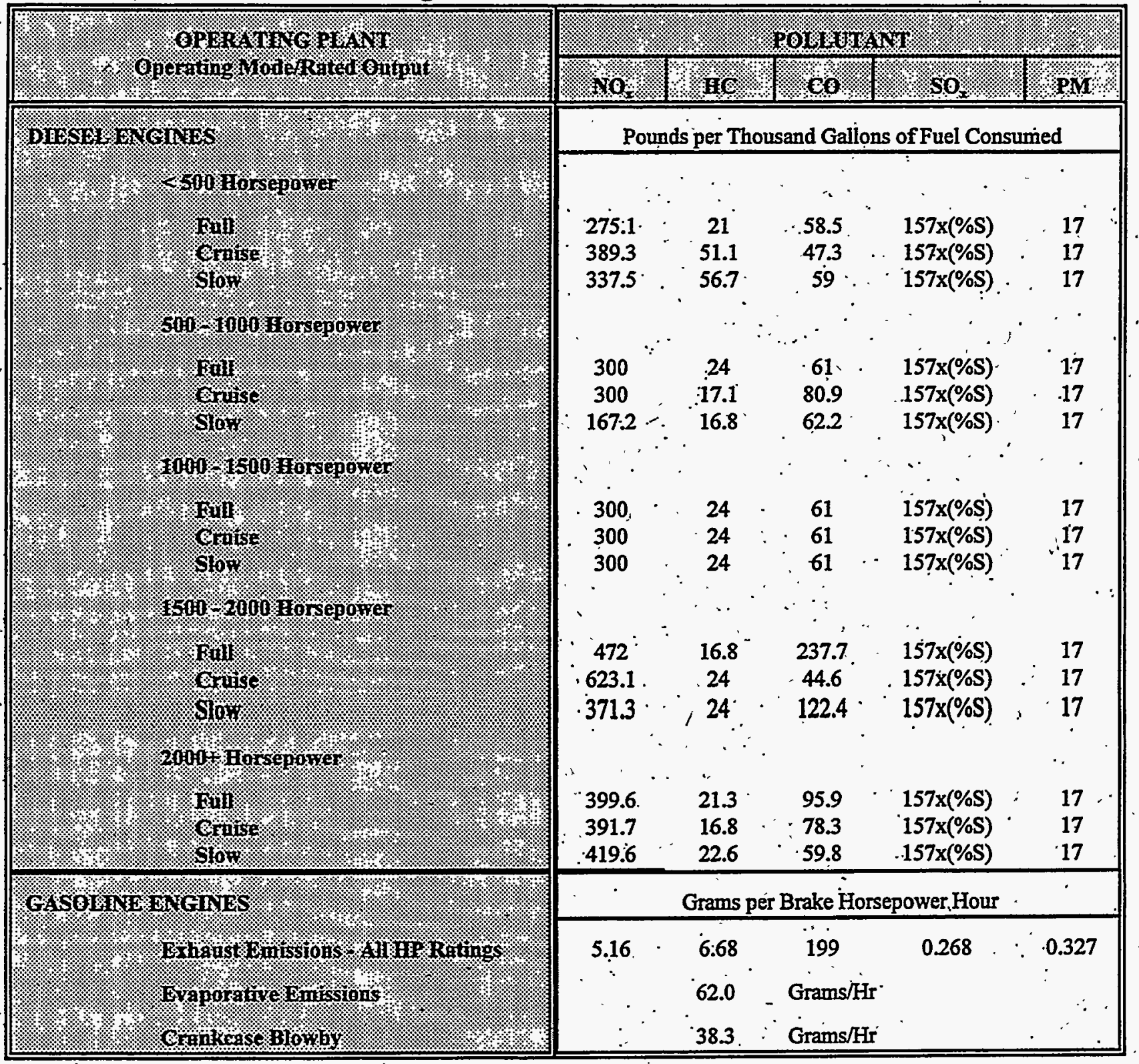

Notes: 1). Average sulfur concentration for marine diesel fuel $=0.8$ percent.

Sources: 1) U.S. Environmental Protection Agency. Compilation of Air Pollutant Emission Factors, 1985.

2) U.S. Department of Transportation, Port.Vessel Emissions Model, 1986.

-3) California Air Resources Board, Report to the California Legislature on Air pollutant Emissions from Marine Vessels. 


\section{Attachment 8: LDV Stock Model}

Fuel Economy, Vehicle Choice, and Changing Demographics

This attachment documents the methodology used to forecast the light truck (e.g. pickup trucks, sport utility vehicles) share of total light duty vehicle sales in the NEMS Transportation model. Given the marked difference in fuel economy standards for cars and light trucks this share directly. affects both the forecast level of oil consumption and the level of carbon emissions. More generally, the presentation highlights the importance of considering structural shifts in developing long-term. energy forecasts.

\section{Background}

Shiort-term (one to two years) forecasts assume that past trends in energy.use and past relationships between economic and demographic factors and energy use will continue in the near term. They implicitly assume that structural changes are relatively unimportant as a cause of forecast error compared to errors introduced by uncertainty in estimates of forecasts of variables such as economic growth and energy prices. Those who tinker with long-term energy forecasts don't have this luxury. Certain physical assumptions may be accepted without further consideration (e.g. first law of thermodynamics, heating-degree days in a "normal" year in Southwest Census region): However, the longer the time horizon of the forecast is the more important it is to scrutinize assumptions that remain implicit in short-term forecasting. For example, to develop short-term forecasts of electricity use in buildings it isn't necessary to disaggregate this use by type and efficiency of equipment; it is reasonable to assume that changes in these factors are not an important source of uncertainty. This same assumption would be entirely inappropriate in a methodology used to forecast long-term building sector electricity use. The Energy Information Administration's Annual Energy Outlook 1996 provides energy forecasts through 2015. Within this time frame most of the electricity-using equipment now in buildings will be replaced and even the currently known menu of replacement choices vary considerably in energy efficiency.

This attachment scrutinizes a single variable in the NEMS Transportation model--the share of light trucks relative to total light-duty vehicle annual sales. It compares estimates of the light truck sales share based on extrapolating past trends to an approach that makes explicitassumptions concerning the impact future demographic changes will have on vehicle choice decisions. We know with a fair degree of certainty that as the generation of "baby boomers" reach age 55 , the share of the population under the age of 55. will decrease sharply from the share maintained for many decades. We also 
know the age distribution of current truck purchasers: The methodology described provides forecasts of the light truck share based on knowledge of an aging population. The methodology does not address the question raised in the subtitle of this paper. To the extent that the population over age 55 in 2015 , behave differently from the current over 55 population in terms of their vehicle purchases, the forecasts either under or over estimate the level of new light truck sales.

\section{Methodology}

Information on the characteristics of light truck buyers were obtained from the 1989 Buyers of New Compact Trucks, Summary Report, published by Newsweek. Light trucks are divided into two types, pickup and sport utility.

\begin{tabular}{|c|c|c|}
\hline ক. & : & 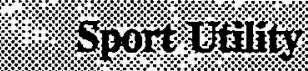 \\
\hline 1:1: & $53 \%$ & $47 \%$ \\
\hline । & $\because$ &. \\
\hline 16. & $88 \%$ & . $\quad 73 \%$ \\
\hline Tenale & $12 \% \cdots$ & $27 \%$ \\
\hline ? & $\therefore$ & - \\
\hline 1.1 .1 .6 .19 & $3 \%$ & $\cdot \quad 1 \%$ \\
\hline \&ি. & $\therefore .13 \%$ & $7 \%$ \\
\hline $25-29$ & $\because \quad 13 \%$ & $15 \%$ \\
\hline 14.8 .30 .348 & $11 \%$ & . $\quad 15 \%=$ \\
\hline 18.539 & $\because \quad 13 \%$ & $17 \%$ \\
\hline 144.4 & $\because \quad 12 \%$ & $16 \%$ \\
\hline 45-9. & : $9 \%$ & $11 \%$ \\
\hline 1.7 .5054 & $7 \%$ &.$\quad 8 \%$ \\
\hline 8.8 .8559 & $6 \%$ & $5 \%$ \\
\hline $60.6 \%$ & $5 \%$ & $3 \%$ \\
\hline .265 & $.8 \%$ & $2 \%$ \\
\hline
\end{tabular}

The first step in the methodology used was to aggregate the data across the type of truck, in order to determine a combined age and sex distribution among truck purchasers. 
Let: $\quad \mathbf{P}_{\text {Type }}=$ the percentage of total light truck purchases of a given type.

$P_{\text {Sex, Type }}=$ the percentage of each type purchased by a given sex.

$\mathrm{P}_{\mathrm{Age}, \mathrm{Type}}=$ the percentage of each type purchased by a given age group.

Then, aggregating across truck types:

$$
\dot{P}_{\text {Sex,Age }}=\sum_{\text {Type }} P_{\text {Type }}: P_{\text {Sex }, \text { Type }}: P_{\text {Age }, \text { Type }}
$$

as displayed below. A summation across sex within each age group provides the age distribution of light truck purchasers, depicted in the chart below, and in Figure F-24.

Table F-88: Light Duty Vehicle.Purchases by Age and Sex, 1989

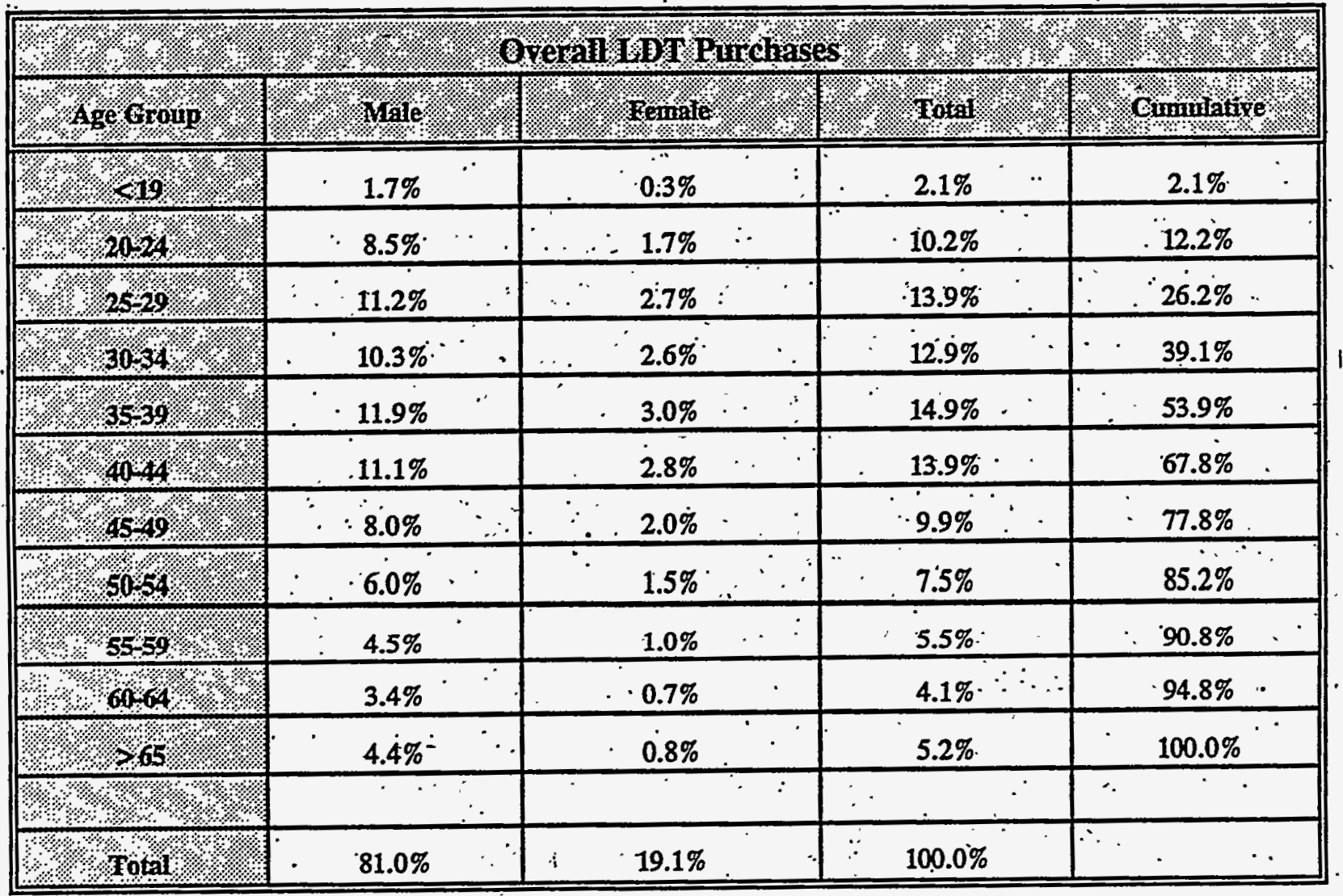

Looking at the cumulative percentages (Figure F-25), approximately 85 percent of all light truck purchases are made by people under 55 years old. Of this group approximately 81 percent are men and 19 percent are women (Table F-88). The historical and projected proportion of the population under 55 years is subsequently graphed in Figure F-26. 
Figure F-24: Age Distribution of Truck Purchasers

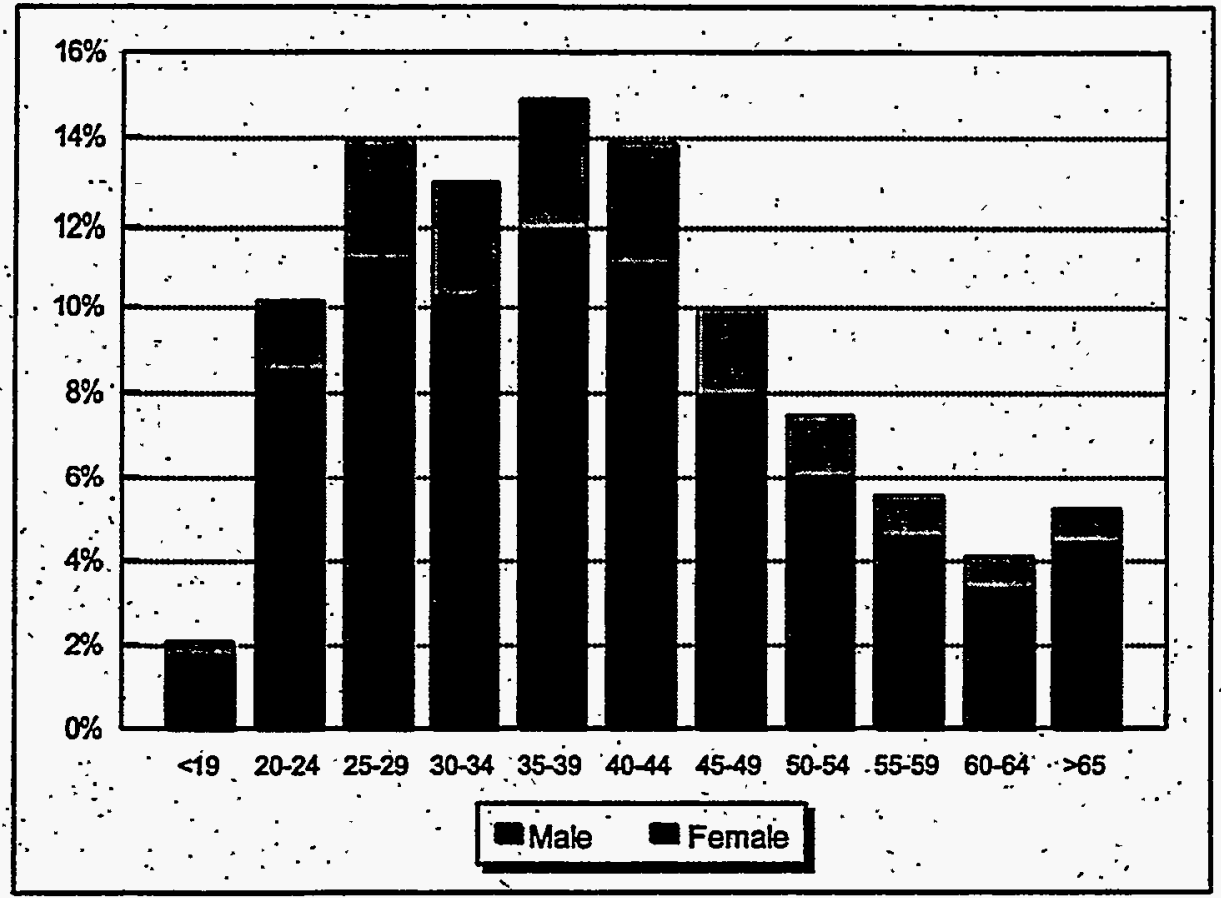

Figure F-25: Cumulative Percentage of Truck Purchasers

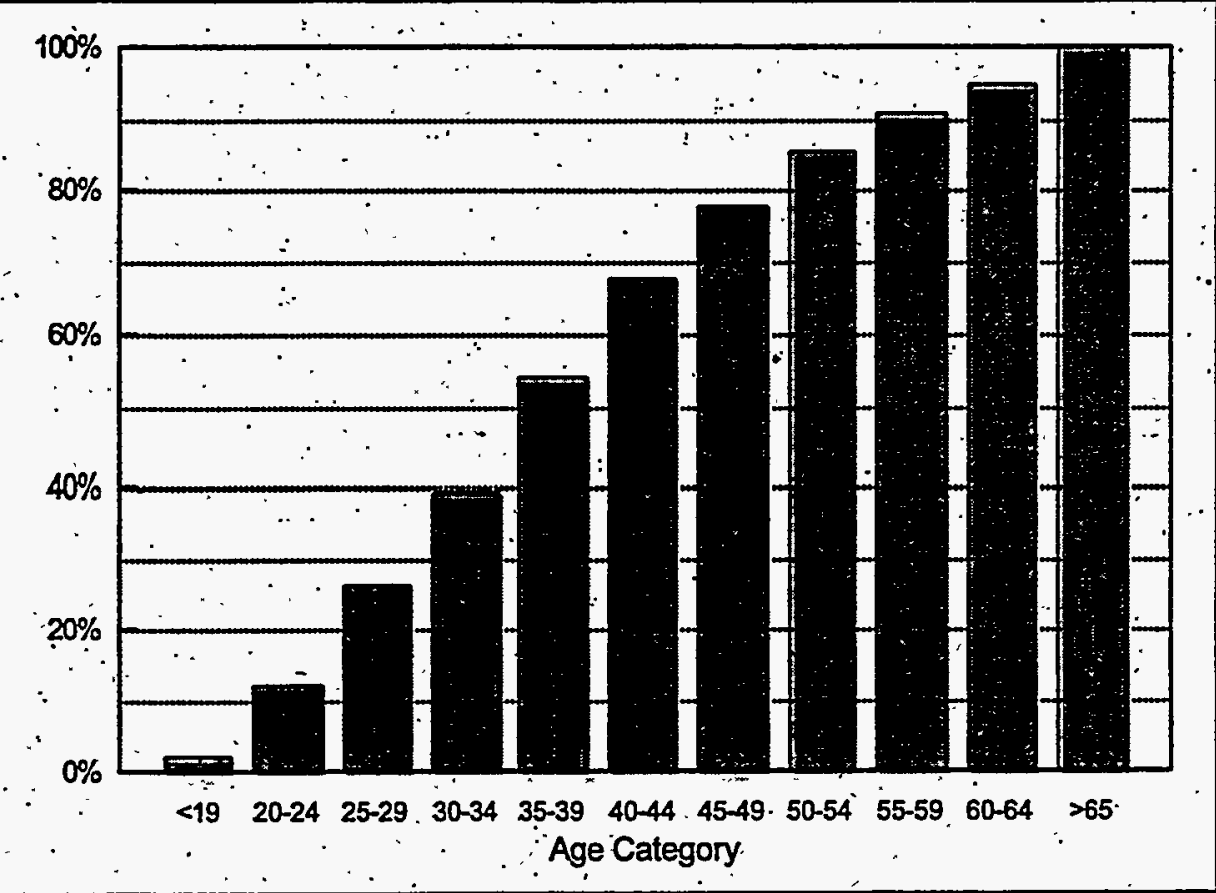

A weighted average of the share of the driving age population under 55 years is used as a proxy to measure the demographic impact of an aging population on future truck purchase trends. Note the methodology developed here assumes that people over age 55 will continue to represent only about 15 percent of the light truck purchasing market (Table F-88). Given this assumption, as the 
proportion of the population under age 55 falls after 2000 (Figure F-26), trick sales will as a proportion of light-duty vehicle sales will stabilize (Figure F-28). In 2015, the unadjusted light truck market share is 49 percent compared to a population-adjusted share of 43 percent.

\section{Figure F-26: Proportion of Population Under 55 Years}

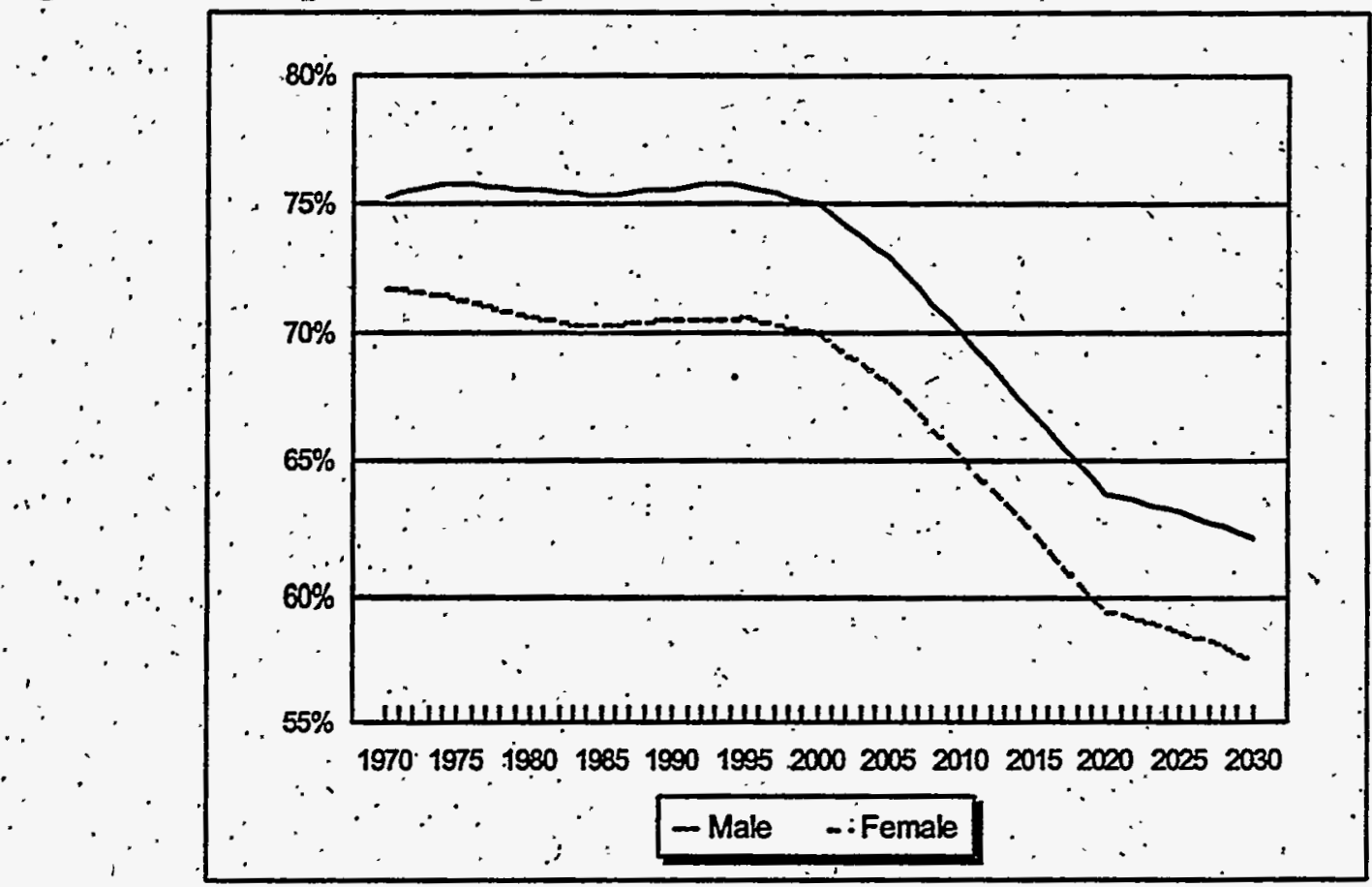

The specific methodology used in $A E O 96$ to develop a demographic index to dampen future truck sales is detailed below. It is certainly not the only index that could have been developed, however, under the assumption that "Grandma will not choose to drive a pick up truck" any approach would dampen light truck sales beyond 2000.

\section{Weighted Population Index}

Since the cumulative total (Table F-88) indicates that people inder the age of 55 are responsible for 85 percent of all light truck purchases, declines in this share of the population is used as a moderating influence relative to a trend based estimate of light truck sales based on extrapolating recent history. The population index is weighted by the male/female distribution (Table F-88) of truck buyers, as follows: .

Let $\quad \mathrm{P}_{\text {Sex, } \mathrm{Age}}=$ the fraction of all LDT buyers of a given sex and age group

$\Pi_{\text {Sex }, A g e s 5, T}=$ the percentage of the population under the age of 55 , by sex, in year $T$ 
The weighted share of the population under the age of 55 is then:

$$
P<55_{T}=\sum_{S e x \in}\left[\Pi_{S e x, A g e<55, T} \cdot\left(\sum_{\text {Age }} P_{S e x, A g e}\right)\right]
$$

This share is subsequently indexed $(1990=1.0)$. Index values are included in the data provided with this paper. The effect of the aging of the "baby boomers" is dramatic (Figure F-27). The aging population has nearly a 15 percent dampening effect on new truck sales relative to a straightforward extrapolation estimate based on recent trends.

Figure F-27: Weighted Population Index

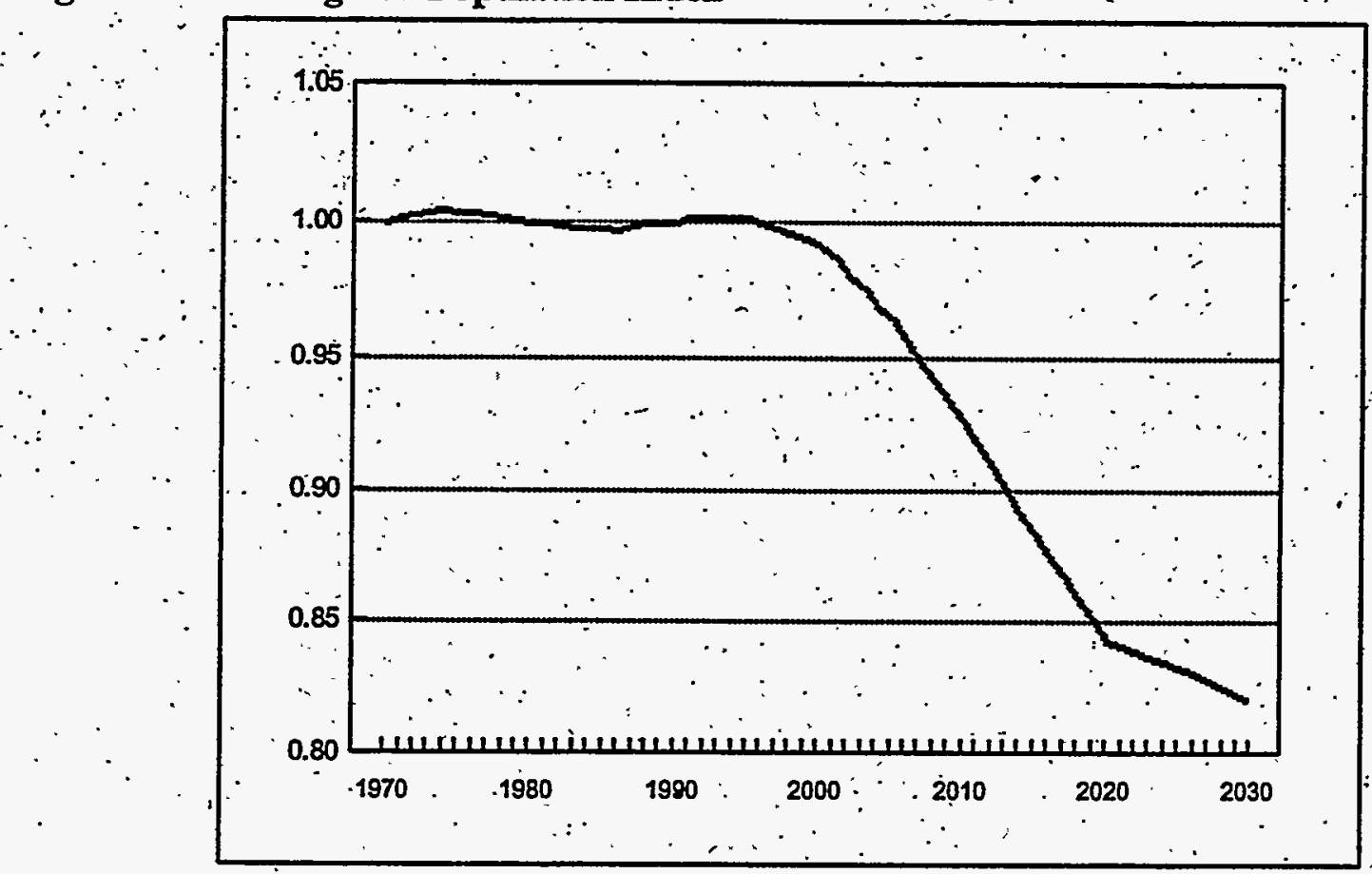

\section{Extrapolation of Recent Trends}

The unadjusted share of total LDV purchases accounted for by trucks is extrapolated using the 1982 and 1992 values as anchor points; and an assumed maximum value: The functional form of the curve is as follows:

$$
\operatorname{LTS}_{T}=\operatorname{LTS}_{1982}+\left(\operatorname{LTS}_{M a x}-\operatorname{LTS}_{1982}\right) \cdot\left(1-\exp ^{-k\left(T-1982 T_{0}\right)}\right)
$$

where LTS indicates the Light Truck Share of total LDV sales (referred to in the model code by the 
variable name CARLTSHR), and the constant, $\mathrm{k}$, is determined as followis:

$$
k=\frac{-\operatorname{Ln}\left[I-\frac{\left(L T S_{1992}-L T \dot{S}_{1982}\right)}{\left(L T S_{M_{a x}}-L T S_{1982}\right)}\right]}{10}
$$

Using the data in the table below, $k$.is calculated and the curve is explicitly defined.

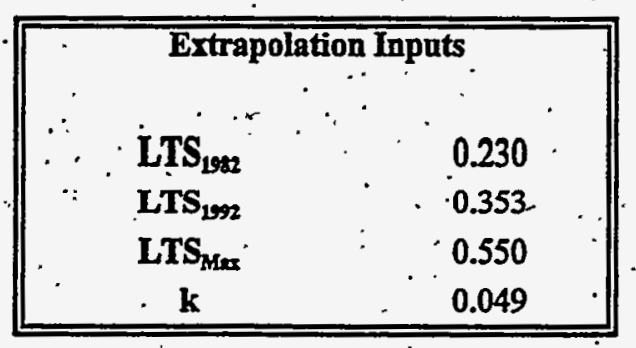

The value of $k$ was chosen so that the truck market share of light duty vehicles in 2015 is comparable to the share projected in a recent report.

Figure F-28: Forecasts of Truck Sales Shares

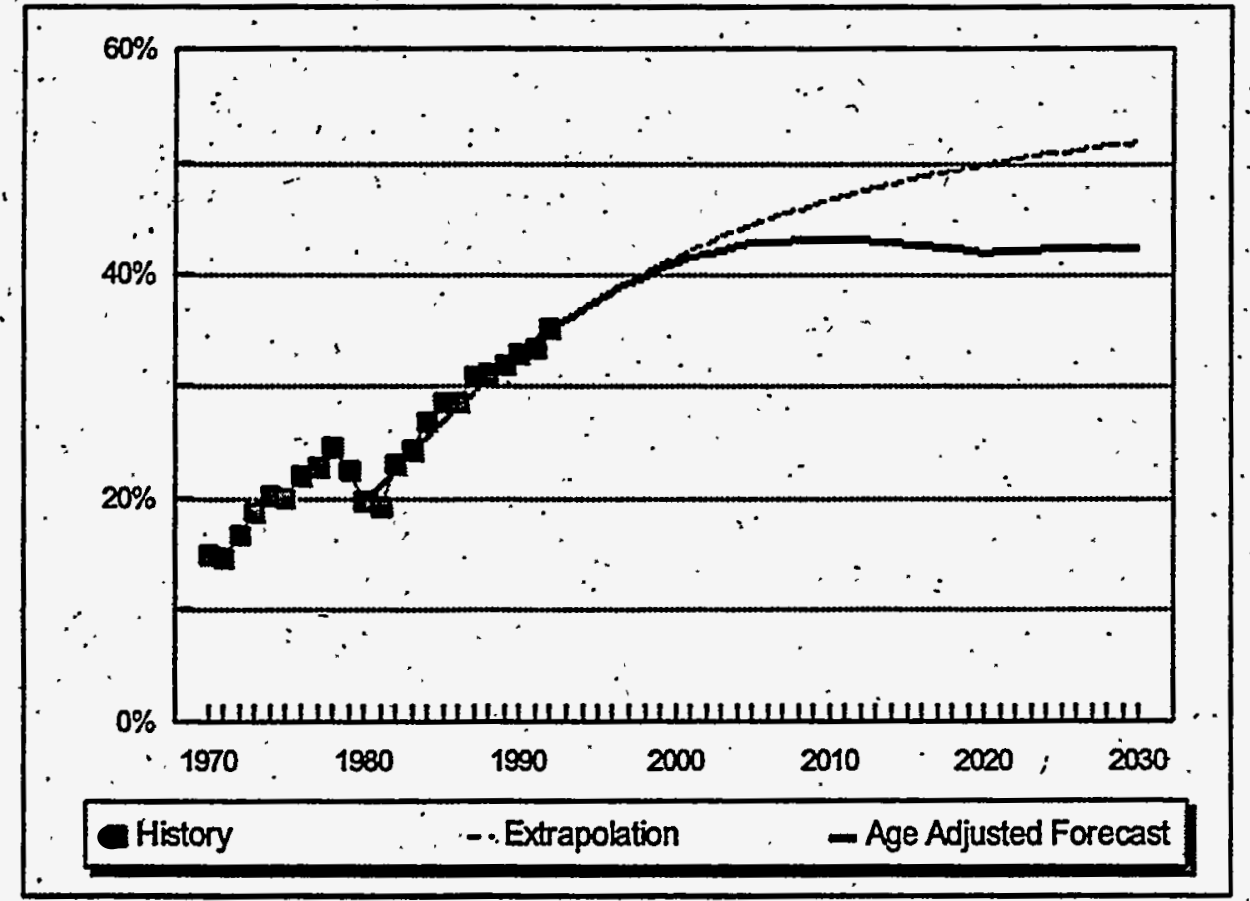

For any forecast year, the population-adjusted estimate is calculated simply by multiplying the extrapolated estimates by the demographic index described above. 